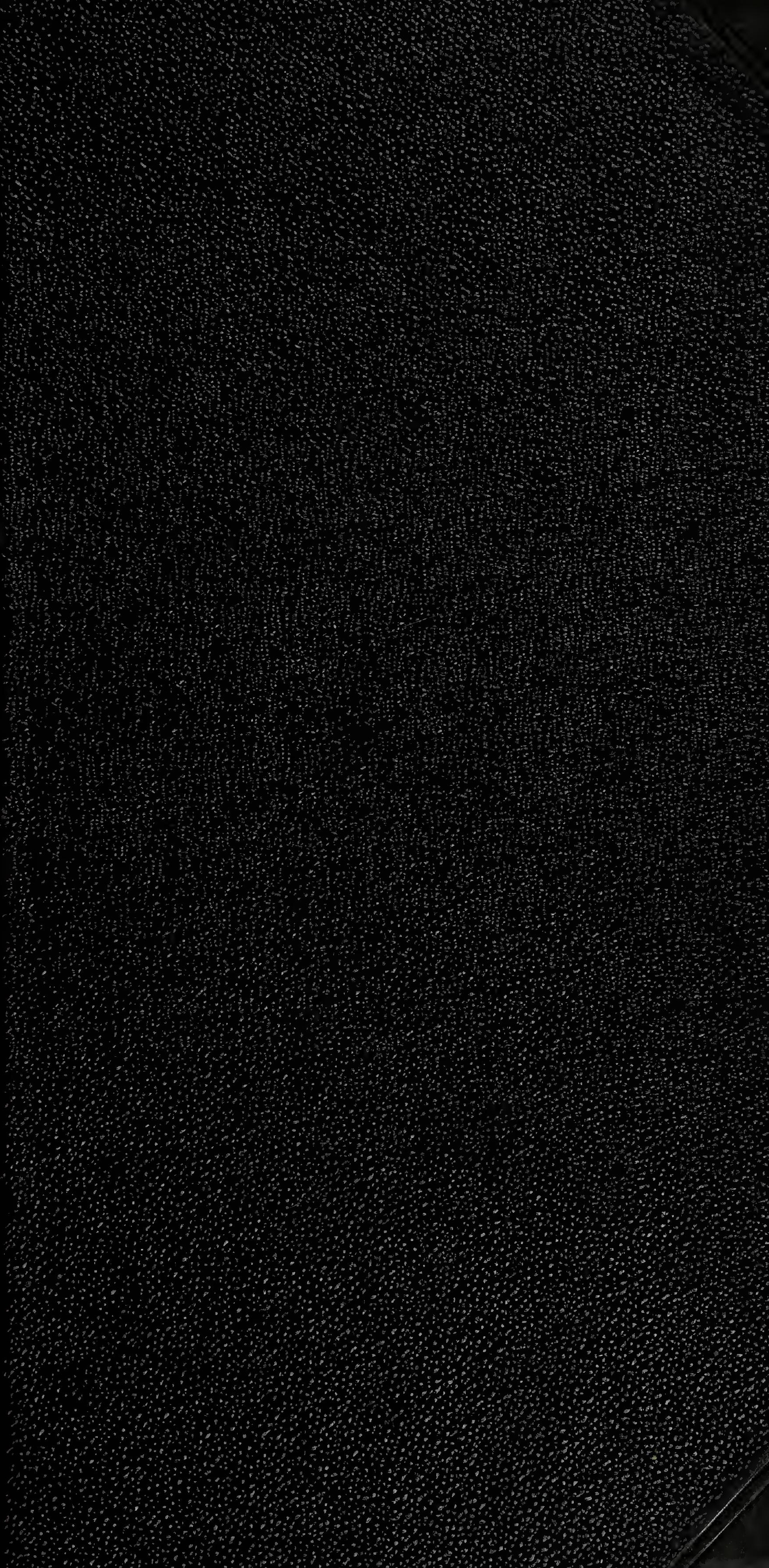



.
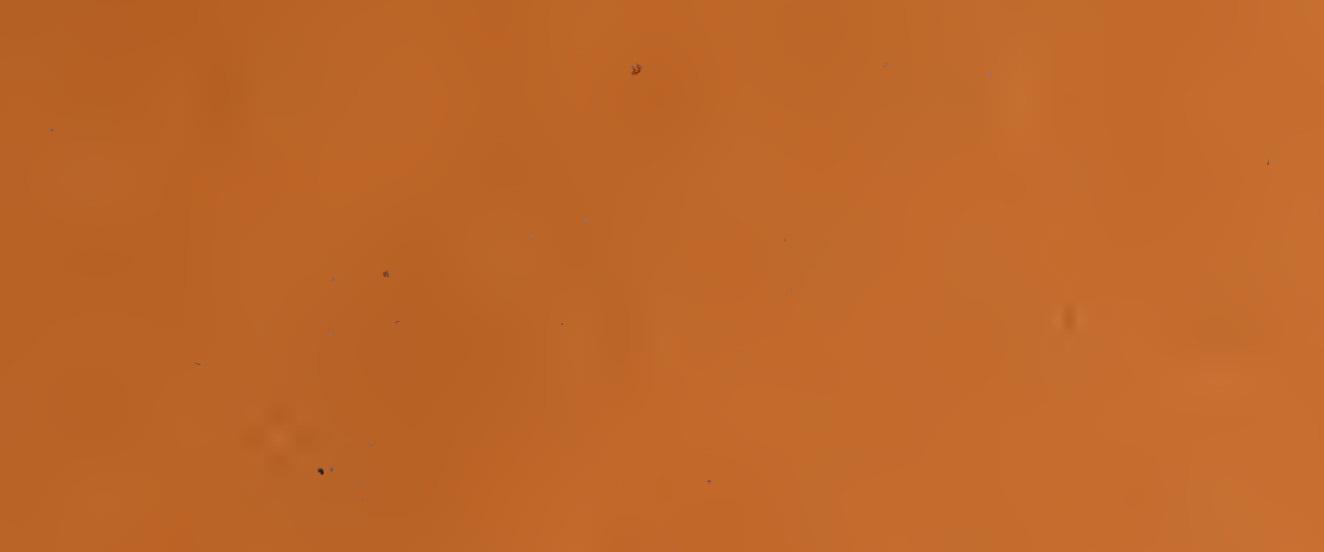

1

1

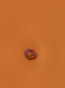

0

,

2.

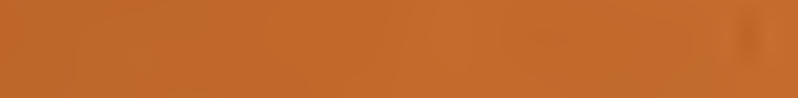

$x$

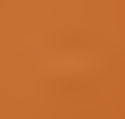

$1+1-1+1$ 





\title{
ENUMERATIO DIAGNOSTICA
}

\section{CACTEAR UI}

\author{
HUCUSQUE COGNITARUM.
}

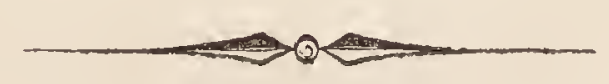

A UCTORE

\section{LUDOVICO PEWTHER, Med. Doct., Casseluano.}

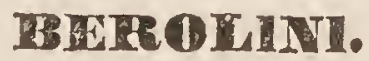

SUMTIBUS LUDOVICI OEMMIGR.

$183 \%$ 
Digitized by the Internet Archive in 2018 with funding from Wellcome Library 
Viro doctissimo, summe venerando,

\author{
Serenissimo Principi
}

\title{
J. de Salm - Heifierscheid - Dyck,
}

in naturae studio versantium

fautori benevolentissimo,

Opnusculam, quod abstue Eijus anuxilio et consiliis

perfici vix poluisset,

gratissimo animo offert 





\section{raction.}

Quae de materia nostra hucusque tractata sunt, in singulis partibus versantur, et mihi quoque monographiam ordinis Cactearum edere hoc tempore non in mente est. Nihil aliud volui, quam colligere definitiones et descriptiones in pluribus libris dispersas, comparare eas inter se et cum plantis viventibus, ut synonyma recte statui possent, et addere descriptiones onnium specierum, in hortis cultarum, hucusque non descriptarum.

Quem ad finem hortos praecipuos botanicos Germaniae perscrutans, auxilio et consiliis gavisus sum virorum doctissimorum, inprinis Serenissim: Principis "de SaLm-Dyck, nec non dominorum Otro, directoris horti Berolinensis, ZUUCCARINI, professoris Monacensis, Lehmann, Hamburgensis, Wenduand, Hannoverani, aliorumque, quibus omnibus gratias quam maximas ago.

Scriptores antiquissimi de Cacteis species nonnullas in earum patria descripserunt, ex gr. PLu- 
mierus, Piso et Marcgravius, et ex eorum iconibus rudibus Lamarckus et Linvaeus species constituerunt, vagas et nunc parum notas. Mirum nempe est, ex illarum specierum numero, quae in insulis Indiae occidentalis, nobis proximis et commercio regulari junctis, a Puvmicro delineatae sunt, perpancas hucusque in hortos europaeos translatas esse; et de his paucis vix certi sumus, num revera easdem species possideamus? Descriptiones scilicet antiquae, brevissimae, non sufficiunt ad distinctionem specierum affinium, et regula botanica, ut diagnoses paucissimis verbis absolvantur, in speciebus ordinis nostri applicari non potest. Quare omnium Cactearum, hodie in hortis cultarum, descriptiones jam existentes breves, nunc non sufficientes, ampliores et completiores reddidi, ut plantae affines facilius inter se distingui, et dubiae, si jam descriptae sunt, facile dignosci possent.

Genera Cactearum secundum affinitates naturales in singulos paragraphos distributa sunt, in qua distributione elaboranda consiliis 11l. Principis DE Saun-Dyck plurima debeo, Plerumque tamen ad formandos paragraphos characteribus usus sum, etiam in planta non florente couspicuis, ex. gr. in Echinocactis distribuendis, quos IIl. Princeps (Orтo's GZ. 1836. \$. 146.) in \$. 1. Bacca laevi et \$. 2. Bacca squamosa dividere proponit. Sed cum in fere omnibus specierum descriptionibus flores et fructus minimi sint momenti, speciesque hucusque solummodo e trunci qualitatibus definiri possint, aptius mihi visum est, Echinacactos secundum formationem costa- 


rum dividere. Distributiones Cereorum et Opuntiarum a Cl. Haworth et de Candolle propositae, nunc etiam minus sufficientes apparent, et quas illis substitui, pro maxima parte III. Pr. De Salm debeo. In distribuendis Mammillariis neque Hortum Dyckensem (p. 155.), neque Cl. Zuccarini propositionem (Ind. Cact. hort. Monac. 1836. p. 6.) secutus sum, sed proprian divisionem proposui. Altera scilicet characteres praebet non satis constantes, altera vero, secundum succum limpidum vel lactescentem dividens, species nonnullas separat affinitate naturali proximas, aliasque conjungit toto habitu valde discrepantes.

Diagnosis Echinocactorum a Cereis, praecedentibus Cl. De Candolle, Link et Otro in opusculo meo proposita, nondum satis accurata reperitur. Longitudo tubi calycinalis fere nullius momenti mihi esse videtur, et florescentia potius terminalis, nempe origo florum ex areolis modo nascentibus, signum praecipuum diagnosticum praebet. Praeterea florescentiam interruptam (quodsi nempe flores per plures dies sole lucente aperti, noctu vero clausi sunt,) et remanentiam corollae exsiccatae in vertice receptaculi usque ad fructus maturitatem signis diagnosticis Echinocactorum adnumerare proponerem, dum Cerei omnes noti semel tantum per brevius vel longius temporis spatium continuo florent et corolla mox decidere solet. Quodsi vero haec signa characteristica agnoscamus, Cereus denudatus et gibbosus Echinocactis adscribendi erunt! 
Multa certe in systemate hic proposito occurrunt, quae serius mutanda erunt, necnullae species sine dubio sub pluribus nominibus adhuc descriptae reperiuntur, quia descriptiones non adeo accuratae sunt, ut cum certitudine aliqua de specierum identitate judicare possimus, id quod inprimis Opuntias spectat.

Quare lectorem benevolum rogo, semper reminiscatur, opusculum meum non esse monographiam, sed collectanea modo, ad solvenda dubia, quantum fieri potest, proposita!

Cassellis, mense Decembri 1836.

\section{Peiffer.}





\section{CA C T E E.}

DC. Ordo 89. Prodr. IIT. p. 45\% - Cactoideae Vent. tabl. 3. p. 289. - Nopaleae DC. théor. élém. 216. Cacti Juss. gen. p. 310. excl. Grossul. - Opuntiaceae Juss. dict. 35. p. 144. excl. Grossul. H. B. et Кunth nov. gen. am. 6. p. 65. - Cactus Livv. gen. n. 613. WiLLid. enum. h. berol. 30. LINK enum. 2. p. 21.

Haworth synopsis plantarum succulentarum. Lond. 1812. p. 172.

Haworті supplementum plantarum succulentarum. Lond. 1819.

Hawonth Saxifragearum enumeratio; accedunt Revisiones plantarum succulentarum. Lond. 1821.

De Candolle prodromus systemat. natural. regni vegetabilis. P. III. 1828. pag. $45 \%$.

De Candollie revue de la famille des Cactées. Paris 1829.

De Candolue mémoire sur quelques espèces de Cactées, nouvelles ou peu connues. Paris 1834 .

'Turpiv observations sur la famille des Cactées. (Annales de l'Institut hortic. de Fromont. Tome II. 1831.) Отто's Garten-'Zeitung 1833. No. 39. 40.

LeHMANv pugillus plantarum in botan. Hamburgensium horto occurrentium 1828 in: Nova acta physico-medica academ. caesar. nat. cur. XVI. P. I. 1832. p. 315. 
v. Mantrus Beschreibung einiger neuen Nopaleen 1832 in: Nova act. nat. cur. XVI. P. I. p. 323.

Zuuccarin in: Abhandl. d. k. b. Akad. d. Wiss. 1832. B. I. S. 326 .

Verhandlungen des Gartenbau-Vereins für Preussen. B. III. et VI.

Hort. Dyckensis. Düsseld. 1834.

\section{Character ordinis.}

Calyx constans sepalis plurimis saepius numero indefinitis, basi in tubum ovario longe adnatum concretis, tubo nunc laevi, et tunc sepalorum lobi fructum coronant, nunc squamoso, nempe sepalorum lobi ab ipsa ovarii basi subliberi imbricati spiraliter seriales, inferiores breviores subfiliformes, superiores majores petaliformes ovarium a basi ad apicem umbilicatum tegentes. Petala bi-aut multiserialia a sepalis interioribus vix distincta et cum iis subconcreta, nunc in tubum longum digesta, apice tantum libera, nunc a basi fere libera et corollam rotatam conficientia. Stamina numerosa multiserialia numero indefinita, cum petalis et sepalis interioribus plus minus concreta, filamentis tenuibus, antheris ovatis oscillatoriis bilocularibus. Ovarium obovatum carnosum uniloculare multiovulatum, ovulis placentis parietalibus in series verticales (tot quot stigmata?) digestis. Stylus filiformis, nunc plenus, nunc fistulosus. Stigmata plurima nunc patula, nunc aggregata. Bacca carnosa, nunc laevis, calyce coronata, nunc squamis aut areolis aut tuberculis a basi instructa, apice umbilicata, unilocularis, polysperma. Semina juniora parietalia, adulta in pulpa loculum replente nidulantia, ovalia aut obovata, exalbuminosa. Embryo nunc incurvus aut spiralis radicula subgracili, nunc rectus radicula crassa brevi obtusa. Cotyledones germinantes planae crassae foliaceae in generibus foliiferis, parvulae, plus minusve acuminatae in reliquis. 


Frutices omnes ex America orti, habitu valde varii, carnosi. Caules saepe verticaliter angulati, alati, aut tuberculis regulariter instructi, rarius teretes, saepe articulati, articulis compressis. Folia saepe nulla, parva caduca teretia sediformia, rarius plana expansa et tunc alternt ordine spirali quincunciali digesta, semper glabra carnosa. Aculeorum aut setarum fasciculi ex foliorum (ubi adsunt) axillis orti, in aphyllis loco foliorum spiraliter ad angulos tuberculaque caulis dispositi. Flores valde varii, saepius solitarii sessiles, e fasciculis orti, plures ephemeri, nocturni aut diurni, alii minimi, alii speciosissimi. Baccae omnes (aculeis ablatis) edules acidulae, in regionibus calidis gratae (DC.).

C. a Linvé paucas solummodo species huc pertinentes descripsit, quas omnes sub nomine Cacli (Icosand. Monogyn.) in uno genere *) comprehendit, quatuor statuens sectiones, nempe: Echinomelocactos, Cereos erectos, Cereos repentes et Opuntias.

In systemate naturali Cl. Jussreu hoc genus cum Grossulariis in unum ordinem conjunxit, sed haec genera evidenter separanda sunt, et cum $\mathrm{Cl}$. De Candolle ordo Cactearum instituendus, qui ex affinitate naturali Ficoideas sequitur et Grossularieas praecedit, ad quas Pereskiae facillimum formant transitum.

Cl. De Candolce ordinem in duas tribus dividit, quarum altera Opuntiaceas ( Ovula et ideo semina parietibus baccae affixa"), altera Rhipsalideas ("Ovula et ideo semina axi baccae centrali affixa(i) comprehendit. Sed insertio ovulorum in omnibus Cacteis indagatis eadem est, nempe parietalis, id quod observationes accuratissimae IIl. principis de SALM-DYCK et nostrae evidenter monstrarunt, quare omissa subdivisione ordinem in decem genera dividendum censemus:

*) Cal. 1-phyllus, superis, imbricatus. Cor. multiplex. Bacca 1-locularis, polysperma. 


\section{4}

Conspectus

Cactearum synopticus.

\section{Cacteae.}

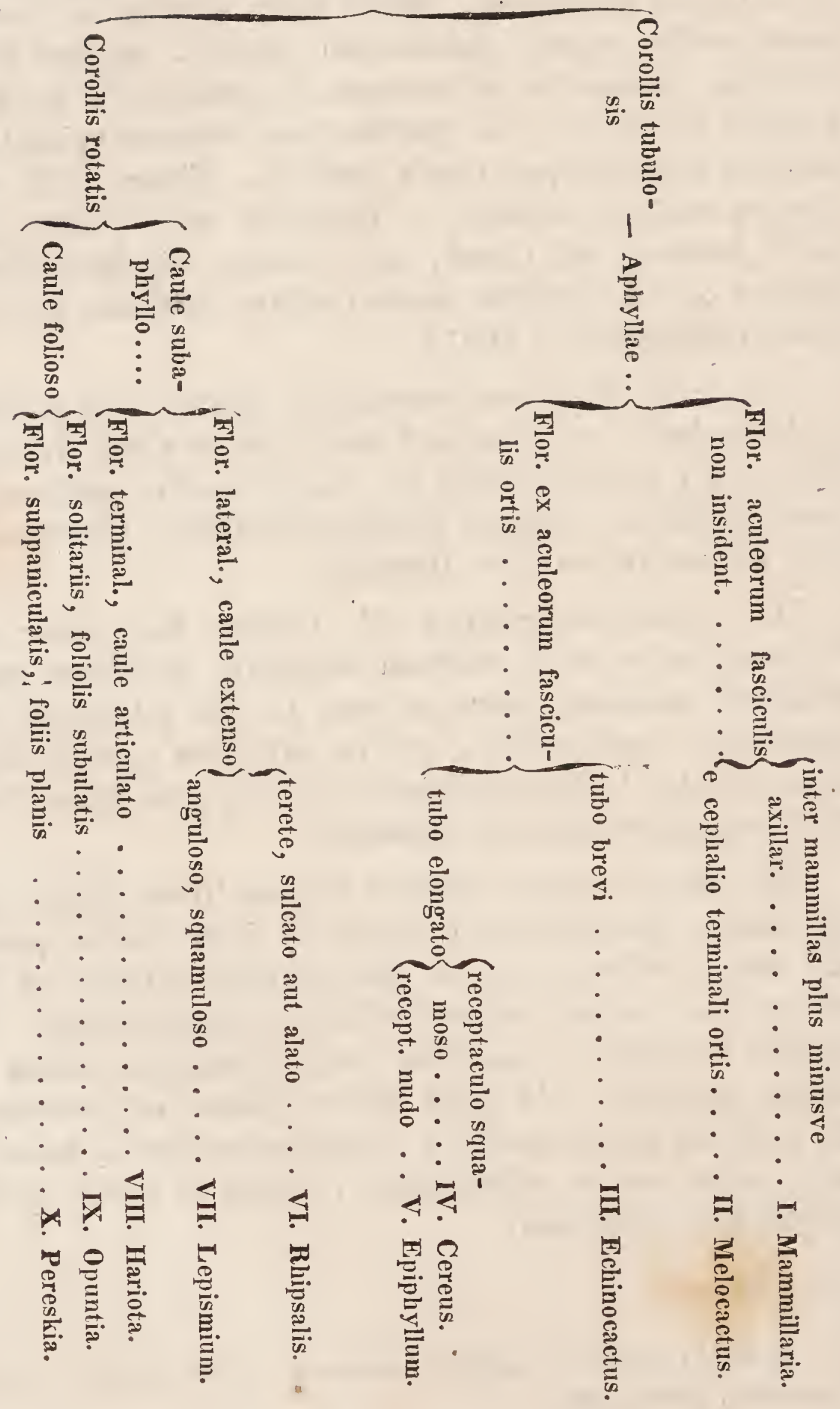





\section{Mammillaria.}

HAW. syn. p. 18\%. - DC. prodr. III. p. 458.

Char. gen. Calycis tubus ovario adhaerens; lobi 5-6 colorati fructum juniorem coronantes. Petala 5-25 a calyce vix distincta, eo longiora et cum sepalis in tubum concreta. Stamina filiformia pluriserialia. Stylus filiformis. Stigma 3-Zfidum radiatum. Bacca laevis oblonga. Semina nidulantia. Cotyledones minutae, acuminatae.

Suffrutices carnosi subrotundi aut cylindracei, lactescentes aut succo limpido repleti, aphyll, tuberculis subconicis mammaeformibus spiraliter dispositis, apice spinulas radiantes et tomentum demum deciduum gerentibus obtecti. Flores inter basin mammillarum sessiles, saepius in zonam transversam dispositi. Bacca obovata edulis, calyce marcescente, demum deciduo, coronata.

\section{S. 1. Homoeacanthae.}

Aculeis omnibus subaequalibus, rigidis vel setaceis, centralibus nullis vel ab exterioribus vix distinctis.

\section{* Tenues, ramosae.}

Caule tenuissimo elongato suberecto, ramis divergentibus, e basi vel lateribus provenientibus.

\section{M. echinala De Candolle.}

Mémoire p. 3. - M. Echinaria DC. revue p. 110.

Pa: Mexico.

M. basi saepius multiplex, cylindracea, elongata; axillis latis nudis; mammillis nudis, basi latis, brevissimis, apice obtusis; areola juniorum subtomentosa; aculeis setiformibus 16-18 radiantibus, patulo-recurvis flavidis, mamma multo longioribus, centralibus 2 rigidioribus subfuscis.

Truncus $1-$ 1 $1 / 2^{1 / 2}$ poll., diam. Mammillae basi 5 lin. diam., 3 lin. longae. Aculei $4-6$ lin. Iongi.

Flores (mense Majo) sub aculeis fere absconditi, 9 lin. longi, cylindracei, extus rufescentes, intus albidi; stamina petalis dimidio breviora, antherae minimae albidae. Stylus cylindricus, staminibus paulo longior; stigmata 5 oblonga papillosa. 
B. densa. - M. densa Livk et Otro icon. t. 35. M. caespitosa Hort. - Mammillis confertioribus, aculeis numerosioribus et gracilioribus.

\section{Nolongala DC.}

Revuo p. 109. Mém. p. 2.

Pa: Mexico.

M. basi saepius multiplex, cylindracea, elongata, subramosa; axillis latis nudis; mammillis brevissimis basi latis, apice obtusis; areola juniorum subtomentosa; aculeis setiformibus 16-18 radiantibus flavidis mamma multo longioribus, centralibus nullis.

Truncus 1 poll. diam. Aculei 6 lin. longi. Nonnunquam centralis 1 subulatus.

\section{M. tenuis DC.}

Revue p. 110. Mém. p. 4. t. 1. - Bot. reg. t. 1523. Pa: Mexico.

M. basi saepe multiplex, cylindracea; axillis angustis nudis; mammillis ovatis; areola juniorum sublanata; aculeis setiformibus 20 -25 flavidis radiantibus, mamma paulo longioribus, centralibus nullis.

. Truncus $1 / 2$ poll. diam. Aculei $3-4$ lin. Iongi, intertexti. Floret mens. Aprili et Majo. Flores circa verticem albi, parvuli, attamen éx aculeorum fásciculis prominentes; sépala 5 , petala 10 denticulata; stamina numerosa pètalis breviora; stylus cylindricus staminibus longior; stigmata 3 retroflexa, sinus quasi formantia sinubus calycis Campanularum quarundam similes. (Qui sinus, cum in IMamm. affini etiam reperiantur, ex Cl. De Candolle opinione aliquando divisionem Mammillariarum in sectiones formare possunt). Baccae oblongae basi valdé attenuatae, initio flavidae, hieme rubescentes, seminibus aurantiacis repletae.

ß. media DC. revue p. 110. - Mamm. stella aurata MarT. - Caule crassiore, 10-12 lin. diam., aculeis centralibus nullis aut solitariis.

\section{M. subcrocea DC.}

Revue p. 110. Mém. p. 3.

Pa: Mexico.

M. basi saepius multiplex, cylindracea; axillis angustis sublanatis; mammillis ovatis brevibus; areola juniorum subtomentosa; aculeis setiformibus 16 -18 radian- 

tibus, mamma longioribus, flavidis, nascentibus croceis, centralibus nullis.

Truncus $9-11$ lin. diam. Aculei 3 lin. longi. In plantarum sub divo cultarum areolis saepe aculeus centralis solitarius brunneus, subulatus, reliquis brevior, sed validior, nascitur.

Flores (mens. vernalibus) ex aculeis prominentes, 6 lin. longi. Sepala et petala circa 25, stramineo-albida; stamina petalis breviora, alba, antherae pallide flavae; stylus filiformis, staminibus paulo longior; stigmata 5 crassa, ovata, papillosa. Baccae oblongae, sordido rubrae.

\section{M. intertexta DC.}

Revue p. 110. Mém. p. 5.

Pa: Mexico.

M. basi saepe multiplex, cylindracea; axillis angustis; mammillis ovatis confertissimis, aculeorum congerie omnino occultatis; areola glabriuscula; aculeis 20 - 25 rigidis flavidis radiantibus, ob mammarum vicinitatem intertextis.

Planta descripta 4 poll. longa, 1 poll. diam. Aculei 3 - 4 lin. longi. - A M. subcrocea solummodo aculeis rigidioribus et longioribus, mammillis magis confertis et floribus paulo majoribus, quorum stigma e staminibus non prominet, differre videtur. Quare pro mera varietate habenda?

Ex opinione doct. Coulter, qui omnes hasce species primus e Mexico misit, M. tenuis, echinata, elongata," subcrocea et intertexta forsan varietates ejusdem speciei constituere videntur. Cl. De Candolle autem distinctas species esse, sed unam sectionem formare putat, quam nominat elongatas flavescentes. Nobis vero $M$. sphacelata huic sectioni naturali adscribenda, ideoque nomen sectionis mutandum videtur,

\section{M. sphacelata MART.}

Act. nov, nat. cur. XVI. P. I. p. 339. to XXV. f. I. Pa: Mexico.

M. cylindrica, tandem prolifera; axillis subnudis; mammillis subconicis, basi rhombeis; aculeis e tomento parcissimo rectis eburneo-albis, apice sanguineo- et tandem nigro - sphacelatis $14-18$, centralibus $3-4$ erectis, reliquis subhorizontaliter patentibus.

Truncus semipedalis et nltra, $10-12$ lin. diam. Mammillae diam. transverso 4 lin., 3 lin. longae. Aculei 3 - lin. longi. Florentem vidimus mense Majo 1835 in horto Berolinensi. Flores 
solitarii, parvuli. Calycis folioli rubro-fusca obtusiuscula. Petala acuta, sanguinea.

\section{*** Conothelae.}

Caule crasso, subgloboso vel columnari, simplice vel prolifero, mammillis conicis.

\section{\%. M. polythele MAnT.}

Act. nov. nat. cur. XVI. P. I. p. 328. tab. XIX.

Pa: Mexico (Yxmiquilpan).

M. simplex cylindrica, subarticulata; axillis nudis; mammillis conicis; aculeis $2,3-4$ teretibus subrectis, infimo robustiore, fuscis; lana alba in mammillarum juniorum vertice et circa flores.

Truncus sesquipedalis et ultra, $3-5$ poll. diam., atrovirens. Mammillae 6 lin. longae, basi 5 lin. diam., dorso fere planae, facie inferiore convexae. Aculeus infinus 6-7 lin., superior 3, laterales (si adsunt) $2 \frac{1 / 2}{-3}$ lin. longi. Flores inter mammillas superiores. Sepala 8-9 angusto - lanceolata, acuminata, a medio deorsum cum corolla confluentia, dorso fuscidulo - purpurascentia, margine teneriora roseo - purpurea, in parte inferiore alba. Petala 12-16 rosea; erecta, in limbi apice solum expausa, ima parte alba. Stamina in seriebus $6-7$, sub-66, aestivatione introrsum curvatae; antherae minutae. Stylus teres, basi nonnilil incrassatus et albus, superne purpureus, abiens in stigma 5-radiatum, cujus radii triangulares erecti, in medio sulcati et stigmatosi, purpurascentes.

\section{M. quadrispina MaRT.}

\section{Act. nov. nat. cur. XVI. P. I. p. 329.}

Pa: Mexico.

M. simplex elongato-cylindrica; mammillis conicis; aculeis 4 (raro 5 -6) rectis oblique cruciato - patentibus, mammillarum longitudine, fuscis, imo paulo longiore, subinde annulo setarum parvarum albarum cinctis; lana inter mammillas, in eorum areolis et super flores 'parca.

Truncus $2-3$ poll. diam. Mammillae 5 lin. longae, 4 lin. diam. Aculei 5-6 lin. longi. Flores (miense Julio) purpurei, tubo crassiusculo, petalis numerosis linearibus. Stylus purpureus 4- partitus, stamina aequans; antherae flavae.

A pracedente aculeorum numero, aculeolis exterioribus setitormibus (etsi saepe deficientibus), et stigmate obscure purpureo 4- radiato discernilur. Plantae vero seminales primo anno neque 


a $M$. columnari, neque a polythele distingui possunt, cum omnes ab initio aculeos 6 in singulis tuberculis gerant.

\section{II. columnaris MART.}

Act. nov. nat. cur. XVI. P. I. p. 330. Pa: Mexico.

M. simplex elongata cylindrica, hinc inde constricta; mammillis conicis; aculeis 5-6 rectiusculis, fuscis, erecto - patulis, quorum inferiores reliquis nonnihil longiores; lana inter mammillas et infra flores purpureos parca.

Specimina ultrapedalia hujus duarumque praecedentium specierum, copiose florentia, baccisque magnis elongatis coccineis instructa, mense Septembri 1835 et 1836 in horto Monacensi vidimus.

M. quadrispinae valde affinis, mammillis longioribus, aculeis pluribus et brevioribus, aculeolorum defectu, colore aculeorum magis in rubrum vergente, et stigmate roseo 5 -radiato facile distinguitur.

\section{M. parvimamma HAW.}

Suppl. p. 92. - C. microthele Spr. - Cact. prolifer W. - Mamm. prolifera Hont.

Pa: India occidental.

M. subglobosa superne prolifera, tuberculis numerosis minimis, apice albo-tomentosis, spinis $10-12$ subrigidis atro-purpureis (DC. pr.).

M. subcylindrica obscure viridis; axillis nudis ; mammillis confertissimis obtuse conicis, in dorso sulco barbato prolifero instructis; areolis junioribus albo-lanuginosis; aculeis gracilibus, rectis, subrigidis, initio atro-purpureis, dein nigris, tandem cinerascentibus, subaequalibus, exterioribus $8-10$ irregulariter radiantibus, centralibus $2-\mathbf{3}$ paulo longioribus.

Truncus $4-6$ poll. altus, $2-3$ diam. Mammillae 4 lin. longae, basi 3 lin. diam. Aculei 2 - 3 lin. longi. - Proles e sulcis mamnillarum circa verticem copiose' enascuntur, ita ut, plantae saepe pluribus ramorum zonis instructae sint. Flores (ex iisdem sulcis provenientes?) in hortis europaeis nondum observati esse videntur.

\section{M. simplex HAw.}

Syn. p. 17\%. - DC. pl. gr. t. 111. Mém. t. \%. Cact. mammillaris $\mathrm{L}$. 
Pa: America calid., Antill., Caracas et (Nutr. gen. am. 1. p. 295.) mont. Missouriens.

M. simplicissima, junior globosa, tandem oblonga; axillis glabris; mammillis ovato-conicis; aculeis e tomento parco albo $12-16$ radiantibus, $4-5$ centralibus vix validioribus, omnibus rectis, rigidis, primum sanguineis, dein griseo - rubris.

Truncus $4-5$ poll. altus, $2-3$ diam. Mammillae $6-7$ lin. Iongae, basi 4 diam. Aculei subaequales, 4 lin. longi. Flores per totam aestatem in plures series inter mammillas a vertice remotiores dispositi, parvuli, virescenti-albidi; stigma 5 - 6-partitum. Baccae oblongae coccineae, plerumque vere sequente maturescentes, semina continentes nigra facillime germinantia.

\section{M. Alavescens DC.}

Cact. flavescens DC. catal. h. monsp. p. 83. - Mamm. straminea HAw. suppl. p. 71. - C. flavescens et stramineus Spr.

\section{Pa: Amer. calida.}

M. obovata superne subprolifera, axillis lanatis, tuberculis ovatis, apice lanigeris et spiniferis, spinis rigidis longis rectis flavicantibus (DC, pr.).

M. subglobosa perviridis, tandem e lateribus prolifera; axillis lanatis; mammillis conicis; areolis albo-villosis; aculeis rectis rigidis subaequalibus, junioribus fiavescentibus, tandem brunneis, centralibus 4 , exterioribus $9-10,4$ supremis minimis.

Floret mense Julio. Flores copiosi circa verticem pallide sulphurei, expansi pollicares.

\section{M. prolifera HAW.}

Syn. p. 178. suppl. p. 71. - Cact. mammillaris prolifer Aıt. kew. ed. 2. v. 3. p. 175. - Mamm. Parmentieri H. BenoL.

Pa: Amer. calida.

M. obovata, basi prolifera, axillis lanatis, spinis longis rectis stramineo-albicantibus (DC. pr.).

M. subcylindrica e basi prolifera; axillis lanatissimis; mammillis obscure viridibus conicis; areolis albo-floccosis; 

pillosi, laete rosea, basi sinubus crassis et rotundatis conjuncta (sicut in $\boldsymbol{M}$. tenui).

Hanc plantam Cl. De Candolle initio M. simplici aequalem putavit, mox autem propriam speciem formare agnovit, quia absentia aculeorum radiantium et flores coccinei H. affinem satis ab illa discernunt. - Sed M. cataphracta H. Monac., cujus mortuae icon tantum superest, procul dubio non cum $\mathbb{M}$. angulari, sed cum affini, omnibus characteribus congruis, jungenda est.

17. M. angularis H. BeroL.

M. compressa DC. revue p. 112.

Pa: Mexico.

M. simplex (tandem e parte superiore copiose prolifera) clavato-cylindracea; axillis junioribus lanatis setosisque; mammillis ovatis brevibus, basi angulatis et subtus quasi compressis; areola subtomentosa; aculeis rigidis rectis $4-5$ inaequalibus albidis, apice nigris, infimo longissimo.

Truncus $6-8$ poll. altus, $2-3$ diam. Mammillae virides, vix glaucescentes, ovatae, undique compressae, 3 lin. longae, diam. transverso 5 lin. Aculei summi 2 , laterales $3-4$, infimus $4-6$ lin.

\section{M. Iriacantha DC.}

Revue p. 113.

Pa: Mexico.

I. simplex obovata, subcylindracea, obtuse truncata; axillis parce lanatis setosisque; mammillis ovatis brevibus confertis; areola juniorum tomentosa; aculeis 3 rectis albis, inferiore longiore, deorsum tendente, 2 lateralibus brevioribus.

Planta descripta 3 poll. longa, 11/2 diam. Interdum aculeus quartus brevissimus adest. Num a M. angulari satis diversa?

\section{M. divergens DC.}

Revue p. 113. Mém. p. 11.

\section{Pa: Mexico.}

M. basi multiplex, subglobosa, depressa; axillis Ianatis setosisque; mammillis ovatis confertis; areola juniorum lanata; aculeis $5-6$ inaequalibus pungentibus albis, apice subfuscis, divergentibus, subtetragonis. 


M. triacanthae valde affinis. Aculei minores $3-4$, majores 18 - 30 lin. Iongi.

\section{M. cirrhifera MART.}

Act. nov. nat. cur. XVI. P. I. p. 334.

Pa: Mexico.

M. subcylindrica vel clavata, inferne prolifera; axillis lanatis et setosis; mammillis crassis glaucescenti-viridibus, compressis, margine inferiore subacuatis; areolis rotundis, junioribus dense tomentosis, tandem subnudis immersis; aculeis interioribus 5 , supremis 2 brevissimis rectis, lateralibus longioribus rectiusculis, infimo longissimo, flexuoso, omnibus rigidis albis, apice nigris, exterioribus $2-3$ gracilioribus brevibus albis.

Mammillae $5-6$ lin. diam., $4-5$ longae; aculei supremi $4-5$, laterales 12 , infimus $20-24$, exteriores $2-3$ lin. longi. - Flores rosei, setis copiose cincti.

\section{M. subangularis DC.}

Revue p. 112. Mém. p. 10. - M, cirrhifera spin. fusc. H. Monac.

\section{Pa: Mexico.}

M. subglobosa, valde prolifera; axillis lanatis, parcissime setosis; mammillis crassis viridibus, infra obtuse angulosis; areolis ovalibus, junioribus villosis, mox nudis, immersis; aculeis 6 rigidis rectiusculis, laete corneis, apice fuscis, 3 supremis brevibus, 2 lateralibus longioribus, infimo longissimo.

Mamm. 5 - 6 lin. diam., 3 - $3 \frac{1 / 2}{2}$ longae, virides, obtusae, infra minus acuatae, quam praecedentis. Aculei supremi $\mathbf{2}-\mathbf{3}$, laterales $6-8$, infimus $10-\mathbf{1 2}$ lin. longi, multo minus rigidi, quam $\boldsymbol{M}$. angularis.--Setae circum flores purpureos parcissimae.

\section{M. loricalu MART.}

M. heteracantha H. BERoL.

Pa: Mexico.

M. simplex subglobosa glaucescenti-viridis; axillis et mammarum interstitiis lanatis; mammillis brevibus ovatis, basi tetragonis; areolis magnis tomentosis; aculeis exterioribus $\mathbf{1 2}$ horizontaliter radiantibus rigidis flavidis, centra- 
libus 2 crassioribus, apice nigris, summo recto; inferiore deorsum curvato.

Truncus 1/1/2 2 poll. diam. Mammillae $2^{1 / 2}$ lin. longae, basi 4 lin. diam. Aculei radiantes $3-4$, centrales $4-5$ lin. longi. - Plantis adultis interdum, junioribus semper aculei centrales ambo vel alter desunt.

\section{M. radians DC.}

Revue p. 111. Mém. p. .5.

Pa: Mexico.

M. simplex subglobosa; axillis nudis; mammillis ovatis magnis; areola glabriuscula; aculeis $16-18$ radiantibus albidis rigidis, junioribus subtomentosis, centralibus nullis.

Variat apice obtuso aut subdepresso, acnleis albis aut subflavidis. Plantae circiter 3 poll. alt. et diam. Acnlei $5-6$ lin. longi.

\section{M. gladiata MART.}

Act. nov. nat. cur. XVI. P. I. p. 336.

Pa: Mexico (Yxmiquilpan).

M. subsimplex, tandem prolifera, obscure viridis; axillis sublanatis; mammillis crassis conicis, obsolete angulatis; areolis junioribus villosis, tandem nudis; aculeis 4, rigidis, albidis vel corneis, apice nigris, 3 superioribus divergentibus brevissimis, infimo multo longiore et crassiore, angulato, arcuato-deflexo.

Truncus $3-4$ poll. diam. lactescens. Mammillae 4 lin. longae, basi $5-6$ lin. diam. Aculei supremi $2-4$ lin., infimus subpollicaris.

\section{N. magnimamma HAw.}

Thu. phil. mag. 63. p. 41. - M. ceratophora LeHr. (Otro's Garten-Zeitung 1835. No. 29. S. 283.) - M. Schiedeana Hor'T.

Pa: Mexico.

M. subglobosa depressa; tuberculis magnis duris perviridibus, junioribus apice lanatis, senioribus glaberrimis, spinis 4 rigidissimis radiantibus recurvis lutescentibus, suprema minutissima, infima valde elongata (HAw.).

M. globosa simplex obscure viridis; axillis lanatis; 

mammillis magnis ovato-conicis obtusis duris; areolis junioribus albo-villosis; aculeis validis rigidis latiusculis fuscescentibus recurvulis, plerumque 3 , supremo 1 breviore erecto, 2 lateralibus patenti-deflexis; rarius 4 decussatis, summo brevissimo.

Mammillae 5 lin. longae, basi $8-10$ diam. Aculei superiores $3-5$, inferiores $8-10$ lin. Iongi. - Tubercula maxima tetragona cylindracea basi latissima valde depressa. Spinae validissimae rigidissimae latiusculae longitudinaliter sulcatae recurvodeflexae, janiores pallide fuscae, apice nigrae, seniores nigricantes. Lana mox evanida ad basin spinarum, in axillis quibusdam persistens (DC. pr. HI. p. 458.).

Aculeorum forma numerusque maxime variant; plantarum juniorum (inprimis seminalium) mammillae plerumque $5-6$ aculeos gerunt, quorum supremus longior incurvatus.

\section{M. recurva LEHM.}

\section{Lehmanni HorT.}

\section{Pa: Mexico.}

M. simplex globosa, obscure viridis, laete punctata, tandem glaucescens; axillis subnudis; mammillis magnis oblique conicis, basi subtetragonis, apice attenuatis, deorsum curvatulis; areolis infra apicem mammillarum, fere nudis; aculeis $3-4$ albis, apice fuscis, parvulis, deciduis, persistentibus $\mathbf{1}-\mathbf{2}$ rigidis, reliquis quadruplo longioribus, brunneis vel nigris.

Specimen in horte dom. Ha age mense Majo floriferum circa 5 poll. diam., 4 altum. Mammillae basi $5-6$ lin. diam., 5 lin. longae. Aculei persistentes subpollicares. Flores in annulo circa verticem positi fere poll. diam, laete coccinei. Calyx ventricosus, sepalis fuscidulis; petala lanceolato-acuminata subreflexa; stamina limbum aequantia rubra circa stylum purpureum, vix longiorem, conniventia.

\section{M. exsudans Zưcc.}

M. curvata H. BeroL.

Pa: Mexico (inter Yxmiquilpan et Zimapan KARw.).

M. subcylindrica; axillis subnudis glandulosis, glandulis pallide flavescentibus, novellis succum albidum exsudantibus ; mammillis obscure viridibus crassis ovatis; areolis junioribus vix tomentosis, mox nudis; aculeis exterioribus $6-7$ gracilibus rectiusculis, flavidis, patentibus, 
subaequalibus, centrali 1 vix distincto, erecto, flavo, apice fusco.

'Truncus $1 \frac{1}{2}$ poll. diam. Mammillae $3-4$ lin. longae, basi 6 lin. diau. Aculei $3-5$ lin. longi.

28. M. pycnacanthu MART.

Act. nov. nat. cur. XVI. P. I. p. 325. t. XVII.

Pa: Mexico (prope urbem Oaxaca KAnw.).

M. simplex obovato-cylindrica; mammillis latiusculis superne emarginato-bilobis; aculeis sub-16 pallidis ante curvatis et purpureo-fuscis, $\mathbf{4}-\mathbf{5}$ interioribus robustioribus; lana floccosa in axillis areolisque superioribus et circum flores.

Truncus 6 poll. alt., $3-4$ diam. Mamnillae $4-5$ lin. longae, basi $9-10$ diam. Acilei exteriores 5-6, centrales $6-8$ lin. longi. - Flores mense Julio ex axillis vertici proximis, majnscnli, diam. sesquipollicari. Foliola calycina et petala augusto-lanceolata, acuminata, citrina, illa dorso medio roseo-rubella. Stamina limbo cos rollae breviora, antheris aureis. Stigma in 5 radios antheras exsuperantes divisum, albidum.

Proles e mammillarum sulco dorsali enascuntur. Plantis junioribus hic sulcus deest.

\section{M. latimamma DC.}

Revue p. 114. Mém. p. $1 \%$.

Pa: Mexico.

M. simplex depressa subdiscoidea; axillis junioribus lanatis; mammillis brevibus, late ovatis, demum depressis, transverse oblongis; areola juniorum lanata; aculeis 16 - 17 rigidis flavicantibus, apice subfuscescentibus, divergentibus, inaequalibus.

Planta descripta $5 \frac{1 / 2}{2}$ poll. diam., vix $1 \frac{1 / 2}{2}$ poll. alta. Serius Cl. De Caudolle eam Th. magrimammae aequalem putavit (uémoire 1. c.), sed aculeorum numero valde differt! M. pycnacanthae potius adscribenda esse videtur.

\section{M. acanthostephes LeHм.}

Oтто's GZ. 1825. No. 29. S. 228.

Pa: Mexico.

M. subglobosa simplex; axillis nudis; mammillis latis subglobosis difformibus, supra profunde sulcatis subbilobis; areola glabriuscula; aculeis $13-17$ radiantibus, griseis, 


centralibus plerumque 5 , rarius 6 , multo majoribus, rigidioribus, ensiformibus.

M. pycnacanthae adeo affinis, ut vix distingui possint. Sed flores (ex Cl. Lehmann litteris) multo minores, petalis subspathulatis, a medio sursum inaequaliter atque minutim serrulatis, albis vel rubore suffusis.

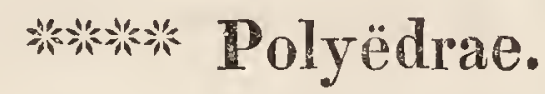

Caule globoso, saepe bicipite, semper lactescente; mammillis angulosis, pyramidatis.

\section{M. polyëdra Mart.}

Act. nov. nat. cur. XVI. P. I. p. 326. t. XVIII.

Pa: Mexico (prope Oaxaca KAnw.).

M. simplex subcylindrica, tandem ramulis lateraliter propullulantibus; mammillis pyramidato-applanatis in facies $6-7, z$ inferiores, 4 superiores, quarum altera minima; aculeis e lana alba $4-5$ rectis eburneis, apice purpurascentibus sphacelatisque, summo duplo majore, villo flores involvente fulvo contorto.

Truncus $4-6$ poll. altus, $3-4$ diam. Mammillae basi 6 lin. diam., 6 lin. longae. Aculeus supremus $8-10$, reliqui $4-6$ lin. longi. - Flores circiter pollicem longi. Calyx constat foliolis 15-16 lineari-lanceolatis acuminatis rubro-virentibus, niargine membranaceo albo, sub lente ciliato. Petala pauciora, parum longiora et latiora, acuminata, rosea, versus apicem nonnihil denticulata. Stamina numerosa, alba, petalis breviora. Antherae breviter ellipticae, flavae. Stylus albus, stamina superans. Stigma radiis 8 viridi-citrinis, suirsum curvatis, teretiusculis, obtusis; ubique papillosis, praeter lineam dorsalem posticam.

\section{M. subpolyëdra SALM.}

Hort. Dyck. p. 343. - M. polygona ZuCC. - N. anisacantha, jalappensis HorT.

Pa: Mexico.

M. simplex (tandem e lateribus prolifera) subcylindracea; axillis lanatis; mammillis pyramidato-applanatis fasciis 5-6; aculeis e lana alba 4 , primo atro-purpureis, dein pallidis, apice purpurascentibus, infimo majore.

Specimen Majo 1836 in horto dom. Ha g e floriferum 8 poll. altum, 5 poll. diam. Flores in tribus zonis circa verficeni. Corolla poll. diam. Sepala viridia, petala exteriora flavescenti-ru- 
bra, interiora rosea, nervo saturatiore. Stamina conferta alba, antheris flavis. - Bacca matura pollicaris, coccinea, pyriformis, apice $1 / 2$ poll. diam.

Plantarum juniorum aculei valde diversi, plerumque 6, 3 inferiores, 2 superiores minores, 1 supremus erectus, omnes carnei. anice nigricantes.

\section{\$3. M. Seitriana Mant.}

\section{Pa: Mexico (Yxmiquilpan).}

M. subglobosa, tandem basi prolifera; axillis lanatis; mammillis viridibus conicis, vix angulosis, basi tetragonis; areolis junioribus albo-villosis, tandem subnudis; aculeis 4 rectis rigidis decussatis (summo et imo aequalibus longioribus) carneis, apice nigris, lateralibus juxta supremum 2, multo minoribus, carneis.

Truncus 5 poll. alt., $3^{1 / 2}$ diam. Mammillae 5 lin. longae, basi $3^{1 / 3}$ diam. Aculei maximi 6', minores 4,2 minimi (quorum alter rarius deest) $1 \frac{1}{1} / 2-2$ lin.

Flores mensibus vernalibus pallide rosei, fere pollicem longi, parum expansi, 1/a poll. diam. Sepala olivacea. Petala linearilanceolata albida, nervo rubro. Stamina albida, antheris flavis; stylus 6-partitus.

\section{M. tetracantha SALm.}

\section{l'a: Mexico.}

M. subglobosa simplex; axillis lanatis ; mammillis confertissimis gracilibus anguloso-pyramidatis; aculeis ex areola fere nuda regulariter 4 brevibus rigidis, infimo caeteris paulo longiore, junioribus rubellis, apice nigricantibus, tandem albidis.

Planta descripta 4 poll. alta, $3^{1 / 2}$ diam. Mammillae $4-5$ lin. longae, basi vix 2 lin. diam. Aculei $2-3$ lin. longi.

\section{ณัด. M. villifera 0 тто.}

\section{Mystax Hont.}

Pa: Mexico.

M. subglobosa, tandem e lateribus prolifera; axillis lanatis et setosis; mammillis obscure viridibus angulosis, basi tetragonis; areolis junioribus lanatis, tandem nudis; aculeis 4 rigidis rectis, infimo longiore, nascentibus atropurpureis, dein nigris, tandem cinereis.

Specimen in horto Berolinensi 6 poll. altum, 5 poll. diam. 


Mammillae basi 4 lin. diam., 6 lin. Iongae; aculeus infimus 4 lin. longus.

Flores mense Majo pallide rosei. Petala 14 acuta, dorso linea purpurea notata. Stylus 4-partitus, staminibus longior; antherae 䲞avae.

\section{M. carnea Zucc.}

\section{Pa: Mexico (Yxmiquilpan.).}

II. globosa obscure viridis; axillis lanatis; mammillis pyramidato-conicis confertis; areolis junioribus lanatis, tandem nudis; aculeis 4 rigidis, subdecussatis, carneis, apice nigris, lateralibus 2 minimis rectis, summo et imo multo longioribus rectiusculis.

Mammillae basi 4 lin. diam., 5 lin. longae. Aculei laterales 3, summus $4-6$, infimus $5-8$ lin. longi.

11. villiferae affinis, sed colore et longitudine aculeorum satis diversa!

Flores carnei vel pallide rosei. Sepala et petala ciliato-denticulata. Stamina circiter 130 , filamentis albis, antheris pallide flavescentibus, Stigma ti-radiatum viride. Setae infra flores breves, lana absconditae (Cl. Z Zuc. in litt. $)$.

\section{3\%. M. Tarvinstiana MART.}

Act. nov. nat. cur. XVI. P. I. p. 335. t. XXII.

Pa: Mexico (Yxmiquilpan.).

IM. simplex subcylindrica; axillis lanatis et setosis; mammillis subpyramidato-conicis; aculeis e lana nivea 5 - 6 brevibus, rectiusculis, infeme albis, superne sanguineo-sphacelatis, 3 superioribus approximatis, medio majore toto sanguineo-fusco, 3 inferioribus longioribus subpatentibus.

Truncus saepe biceps. Proles plerumque ex axillis, rarius e mammillarum apice proveniunt.

Floret mensibus vernalibus. Flores fere pollicares, rubelli, setis eburneis cincti. Sepala 10-16 lanceolato-acuminata, basi viridi-oflavescentia, sursum purpurascentia; petala 12 angustiora, extus medio purpurascentia, caeterum et intus alba, pluriseriata. Stamina multiseriata, duplo breviora, flavescenti-alba, filiformia (112). Antherae parvae, sulphureae, ovatae. Stylus cylindricus, stamina paulo superans, glaber, albidus. Stigma lobis 5-6 linearibus sulphureis tenuiter papillosis.

B. flavescens Lucc. - Nloribus minoribus pallide flavis. 
38. M. centrispina Pfeiffen.

Onto's GZ. 1836. No. 33. S. 258.

Pa: Mexico.

M. subglobosa simplex; axillis lanatis, parce setosis; mammillis obtuse conicis, subangulosis, obscure viridibus; areolis infra apicem mammillarum, junioribus lanatis, dein nudis; aculeis exterioribus $5-6$ rigidis albis, apice nigris, centrali 1 rigidiore, nigro, longiore, rarius deficiente.

Truncus $3-4$ poll. diam. Mammillae $6-8$ lin. longae, 4 lin. diam. Aculei exteriores $2-4$ lin. longi, centralis (in plantis origin.) subpollicaris.

Flores mense Junio copiosi purpurei circa verticem. Baccae elongatae coccineae.

\section{M. Zuccariniana MART.}

Act. nov. nat. cur. XVI. P. I. p. 331. t. XX. - M. macracantha DC. revue p. 113. Mém. p. 15. t. 9.

Pa: Mexico (Yxmiquilpan.).

M. simplex subglobosa; axillis subnudis (floriferis lanatissimis); mammillis obscure viridibus conico-pyramidatis, apice acuto nudis; areolis infra apicem ovalibus immersis subnudis; aculeis centralibus 2 , sursum et deorsum versis, rigidis, cinereis, apice nigris, inferiore longiore, periphericis $2-3$ brevissimis albis, saepe deciduis.

Specimen in horto Monac. 8 poll. alt., 6 diam. Mammillae 6 lin. longae, basi 5 diam. Aculeus superior 4-6, inferior 8-12 lin. - Flores in superiore stirpis parte nunc sparsi, nune circulariter e zona axillarum erumpunt, $9-\mathbf{1 2}$ lin. longi, pilis longis albis contortis involuti. Foliola calycina lineari-oblonga purpurascenti-fusca. Petala numero dupla campanulato-expansa, angustiora et longiora, linearia, nitida, purpureo-rosea, mucronulata. Stamina numerosa alba, antheris flavis. Stylus teres, apice roseus, inferne albus, stigmatibus $4-5$.

\section{I1. Fischeri PrR.}

Отто's GZ. 1836. No. 33. S. $25 \%$.

Pa: Mexico.

N. subglobosa, saepe biceps; axillis valde lanatis, vix setosis; manmillis obscure viridibus polyëdris, basi tetragonis; areolis infra apicem, junioribus albo-villosis, tandem 


nudis; aculeis $5-6$ albis, apice nigris, elongatis, rigidis, patentissimis, summo (si adest) et imo longissimis, centrali nullo.

Species distinctissima, in honorem doctissimi dom. Fis cher, horti botanici Göttingensis inspectoris, dicta.

Specimina 4 poll. alta, $4^{1 / 2}-5$ diam. Mammillae $10-12$ lin. longae, basi 4 lin. Aculeus summus $1 / 2$, infimus $1-1 \frac{1}{4}$ poll., reliqui $4-5$ lin. longi.

\section{M. Hystrix Man't.}

\section{Pa: Mexico.}

M. depresso-globosa obscure viridis; axillis lanatis setosissimis; mammillis confertis subtetragonis; areolis junioribus albo-lanuginosis; aculeis exterioribus $5-6$ (infimo maximo), centrali 1, rigidis, rectis, nascentibus atropurpureis, dein albis, apice nigris.

Specimen descriptum $3 \frac{1 / 2}{1}$ poll. altum, 5 poll. diam. Mamnillae 6 lin. longae, basi $3-4$ lin. diam. Acule: $3-4$ lin. Setae axillares $6-10 \mathrm{lin}$.

Flores hucusque ignoti.

\section{M. Mystax Mant.}

Act. nov, nat. cur. XVI. P. I. p. 332, t. XXI.

* Pa: Mexico (Yxmiquilpan.).

M. simplex cylindrica; axillis lanatis et setosis; mammillis confertis pyramidatis, apice valde attenuatis; areolis junioribus lanatis, tandem nudis; aculeis exterioribus 6 albidis, apice nigris (superioribus minoribus), interioribus 4 decussatis fuscescentibus, longioribus, crassioribus, saepe centrali 1 erecto nigro.

Specimen unicum in horto Monacensi nunc 9 poll. alt, 5 diam. Man̂millae 6-7 lin. longae, basi 4 diam. Aculei exteriores $2-5$, interiores $4-6$, centralis 4 lin. - In parte originaria aculei multo longiores, cinerei, omnes aut unus alterve torti implexique lateraliter dependent.

Flores in axillis mammillarum superiorum prodeunt, saepe per zonam circularem dispositi, pollicem longi, extus muniti pilis nonnullis brevioribus et setis $8-12$ filiformibus eburne-albis, apice sphacelatis. Flores canpanulati. Sepala $6 \rightarrow 8$ lineari-lanceolata, acuta, purpureo - fusca, margine alba, primum erecta, dein silperne revoluta, uninervia. Petala 8-10 latiora, fere pollicem longa, in mucronem acutissinum reflexum excurentia, roseo-purpurea, 


\section{2}

nitida. Stamina inclusa, petalis breviora, alba, antheris ellipticis citrinis. Stylus staminibus nounihil longior, coronatus stigmatibus 4--5 linearibus obtusinsculis, medio utrinque sulco exaratis, ad marginem stigmatosis, pallide flavis.

\section{M. Caput Medusae Oтто.}

M. Sempervivi DC. revue p. 114. Mém. p. 13. t. 8 . Pa: Mexico (in frigid. provinc. Jalapp.).

M. simplex, basi attenuata, superne depressa, disciformis; axillis lanatis; mammillis erectis ovato-tetragonis; areola glabriuscula; setis $3-4$ rigidis brevibus, albidis, aculeis 2 crassis brevibus divergentibus (DC.).

M. irregulariter columnaris, vertice impressa; axillis lanatis; mammillis obscure viridibus confertis polyëdris; areolis fere nudis; aculeis 2 minutissimis rigidis albis, apice nigricantibus.

Specimen in horto Berol. 6 poll. altum, 21/2 poll. diam. Mammillae basi 2 lin. diam., aculei 1 lin. longi. In nonnullis areolis 4 aculei decussati et setae 5-6 exteriores, deciduae inveniuntur, quare varietas $\beta$. tetracantha DC. delenda.

Flores solitarii sessiles, mammillis vix longiores, 8 lin. diam. Sepala dorso sordide olivacea, petala sordide alba, linearia, expansa; stamina petalis dimidio breviora; stylus staminibus aequalis.

\section{M. disciformis DC.}

Revue p. 114. Mém. p. 14.

Pa: Mexico.

M. simplex depressa disciformis; axillis nudis; mammillis confertis brevibus depresso-tetragonis; areola juniorum subtomentosa, adultorum subinermi; aculeis (in mammis centralibus) 5 rigidis albis erectis.

Haec planta, forma sua distinctissima (1 poll. alta, 3 poll. diam.) in horto Genevensi mox obiit, nec amplius in hortis europaeis occurrere videtur.

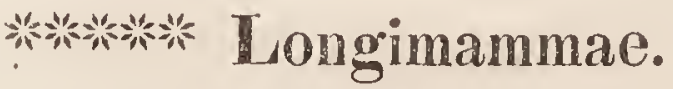

Caule humili, basi prolifero, vel cylindrico, mammillis subeylindricis vel conicis, elongatis, divergentibus.

\section{4.). M. longimamma DC.}

Revue p. 113. Mém. p. 10. t. 5. 


Pa: Mexico.

M. simplex aut basi submultiplex, ovata aut subcylindracea; axillis lanatis; mammillis ovato-oblongis dissitis; areola tomentosa; aculeis pungentibus cinereo-fuscis, sulb lente scabro-velutinis, $7-8$ patentibus, centralibus $1-3$, vix longioribus.

Mammillae $1-1^{3 / 4}$ poll. longae, basi $9-10$ lin. transverse latae; aculei $8-12$ lin. Flores mense Junio et Julio, citrini, $11 / 4$ poll. longi, expansi (sole lucente) $1^{1 / 2}$ poll. diam. Calyx tubulosus, viridis; petala exteriora dorso rubentia, interiora citrina, linearia, acuta. Stamina petalis dimidio breviora, flava, spiraliter contorta, antheris vitellinis; stylus staminibus aequalis, stigmata 5 - 6 flava, crassa, obtusa.

Proles sponte quidem ex axillis nascuntur, sed mammillae singulae $\Theta$ planta excisae facile radicant, plantulasque novas gignunt.

\section{II. uberiformis Zucc.}

Pa: Mexico (in pratis prope Pachuca KARw.).

M. humilis subglobosa; axillis nudis; mammillis obscure viridibus nitidis, elongatis, crassis, divergentibus, cylindraceis, apice obtusis, lateribus hinc inde compressis; areolis subnudis; aculeis 4 (rarius 3 ) subdecussatis, rigidis, corneis, subaequalibus, pubescentibus, centrali nullo.

Truncus 3 poll. alt., 4 diam. Mammillae $1-1^{1 / 2}$ poll. longae, basi 6-8 lin. diam., succo limpido scatentes, subflaccidae. Aculei $6-8$ lin. - Flores subtubulosi lutei, expansi $1^{1 / 2}$ poll. diam. Tubus gracilis albidus, corollam versus ventricosus, sepalis ruhellis. Petala biserialia, apicem versus latiora, lacinulata, acuminata. Stamina filiformia, spiraliter contorta, alba, antheris flavis; stylus flavus, stigmatibus $5-6$ reflexis.

\section{M. Lehmanni H. Beror.}

M. octacantha et leucacantha DC. revue p. 113. Mém. p. 11?

\section{Pa: Mexico.}

M. (octacantha) simplex ovato-oblonga, subcylindracea; axillis nudis; mammillis oblongis subtetragonis; areola juniorum subtomentosa; aculeis rigidis, exterioribus radiantibus albis, centrali 1 longiore, rigidiore, subiuscescente (DC.).

M. simplex elongata; axillis primum lanatis, deinde puncto rubro glanduloso instructis; mammillis elongatis so- 
litariis conicis, basi latissimis; areolis infra apicem mammillarum, albo-tomentosis; aculeis subrigidis rectis, -8 regulariter radiantibus, albis, apice fuscis, centrali 1 fusco.

Truncus 2-21/2 poll. diam. Mammillae 1 poll. longae, aculeus centralis pollicaris, reliqui paulo breviores, juniores quasi tunicati.

\section{II. macrothele MART.}

Pa: Mexico.

N. simplex cylindrica; axillis latis, $\mathbf{1}$ - 2 glandulis rubris, tomento albo cinctis, instructis; mammillis elongatis divergentibus, basi latis, subtetragonis, obtuse conicis, valde attenuatis, saepe recurvatis; areolis oblongis infra apicem mammillarum, subnudis, glandula rubra supra aculeorum fasciculum notatis; aculeis exterioribus 8 patentibus rigidis, coneis, apice nigris, centralibus $1-2$ paulo crassioribus brunneis.

M. L e hmanni affinis, $3-4$ poll. diam., pedalis. Mammillae basi 6 lin. diam, poll. longae. Aculei radiantes 5-6 lin., centrales pollicares.

\section{M. Plaschnickii Отто.}

Pa: Mexico.

M. cylindrica glaucescens; axillis glandulosis et lanae denso fasciculo instructis; mammillis magnis solitariis, basi lata subtetragonis; areolis infra apicem mammillarum, junioribus albo-tomentosis; aculeis exterioribus 9 rigidis nigricantibus, centralibus 4 longioribus, infimo longissimo horizontali.

Specimen descriptum basi 3 poll. diam. Mammillae 12-14 lin. longae, aculeus infimus $1^{1 / 2}-1^{3 / 4}$ poll. longus. - In honorem dom. Plaschnick, strenuissimi Cactearum in horto Berolinensi cultoris, dicta.

\section{S. 2. Heteracanthae.}

Aculeis diversiformibus, centralibus forma et colore ab exterioribus (plerumque setaceis) distinctis.

\section{* Vicrothelae.}

Caule subeylindrico vel globoso, mammillis parvulis conicis confertis. 




\section{M. crucigera MART.}

Act. nov. nat. cur. XVI. P. I. p. 340. t. XXV. f. II. Pa: Mexico.

M. cylindrica aut obovata, prolifera; axillis floccosis; mammillis conicis laete viridibus, in vertice cruce horizontali aculeorum 4 parvorum flavescentium et circulo setarum albarum aequilongarum instructis.

Planta originaria in horto Monacensi culta quasi e 3 caulibus confluentibus composita, triceps, figura obovata, 6 poll. alta fuit, sed unum tantum horum capitum servatum est, plantam formans subglobosam. Specimen maximum in horto Berolinensi cylindricum potius est, prolesque e lateribus edidit. Mammillae recentiores saepe $5-6$ aculeolis centralibus instructae sunt. Mammillae 2 lin. longae, $2^{\mathrm{y} / 2}$ lin. diam. Aculei 2 , setae radiantes $1^{1 / 2}$ lin. longae.

Species hucusque rarissima. Quae sub hoc nomine coluntur plantae, plerumque ad $\boldsymbol{M}$. elegantem $\mathbf{D C}$., similesque species referendae sunt.

Floruit in horto Berolinensi mense Majo 1833. - Flores (ex Cl. Martii descriptione) ejusdem magnitudinis ac $M$. sphacelatae, pulchre purpurei. Sepala et petala lanceolata, acuta, haec subhorizontaliter patentia ant recurva. Stamina numerosa, tubo paulo longiora, antheris aureis. Stigma purpureum, antheras superans, in crura cylindrica $4-5$ divisum.

\section{M. supertexta MART.}

\section{Pa: Mexico.}

M. subglobosa vel oblongata simplex; axillis et interstitiis adeo lanatis, ut mammillarum apices vix promineant; mammillis parvulis conicis confertis viridibus; areolis subnudis; aculeis e tomento parco fulvo, centralibus 2 brevibus rigidis albis, nonnullis apice nigricantibus, exterioribus $16-18$ albis rigidiusculis bifarie radiantibus.

Specimen in horto Monac. 6 poll. alt., $2^{3 / 4}$ diam. - Differt a speciebus affinibus aculeis radiaritibus multo rigidioribus, $21 / 2$ lin. longis, centralibus brevioribus, applanatis, albis, 11/2 lin. longis.

\section{M. elegans DC.}

Revue p. 111. Mém. p. 5. - M. supertexta Hon'r. Pa: Mexico.

M. simplex obovata, apice subumbilicata; axillis nudis; mammillis ovatis; areola juniorum tomentosa; setis $25-30$ 


\section{6}

albis radiantibus subrigidulis, aculeis $1-3$ rigidis erectis setas paulo superantibus (DC.).

ß. minor DC.: exactius obovata, dimidio minor. Eadem junior?

$\gamma \cdot$ globosa: subglobosa, major, axillis superioribus barbatis. Eadem vetustior?

Varietates $\beta$. et $\gamma$. delendae videntur! Mammillae 4 lin. longae, basi $2^{1 / 2}$ diam., glaucescentes, areolae subnudae, aculei centrales plerumque 2 , rarius 3 vel 4 decussati nigri, basi pallidi, $31 / 2$ lin. longi, radiantes $20-28,2$ lin. longi.

\section{M. Haageana PFR.}

\section{Oтто's GZ. 18:6. No. 33. S. 25\%.-M. Perote Hont.} - M. diacantha nigra HAAge catal. 1836.

\section{Pa: Mexico (Perote).}

M. subglobosa glaucescenti-viridis; axillis parum lanatis; mammillis confertis minutis, basi tetragonis; areolis subnudis; aculeis centralibus 2 nigris gracilibus elongatis, exterioribus 20 albis, brevibus, setiformibus, radiantibus.

Specimen maximum in horto dom. Hage, experientissimi Cactearum cultoris, 11/4 poll. diam. Aculeus centralis superior 3, inferior 4 lin., radiantes $1 \frac{1 / 2}{2}$ lin. longi.

\section{5ุ. I. acanthoplegma LEHM.}

Delect. sem. Hamb. 1833. - M. geminispina DC. revue p. 30. t. 3. - Cact. columnaris fl. mexic. ic. ined.

\section{Pa: Mexico.}

M. subglobosa; axillis lanatis; mammillis obovatis brevibus confertis; areola lanata; aculeis $\mathbf{2 1 - 2 4}$ albidis setiformibus, horizontaliter patentibus, irregulariter radiantibus et vicinis undique intertextis totam plantam tegentibus, centralibus 1-2 erectis robustioribus, apice nigris.

Flores imense Majo copiosi, 5-6 lin. diam., lilaceo-purpurei, per plures dies aperti. Tubus brevissimus pallidus, lana alba involutus. Petala linearia reflexa. Stamina rubra, antheris magnis sulphureis; stylus roseus, staminibus vix longior, stigmatibus 4-6 coufertis sulphureis.

Cactum columnarem fl. mexic. Cl. De Candolle pro $\mathbf{M}$. geminispina $\mathrm{Haw}$. habuit, sed figura delineata procul dubio hue referenda est.

Pa: Mexico.

55. M. Dyckiana Zucc. 


M. subcylindrica simplex; axillis lanatis; mammillis brevibus conicis, confertis, glaucescenti-viridibus; areolis junioribus fusco-lanatis, tandem nudis; aculeis radiantibus 16-18 diaphane albis, rigidis, patentissimis, subintertextis, centralibus 2, sursum et deorsum spectantibus, multo crassioribus, longioribus (infimo longissimo), corneis, apice rubellis.

Specimen hucusque unicum in horto Monacensi $1^{1 / 2}$ poll. diam. Mammillae $2^{1 / 3}$ lin. longae, basi 2 lin. diam. Aculei radiantes 2 , centrales $4-7$ lin. longi.

\section{II. bicolor LEHM.}

Delect. sem. Hamb. 1830. Linnaea VI. Lit. p. 11. M. geminispina HAw. philos. mag. 63. p. 42.

M. simplex cylindraceo-columnaris; axillis valde lanatis ; tuberculis exiguis numerosissimis; spinis parvis intertextis albis, 2 in singulo fasciculo caeteris multoties longioribus (Haw.).

M. obovata, superne prolifera; axillis lanatis; mammillis spiraliter contortuplicatis ovato-pyramidalibus, apice lanigeris et spiniferis; aculeis setaceis 16- 20 divaricatis candidis, 2 erectis multo longioribus apice sphacelatis (Lенм.).

Plantae plus quam semipedales, fere omnino simplices, teretes, superne sensim crassiores, apice vix convexo. Mammae pallide virides, spinis recurvo-radiantibus capillaceis albis, duabus in singulo fasciculo validioribus, gemination semierectis pungentibus, apice nigris ( $\mathrm{H} \mathrm{aw}$ ). - Plantae 2-21/2 poll. diam. Aculei centrales subpollicares, interdum $3-4$, quare nomen Lehmanni praeferendum.

\section{5\%. M. nivea WENDL.}

Catal. h. Herrnlius. 1835. - M. Toaldoae Lemm. (in litt.). Pa: Mexico.

II. obovata prolifera; axillis lanatis; tuberculis conicis apice lanatis spiniferis; spinis exterioribus albis adpressis capillaribus, interioribus 4 albis, apice fuscis, supremis incurvis elongatis, longitudine pollicis.

An a praecedente satis diversa?

\section{***is Conothelae.}

Caule crasso globoso vel cylindraceo, mammillis conicis. 


\section{8}

\section{M. discolor HAw.}

Syn. p. 17\%. - M. depressa DC. revue t. 2. f. 2. Cactus Spinii Colta antol. 6. p. 501. - M. pulchella H. Berol. - M. canescens Hort.

Pa: Mexico, Amer. calid.

M. globosa vel ovata subsimplex glaucescenti-viridis; axillis vix tomentosis; mammillis ovato-conicis; areolis fere nudis; aculeis exterioribus 16-20 albis setaceis subrigidis radiantibus, interioribus 6 rigidioribus recurvulis, junioribus nigris, basi albidis, serius cinereis, summo et imo longissimis, rarissime 1 centrali erecto.

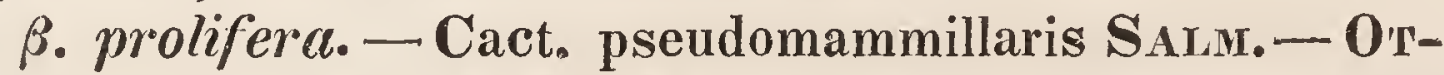
To's GZ. 1835. No. 8. S. 58. - Caule cylindrico e lateribus copiose prolifero, aculeis centralibus $4-5$, rarius 6 longioribus, magisque curvatis.

Flores plerumque mense Februario - Aprili, rosei, aperti 8 lin. diam. Sepala fusco-rubentia, petala linearia albido-rosea, dorso linea rubra distincta, reflexa. - Bacca pollicaris, sordide rubra.

\section{M. albida HAAGE.}

M. confinis HAAGE catal. Cact. 1836.

Pa: Mexico.

M. globosa; axillis laete viridibus, parum lanatis; mammillis perviridibus conicis; areolis albo-lanuginosis; aculeis exterioribus $16-20$ tenuissimis setiformibus albis radiantibus, centralibus $4-5$ fulvis vix rigidioribus curvatulis.

Praecedenti valde affinis! - Flores rosei.

60. M. chrysacantha H. BenoL.

Pa: Mexico.

M. subglobosa simplex; axillis nudis; mammillis conicis; aculeis $15-18$ radiantibus aureis, centralibus 4 validioribus, 3 fuscescentibus divergentibus, summo longiore brunneo erecto.

Truncus $4-6$ poll. diam., $3-4$ altus. Mammillae 5 lin. Iongae, diam. transverso 5 lin. Aculei exteriores $3-4$, centrales 4-6 lin. longi.

\section{M. fuscata H. BEROL.}

Pa: Mexico. 


M. globosa simplex; axillis nudis; mammillis conicis basi 4 -angularibus; aculeis $25-28$ tenuibus radiantibus laete fuscis, centralibus 6 brunneis validioribus, supremo longissimo, verticem versus incurvato.

Praecedenti affinis, sed aculeorum numero, colore et forma satis diversa. Aculei horizontaliter adpressi quasi rete formant, quod impune tangere possis, dum M. chrysacanthae aculei centrales erecti et pungentes tactum incautum non permittunt. Mammillae 4 lin. longae, 3 lin. diam. Aculei radiantes $3-4$, centrales $5-6$ lin. longi.

Flores mensibus Majo-Julio in pluribus zonis circa verticem, purpurei, 8 lin. diam. Petala circa 20 acuta; stamina stylo 5-partito breviora.

\section{I1. rutila Zucc.}

\section{Pa: Mexico.}

M. globosa simplex; axillis subnudis; mammillis confertis conicis, obscure viridibus, areolis junioribus tomentosis; aculeis radiantibus $\mathbf{1 4 - 1 6}$ albis setiformibus, supremis minimis, centralibus $4-6$ longis divaricatis rigidis, curvatulis, fusco-coccineis, basi corneis, infimo longissimo.

Mammillae 5 lin. longae, basi 3 diam. Aculei radiantes $2-4$, centrales $4-6$ lin. longi.

\section{M. aciculata 0тто.}

Pa: Mexico (frigid.).

M. subglobosa glaucescenti-viridis; axillis subnudis; mammillis confertis obtuse conicis; aculeis radiantibus 20 albis gracilibus, centralibus 4 (rarius 6) brunneis rectis rigidis, infimo longissimo.

Mammillarum series fere verticales. Aculei infimi 11/2 pollicares, valde pungentes. Flores mense Junio purpurei.

\section{II. tentaculata H. BeroL.}

M. puichra HAw. (bot. reg. t. 1329)?

Pa: Mexico.

M. subglobosa (interdum biceps) subglaucescens; axillis lanatis; mammillis confertis obtuse conicis, basi tetragonis; areolis junioribus albo-lanatis, tandem nudis; aculeis $4-6$ centralibus fulvis rigidis, summo longissimo, vix incurvo, radiantibus sub-25 tenuibus albis. 
Truncus 3-4 poll. diam. Mammillae 5 lin. Iongae, 3 lin. diam. Aculei radiantes $3-4$, centrales 5 lin. longi.

Floret per totam aestatem in pluribus zonis circa verticem. Flores parvuli, purpurei, mane solum aperti, limbo reflexo supra mammillas prominente, petalis linearibus. - Bacca matura 10 lin. longan, tentis, cylindracea, lilaceo-coccinea.

\section{M. fulvispina HAw.}

Philos. mag. 1830. p. 109.

Pa: Brasilia, Mexico.

M. subrotunda, mammillis sub-13-spinosis, spinis sub4 caeteris plus duplo longioribus, extimis horizontalibus (Haw. 1. c.).

M. globosa simplex; axillis sublanatis; mammillis conicis perviridibus; areolis junioribús tomentosis; aculeis centralibus 4-6 rigidis, rectiusculis, subaequalibus, fulvis, exterioribus 16 brevissimis albis rigidis regulariter radiantibus.

Ex Haworthii descriptione (flores majusculos rubros apicales dicit) et patria illam plantam pro Echinocacti specie (forsan centeterio) facile habere possemus, nisi Haworthius ipse in descriptione M. pulchrae affirmaret, hanc fulvispinosae esse affinem.

Plantae nostrae aculei centrales $6-7$, radiantes $11 / 2$ lin. longi.

\section{M. hexacantha SAMM.}

\section{Hort. Dyck. p. 344.}

Pa: Mexico.

M. simplex depressa; mammillis subcompressis; areolis ovalibus, junioribus albo-tomentosis; aculeis biformibus, exterioribus subsetaceis $25-30$ radiantibus albis, centralibus 6 validis brunneis, infimo longissimo.

Planta descripta sine prole obiit!

\section{6\%. M. selosa Prr.}

Orro's GR. 1835. No. 48. \$. 389.

Pa. Rirexico.

M. simplex robusta cylindrica; axillis et interstitiis mammillarum lanatis; mammillis obscure viridibus confertis conicis, basi rhombeis; areolis albo-tomentosis; aculeis 6 (rarius 4 vel 8 cum uno centrali erecto) rigidis, junio- 


ribus atropurpureis, dein albidis, subrecurvis, infimo longissimo, setisque a parte inferiore areolarum defluentibus $8-14$ albis multo brevioribus inaequalibus.

Flores per totam aestatem copiosi, parum expansi, matutini, M. tentaculatce similes. Sepala fusco-rubra, petala linearia saturate rosea; stamina numerosa versus stigma curvata purpurea, antheris sulphureis; stigmata $3-5$ purpurea.

Axillae plantarum juniorum nudae. Truncus $6-8$ poll. altus, 3-4 diam. Aculei 4-6 lin., setae decurrentes $1-3$ lin. longae. Planta nostra habitu proxime ad $M$. columnarem accedit, nec nunquam sub hoc romine colitur, sed facile distinguitur barba setosa, aculeisque multo longioribus et magis curvatis.

\section{IN. rhodantha Link et OTto.}

1. et O. icon. t. 26. - M. atrata, aurata, hybrida HoRT. Pa: Mexico.

M. oblonga, subcylindrica, plerumque bipartita; axillis lanatis et setosis; mammillis perviridibus conicis; areolis albo-villosis; aculeis radiantibus $16-20$ albis setiformibus, interioribus 6 rigidis albis vel flavescentibus, summo apice nigris, interdum centrali 1 breviore.

Truncus ultrapedalis, $3-4$ poll. diam., a medio plerumqque duplex. Mammillae 6 lin. longae, 4 lin. diam. Aculei superiores 3, inferiores $4-5$, centrales 6 lin. longi.

Flores copiosi per totam aestatem, rosei, 1/2 poll. diam., vix e spinis prominentes, petalis linearibus, vix expansis. Stamina rubra conniventia, stigmata $4-5$ rosea. - Bacca pollicaris, cylindracea, lilaceo-coccinea.

$\beta$. prolifera. - Ramis ex axillis lateralibus undique propullulantibus.

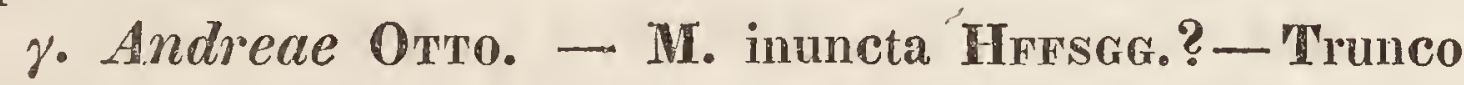
humiliore multicipite, mammillis paulo minoribus et gracilioribus, aculeis rigidioribus et brevioribus, apice fuscis.

d. Wendlandii. - M. erinacea WENDL. catal. hort. Herrnhus. 183ă. - Trunco obovato subsimplice, aculeis multo rigidioribus.

E. neglecta H. Berou. - Trunco subcylindrico, saepe bipartito, areolis villosis, aculeis centralibus aureis curvatulis, radiantibus $12-16$ tenuissimis.

Ђ. mbens. - M. pyramidalis H. Beror. - Trunco subconico simplice, aculeis centralibus 6 rubescenti-fulvis, summo longissimo. 


\section{2}

\section{M. eriacantha H. BEROL.}

M. cylindrica, eriantha IIonT.

Pa: Mexico (loci montosi).

M. simplex cylindrica elongata; axillis lanatis; mammillis confertis acute conicis ; areolis albo-lanuginosis; aculeis radiantibus $20-24$ setaceis flavescentibus, centralibus 2 rectis rigidis, sursum et deorsum spectantibus, aureis, pubescentibus.

Truncus semipedalis et ultra, $2-2 \frac{1}{2}$ poll. diam. Nammillae 4 lin. longae, $2^{1 / 2}-3$ diam. Aculei centrales 4 et 5 , radiantes 3 lin. longi.

Flores mense Junio parvuli flavidi, expansi $6-7$ lịn. diam. Petala linearia acuta, straminea, circa 14. Stamina numerosa, antheris flavis; stylus 4 partitus. Bacca initio pallide flavo-rosea, mature aurantiaca, obclavata.

\section{\%. M. cylindracea DC.}

\section{Revue p. 111.}

$\mathrm{Pa}$ : Mexico.

II. simplex, cylindrica; axillis parce setosis; mammillis ovatis; areola glabriuscula; setis $25-30$ radiantibus albis, mamma brevioribus, aculeis centralibus 2 rigidis divergentibus, setas duplo superantibus.

An praecedenti aequalis?

\section{M. vetula MART.}

Act. nov. nat. cur. XVI. P. I. p. 338. t. XXIV.

\section{Pa: Mexico.}

M. cylindrica, tandem e lateribus prolifera; axillis subnudis; mammillis nitide viridibus conicis; aculeis e tomento parcissimo, exterioribus plurimis (primo $25-30$ ) setiformibus albis horizontalibus (tandem sub-50 incompte intertextis) centralibus $1-3$ robustioribus fuscis surrectis.

Truncus 4-6 poll. altus, 2 diam. Aculei 3-4 lin. Iongi.

Flores plerumque mensibus Octobri-Decembri, unguem longi, cylindrico-campanulati. Sepala et petala lanceolata, acuta, citrina; illa dorso nervo obscuriore subrubello percursa. Stamina inclusa, antheris flavidis. Stigma albidum, radiis quinque. 

72. M. vivipara Haw.

p. 295.

Suppl. p. $2 \%$ - Cact. viviparus Nurt. gen. am. 1.

$\mathrm{Pa}$ : Louisiana (in collibus altis ad flumen Missouri.).

II. parvula subglobosa, caespites formans; axillis nudis; mammillis obscure viridibus, obtuse conicis, sulco prolifero barbato superne notatis; areolis junioribus majusculis, albo-tomentosis; aculeis radiantibus $1 \mathfrak{1}$ albis, centralibus 2-4 brunneis, omnibus rectis gracilibus.

Caespites 2-3 ped. diam. Flores fere Cerei flagelliformis laete rubri. Calycis lobi exteriores ciliati. Bacca nvae magnit. (DC. pr. III. p. 459.). - Flores in hortis europaeis nondum observati esse videntur.

\section{*䓋济 Brachythelae.}

Caule cylindrico vel subgloboso, mammillis ovatis. Fere omnes minus notae.

\section{11. grandiflora Oтто.}

\section{M. canescens H. BeroL.}

Pa: Mexico.

II. simplex cylindrica; axillis lanatis; mammillis magnis ovatis; aculeis centralibus $3-4$ rectis nigricantibus, radiantibus $16-20$ setaceis albis.

Planta nunc mortua floruit in horto Berolinensi 13. Aug. 1830. Flos speciosissimus, fere apicalis, roseus, 2 poll. diam. Petala angusta, acuminata; stamina uumerosa, antheris flavis, styio 5-partito breviora.

\section{M. coronaria Haw.}

Rev. p. 69. - Cact. coronatus W. enum. suppl. $30 .-$ Cact. cylindric. ORT. dec. 198, t. 16.

$\mathbb{P a}$ : Nexico, Guatimala.

M. robusta cylindrica, tandem e parte inferiore prolifera; axillis subnudis; mammillis glaucescentibus magnis oratis; aculeis e tomento parco, exterioribus 13-16 pellucidis albis rigidis radiantibus, centralibus 4 longioribus fuscis, infimo longissimo, in plantis junioribus valde elongato et apice uncinato.

Species pulcherrima, generis altissima 5-pedalis, diametro semipedali (DC. pr.). IVammillae $6-7$ lin. longae, 6 lin. diam. Aculei exteriores 6 (supremi 3), centrales $4-12$ lin. longi. - 
Flores coccinei, tuberculis longiores, in apice caulis quasi corona dispositi. - Rarissime tantum in hortis floret, forsan prima vice vere 1836 in horto Arnstadiensi.

\section{\%5. M. humala LEHY.}

Delect. sem. Hamb. 1832.

Pa: Mexico.

M. simplex obovato-oblonga; axillis subnudis; mammillis pyramidato-conicis; areola lanata; setis 15-20 inaequalibus pungentibus, exterioribus radiantibus albis, centralibus $3-4$ erectis fuscis, terminali valde elongata hamata.

Praecedenti affinis, attamen diversa! Ex litteris Cl. L ehmann planta descripta obiit et species in hortis haud anplius occurrit.

\section{M. cornifera DC.}

\section{Revue p. 111.}

Pa: Mexico.

M. simplex globosa; axillis nudis; mammillis ovatis crassis confertis; areola glabriuscula; aculeis exterioribus $16-17$ radiantibus griseis, centrali 1 valido, longiore, erecto, subincurvo.

Pl. 3 poll. diam., 21/2 alta; aculei radiantes $5-6$ lin. longi, centralis $7-8$.

\section{\%\%. M. uncinata Zucc.}

Pa: Mexico.

M. globosa simplex; axillis inferioribus nudis, superioribus lanatis; mammillis obscure coerulescenti-viridibus confertis crassis, mutua pressione subangulosis; areolis junioribus lanatissimis, tandem nudis; aculeis exterioribus 4 decussatis subaequalibus, rigidis, supremo carneo curvatulo, reliquis albis, apice nigris, rectis, centrali 1 longiore, crassiore, carneo, apice fusco, uncinato.

Mammillat $4-5$ lin. longae, basi 4 diam. Aculei exteriores $2^{1 / 2}-3$, centralis 5 lin.

Flores parvi purpurei.

\section{M. brevimamma Zucc.}

Pa: Nexico.

M. subglobosa vel cylindracea simplex; axillis glandulosis, parce tomentosis; mammillis brevibus latis mammae- 


formibus, obscure viridibus; areolis tomentosis; aculeis exterioribus 6 horizontalibus, rigidis, corneis, apice nigricantibus ( 3 superioribus brevioribus), centrali 1 erecto, uncinato, paulo crassiore, fusco.

Specimina 2-21/2 poll, diam. Mammillae 3 lin. longae, basi 6-7 diam. Aculei superiores 3, inferiores 4, centralis 3-4 lin.

\section{M. conoidea DC.}

Revue p. 112. Mém. p. 6. t. 2.

Pa: Mexico.

M. simplex ovata conica; axillis junioribus lanatis; mammillis ovatis confertis; areola juniorum subtomentosa; aculeis rectis rigidis, exterioribus $15-16$ radiantibus, centralibus $3-5$ erecto-divergentibus fuscis longioribus.

Planta florifera 4 poll. alta, basi $2^{3 / 4}$ diam. Flos sessilis soli= tarius in axilla vertici proxima, ita ut terminalis appareat, 10-12 lin. longus, supra mammillas prominens, purpureus. Sepala extus virescentia, intus rubra, petala $3-4$-serialia, linearia, mucronata. Stamina numerosa, petalis dimidio breviora, antherae aurantiacae. Stylus longior, filiformis, stigmata 6 flavescentia, obtusa, extus sulcata.

\section{M. crebrispina DC.}

\section{Revue p. 111.}

\section{Pa: Mexico.}

M. basi multiplex, surculis ovatis; axillis nudis; mammillis ovatis brevibus confertis; areola glabriuscula; aculeis rectis, exterioribus $\mathbf{1 6}-\mathbf{1 7}$ radiantibus albis, centralibus3 fuscis erectis.

M. conoideae affinis! Pl. 2 poll. alta, 11/2 diam. Aculei ob mammas confertas caulem fere ocwiltant.

\section{M. caespiticia DC.}

Revue p. 112.

Pa: Mexico.

M. basi multiplex, caespitosa, aggregata, globosa; axillis nudis; mammillis paucis ovatis; areola glabriuscula; aculeis rectis rigidis, junioribus albido-flavidis, adultis griseis, exterioribus 9--11 radiantibus, centralibus $1-2$ longioribus erectis.

Caespes 4 poll. latus. Surculus quisque pollicem diam. 


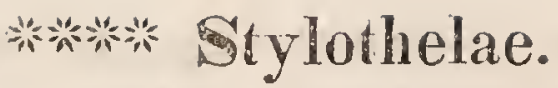

Caule humili, prolifero, mammillis confertis columnaribus elongatis.

\section{M. pusilla DC.}

Revue p. 29. t.2. f. 1. - Cact. [usillas DC. cat, hort。 monsp. 184. - Cact. stellatus Lobd. bot. cab. 1. t. 79. Pick. phyt. t. 29. f. 2? - Cactus stellaris L. - Mamm. stellaris Hon'r.

Pa: India occidentalis.

M. globosa multiplex, caespites formans fere hemisphaericos; axillis subbarbatis; mammillis gracilibus cylindraceis; areolis villosis; aculeis $4-6$ rigidis rectiusculis albido-flavis pubescentibus, exterioribus $1 \mathbf{2}$-20 piliformibus albis.

Mammillae 5-6 lin. longae, aculei 4 lin. longi. Flores copiosi, mammillis longiores; petala inucronulata flavida, nervo roseo; stamina alba, antheris flavis; stylus vix longior, stigmatibus 5 flavis. - Baccae hieme et vere maturescentes oblongae, basi attenuatae, coccineae.

ß. major. - Caule cinerascente, subsimplice, mammillis duplo longioribus, aculeis 6 lin. longis, floribus minjoribus.

\section{M. glochidiata MART.}

Act. nov, nat. cur. XVI. P. I. p. 33\%. t. XXIII. H. ancistroides Lern. delect. sem. Hamb. 1832. - M. criiiiformis DC. mémoire p. 8. t. 4 .

Pa: Mexico.

M. tandem dense caespitosa; mammillis nitide viridibus cylindricis obiusis; aculeis e lana parca, exterioribus setiformibus $12-15$ albis horizontalibus, interioribus $3-4$ fuscidulis, centrali surrecto uncato, reliquis posticis horizontalibus (ManT.).

M. subglobosa basi multiplex; axillis lanatis setosisque; mammillis cylindricis elongatis distantibus oblique truncatis ; areola lanata, interiore latere setis $6-8$ tenuissimis albis, exteriore aculeis $2-3$ flavidis, aculeo terminali ancistroideo, apice fusco, longitudine setarum (Lенм.).

M. irregulariter caespitosa, basi multiplex; axillis subnudis; tuberculis ovato-oblongis subdistantibus; setis 8-10 




\section{7}

albidis mammae longitudini aequalibus; aculeis solitariis rigidulis flavidis, apice uncinatis (DC.).

a. rosea DC. - Floribus roseis, stigmatis staminibus aequalis lobis obtusis, petalis brevius apiculatis.

B. albirla DC. - Floribus albidis, stigmatis ultra stamina subexserti lobis paulo longioribus et acutioribus, petalis angustioribus longius apiculatis.

Caespites $6-8$ poll. diam., $3-4$ alti. Nammillae $6-8$, aculei exteriores $5-6$, centrales $4-5$ lin. longi.

Utraque varietas per omnes aestatis menses copiose floret. Flores ex axillis mammillarum superiorum, 8 lin. longi, tubo brevi viridulo, limbo campanulato. Foliola calycina $5-6$, longe adnata, basi virentia, sursum, praesertim extus in nervo, virenti-rubentia vel flavescentia. Petala alba (Mart.). Apex omnium foliolorum acuminatus. Stamina pluriseriata, filamentis albis, antheris stramineis. Stylus longitudine staminum. Stigma in crura $4-5$ papillosa flava divisum. Bacca cuneata, coccinea, seminibus nigris repleta.

\section{M. Wildiana Oтто.}

M. glochidiata var. aurea Hont?

Pa: Mexico.

M. cylindraceo-globosa e basi prolifera; axillis roseis lanatis setosisque; mammillis gracilibus elongatis, obtuse cylindraceis viridibus, basi angustioribus roseis; areolis junioribus tomentosis; aculeis superioribus 3 rectis rigidiusculis flavis, mammillas fere aequantibus, centrali 1 uncinato aureo, mammillis dimidio breviore, omnibus pubescentibus, exterioribus 8-10 tenuissimis setiformibus albis radiantibus.

Mammillae 4-5 lin. longae, $1-\cdot 1 \frac{1}{2}$ diam. Aculei exteriores 4 , ceutrales 3 lin. longi, tandem brunnei.

Flores jam in plantis biennibus per omnes fere anni menses copiosi circa verticem, floribus $\mathbb{I I}$. pusillae similes, 6 lin. diam. Petala acuminata sordide albida, dorso nervo fuscescente notata. Stigma 4-5-partitum stramineum; stamina breviora, antheris luteis.

8əั. M. crinita DC.

Revue p. 112. Mém. p. \%. t. 3.

Pa: Mexico.

M. basi multiplex, globosa depressa; axillis nudis; 
mammillis ovatis; areola glabriuscula; setis $15-20$ albidis subradiantibus elongatis, aculeis centralibus flavidis rigidis, apice uncinatis, longitudine setarum.

Species minima forsan generis, 2 poll. diam., $1^{1 / 2}$ poll. alta. Flores sessiles sordide albi, 8 lin. longi, mammillis longiores, setis breviores. Sepala 5 extus linea rufescente distincia. Post florescentiam sepala et petala convoluta quasi nodum formant decagonum circum stylum et staminum reliquias. Stamina petalis dimidio breviora, antherae flavescentes. Stylus cylindricus flavo-albidus, staminibus aequalis; stigmata 5 crassa abtusa.

An praecedenti aequalis?

\section{粠棌垱 Gibbosae?}

Mammillis gibbosis.

\section{M? gibbosa SalM.}

Hort. Dyck. p. 343.

$\mathrm{Pa}$ ?

M. simplex clavata; mammillis basi latis, apice compressis, sub areola tuberculato-gibbosis; areolis oblongis vix tomentosis; aculeis exterioribus numerosis radiantibus albis, centralibus 4 validioribus fulvis, apice brunneis.

Caulis semipedalis superne incrassatus. Mammillae distantes, hasi latae subquadrangulares, apice lateraliter compressae, quasi truncatae, et sub areola gibbo notabili instructae. Areolae compressae, oblongae, grise 0 -tomentosae. Aculei homogeni, exteriores $20-25$ radiantes, in parte supera areolae confertiores, albicantes, centrales 4 rigidiores, fulvi, brunneo-sphacelati, infimo longiore 6-lineari.

An Echinocactus exsculptus 0 tto?

\section{S. 3. Species non satis notae.}

8\%. M. conica HaW.

Suppl. p. 1.

$\mathrm{Pa}$ ?

II. tuberculis majoribus conicis, spinis sub-10 in singulo fasciculo rubris, basi pallidioribus.

88. M. lanifera HAw.

Tinc. philos. mag. 63. p. 41.-DC. revue p. 31. t. 4. - Cactus canescens FI. mexic. ic. ined. 




\section{Pa: Mexico.}

M. simplex tereti-obovata undique lanato-tomentosa, tuberculis apice spiniferis, spinis 20 et ultra radiantibus rectis patentibus, exterioribus minoribus albis, interioribus validis fulvescentibus.

Spinae exteriores in singulo fasciculo minores albae (mortuis nigris) sub-6 interiores 3-5-plo longiores quam ultimae et 3-7plo validiores, fulvo-fuscescentes, superne nigrae seu nigricantes (H aw. 1. c.). - Flores rubri tuberculis longiores ex Fl. mexic.

\section{M. Helicteris DC.}

Revue p. 31. t. 5. - Cact. Helicteres Moçivo.

Pa: Mexico.

M. simplex obovata glabrata, tuberculis in series numerosas subverticales regulariter spirales dispositis, apice spiniferis, spinis patentibus rectis.

Planta 3-4-uncialis. Flores rosei tuberculis paulo longiores (DC. pr.).

\section{M. glomerata DC.}

Prodr. III. p. 459. - Cact. glomeratus LAM. dict. 1. p. 25\%. - Plum. ed Burm. t. 201. f. 1. - Spreng. syst. 2. p. 494, excl. Haw. syn.

Pa: S. Domingo.

M. caespitosa, tuberculis subdiscretis clavatis glaucis tomentosis, apice stellato-spinulosis.

Flores rubri.

91. M. nuda DC.

Prodr. III. p. 460. - Cact. nudus Fl. mex. ic. ined. Pa: Mexico.

M. simplex cylindracea adscendens glabra, tuberculis inermibus.

Flores rosei.

92. M. mitis Mill. 


\section{MEGOCACTUS.}

DC. prodr. III. p. 460. - Cactus Haw. syn. p. 172. excl. spec.

Char. grv. Calycis tubus ovario adhaerens; lobi 5-6 petaloidei fructum juniorem coronantes. Petala 6- $\$ 8$, cum sepalis in tubum cylindraceum longe concreta. Stamina filiformia pluriserialia. Stylus filiformis. Stigma 5-radiatum. Bacca laevis calycis et corollae lobis marcescentibus coronata. Semina nidulantia. Cotyledones minimac. Plumula subglobosa maxima.

Suffrutices carnosi, caudice aphyllo simplice rotundato, sulcis profundis et costis verticalibus alternantibus, costis rarissime Mammillariarum instar tuberculosis. Costae tuberculis confluentibus, in apice fasciculis aculeorum insignitae. Spadix ceu cephalium terminale cylindraceum vel planum, tuberculis mammaeformibus confertissimis tomentosis et setiferis constans, flores in tomento subimmersos sub apice gerens.

\section{S. 1. Cephatio plano.}

Cephalium disciforme, planum, e tuberculis lanatis et setosis constans, et margine semper crescens. Flores primi e centro prodeunt, et sequentes sensim in annulis circa illos positi sunt. Num M.placentiformis etiam huic \$1 adscribendus sit, nondum satis constat, sed verosimile est.

\section{M. mammillariaeformis SALM.}

Oтто's GZ. 1836. No. 19. \$. 148.

Pa: Mexico.

M. depresso-globosus mammatus, mammis spiraliter inseries 20 - 25 confertissime dispositis, aculeatis; aculeis radiantibus 8 subulatis recurvato-patentissimis stramineofuscis, summis 3-5 gracilioribus; cephalio plano lanuginoso.

Caulis poll. 3 altus et poll. $3^{1 / 2}$ crassus, supra depressus, basi attenatus, fuberculosus nec sulcatus. Tubercula omnino mammacformia in lineas $20-25$ valde spirales caulem ambientia, di- 


stincta, conferta, patentia, dura, perviridia, lin. 4 iongá, bixi latissima depressa, apice rotundata aculeifera. Aculei 10-12 ex areola oblonga primo lanata, mox nuda, radiantes (uno quandoque centrali), sex laterales infimusque septimus lin. 6 - 7 longi, crassi, subulati, recurvati, rigidissimi, patentissimi et valde intertexti, $3-5$ graciliores in arenla superne positi; juniores stramineo-, seniores cinereo-fusci, mortui nigricantes. Cephalium in vertice impresso positum, lanuginosum, latum, e basi disciformi aut receptaculo plano, mammillis instructo floriferis confertis, circulatim dispositis, lana densa persistente albida tectis, setisque spinosis nonnallis armatis ( 5 alm-D. l. c.).

Flores ignoti.

Semina e cephalio plantae mortuae collecta plantas praebuerunt, initio Mamm. coronariae simillimas, mammillosas, in quovis tuberculo setas 20 albas et aculeos 4 brunneos rigidiores gerentibus, quorum infimus, tandem $3-4$ uncinati. Axillae parce lanatae et setosae. Plantae seminales nunc circa 1/1/3 poll, altae.

In collectione sceletorum in horto Monacensi specimen observavimus, a Cl. de Karwinski 1828 e Mexico missum, huic formae valde analogum. Mammillaria nempe esse videtur tuberculis distinctis, aculeos multos rigidos radiantes, unumque centralem uncinatum gerentibus, cephalio compacto lanato, quod usque ad tubum medullarem persequi potuimus, et in quo florum reliquias deteximus.

\section{M. placenliformis LeHм.}

Act. nov, nat. cur. XVI. P.I. p. 318. t. XVI. - Meloc. Besleri Link et Otro (Verhandl. d. Gartenbauver. f. Pr. III. S. 420. T. 21.). - Cact. Melocactus BesLeni hort. eystet. 4 ord. f. 1. (??)

\section{Pa: Brasilia meridionalis.}

M. hemisphaerico-depressus 12-angulatus; spinis crassis sulcatis, lateralibus $\boldsymbol{\gamma}$ inaequalibus patentissimis, centrali 1 pollicari, vertice florifero (cephalio) distincto hemisphaerico-depresso spinuloso (LEHM.).

II. caule depresso viridi, costis $\mathbf{1 4}$ obtusissimis, spinis 8-12 inacqualibus, recurvis validis ( $L$. et 0.$)$.

Species rarissima! Planta florifera a $\mathrm{Cl}$. L e lumann descripta 3 poll. alta, 9 poll. diam., flores praebuit $\mathbf{3}-\mathbf{4}$ suaveolentes', e cephalio densissime lanato provenientes. Calyx tubulosus laxe imbricatus $2 \mathbf{1} / 2$-pollicaris, squamis lineari-lanceolatis, obtusissimis, integerrimis, glabris, patentibus, apice reflexis rubescentibus. Petala numerosa albida, lineari-lanceolata obtusa. 


\section{S. 2. Spadice cylindraceo.}

Spadix initio disciformis, e centro semper crescens et flores gerens, tandem conicus vel cylindraceus.

\section{M. communis DC.}

Revue t. 6. - Pl. gr. t. 112. - Bot. mag. 3090. Cact. Melocactus L. - HAW. syn. p. 173. - C. Melocactus et communis AIt. hort. Kew. t. 3.-C. Melocactus et C. coronatus LAM. dict. 1. p. 53\% - Echinomelocactos Cuus. exot. p. 92.-- Bradu. succ. t. 32.

Pa: India occidentalis.

M. ovato-subrotundus atrovirens 8-12-angularis, costis rectis, spinis fasciculatis fuscis subaequalibus (DC. pr. III. p. 460.).

M. subglobosus vel ovatus, obscure viridis, 12-angulatus; sinubus latis profundis; costis subacuatis; areolis confertis, magnis, ovalibus, griseo-tomentosis; aculeis rectis rigidis flavescentibus vel fuscescentibus, exterioribus 8-9 patentibus, infimo longissimo, centralibus 3 , sursum 2, deorsum 1 spectante.

Planta adulta 7 - 8 poll. diam. et alta. Costae 1 poll. altae; areolae 4 lin. distantes, aculei exteriores $6-10$, centrales $6-8$ lin. Iongi.

Flores per totam aestatem copiosi, saturate rosei, expansi $6-8$ lin. diam., plus minusve e cephalio prominentes. Petala 12 denticulata. Stamina brevia alba, antheris flavis. Stylus roseus, staminibus longior, stigmatibus 5 roseis. - Baccae saturate roseae, clavatae.

B. macrocephalus H. BeroL. - Verh. d. GBV. III. S. 417. T. 11. - S. Domingo, S. Thomas etc. - Caule subgloboso vel oblongo, glaucescente, costis $13-14$, interdum duplicatis, acuatis, spinis 9 patentibus, centrali erecta (LiNk et Otro.).

\%. oblongus H. Beroc. - S. Domingo. - Caule 15angulari oblongo, costis acutis, areolis confertis, aculeis exterioribus $6-7$, centrali 1 vel nullo.

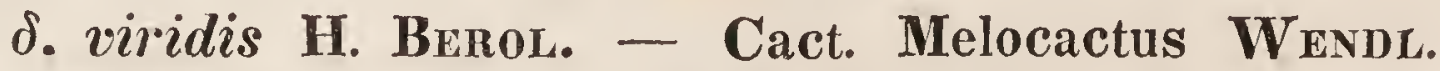
collect. pl. S. 1. p. 22. t. 5. - S. Thomas.-Costis acutis subcrenatis, aculeis exterioribus \%, centrali 1 . 


E. laniferus H. Berot. - India occid. - Costis farctis glaucescentibus subacuatis, areolis remotis villosis albis, aculeis exterioribus 8 , centrali 1 , rubellis.

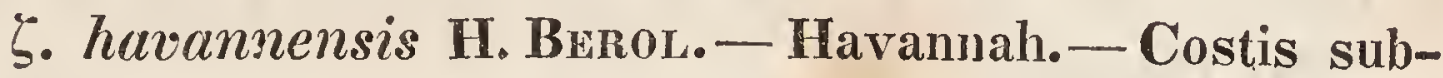
compressis obrepandis, areolis magnis rotundis villosis, aculeis rigidis flavescentibus, exterioribus 9 ( 2 summis minimis), centralibus 2.

$\eta$. Grengeli H. DresD. - Caule ovali, aculeis brevibus gracilibus albis.

ף. conicus. - Caule conico, costis acuatis, obrepandis (1 $1 / 2$ poll. altis), areolis subconfertis, aculeis exterioribus $8-10$, centralibus 2 , omnibus rigidis, rubellis.

\section{M. rubens PrR.}

Pa: India occidentalis.

M. depresso-globosus obscure cinereo-viridis; sinubus profundis acutis; costis 14 acuatis, obrepandis, circa areolas inflatis; areolis remotis ovalibus, junioribus dense albovillosis, tandem nudis ; aculeis rigidis, rectiusculis, nascentibus ignescenti-brunneis, tandem fulvis, exterioribus $9-10$ (summis 1-2 minoribus, infimo longissimo), centralibus 2.

Specim. 8 poll. diam., 6 poll. alt. Areolae 1 poll. distantes, 5 lin. longae. Aculeus centralis superior 1, inferior 1/1/2 poll, exteriores supremi 4 lin., laterales $1-1^{1 / 4}$, infimus $1^{1 / 2}-1^{3 / 4}$ poll.

An $\mathbb{M}$. communis varietas?

\section{M. amoenus HFFG.}

M. comm. Jördensii Otro, - M. rubens Hont. Pa: Columbia.

M. depresso-conicus glaucescenti-viridis 10-12-angularis; costis subcompressis ; areolis remotis immersis, junioribus convexis albo-tomentosis; aculeis exterioribus 8, supremo brevissimo, infimo longissimo, centrali 1 erecto longiore, omnibus rectiusculis subulatis rubellis.

In plantis junioribus aculeus centralis plerumque deest. Plantae adultae 5 poll. altae, 6 poll. diam. Areolae 10-12 lin. distantes. Aculei supremi 2-3, infimi $5-6$, centralis $6-8$ lin. longi. Cephalium convexum albidum. Flores mense Julio rosei, cxpansi pollicares, petalis elongatis linearibus patentibus. 


\section{M. pyramidalis SAIM.}

Cactus pyramidalis Salm obs. bot. 1820. p. 4. - Verh. d. GBV. f. Pr. III. S. 419. T. 25. - Hort. Dyck. p. 344. Pa: Curaça.

M. conicus, costis 17-18 subrerticalibus obrepandis, ad latera tuberculato-inflatis; areolis approximatis; aculeis rectis longis, pallide flavis, apice fusco-rubris, exterioribus 18 bifarie divaricantibus, centralibus 3 validissimis.

Planta plus minusve conica seu pyramidata, aculeis intertextis omnino tecta. Aculei exteriores non stellatim, sed bifarie radiantes, aciculares; centrales tripollicares rigidissimi subulati. Spadix seu cephalium cylindraceun. Flores laetissime rosei, parvuli, sepalis petaloideis $16-\mathbf{1 8}$ angustis, recurvulis; stylus staminaque inclusa; stigma 5-fidum (Sal m-D. 1. c.).

Plantae seminales $11 / 2-2$ poll. ab adultis valde diversae sunt. Costae 13 subacuatae, areolae $3-4$ lin. distantes, acule exteriores 9 , bifarie radiantes, infimus rigidissimus, centrales $1-2$ rigidi, erecti, omnes nascentes rufi, mox basi flavescentes.

\section{M. Salmianus Oтто.}

Hort. Dyck. p. 345. - Echinoc. Salmianus Livk et Oтто Verh. d. GBV. f. Pr. III. S. 423. T. 13. - Cactus Hystrix Haw. suppl. p. 193?

\section{Pa: Curaça.}

M. subrotundus, costis 15 verticalibus, ad latera tuberculato-subsinuatis; areolis remotiusculis, junioribus albidis; aculeis rectis longis fusco-rubris, exterioribus 10 radiantibus, centralibus 3 validissimis subulatis, infimo longiore.

Spadix s. cephalium (in planta ab Ill. Pr. a Salm-Dyck descripta) hucusque vix e vertice enatum. A Mel. puramidali differt aculeis rarioribus, exterioribus stellatim radiantibus et centralibus binis supremis brevioribus, quandoque abortivis. Flores rosei paulo majores, quam in $M$. pyramidali (Salm-D. l. c.).

Plantae seminales 2 poll. dian. costis instructae sunt 13, subacuatis, subrepandis, aculeis centralibus 2 elongatis.

\section{M. atrosanguineus H. BenoL.}

Pa: S. Thomas.

M. globosus atrovirens 12-15-angularis; costis subcompressis sinuosis; areolis subremotis ovalibus albidis; 


aculeis exterioribus 10 rectis rigidis, centrali 1 longiore subulato, omnibus atrosanguineis.

Plantae intus sanguineae esse dicuntur. Descriptae 5 poll. diam. et alt., aculei supremi 1/2 poll., centralis pollicaris et ultra.

\section{M. spatangus H. BeroL.}

\section{Pa: Curaçao.}

M. depresso-globosus viridis 16-angularis; costis verticalibus obtusis obrepandis, circum areolas inflatis; areolis magnis albis, junioribus velutinis, dein cinereis; aculeo centrali longo rigido, exterioribus $12-13$ bifarie patentissimis, multo minoribus, gracilibus, omnibus nascentibus fulvis, tandem stramineis.

Planta in horto Berolinensi 4 poll. alta, 8 poll. diam. Areolae $6-8$ lin. distantes; aculei $1 \frac{1 / 3}{2}-2$-pollicares, 3 infimi reliquis radiantibus semper validiores.

\section{M. macracanthus SALM.}

Cactus macrocanthos SALM obs. bot. 1820. p. 3. Haw. rev. p. 69. - Verh. d. GBV. f. Pr. III. S. 418. T. 12. - Hort. Dyck. p. 344.

Pa: Curaçao, S. Domingo.

M. subrotundus, costis $14-16$ verticalibus obrepandis, ad latera tuberculato-inflatis; areolis approximatis, junioribus sublanatis griseis; aculeis praegrossis rectis brevibus purpurascentibus, exterioribus 18 radiantibus, centralibus 4 crassissimis subulatis.

Cephalium cylindraceum supra depressum. Flores ignoti. Color plantae laete viridis, quandoque plumbagineus evadit. Aculei subulati, praegrossi, vix pollicis longitudinem superant ( $\mathbf{S}$ a l m-D. 1. c.).

Plantae seminales 2 poll. diam. depresso-globosae, atrovirentes; costae obtusae obrepandae. Aculei centrales $2-3$ crassiusculi nigricantes, 6-y lin. longi.

\section{II. violaceus PrR.}

Orro's GZ. 1835, No. 40. S. 313.

Pa: Brasilia.

M. subpyramidalis vel conicus griseo-viridis, 10-12 ansularis; costis verticalibus obrepandis, acuatis; sinubus 
latis; areolis subremotis immersis, junioribus albido-tomentosis, tandem nudis; aculeis 6-8 divaricatis longis rectis rigidis, junioribus fusco-coccincis, dein violaceis, transverse striatulis, supremo brevissimo, centrali nullo.

Plantae adultae 5 poll. diam. et $2^{1 / 2}$ poll. usque ad cephalium altae. Cephalium bipolicare obtuse conicum. Flores mense Julio et Aug. laete coccinei, e cephalio vix prominentes, 1/2 poll. diam. Petala exteriora $\mathbf{1 0 - 1 1}$ patentia, apice crenulata, interiora $7 \mathrm{mi}-$ nora, recta, denticulata. Stamina alba corolla breviora, antheris 'flavescentibus. Stigma rubellum 5-partitum.

12. M. meonacanthus Link et Oтто.

Verh. d. GBV. f. Pr. III. S. 428. TT. 15. - Echinoc. meonacanthus Ind. Berol. 182\%.

Pa: Jamaica.

M. oblongus viridis 14-angularis; costis verticalibus acuatis subcrenatis; areolis oblongis albido-tomentosis; aculeis exterioribus 9 patentibus rectiusculis ( 2 supremis minimis, infimo longissimo), flavidis, apice fuscis, centrali 1 erecto subulato fuscescente.

Spec. ultrapedalia, 4-6 poll. diam. Areolae 5-6 lin. distantes. Aculei subaequales, $6-7$ lin. longi. - Capite resecto proles e basi copiose proveniunt.

\section{M. curvispinus H. BERoL.}

\section{Pa: Mexico.}

M. depresso-globosus 10-12-angularis; costis subcompressis subverticalibus, inter areolas vix convexis; areolis magnis rotundis albo - velutinis; aculeis centralibus 2 erectis subulatis nigricantibus, exterioribus $\gamma$ paulo minoribus curvatis, fuscescentibus vel albidis.

Spec. 4 poll. diam., 3 poll. alta. Areolae 6 lin. distantes; aculei centrales vix pollicares, reliqui $6-8$ lin.

\section{S. 3? Spadice laterali.}

Melocacti cereiformes altissimi.

\section{M. columna Trajani?}

Conf. Cereus columna Trajani. 




\section{Echinocactus.}

Link et Otтo in: Verh. d. GBV. f. Pr. III. S.420.DC. prodr. III. p. 461.

Char. ars. Sepala numerosa imbricata, basi ovario adnata, in tubum brevissimum concreta, exteriora involucriformia, intima petaliformia. Stamina numerosa, calyci affixa, inaequalia, intima brevissima, filiformia, antheris oblongis. Stylus cylindricus, subfistulosus, apice multifidus. Bacca sepalorun reliquiis subsquamata, rarissime laevis. Cotyledones parvulae.

Frutices simplicissimi carnosi, ovati aut globosi, melocactoidei aut mammillariaeformes, aphylli, costati aut tuberculati, costis tuberculis confluentibus quasi formatis, dorso aculeorum fasciculos gerentibus. Cephalium seu spadix nullus. Flores e fasciculis aculeorum ad apicem costarum (ita quidem, ut in areolis noviter e vertice erumpentibus florum origines jam conspicui sint,) orti, similes floribus Cerei, sed tubo vix supra receptaculum elongato.

\section{S. 1. Costati.}

Costis et sinubus regulariter alternantibus, subverticalibus, areolatis, crenatis, vel tuberosis, nunquam interruptis.

* Costis rotundis.

\section{R. Ottonis LeHn.}

Cereus Ottonis Lemm. (Act, nov. nat. cur. XVI. P.I. p. 31\%. t. XV.) - LinK et Orwo icon. t. 16. - Bot. mag. t. $311 \%$.

\section{Pa: Mexico.}

E. ovalis viridis basi attenuatus, 10-angularis; costis obtusis, superne e spinarum fasciculis floriferis; spinis centralibus 4 , radiantibus $10-14$ tenuibus patentibus (Leнm.).

E. depresso-globosus vel ovatus, viridis, basi tandem 
lignosus, 10 - 12-angulatus; sinubus acutis ; costis rotundis; areolis albis tomentosis immersis; aculeis exterioribus 12-18 radiantibus flavidis, tenuibus, rectiusculis, centralibus 4 fusco-rubris, validioribus, supremo brevissimo, 2 lateralibus horizontalibus, infimo longissimo deflexo, omnibus rigidis patentibus.

Truncus 3-4-pollicaris. Areolae 5-6 lin. distantes. Aculei radiantes $5-6$, centrales $4-12$ lin. longi. - Proles e radice copiose enascuntur. - Plantae triennes (11/2-pollicares) jam floriferae.

Flores per totam aestatem, citrini, per plures dies mane expansi. Tubus calycinalis squamulis minutis, setas brunneas lanamque griseam gerentibus instructus. Petala linearia, biserialia, acuminata, mucronulata, flava, extima dorso rubella, limbun tandem retroflexum, formantia $2-3$ poll. diam. Stamina numerosa flava, basi purpurea, stylo breviora, antheris flavidis. Styo lus flavus, longitudinaliter sulcatus, stigmatibus 14 igneo-purpureis. - Fructus globosis atro-vel rubro-virens, squamulis mininis, setis et lana obsitus. Semina copiosa nigra, funiculis longis baccae parietibus affixa.

B. tenuispinus. - E. tenuispinus Link et Otтo Verh. d. GBV. f. Pr. S. 421. T. 19. - Aculeis centralibus 3-4, omnibus brevioribus et tenuioribus, fere setiformibus, vertice valde impresso (Brasilia, prov. Rio grande.).

Flores minores et pallidiores. Tubus calycinalis fere nudus, pilis parcis brumneis obsitus. Petala subvirescenti-flava, obtusiuscula, mucronulo flavo aut rubescente terminata. Stamina stylum et stigmata 10 atro-purpurea aequantia.

\section{E. Lintii LeHy.}

Cereus Linkii LEHM. (Act. nov, nat. cur. XVI. P. I. p. 316. t. XIV.)

Pa: Mexico.

E. ovalis viridis 13 -angulatus, vertice impresso; costis obtusis; areolis impressis subremotis; aculeis fuscis subaequalibus gracilibus, centralibus $3-4$ erecto-patentibus, radiantibus 10 tenuioribus patentissimis (LEHM.).

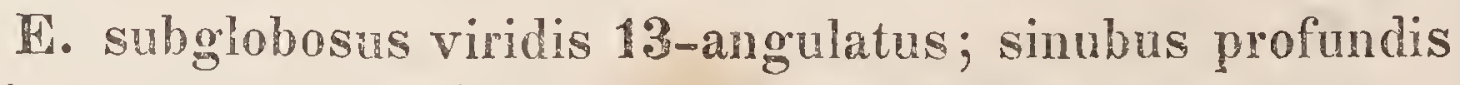
acutis; costis angustis lateraliter compressis, crista obtusa; areolis albido-tomentosis, immersis; aculeis omnibus setiformibus, centralibus $\$$ brunneis, interdum 1 brevissimo supremo, axterioribre $10-12$ albis, apice brunneis. 




\section{9}

Planta nostra descripta 3 poll. diam., areolis 4 lin. distantibus, aculeis exterioribus infimis 3 , lateralibus $4-5$ lin. longis, supremis nullis, centralibus 6 et 8 lin. longis.

Specimen in horto Hamburgensi floriferum 6 poll. altum, 51/2 poll. diam. Flores $2-\mathbf{4}$ in margine verticis e spinarum fasciculis. Calyx tubulosus, imbricatus, semipollicaris, squamis acutis basi connatis, e viridi flavescentibus, intus medio fasciculo crinium purpureorum et lana arachnoidea albida instructis. Corolla inodora, aperta 2 poll. diam., 1 poll. longa. Petala numerosa, obovato-cuneata, apice truncata, denticulata, lutea, sericeonitentia. Stamina calyci inserta, numerosa, filiformia, erecta, lutea, basi purpurea. Stylus luteus, complanatus, tubulosus, e stylis pluribus connatis compositus. Stigmata 8 distincta, purpurea.

Plantae juniores ab $\mathbb{E}$. Ottonis facile distinguuntur costis numerosioribus et angustioribus, aculeis radiantibus $9-10$, albis, brevibus, centralibus nigris, minoribus.

\section{L. tortuosus Link et Отто.}

Icon. t. 15. - E. muricatus HorT.

Pa: Brasilia (prov. Rio grande.).

E. depresso-globosus, 13-angularis, obscure viridis; vertice parum impresso; sinubus acutis profundis; costis subverticalibus compressis, crista obtusa; areolis immersis, magnis, subconfertis, junioribus albo-velutinis, tandem griseis; aculeis rectiusculis rigidis, exterioribus 12-13, flavidis vel fulvis, supremis minimis, gracilioribus, centralibus 4 -6, erecto-patentibus brumeis crassioribus, summo minimo.

Planta descripta $3^{1 / 2}$ poll. diam., $2^{1 / 2}$ poll. alta. Costae 8 lin. altac. Areolae 4 lin. distantes. Aculei exteriores 4, summi 2, centrales 5-8, summus 3 lin. longi. - Flores mense Julio, citrini, 2 poll. diam. Tubus brevis viridi-squamosus, brunneo-setosus. Petala biserialia, apice obtusa, denticulata. Stamina flava, antheris albidis. Stylus vix longior flavus, stigmatibus $6-10$ purpureis.

Plantae juniores ab $\mathbb{E}$. Ottonis facile distinguuntur areolis majoribus, medio fusco-tomentosis, aculeis radiantibus 12 , nascentibus flavis, mox albis, semper rigidis.

\section{2. muricatus H. BeroL.}

Pa: Brasilia australis.

E. ovatus, tandem irregulariter columnaris (hine inde constrictus), 16-angularis, viridis, interdum e lateribus 
prolifer; vertice impresso; costis obtusis obrepandis; sinubus latis et planis; areolis confertis latis albo-tomentosis, junioribus velutinis; aculeis exterioribus sub-12 patentissimis, centralibus $3-4$ patentibus, omnibus gracillimis, fere setiformibus, vix pungentibus, fulvis.

Specimen descriptum 8 poll. altum, $2^{3 / 4}$ poll. diam. Aculei 2-3 lin. longi. Nondum floruit.

\section{E. formosus H, ANGL.}

\section{Meloc. Gilliesii Hont.}

Pa: Mendoza.

E. subglobosus vel oblongus pallide virens; costis $\mathbf{1 6}$ verticalibus obtusis repandis; areolis subremotis ovalibus sublanatis griseis; aculeis acicularibus rigidis, centralibus 2-4 longis brunneis, exterioribus $8-10$, superioribus fuscis, inferioribus albis.

Spec. 5 poll. diam., $4^{1 / 2}$ poll. altum. Areolae $4-5$ lin. distan= tes. Aculei centrales $1-1 \frac{1}{2}$ poll. longi.

\section{Fo rhodacanthus SALM.}

Hort. Dyck. p. 341. - E. coccineus H. BeroL.

Pa: Mendoza.

E. globosus, costis $12-15$ verticalibus tuberculatis; areolis remotis oblongis, junioribus sublanatis albidis; aculeis subulatis rigidissinis recurvatis atrorubris, ad lucem sanguineis, exterioribus $6-8$ radiantibus, infimo brevissimo, centrali 1 vel nullo.

Specimen descriptum nunc 4 poll. diam. et 3 poll. altum. Areolae $1-1^{1 / 2}$ poll. remotae, 4 lin. longae, aculei subpollicares.

\section{\%. E. Karwinstii ZuCC.}

Pa: Mexico.

E. globosus 13-20-angularis, obscure viridis, vertice lanuginosus; sinubus latis; costis obtusissimis, sursum duplicatis; areolis subremotis oblongis, vix tomentosis, supra aculeorum fasciculos elongatis; aculeis rigidis rectiusculis corneis, lateraliter compressis, transverse striatulis, exterioribus $6-8$ irregulariter radiantibus, centralibus $1-3$ validissimis divergentibus. 


Specimen unicum in horto Monacensi 8 poll. diam., 7 poll. altum. Aculei originarii $1-1^{1 / 2}$ poll., recentiores $6-10$ lin. longi.

\section{E. Ceratistes OTто.}

\section{Pa: Chile (Bellavista).}

E. globosus pallide virens 10 - 16 -angularis; costis obliquis, obtusis, tuberculatis; sinubus linea saturatiore serpentina notatis; areolis remotis oblongis albidis; aculeis exterioribus 8 curvatis, infimo minimo, centrali 1 incurvato, omnibus crassis nigris.

Plantae seminales quadriennes 21/2 poll. altae et diam. Areolae 6-8 lin. distantes. Aculei $6-8$ lin. longi.

An Melocacti species?

\section{E. aciculatus SALM.}

Hort. Dyck. p. 341.

Pa: Brasilia.

E. globosus subdepressus; costis $\mathbf{1 1}$-12 verticalibus obtusis; areolis approximatis, junioribus lanatis albidis; aculeis tenuibus rectis subrigidis, stramineis, exterioribus 10 radiantibus, infimo longissimo, centrali uno.

Planta unica in horto Dyckensi e semine enata nunc 6 poll. diam. et 4 poll. alta. Aculei 6 lin., infimus $1^{1 / 2}$ poll. longus.

An Melocacti species?

10. E. gladiatus Link et O'тто.

VhdI. d. GBV. f. Pr. III. S. 426. T. $1 \%$.

Pa: Mexico.

E. caule ovali-oblongo glaucescente; costis 14-22 obtusatis; spinis 10, tribus centralibus majoribus complanatis elongatis, media erecta, radiantibus patentissimis.

Planta (in horto Berolinensi unox mortua) 5 poll. alta, 4 poll. diam., costae prominentiis distinctis, latere impressis, sulcis angustis. Spina maxima ad 2 poll. longa, omnes canescentes. Vertex depressus, spinis confertis.

Distinctissimae hujus speciei duo exemplaria dom. Dr. Schiede aestate 1834 Cassellas misit, sed ehen! ambo unortua. Quare species nunc in hortis Europaeis adesse non videtur.

洋 Costis obtuse angulatis.

11. H. Langsdorffii LEHM.

Act. nov. nat. cur. XVI. P. I. p. 316. t. XII.- - LINK 
et Orтo icon. t. 40, - Meloc. Langsdorffii DC. prodr. III. p. 461 .

Pa: Brasilia merid.

E. oblongus 1\%-angulatus saturate viridis, vertice plano villosissimo; costis obtusis subtuberculatis; sinubus acutis; areolis approximatis, junioribus lanatis albidis; aculeis exterioribus 6 inaequalibus, reflexo-patentibus, centrali 1 longiore deflexo, omnibus corneis, rigidis, gracilibus.

Planta in horto Hamburgensi florifera 4 poll. longa, totidemque crassa. Areolae 4-8 lin. distantes. Aculeus centralis pollicaris. Flores $2-4$ in vertice inter lanam et spinas, $1-2$ poll. longi. Receptaculum squamulis lanceolatis acutis viridibus tectum. Tubus $1 / 2$ poll. longus, basi lana lectus. Corolla parva, expansa subpollicaris. Petala circiter 20 lanceolata, acuta, flava, calyci inserta. Stamina corolla breviora, numerosa, flava. Stigma radiatum, multipartitum, purpureum.

\section{Rolyacunthus DINK et OTTo.}

Vhdl. d. GBV. f. Pr. II. S. 422. T, 16. F.1.-Cact. Erinaceus $\mathbb{H}_{A W}$. suppl. p. 74.

Pa: Brasilia (prov. Rio grande.).

E. ovalis vel subcylindricus viridis 15 - 20 -angularis; costis subcompressis crenatis; sinubus profundis acutis; areolis confertis, infra costae crenas positis, junioribus albo-velutinis, tandem vix tomentosis; aculeis exterioribus 6 - 8 divergentibus, centralibus $3-4$ majoribus, omnibus rectis, rigidis corneis.

Planta descripta 12 poll. alta, $3 \frac{1 / 2}{d i a m}$. Areolae $4-5$ lin. distantes. Aculei exteriores 3-4, centrales 6 lin. longi, originarii ultrapollicares, cinerei.

\section{F. parvispinus DC.} p. 73.

Prodi. III. p. 463. - Cactus parvispineus Haw. suppl.

Pa: Amer. calid., India occidental.

C. subcucumeriformis sub-12-angularis, apice depressus; spinis parvis albis, apice fulvis, una alterave in sillgulo fasciculo subadunca seu recurvante (HAw.).

E. subglobosus; apice umbilicatus; costis 15 compressis; aculeis parvis albis, apice fulvis, e tomento albido, uno centrali recto, radiantibus $6-8$ subrecurvulis (DC.). 


14. E. tephracanthus Link et Otro.

Vhdl. d. GBV. f. Pr. III. S. 422. 'T. 14. F. æ.

Pa: Brasilia (prov. Rio grande.).

E. irregulariter columnaris, 17-angularis laete virens; vertice plano lanuginoso; costis compressis crenatis; areolis approximatis, junioribus albo-velutinis; aculeis 6-10 irregulariter radiantibus, gracilibus, albis, centrali nullo.

Plantae in horto Berolin. 4 poll. altae, $1-1 \frac{1}{2}$ poil. dian. Areolae 3 lin. distantes. Aculei $2-4$ lin. longi.

15. E. intricatus H. BEROL。

Vhdī. d. GBV. III. S. 428. T. 24 .

Pa: Montevideo.

E. caule ovali viridi; costis 20 obtusatis; spinis 4 centralibus majoribus erectis, reliquis $14-16$ patentibus, extimis divaricatis.

Caulis 4 poll. altus, $31 / 4$ poll. crassus. Costae prominentiis distinctis, latere impressae. Vertex tuberculatus impressus. Spi nae majores 8 lin., parvae 4 lin. longae, omnes cano fuscescentes, fasciculi approximati.

Specimine Berolinensi mortuo planta in hortis non amplius occurrit.

16. E. orthácanthus LiNk et Oтro.

Vhdl. d. GBV. III. S. 42\%. T. 18.

$\mathrm{Pa}$ : Montevideo.

E. caule globoso glaucescente; costis 18 obtusatis; spinis $\boldsymbol{\gamma}$, centrali majore valida recta, reliquis patentibus.

Caulis $23 / 4$ 霹poll. alt., totidemque crassus. Costae prominentiis distinctis, latere impressae; sulci angusti. Vertex depressus. Spina maxima $3 / 4$ poll. longa, reliquae 6 lin., omnes canescentes.

Specimine Berolinensi mortuo haec species in hortis non amplius occurrit.

\section{1\%. E. oligacanthus MART.}

Pa: Mexico.

E. globosus 12-angularis; costis subcompressis crenatis; areolis magnis subnudis; aculeis plerumque 5 crassis curvatulis albidis, infimis $\mathbf{2}$ minimis, summo maximo.

Specimen unicum in horto Monacensi sine prole obiit! 


\section{E. ingens Zucc.}

Meloc. ingens KAnW.

Pa: Mexico.

E. globosus vel oblongus, basi lignea attenuatus, glaucescens, ad cristas purpurascens, 8-angularis; vertice lanatissimo; sinubus latis acutis; costis obtusis tuberculatis; areolis magnis remotis, lana copiosissima flavescente et aculeis exterioribus 8 , centrali 1 , brunneis, rectis, rigidis, instructis.

Specimen originarium in horto Haageano 6 poll. altum, 5 poll. diam. Areolae $1-1^{1 / 2}$ poll. distantes. Aculei originarii 11/2 poll., recentiores subpollicares. - In patria secundum Cl. de Karwinsk i plantae occurrunt 5-6 ped. altae et dianı.

Fructus (anno 1828 e Mexico advecti) ovati, 1//s poll. longi, squamulis minutissimis, lanaque copiosissiua involuti, corollae reliquiis coronati. Corolla $3 / 4$ poll. longa, $\mathbf{1}^{1 / 2}$ diam., petalis $\mathrm{He}-$ lianthi annui flavis obtusis. - Semina majuscula, nitide nigricantia, reniformia.

\section{W. pruinosus 0тто.}

Cer. roridus H. BERoL.

$\mathrm{Pa}$ : Mexico.

E. subglobosus 5-6-angularis cinereus; sinubus junioribus acutis, mox omnino planis; costis subacuatis repandis; areolis subremotis, cinereis, convexis; aculeis extetioribus $4-5$, centrali 1 vix longiore, ominibus rectis, rigidis, nascentibus flavis, apice brunnẹis, tandem nigris.

Specimina adulta in Europa non adesse videntur. Plantae seminales maximae $3-4$ poll. diam., aculeis vix semipollicaribus. Habita E. ingenti proxime affinis, quare rite Echinocactis adscribendus.

\section{档棌 Costis acuatis.}

\section{E. acualus Link et Отro.}

\section{Pa: Montevideo.}

E. caule subgloboso glaucescente; costis 20 acuatis; spinis 8 patentibus recurvis ( $L$. et $\mathbf{0}$.).

E. subglobosus, obscure viridis, 13-angularis, vertice depresso; sinubus acutis; costis compresso-acuatis, deorsum crenulatis; areolis haud prominentibus, junioribus lanatis; aculeis exterioribus 10 subradiantibus flavidis, cen- 

tralibus 4 rigidioribus, longioribus, luteis, supremo brevissimo. (Planta seminalis $1 \frac{3}{4}$ poll, alta, $2^{1 / 2}$ diam.)

Specimen originarium in horto Berolinensi mense Majo jam pluries floruit. Flos expausus 11/2 poll. diam., flavus, tubo brevissimo piloso, petalis citrinis, linearibus, apice obtusis, st̂ylo purpureo, stigmatibus circa 8 purpureis, staminibus stylo brevioribus, antheris flavis.

\section{E. corynodes H. BEnoL.}

E. acutangulus Zucc. - E. rosaceus, Sellowianus Honq. Pa: Montevideo, Mexico.

E. depresso-globosus, basi attenuatus, obscure viridis, 16-angularis; vertice impresso; sinubus angustis acutis; costis acuatis crenatis; areolis immersis, junioribus albis villosissimis, tandem nudis; aculeis exterioribus 9 patentibus, nascentibus rubris, dein fuscescentibus, centrali 1 erecto subulato brunneo, reliquos non superante, omnibus rectis rigidis.

Plantae juniores $a b$ adultis valde diversae, laetius virides, areolis confertis, aculeis exterioribus $\mathbf{1 0}$ albis setaceis patentibus, centralibus 4-6 longioribus rigidioribus fuscis. Adultae 3-4 poll. diam., 2-3 altae. Areolae 6-8 lin. distantes. Aculei 5-6 lin. longi.

Flores per totam aestatem ex areolis circa verticem, sulphurei, 2 poll. diam., per plures dies sole lucente expansi. Gemma floralis fasciculo lanae brunneae involuta. Tubus brevissimus lanatus; petala biserialia linearia, apice denticulata, diaphane flava. Stamina numerosa filiformia rubra, antheris fiavis. Stylus staminibus longior, sulphureus, stigmatibus 10 coccineis.-Bacca e law nugine prodit glabra, sordide rubra, oblonga.

\section{E. Sellowianus Link et Oтto.}

Vhdl. d. GBV. f. Pr. III. S. 425. 'T. 22.

Pa: Montevideo.

E. caule depresso, glaucescente, costis 10 acuatis; spinis 7 recurvis, 3 multo majoribus centralibus (L. et 0. ).

E. depresso-globosus obscure viridis, vertice umbilicato; costis $15-20$ acutis vix crenulatis; areolis remotis albo-tomentosis; aculeis 5 - flavidis rigidis rectiusculis, patentibus, in planta juniore centrali 1, tandem nullo. (Plantae seminales in horto Berolinensi ortae, $2^{1 / 2}$ poll. diam., $1 \frac{1}{2}$ poll. alt.).

Planta originaria mense Majo 1833 et Julio 1836 Berolini flo- 
ruit, seminaque matura praebuit. Flores citrini, expansi 2 poll. diam. Calyx pyriformis, pollicaris, basi tenuissimus, infra corolIam 1 poll. diam., fuscescens, pilis albis et setis solitariis brunneis obtectus. Petala biserialia, 8-10 lin. longa, 3-4 lata, spathulata. Stamina lutea, exteriora longiora, antheris luteis. Stylus, stamina externa aequans, fiavus, stigmatibus 8 coccineis.

\section{2:3. E. sessiliflorus H. AvgL.}

Pa?

E. depresso-globosus obscure viridis, vertice umbilicatus; sinubus acutis; costis 21 verticalibus acutis crenatis, circa areolas inflatis; areolis remotiusculis velutinis albis; aculeis brevibus rigidis brunneis 4 decussatis, vel 5 , quorum 2 supremi minores.

Plantarum juniorum costae obrepandae, aculei 5 retroflexi parvuli albi.

Specimen Junio 1836 in horto Berolinensi floriferum $3 \frac{1 / 2}{\text { poll. }}$ diam., $1 \frac{1}{2}$ altum. Aculei $2-3$ lin. longi. Fiores plures circa verticem, $\boldsymbol{E}$. acuati similes, lutei, $\mathbf{1}^{\mathrm{s} / 4}$ poll. diam. 'Tubus crassus brevissimus brunneo-villosus. Sepala brevia, dorso fuscescentia. Petala biserialia, lanceolata, apice serrulata, citrina. Stamina brevia, antheris flavis. Stylus longior luteus, stigmatibus 6 purpureis, apice dentatis.

\section{H. cornigerus DC.}

Revue p. 36. t. \%. Mémoire p. 1\%. t. 10. - Cactus latispinus HAW. (TILL. philos. mag. 63. p. 41.). - Meloc. latispinus Hort.

Pa: Mexico, Guatimala.

C. depresso-sphaeroideus sub-21-angularis, spinarum radiis variantibus, una infima deflexa latissima plana (HAw.).

E. depresso-g. Tobosus glaucescens 21 -angularis; sinubus acutis; costis compressis acutis crenatis; areolis valde remotis, ovalibus, sursum elongatis, albidis; aculeis extimis 6 - 10 gracilibus albidis, interioribus robustis, subulatis, annulatis, 3 sursum, 2 deorsum spectantibus, rectis, centrali 1 recurvo, applanato, carinato, transversim striato, omnibus nascentibus purpureis, tandem rubellis.

Specimen descriptủm anno 1834 e Mexico advectum, in horto dom. Schelhase vigens, 16 poll. diam., 10 poll. altum. Aculeus centralis $1 \frac{1}{2}$ poll. longus, $3-4$ lin. latus. - In plantis junio- 


ribus costae non crenatae, sed obrepandae. Aculei extimi modo $2-4$, flavescentes, interiores purpurei.

Flores in apice caulis $2-3$, pollicem longi, tubo crasso brevi, sepalis rufo-fuscis imbricatis, limbo purpureo uniseriali, lobis sublinearibus acutis (DC.). - Fructus ovati lignoso-squamosi.

\section{F. recurvus Link et Otro.}

Vhdl. d. GBV. f. Pr. III. S. 426. T.20. - Cactus recurvus Haw. syn. p. 173. - Cact. nobilis Willd. sp. t.2. p. 243. - Art. hort. kew. t. 3. - Cact. multangularis Vorgt. - Echin. glaucus KARw.

Pa: Peru, Mexico.

E. subglobosus glaucescenti-viridis; sinubus acutis; costis $13-14$ subacuatis, crenatis; areolis remotis oblongis tomentosis; aculeis exterioribus 8 subaequalibus rigidis (infimo minore), rectiusculis, centrali 1 multo validiore applanato recurvo, transverse serrato, omnibus nascentibus purpureis, tandem rubellis vel nigricantibus.

Specimen originariam in horto Monacensi descriptum 6 poll. alt. et diam. Costae 8 lin. altre, undulosae, areolae. $1 \frac{1 / 2}{2}$ poll. distantes. Aculei exteriores subpollicares, centralis paulo longior. - Plantarum seminalium costae diu obtusae. Aculei 2 laterales et infimus flavi, reliqui nascentes purpurei, tandem fulvi.

\section{E. Echidne DC.}

Mémoire p. 19. t. 11.

\section{Pa: Mexico.}

E. semigloboso-depressus virescens; sinubus acutis; costis 13 acutis; aresla ovali, juniore velutina; aculeis rigidis glabris 7 rectiusculis flavidis subexpansis, centrali 1 vix caeteris longiore.

Specimen in horto Genevensi 4 poll. altum, 6 diam., areolis $\mathbf{1}^{3 / 4}$ poll. distantibus, aculeis subpollicaribus. Floruit mense Junio in 4 costis non contiguis circa verticem plantae. Flores sessiles, citrini, 13-14 lin. longi, corolla 1 poll. diam. Calyx et corolla e 42-49 partibus constant, in $6-7$ series spirales dispositis. Sepala virescenti-fiava, ovata, obtusa; petala oblonga, fere linearia, citrina, acuminata, denticulata. Stamina numerosissima, petalis intimis dimidio breviora; filamenta gracilia, flava. Stylus filiformis rectus, pallidus, stigmata 12-14, flava, papillosa.

\section{E. oxypterus Zucc.}

Echin. Hystrix DC. revue p. 116. Mém. p. 18? 
Pa: Mexico (S. Rosa de Toliman in temperatis KARw.).

E. oblongus 15-angularis viridis; vertice subnudo; sinubus initio acutis, mox planiusculis; costis compressissimis subverticalibus crenulatis; areolis remotis oblongis, dense lanuginosis; aculeis e tomento flavescente vel albido, exterioribus 8 divergentibus subaequalibus, pungentibus, diaphane flavescentibus, transverse striatulis, centrali 1 majore, basi brunneo.

Specimen unicum in horto Monacensi 1 ped. altum, 8 poll. diam. Costae 1 poll. altae, areolae 11/2-2 poll. distantes, 6 lin. longae. Aculei radiantes subpollicares, centralis $1^{1 / 4}-1 \frac{1}{1 / 2}$ poll. longus. - Differt ab $\boldsymbol{E}$. Echidne costis acutioribus, aculeis crassioribus striatulis, magis expansis. - E. Hystrix DC. non amplius in hortis existit, quare non statui potest, num eadem sit species?

\section{E. glaucescens DC.}

\section{Revue p. 115.}

Pa: Mexico.

E. subgloboso-depressus glaucescens; costis $\mathbf{1 1 - 1 3}$ verticalibus compressis, obtusis; fasciculis cujusque costae 6 ; areola ovali-oblonga, juniore dense velutina; aculeis flavis rectis, $6-7$ radiantibus et 1 centrali.

\section{E. Pfeifferi Zucc.}

Pa: Mexico (prope Toliman in rupestribus KARW.).。

E. oblongo-globosus 11-13-angularis glaucescens; sinubus latis acutis; costis compressis subacuatis; areolis approximatis oblongis, sursum elongatis, flavido - tomentosis; aculeis 6 subaequalibus rigidis divergenti-erectis, rectiusculis, transverse striatulis, pallide flavescentibus, basi fuscis, rarissime centrali 1 aequali.

Specimen in horto Monacensi $1^{1 / 4}$ ped. altum, 1 ped, diam. Costae $1^{1 / 2}$ poll. altae, areolae $4-6$ lin. distantes, $8-10 \mathrm{lin}$. longae. Aculei subpollicares, originarii nigricantes, 11/2poll. longi.

Praecedentibus affinis! Ab E. Echidne colore, forma oblonga et areolis confertis, ab oxyptero colore, costis minus acutis, areolis confertis, aculeorumque numero et positione, a glaucescente (non satis accurate descripto!) forma, costis non obtusis, et aculeis 6 striatulis distinctus. 




\section{0. $\boldsymbol{E}$. platyacanthus Link et Oтто.}

\section{Vhdl. d. GBV. f. Pr. III. S. 423. T. 14.}

\section{Pa: Mexico.}

E. caule subgloboso laete virente; costis 21-24 pluribusque acuatis; spinis centralibus $3-\mathbf{4}$ majoribus deplanatis, radiantibus 4 minoribus, omnibus patentibus (L. et O.).

E. depresso-globosus 30-angularis glaucescens; vertice amplo inermi, vix impresso, lanuginoso; sinubus acutis, parte infima plantae repandis; costis verticalibus compressis, ex areolarum confluxu hinc inde sulcatis; areolis valde elongatis, junioribus lanatis; aculeis validissimis rectis, intimis 4 subdecussatis applanatis, transversim striatis, basi crassioribus, exterioribus $3-4$ minoribus.

Specimen descriptum aestate 1834 a dom. Dr. Schiede e Mexico missum, nunc in horto dom. Wild Cassellis vigens, 11 poll. altum, 20 poll. diam. Areolae pollicem distantes, vel propiores, imo nonnunquam confluentes. Aculei interiores sesquipollicares, exteriores dimidio minores. - Planta rarissima in hortis, et proles hucusque in Europa non obvia. - Specimen in horto Berolinensi mortuum, 18 poll. altum, 22 poll. diam., flores gessit siccos. Flores e lanugine sericea verticis, subsessiles, $\mathbf{1}^{1 / 2} \mathrm{poll}$. longi; lobi calycinales lanceolati, mucronati; petala dilatała, obtusa, flava. Stylus 10-fidus.

\section{E. macrodiscus MART.}

Act. nov. nat. cur. XVI. P. I. p. 341. T. XXVI. Pa: Mexico.

E. plano-convexus magnus; costis 16 obtusiusculis, ad aculeos emarginatis; aculeis sub-12, 4 interioribus majoribus, summo et imo nonnihil latioribus, reliquis 4 anticis, 4 posticis.

Stirps (teste Cl. de Karwinski) interdum in sesquipedalem diametrum excrescens. Specimen in horto Monacensi descriptum mox obiit, sed alterum in horto Berolinensi adhuc viget.

Flores (exsiccati) campanulato-cylindrici, ultra pollicem lati et extus densissimis spiris squamarum lanceolatarum, basi rubrofuscidularum, superne flavescentium, ciliatarum muniuntur. Petala lineari-oblonga, purpurea, nervo medio percursa, margine irregularia. Stamina inclusa (Mart.).

\section{E. Spina Christi Zucc.}

E. Fischeri H. BenoL. 
Pa: Brasil. merid.

E. globosus obscure viridis 13-14-angularis; costis acutis crenatis; areolis magnis ovalibus, junioribus albovelutinis; aculeis exterioribus $6-8$, centrali 1 erecto, omnibus crassis rigidis curvatulis, nascentibus nigricantibus, basi pallidis, tandem flavidis.

Specimina in horto Monacensi et Berolinensi 6 poll. diam. Areolae 8-10 lin. distantes; aculei summi minimi, infimi $1^{1 / 2}$ poll. longi, centralis semper sursum curvatus.

\section{E. tuberculalus Link et Otro.}

Vhdl. d. GBV. III. S. 425. T. 26.

\section{Pa: Mexico.}

E. caule subgloboso viridi, costis 8 obtusatis, spina centrali erecta, radiantibus 8 patentibus, subrecurvis, sensim minoribus (L. et 0.j.

E. oblongus glaucescenti-viridis 12-angularis; costis repando-sinuatis compressis, circa areolas tuberculosis; areolis oblongis albidis, junioribus lanuginosis, tandem nudis; aculeis exterioribus subrecurvis rigidis, centrali 1 erecto.

Spec. in horto Berol. nunc 6 poll. alt., 5 poll. diam. Aculei originarii rigidissimi pollicares, recentiores minores et saepe partim deficientes.

\section{H. spiralis Kanw.}

E. robustus Karw. - Meloc. Besleri affinis, E. agglomeratus HonT.

Pa: Mexico.

E. subglobosus vel oblongus glaucescens (hucusque) 13-angularis; sinubus junioribus acutis, tandem planis, linea modo perviridi notatis; costis subverticalibus acuatis tuberculosis; areolis remotis flavido-, dein griseo-velutinis, sursum elongatis in tuberculorum apice; aculeis exterioribus $7-8$, supremo brevissimo vel nullo, validis, paululum applanatis, recurvis, initio basi et apice purpureis, medio citrinis, tandem fuscis, patentibus, centrali 1 robustiore, plano, apice uncinato.

Specimina adulta in Europa non adesse videntur. Quae in hortis obvia, e semine, anno 1828 a Cl. de Karwinski e Me- 



\section{1}

xico misso, orta sunt. Maxima 3-4 poll. alta, 3 poll. diam. Aculei exteriores $1 / 2-1$, centralis $1 \frac{1 / 2}{2}$ poll.

Fructus oblongo-globosus, 10 lin. long., 6 diam., basi tomentosus, squanis adpressis brumueis obtectus, corollae reliquiis coronatus. Corolla pollicaris, petala lanceolata rubra, margine alba.

\section{E. robustus H. BERoL.}

Echin. spectabilis, subuliferus Hon'T.

Pa: Mexico (Oaxaca, Tehuacan.).

E. clavatus 8-angularis obscure viridis; costis verticalibus compressis, circa areolas inflatis; sinubus latis angulosis; areolis remotis sursum elongatis, junioribus flavo-, dein griseo-tomentosis; culeis centralibus 4 atropurpureis, basi tetragonis, transversire striatis, infimo maximo, exterioribus 14 purpurascentibus, superioribus gracilibus, infimis 3 validioribus, omnibus rectiusculis.

Specimina adulta in hortis non obvia sunt, modo plantae seminales, $4-5$ poll. alt., $2-3$ diam., areolis $1-1 \frac{1}{4}$ poll. distantibus, aculeis centralibus ultrapollicaribus. - Plantae juniores laete virides, omnino tuberculosae, Mammillariae similes; serius tubercula conflumet, tandemque costas formant non interruptas.

Fructus, anno 1828 a Cl. de Karwinski e Mexico missi ovati, pollicem longi, 8 lin. diam., squamis magnis semilunaribus patentibus, ntidis, instructi, corollae reliquiis coronati. Corolla $2-2 \frac{1}{2}$ poll. diam., sepala brevia lata, petala sordide flava, lanceolata, pollicaria.

ß. prolifer. - E. agglomeratus KARW.-Laetius viridis, ex areolis omnibus novas plantulas procreans, ita ut in patria pomis accumulatis comparari possit (KARW.).

$\gamma$. monstrosus. - Specimina nonnulla in horto Göttingensi e semine enata, irregulariter ramosa et sulcata, $\mathrm{Ce}$ reo peruviano monstroso analoga.

\section{K. armatus SAlm.}

Hort. Dyck. p. 341,

$\mathrm{Pa}$ ?

E. globosus; costis 10 compressis verticalibus; sinu acuto; areolis oblongis, junioribus subvelutinis griseis; aculeis subulatis validissimis rigidis subrecurvatis, pallide brer. neis, exterioribus 8 ralliantibus, infimo longissimo, rarissime centrali uno.

Specimen unicum in horto Dyckensi sine prole mortuum! 


\section{2}

\section{E. ornatus DC.}

\section{Revue p. 114.}

\section{Pa: Mexico.}

E. subglobosus; costis 8 profundis compressis verticalibus, floccis albis seriatis transverse ornatis; fasciculis cujusque costae 3 , aculeis rectis flavidis et 1 centrali.

粠粠 Costis compressissimis, crispatis.

\section{H. crispatus DC.}

\section{Revue p. 3\%. t. 8. - Mém. p. 20.}

Pa: Mexico, Guatimala.

E. obovatus, apice retusus, subumbilicatus ; costis subverticalibus $(30-60)$ undulato-crispis, hinc inde tuberculatis ; aculeis fasciculatis rigidis inaequalibus rectiusculis (DC.).

F. obovatus multangularis viridis, vertice convexo; costis compressis crispatis; sinubus (junioribus acutis, dein) repandis; aculeis ex areola rotunda albo-tomentosa, superioribus 3 crassioribus apice brunneis, inferioribus 4 brevioribus albis, omnibus recurvis.

Specimen in horto Monacensi 5 poll. altum, $2^{1 / 2}$ diam. Aculei 3-4 lin. longi. - Flores (sec. DC.) in apice caulis parvuli, purpurei, sepalis secus tubum dense imbricatis, in limbo biserialibus oblongo-linearibus acutis.

ß. horridus DC. revue p. 115. - Fasciculis approximatis, aculeis validioribus, magis erectis, longioribus, griseo-fuscis. - An propria species?

\section{E. dichroacanthus MART.}

\section{Pa: Mexico.}

E. obovatus multangularis, obscure viridis, vertice umbilicatus ; sinubus acutis; costis (32) acutissimis membranaceis irregulariter crispatis; areolis remotis irregulariter dispersis, ovalibus, albo-tomentosis; aculeis superioribus 3 erectis applanatis atropurpureis, inferioribus $4-6$ diaphane albis, omnibus rigidis rectis.

Specimen in horto Monacensi 6 poll. altum, 4 diam. Aculei superiores pollicares, basi $1^{1 / 2}$ lin. lati, inferiores $4-6$ lin. Costae hinc inde oriuntur et evanescunt sine areola. 



\section{3}

\section{E. anfractuosus MART.}

\section{Pa: Mexico.}

E. oblongus, subcolumnaris, obscure viridis, multangularis; sinubus acutissimis; costis membranaceo-compressissimis crispatis; areolis remotissimis parvulis velutinis albis; aculeis subrecurvatis stramineis, apice brunneis, exterioribus 7 rigidiusculis ( 3 summis majoribus, 4 inferioribus gracilibus), centrali 1 validiore fulvo.

Planta in horto Monacensi 5 poll. alta,21/2 diam. Aculei summi ultrapollicares, centralis pollicaris.

\section{E. obvallatus DC.}

Revue p. 37. t. 9. - Hern. mex. 410. ic.

$\mathrm{Pa}$ : Mexico (Tepenexcomitl.).

E. obovato-globosus, apice depresso-umbilicatus; costis plurimis verticalibus; aculeis subalbidis fasciculatis inaequalibus divaricatis longis (DC. pr. III. p. 462.).

E. depressus vel globosus, obscure viridis, multangularis; costis compressissimis crispulis, circa areolas inflatis; areolis remotissimis, junioribus albo-velutinis; aculeis superioribus 4 rigidis ensiformibus decussatis albidis, apice brunneis (2 lateralibus minoribus), inferioribus 4 multo gracilioribus.

Plantas in horto dom. Schelluase e semine mexicano natas ab initio pro $E$. dichroacantho Mart. habuimus, sed nunc ( 2 poll. altae, $1^{3 / 4}$ poll. diam.) ita sese formarunt, ut iconi suprá citatae ominino congruae sint. - Flores (sec. DC.) ad apicem solitarii, spinis obvallati, erecti, purpurei, cum loborum limbo margine albido.

\section{H. phyllacanthus MART.}

Otro's GZ. 1836. No. 26. S. 201.

\section{Pa: Mexico.}

E. cylindricus vel obovatus, obscure viridis multangularis; vertice plano; sinubus acutissimis; costis (35) membranaceis confertissimis undulatis; areolis sparsis albo-tomentosis; aculeis superioribus 1-2 longioribus fuscis, foliaceis, applanatis, inferioribus $4-7$ brevibus rectis albis rigidioribus.

Specimen originarium in horto Monacensi (nunc mortuum) $1 / 2$ ped. altum, 4 poll. diam., aculeis foliaceis pollicaribus. Plantae juniores obclavatae, basi omnino mammillariaeformes, sine costis, aculeis omnibus setiformibus brevibus radiantibus patentissimis albis. 


\section{4}

Flores mensibus Mijo - Julio per plures dies aperti, 9-10 lin. longi, 1 poll. dian., pallidissime sulphurei. Tubus calycinalis 3 lin. longus, infundibuliformis, viridis, parce squamosus. Petala biserialia, linearia, mucronulata, 6 lin. longa, 1 lin. lata, albida vel flavescentia. Stamina brevia, virentia, antheris flavis. Stylus stamina vix superans, stigmatibus 5 obtusis, crassiusculis.

\section{S. 2. Tuberculati.}

Costis plerumque oblique ascendentibus regulariter interruptis, tubercula formantibus discreta, in apice areolas gerentia.

\section{F. Scopa H. BeroL.}

Link et Otro icon. t. 41.-Cereus Scopa DC. prodr. III. p. 464. - Cactus Scopa Link enum. 2. p. 21. - Spneng. syst. 2. p. 494 .

Pa: Brasilia (Capitania do Espiritu santo).

E. erectus clavatus, tandem e parte superiore prolifer, viridis; costis $30-36$ subverticalibus tuberculatis; areolis albo-tomentosis confertissimis; aculeis centralibus $3-4$ purpureis erectis, radiantibus $30-40$ setaceis albis.

Planta pedalis et ultra, $2-4$ poll. diam. Areolae vix 1 lin. distantes. Aculei centrales $3-4$, radiantes $2-3$ lin. longi. Flores aestate copiosi circa verticem, lutei, expansi $1^{1 / 2}$ poll. diam. Tubus brevissimus, squamis lanceolatis acutis pilosis obtectus. Petala biserialia lanceolata acuminata. Stylus multipartitus purpureus, stigmatibus coccineis; stamina stylo breviora, purpurea, antheris flavis.

B. candidus. - Aculeis omnibus niveis, rarissime 1-2 roseis.

\section{H. aculissimus H. BeroL.}

Otro's GZ. 183ว. No. 45. S. 3อ̌3.

Pa: Chile.

E. globosus viridis, vertice impresso; costis 18 subverticalibus tuberculato-crenatis; crenis basi gibbosis, superne deplanatis, areolatis; areolis lanatis; aculeis rectis, rigidis, radiantibus $10-11$, centralibus 3 , nascentibus fuscis, dein albidis.

Specimen in horto Berolinensi autumno 1835 primum floriferum circa 6 poll. diam. Aculei aciculares, basi albidi, apice fus: cescentes, centrales 3 majores, 9 lin. longi, in una linea longitu- 


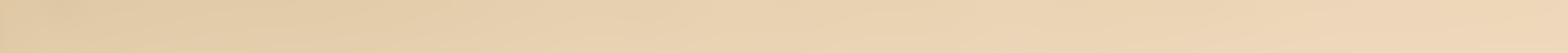



dinali positi. Flores solitarii e vertice prodennt, 21/2 poll. longi, coccinei. Calyx 15 lin. Iongus, clavatus, squamulis lanceolatis imbricatis obsitus; sepala reflexa, intus rosea. Petala, pollicem longa, obscure rosea, inaequalia, lavceolata vel lineari-lanceolatn, acuminata, exteriora magis minusve patentia, interiora erecta et stamina includentia. Stamina numerosa, petalis intimis breviora, antheris pallide flavis. Stylus staminibus paulo longior, apicem versus roseus; stigmata 8 flava. - Flos per 7 dies non omnino expansus, attamen perfectus erat, fructumgue praebuit.

\section{2. exsculptus Отто.}

E. subgibbosus Haw. (philos. mag. 1831. Dec. vol.X. p. 414.). - E. Acanthion et interruptus H. BERol. - Cer. montevidensis HoRT.

Pa: Chile, Montevideo, Mexico.

E. rotundo-oblongus, intertextim valde spinosus, angulis sub-16-lobularibus, sinubus profundis acutis, spinariis distantiusculis (Haw.).

E. oblongus clavatus multangularis viridis; costis obliquis interruptis compressis; sinubus acutis; areolis magnis ovalibus albidis, gibbere nudo suffultis; aculeis centralibus 4 rectis rigidis, exterioribus numerosis, radiantibus, gracilibus, albidis, fulvis vel nigricantibus.

Specimina in horto Berolinensi pedalia, poll. diam. Acule $1 \frac{1}{2}$ pollicares. - Plantae juniores hahitı et aculeornm colore maxime variant.

\section{H. hybocentrus LEHM.}

\section{Pa: Brasilia (prov. Minas Geraes.).}

W. oblongo-subcylindricus saturate viridis; costis 18 obtusis crenato-tuberculatis; tuberculis apice lanatis, valde aculeatis; aculeis 18-22 acicularibus patentibus, centralibus plerumque 4 majoribus (uncialibus) fuscescentibus (Cl. LEHY, in litt.).

Flores (in horto Berol. mense Junio) circa verticem, 2 poll. diam. Tubus brevissimus squamatus; sepala sordide rubentia, brevia; petala latiora coccinea, margine citrina, apice serrulata. Stylus multipartitus, stamina contorta superans.

4\%. F. centeferius LeHM.

Pa: Minas Geraes.

E. subglobosus obscure vixidis tuberculatus, apice vix 
umbilicatus; tuberculis in series $\mathbf{1 5}$ subverticales dispositis, confluentibus, oblongis, infra areolam acuato-prominentibus (gibbosis); areolis ovalibus cano-tomentosis; aculeis exterioribus $10-12$ gracilibus, rectiusculis, bifarie patentibus, centralibus 4 , decussatis, validioribus, nigrescentibus, tandem fusco-cinereis.

Speciminis $2^{3 / 4}$ poll. alti, 31/4 diam. aculei maximi $4-5 \mathrm{lin}$. longi. - Florentem vidimus 4. Julii 1836 Lipsiae in horto Breiteriano plantam 4 poll. diam. Flores copiosi circa verticem. Tubus $1 / 2$-pollicaris viridis, parum squamatus. Sepala imbricata rubra. Corolla expansa vix 11/2 poll. diam. Petala lanceolata, sordide flava, intus rubentia. Stamina contorta alba; stylus longior 6 - partitus.

\section{E. pachycentrus LEHM.}

\section{Pa: Minas Geraes.}

E. oblongo-globosus obscure viridis tuberculatus, vertice umbilicato; tuberculis oblongis confluentibus mammaeformibus, in series irregulares subverticales dispositis; areolis ovalibus tomentosis; aculeis rigidis fuscis brevibus, exterioribus sub-10 erecto-patentibus, centralibus nullis vei 1 - 2 rectiusculis majoribus (Cl. LEHM. in litt.).

Specimen floriferum $3^{1 / 2}$ poll. altum, 4 poll. diam. Flores ex areolis prope verticem, $2^{1 / 2}$ poll. diam. Calyx imbricatus, squamulis viridibus. Petala oblonga acuminata, lutea, linea rubescente notata, dorso rubella. Stamina filiformia, corolla breviora, centro collecta, antheris flavis; stylus staminibus longior et crassior, erectus, multipartitus.

\section{F. leucacanthus Zucc.}

\section{Pa: Mexico (prope Zimapan Karw.).}

E. clavatus laete viridis, tandem e parte superiore inermi areolarum prolifer; sinubus latis subverticalibus; costis 8 compresso-tuberculosis; areolis in vertice tuberculorum, ovalibus, albo-tomentosis, ultra spinarum orbem productis, ibique proli- et floriferis; aculeis exterioribus 8 patentibus, rectiusculis, centrali 1 erecto, vix recurvulo (irierdum nullo), omnibus rigidis, nascentibus flavis, tandem albis.

Specimen unicum in horto Monacensi, 1836 floriferum, 5 poll. altum, basi attenuata lignosum, superne 3 poll. diam. Areolae 6 lin. distantes. Aculei radiantes $4-5$, centralis 6 lin. longus. 




\section{7}

Flores breves stranineo-purpurascentes. Tubus calycinalis 3-4 lin. longus, obconicus, virens. Sepala circiter 20, infima in tubo brevissina, viridia, ovata, superiora sensim longiora, oblonga, acutiuscula, straminea, medio dorso purpurascentia: Petala circiter 30 , lineari-oblonga, acuta, apicem versus irregulariter et obsolete serrulata, nervo medio subcarinata, straminea. Stamina omnia e fundo tubi, basi sordide purpurascentia, sursum pallide straminea, antheris aureis. Stigma 7-radiatum. (Cl. Zucc. in litt.).

\section{E. subuliferus Link et Oтто.}

\section{Vhdl. d. GBV. f. Pr. III. S. 42\%, T. $2 \%$.}

\section{Pa: Mexico.}

E. caule subgloboso viridi; costis $8-10$ tuberculatis; spina centrali maxima erectiuscula recurva, $4-5$ patentissimis, $4-6$ extimis divaricatis tenuibus.

Caulis $2^{3 / 1}$ poll. altus, 2 diam. Costae e tuberculis luculenter compositae. Vertex vix distinctus, costatus. Spinae omnes canofuscae, omnes magis minusve recurvae, maxima fere pollicem longa, quae sequuntur, 8 lin., minimae extimae 4 lin. longae.

Planta Berolinensi mortua haec species in hortis non amplius occurrit!

\section{S. 3. Species parum notae.}

\section{E. intortus DC.}

Cactus intortus MuL. dict. ed, 8, n. 2.- HaW. syn. p. 184 .

Pa: Antigua.

E. oblongus 13-16-angulatus, angulis superne in spiram intortis, aculeis mediocribus, subinde incurvatis.

ß. purpureus Puum. spec. 19. mss. vol. 3. t.8.-Cactus nobilis LAM. dict. 1. p. 537. (S. Domingo). - Totus purpureus, aculeis candidis (DC. prodr. III. p. 462.).

52. $\mathrm{E}$. depressus DC.

Prodr. III. p. 463. - Cactus depressus Haw. syn. p. 173 ?

Pa: Amer. calid.

E. subglobosus, apice depressus; costis verticalibus 20 obtusis subtuberculatis; aculeorum fasciculis confertis; aculeis e tomento albido rigidis, pallidissime fuscis, centralibus $3-4$, radiantibus $10-12$, infimo validissimo. 


\section{8}

53. E. melocacliformis DC.

Revue p. 38. t. 10. - Prodr. III. p. 462.

Pa: Mexico.

E. subrotundo-ovatus obtusus; costis verticalibus circiter 30 ; aculeis fasciculatis divergentibus inaequalibus, subfuscis.

Flores albidi, infra apicem subverticillati, tubo sepalis numerosissimis extus subpurpureis imbricatis adpressis, limbo expanso lobis $2-3$-serialibus oblongis acutis. Stigmata longa $8-12$ supra stamina exserta.

Descriptio iconis, non plantae viventis!

\section{H? aureus MEven.}

Cact. aureus Meyen Reise um die Welt; B. I. S.44\%. - Otro's GZ. 1833. Nr. 2\%. S. 211.

Pa: Peru (prov. Arequipa.).

C. erecto - repens 6-angularis subarticulatus; aculeis 6 longis rigidis, centrali 1 erecto longissimo.

Flores aurei formosissimi, 1 poll. longi, calyce villoso.

\section{E? cereiformis DC.}

Revue p. 115.

Pa: Mexico.

E. subcylindraceus viridis; costis 13 compressis; sinu acuto; crista subobtusa; fasciculis in quaque costa 3 ; areola subvelutina; aculeis subgriseis rigidis tenuibus, 1 :centrali recto, 7 radiantibus.

Specimen mancum 4 poll. longum. An Cereus quidam junior? (DC.) 



\section{Cereus.}

Haw. syn. p. 178. - DC. prodr. HI. p. 463.

Char. Gen. Sepala numerosissima imbricata, basi ovario adnata, in tubum elongatum concreta, exteriora breviora calycinalia, media longiora colorata, intima petaliformia. Stamina numerosissima cum tubo concreta. Stylus filiformis, apice multifidus. Bacea areolata, sepalorum reliquiis squamata aut tuberculosa. Cotyledones acuminatae.

Frutices carnosi, subglobosi vel elongati, stricti, articulati vel repentes, axi ligneo interne medullifero donati, angulis verticalibus, spinarum fasciculos gerentibus vel inermibus, regulariter sulcati. Anguli seu alae nunc plurimae, nunc paucissimae, rarius duae tantum, et tunc rami compresso-alati inermes. Flores ampli e spinarum fasciculis lateralibus trunci aut ramorum vetustiorum, aut crenis angulorum orti. Fructus oviformes, plerumque anno sequente maturescentes, edules.

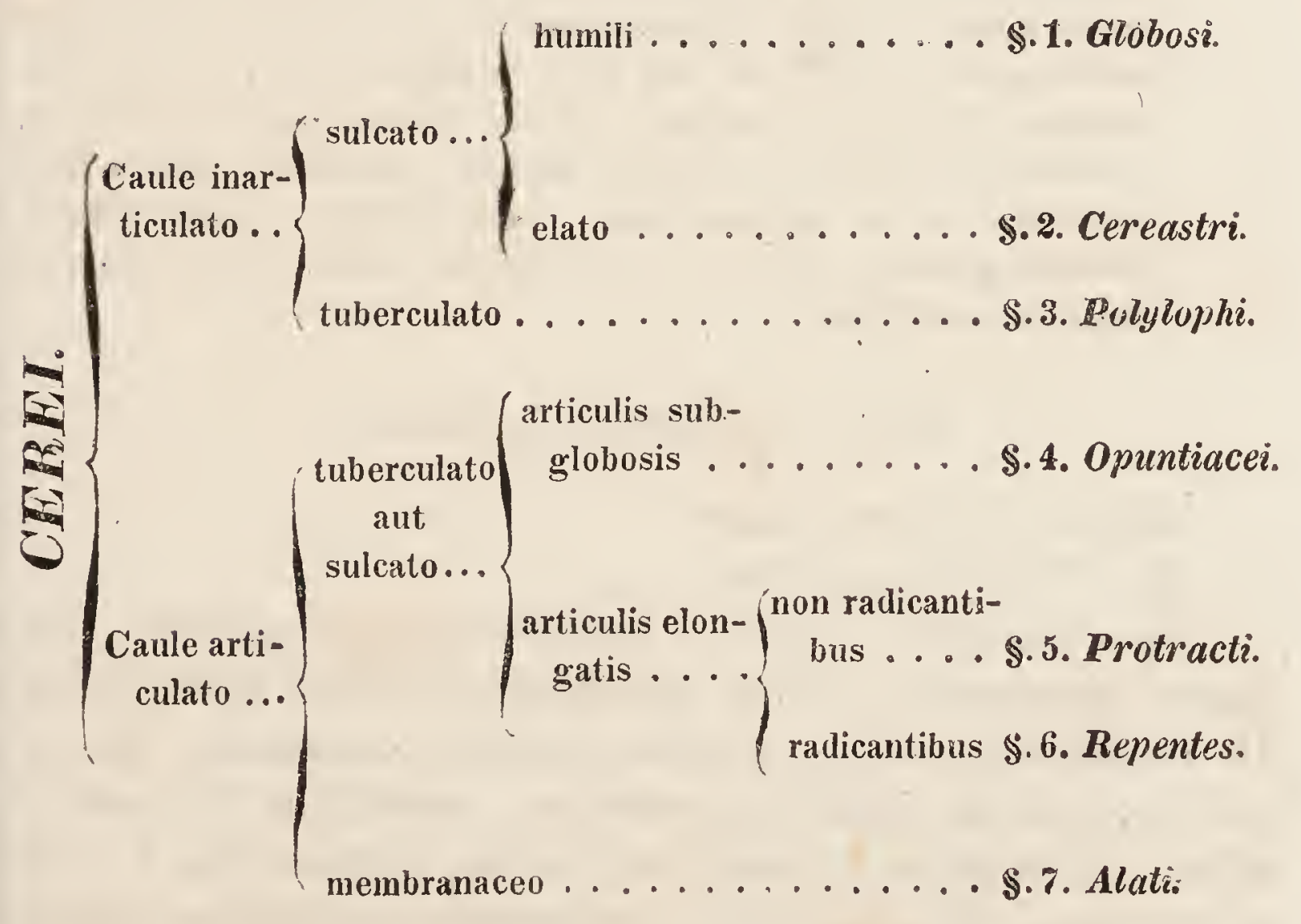




\section{S. 1. Globosi.}

Caule sphaeroideo vel depresso-globoso, sulcato, melocactiformi, floribus lateralibus, plerisque tubo longissimo, aliis breviore, semper tamen supra receptaculum elongato.

\section{C. oxygonus LiNK et Отто.}

Echin. oxygonus Vhdl. d. GBV. f. Pr. VI. S. 419. T. 1. - Bot. regist. 171\%. - E. sulcatus HonT.

$\mathrm{Pa}$ : Brasilia australis.

E. glaucescens subglobosus 14-angularis; costis acutis repandis; spinis patulis inaequalibus, flore longissimo (L. et 0.).

C. obclavatus vel subglobosus 15-angularis glaucescens, tandem e basi prolifer; sinubus repandis; costis verticalibus compressis, circa areolas inflatis; crista acuta; areolis remotis rotundis, junioribus flavido-, dein griseo - tomentosis; aculeis in planta adulta paucis subulatis, inaequalibus, patentibus, brunneis.

Truncus adultus 4-6 poll. diam., 5-6 alt. Areolae 10-12 lin. distantes. Aculei 6-10 lin. longi. - Flores rosei per totam aestatem, ex areolis lateralibus, expansi 4 poll. diam., per $36-48$ horas aperti, inodori. Receptaculum subglobosum, viride, squamis minutis brunneis et pilis albis obtectum; tubus 8-10 poll. longus, 5 lin. diam., pilosus, squamis sparsis, sursum majoribus, virentibus. Sepala fusco-rubra, angusta, acuminata. Petala lata, lanceolata, extus saturate rosea, intus albida, rubore suffusa. Stamina corolla breviora, flava, antheris flavis. Stylus stamina aequans, multifidus.

\section{C. mulliplex H. BeroL.}

Echin. multiplex HorT.

Pa: Brasilia australis.

E. obclavatus viridis, e lateribus copiose prolifer, basi lignea attenuatus; vertice umbilicato; sinubus latis; costis 13 verticalibus acutis; areolis ovalibus tomentosis, flavogriseis; aculeis rigidis acicularibus, centralibus 4 , basi et apice nigricantibus, infimo longissimo, exterioribus 9-10 brevioribus, flavescentibus, irregulariter radiantibus, summis et infimis brevissimis. 


Planta adulta 8 poll. alta, 6 diam., areolis $8-10$ lin. distantibus, aculeis centralibus pollicaribus. - Primum florentem vidimus mense Augusto 1834 in horto dom. Allardt, Berolinensis. Sicut habitus, ita flos quoque $C$. oxygono affinis, 4 poll. diam. Receptaculum oblongum, viride, albo-pilosum, tubus 9-10 poll. longus, sordide rubellus, squamis sparsis viridibus et pilis albis obtectus, infundibuliformis, a medio sursum dilatatus, basi 6 lin., infra corollam $2 \frac{1}{2}$ poll. diam. Sepala lanceolata fusca. Petala rosea, acuminata, $2 \frac{1 / 2}{2}$ oll, longa, 1 poll. lata. Stamina limbo breviora, stylus 12-radiatus, stamina non superans.

B. monstrosus. - Specimina in hortis nonnullis inveniuntur, in formam cristae galli, vel Celosiae cristatae excrescentia, quorum partes excisae eandem formam constanter servant.

\section{C. leucanthus PFR.}

Echin. leucanthus Gillies. - SALm hort. Dyck. p.341. - Meloc. ambiguus, elegans HorT. - Cereus incurvispinus H. Darmst. - Otto's GZ. 1835. No. 31. \$. 244.

Pa: Mendoza (Chile.).

C. globosus vel subconicus; costis $\mathbf{1 2}-14$ verticalibus compressis; areolis approximatis oblongis, junioribus sublanatis albidis; aculeis subulatis rigidissimis, basi brunneis, medio flavicantibus, imo apice nigris, exterioribus 8 radiantibus, centrali 1 validiore, omnibus sursum curvatis.

Specimina fere pedalia, diam. 6-7 poll., areolis $6-8$ lin. distantibus, aculeis ultrapollicaribus. Flores mense Junio et Julio, albi, $3-4$ poll. diam., vespere aperti, circa 36 horas expansi. Receptaculum oblongum, brunneum, dense squamatum et pilosum. Tubus 8-10 poll. longus, nitide brunneus, fere nudus, squamis pilisque sparsis instructus, basi $5-6$ lin., infra corollam 11/2 poll. diam. Sepala angusta, fusco-virentia, reflexa. Petala biserialia nivea, apice rosea, acuminata, 1 poll. lata, $2-21 / 2$ longa. Stamina numerosa, limbo breviora, flava. Stylus staminibus pollice brevior, stigmatibus circa 12. - Versus finem florescentiae odorem observavimus violaceum.

\section{C. tubiflorus PFr.}

Echin. tubiflorus H. ANGL.

Pa?

C. globosus obscure viridis nitens 10-angularis, basi vix attenuatus; vertice impresso; sinubus acutis, inferiore plantae parte obsoletis; coștis compressiș; areolis subre- 
motis prominentibus; aculeis e tomento velutino albo, rectis, tenuibus, subrigidis, centralibus $1-3$ flavescentibus, basi et apice nigris, exterioribus -9 brevioribus, gracilioribus, patentissimis.

Specimen in horto Berolinensi 1835 floriferum $3^{4 / 2}$ poll. altum, 4 diam., areolis 1 poll. distantibus, aculeis centralibus subpollicaribus. - Flores mense Jnnio - Augusto ex areolis lateralibus, nivei, expansi $31 / 2-4$ poll. diam. Receptaculum oblongun viride, villosissimum. Tubus 8 poll. longus gracilis, viridis, squamis pilosis, apice purpurascentibus obsitus, basi $4-5$ lin., infra corollam $1^{1 / 2}$ poll. diam. Sepala linearia, reflexa, pallide viridia. Petala biserialia, nivea, mucronalata, 2 poll. longa, 8 lill. lata. Stamina numerosa alba, antheris sulphureis. Stylus paulo 'ion-' gior, stigmatibus $10-12$ flavescentibus.

\section{C. Fiyriesii H. Berol.}

Richin. Eyriesii 'Turp. observ. p. 58. t. 2. - Bot. regist. 1707. - Bot. magaz. 3411. - O Tro's GZ. 1834. No. 50. S. 399. - 183ว. No. 8. S. 59. No. 40. S. 314.

\section{Pa: Buenos Ayres.}

C. globosus vel depresso-globosus pallide virens; vertice impresso; sinubus latis; costis $12-18$ verticalibus, subacuatis, undulatis; areolis remotis flavido-, serius griseotomentosis; aculeis brevissimis brunneis pungentibus rectis, exterioribus 11 , centralibus 4 .

Specimina in horto Breiteriano pedem alta et diam., areolis 6-8 lin. distantibus, aculeis linearibus. - Plantae juniores a sequente vix distingui possunt ob areolas confertas et aculeos exteriores longiores setaceos albos. Flores per totam aestatem ex areolis inferioribus plantae, vespere aperti, per $36-60$ horas expansi, albi, $3-3^{1 / 2}$ poll. diam., odorem exhalantes fortem narcoticum. Receptaculum viride, dense squanatum et pilosun. Tubus $8-10$ poll. lougus, basi 5 lin. dian., inde a medio incrassatus, infra corollam $1^{1 / 2}$ poll. diam., viridis, parce squamulatus. Sepala linearia, fuscescenti-viridia, reflexa: Petala biserialia, nivea, exteriora apice viridia, longe mucronata, 1/1/2 poll. louga, 10 lin. lata. Stamina numerosissima, partim coroliae orificio, partim tubi inferioribus partibus affixa, alba, antheris flavis. Stylus brevior, stigmatibus $8-12$ albidis.

\section{C. turbinalus PFr.}

OrTo's GZ. 1835. No. 8. S. 59. - No. 40. S. 314. Cer. gemmatus 0тTo, nec Zuccar. - Cer. jasmineus H. Daris't. - Echin. turbinatus Hort.: 




\section{Pa?}

C. obovatus vel clavatus perviridis; vertice subconvexo; sinubus acutis; costis $15-18$ irregulariter turbinatis, compressis, undulato-crenatis; areolis approximatis albis lanuginosis; aculeis centralibus 6 brevissimis nigris, exterioribus 10-12 longioribus albis setaceis.

Plantae adultae semipedales, areolis 2 lin. distantibus, aculeis centralibus $1^{1 / 2}$, exterioribus $2-3$ lin. longis. Flores C. Eyriesii similes, 3 poll. diam., odore jasmineo. Tubus 6 poll. longus viridis, parcissime squamatus et pilosus, a medio dilatatus, infra corollam 2 poll. diam. Sepala linearia obscure viridia. Petala biserialia, lata, alba, mucronata, extus virentia. Stamina numerosa, partim circa orificium tubi, partim in ipso tubo adnata, inferiore limbi margine dense fasciculata incumbentia. Stylus stamina aequans multiradiatus.

\section{\%. C. Schelhasii PrR.}

Onto's GZ. 1835. No. 40. S. 314. - Echin. Boutillieri Parm.

$\mathrm{Pa}$ ?

C. globosus viridis, basi vix attenuatus; vertice paululum impresso; costis 15 -18 verticalibus acutissimis, irregulariter tuberosis ; sinubus profundis (parte superiore acutis, inferiore) repandis; areolis remotis latis, saepe inermibus aut paucis aculeis instructis, alias copiose spiniferis; aculeis brevissimis nigris rigidissimis, acute pungentibus, e tomento griseo brevi, exterioribus 11-13, centralibus $5-7$ brevioribus.

Specimen maximum mihi notum 8 poll. diam., 7 poll. altum. Areolae 10-12 lin. remotae. Aculei 2 lin. longi. Plantae resectae facile et copiose proles edunt, C.turbinato initio haud dissimiles.

\section{C. denudahus H. BeroL.}

Echin. denudatus Link et OTro icon. p. 1\%. t. 9.

Pa: Brasilia australis.

E. caule subgloboso virente, costis $6-8$ obtusatis, spinis $5-8$, omnibus patentissimis (L. et $\mathbf{0}$.).

C. globosus 7 -8-angularis glaucescenti-viridis; vertice plano nudo; costis rotundis tuberculatis; areolis subremotis ovalibus, albidis; aculeis 5 rigidiusculis, curvatulis, dense adpressis, nascentibus flavis, dein albis. 
Specimina in horto Berolinensi 5 poll. diam., areolis 6-8 lin. distantibus, aculeis semipollicaribus. - Flores mense Majo-Julio, prope verticem, per plures dies aperti, post meridiem clausi, albi, 21/2 poll. diam. Tubus viridis, nudus, sparse squamatus, 2 poll. longus. Petala extima dorso virentia, intus albida, interiora nivea linearia. Stamina numerosa stylusque corolla breviora.

Plantae juniores nitide virides, mox floriferae (in horto Haageano Julio 1836 spec. 2 poll. diam.).

\section{C. pulchellus PrR.}

Echin. pulchellus MArT. (Act. nov. nat. cur. XVI. P. I. p. 342. T. XXIII. f. 2.)

\section{Pa: Mexico (Pachuca KARw.).}

C. obovato - cylindraceus, glaucescens, vertice paulo impressus; costis 12 obtusis, interrupte tuberculatis; aculeis e lana parca decidua $4-5$ brevibus rectis flavescentibus, oblique patulis, imo longiore.

Specimen in horto Monacensi mense Aprili jam saepius floriferum $2^{1 / 2}$ poll. altum, $1^{1 / 2}$ poll. diam. Flores e latere costae, albo-rosei, $1^{3 / 4}$ poll. diam. Tubus cylindricus, vix pollicaris, sordide atrovirens, tuberculis obsitus. Sepala pluriseriata, extima circa 8 breviora, lineari-oblonga, obtusa cum mucrone, integerrima, glabra, extus margine albida, dorso linea sordida olivacea, sursum violascente, notata, intus albida; sequentia $6-7$ petala aequant, acuminata, extus minus colorata, intus pallide rosea. Petala pluriseriata, circiter 20, e basi attenuata anguste lanceolata, argute acuminata, in mucronem subulatum terminata, a medio sursum serrulata, deorsum integerrima, glabra, alba et rubore suffusa. Stamina in pluribus seriebus, circiter 260, petalis breviora. Filamenta filiformia, erecta, glabra, alba. Antlerae ovatae, obtusae, erectae, parvae, flavae. Stylus cylindricus, erectus, stamina aequans, glaber, albus, superne divisus in stigmatis radios erecto - patulos 7 obtusos, papillosos, circiter bilineares, virides.

\section{C. gíbbosus Salm.}

Cact. gibbosus Haw. syn. p. 173. - Echin. gibbosus DC. prodr. III. p. 461, - Bot. regist. t. 137. - ReICHB. fl. exot. 326.

Pa: Jamaica.

C. subrotundus profunde sub-16-angularis; apice depresso inermi; angulis gibbero notabili sub singulo fasciculo spinarum, spinis nigris ( HAw.). 


$$
\text { · }
$$



C. subglobosus, basi attenuatus, glaucescens, 12-16angularis; costis subverticalibus latis tuberculosis; areolis in tuberculorum interstitiis, magnis, albido-tomentosis; aculeis 6 divergentibus, rectis, rigidis, brunneo-cinereis, supremis minimis.

Specimina in horto Berolinensi 5 poll. alta, 4 poll. diam., areolis $6-8$ lin. distantibus, aculeis $1^{1 / 4}$-pollicaribus. - Flores prope verticem, albi, 3 poll. diam. Tubus $1 \frac{1 / 2}{2}$ poll. longus, 5 lin. diam., obscure viridis, squamis obtusis albidis sparsis obsitus. Sepala brevia virenti-rubella. Petala numerosa 3-serialia, obcuneato-ligatula, mucronato-obtusa, nivea, dorso linea rosea notata, interiora longiora, vix latiora. Stamina numerosa, exteriora limbum aequantia, interiora breviora, alba, antheris flavis. Stylus stamina aequans, crassus, stigmatibus 11 sulphureis.

\section{S. 2. Cereastri.}

Caule inarticulato erecto, regulariter costato, plerumque simplice, interdum basi ramoso, fulcro non indigente.

\section{* Multangulares.}

Caule crasso vel tenui 12 - 30-sulcato, cylindraceo, erecto, areolis plerumque confertis, floribus (excepto $\boldsymbol{C}$. magno HAw?) ignotis.

\section{a. Robusti.}

\section{C. reductus DC.}

Cactus reductus Link enum. 2. p. 21. - Cact. nobilis HAw. syn. p. 174 (ex DC. prodr. III. p. 463.).

Pa: Mexico, Guatimala.

C. oblongus, multangularis, angulis spinisque mediocribus rectis (HAw.).

C. erectus crassus brunneo-viridis multangularis; vertice nudo, modo tuberculoso; costis rotundatis interrupte tuberculatis, tuberculis conicis nudis; areolis immersis latis tomentosis; aculeis subulatis brunneis, apice corneis, rigidissimis, centrali 1 erecto (rarius nullo), exterioribus $7-9$ divergentibus, summis minimis.

Specimen in horto Berolinensi pede altior, 4 poll. diam. Areolae $4-5$ lin. distantes. Aculeus centralis $1 \frac{1 / 4}{4}$ poll., reliqui paulo minores. 


\section{C. dichroacunthus MART.}

\section{Pa: Mexico.}

C. erectus crassus 18-angularis, obscure viridis; sinubus acutis; costis subverticalibus compresso-tuberculosis, infra areolas gibbosis; areolis approximatis, ovalibus, albotomentosis; aculeis exterioribus 12 albis rigidis gracillimis, patentibus, centralibus $\breve{\jmath}-6$ rigidioribus, longioribus, nascentibus nigricantibus, tandem pallidis.

Specimen in horto Monacensi ultrapedale, $3^{2} / 2$ poll. diam. Are0lae 3-4 lin. distantes. Aculei exteriores 6-10, centrales $10-15$. lin. longi。

\section{C. senilis DC.}

Prodr. IIl. p. 464. - Cact. senilis Haw. (Tru, philos. magaz. 63. p. 41.) - C. Bradypus LeHм. (Act. nov. nat. cur. XVI. P. I. p. 315. T. XII.).

Pa: Mexico, Guatimala et (secundum Cl. Lehmans) Brasilia.

C. erectus obclavatus; costis 20 - 25 verticalibus tuberculatis; aculeorum fasciculis confertis; aculeis basi nudis, radiantibus $15-20$ criniformibus crispis, centrali 1 recto rigido (DC.).

C. oblique oblongus multangulatus, undique tectus crinibus longissimis deflexis, spinis solitariis mediis deflexis, lateralibus brevibus patentibus (Lein.).

Specimina existunt $3-4$ pedes alta, $3-4$ poll. diam. Costae valde approximatae (circiter 30 ), 1-21/2 lin. latae, 11/2 lin. prominentes. Areolae subdistantes, margine crinibus albis instructi. Crines deflexi, longissimi et ita approximati, ut tota planta ab is tecta dorsum fere referat Bradypi tridactyli senioris ( $L$ e h m.).

Plantis junioribus aculei centrales omnino desunt, solummodo crinium fasciculi observantur.

\section{C. columna T'rajune KARw.}

\section{Pa: Mexico.}

C. erectus robustus altissimus multangularis viridis; sinubus verticalibus acutis; costis subcompressis, vix obrepandis; areolis oblongis fusco-tomentosis; aculeis exterioribus 8 -10 radiantibus (superioribus brevioribus), centrali 


1 robustiore, valde elongato, rectiusculo, deflexo, omnibus rigidis, corneis vel albidis, basi et apice brunneis.

Specimen in horto Monacensi $2^{1 / 2}$ ped. altum, 5 poll. diam. Aculei centrales pollicares.

Plantae (e narratione dom. de Karwinski) in patria prope San Sebastian frequentissimae simplicissimae, $\mathbf{4 0 - 4 5}$ ped. altae, aequaliter 18-20 poll. diam. Aculei centrales originarii 6 poll., radiantes $1 / 2-1$ poll. longi, albidi. In apice trunci latere septentrionali quasi cephalium e lana densa fiavida, setisque brunneis elongatis consistens affixum esse dicitur, e quo fiores et baccae proveniunt.

An Melocactis adscribendus?

\section{C. polylophus DC.}

Revue p. 115.

Pa: Mexico.

C. simplicissimus erectus, viridis, cylindricus; costis 15-18 verticalibus; sinu acuto; crista subrepanda; fasciculis approximatis; areola juniore tomentosa convexa; aculeis -8 flavidis rectis divergentibus, centrali longiore erecto.

Planta $30-40$ ped. alta, sine ullo ramo (DC. ex dom. Coulter litteris.).

An idem cum praecedente?

\section{C. foveolatus HaAge.}

Pa?

C. erectus robustus multangularis ; sinubus acutis; costis obtusis alternatim inflatis et attenuatis; cristis repandis; areolis in parte costae inflata positis, ovalibus, griseis; aculeis rectis albis, centralibus $4-5$ longis rigidis, exterioribus 12 - 16 gracilibus brevioribus.

Truncus 21/2-3 poll. diam. Aculei centrales $1-2$ poll. Iongi.

\section{C. multangularis Haw.}

Guppl. p. 75. - Cact. multangularis WiLco, enum. suppl. 33. - C. Kageneckii Gmel. hort. Carlsr.

Pa: Amer. aequinoct.

C. erectus crassus viridis $18-20$-angularis, tandem basi ramosus; angulis approximatis rotundatis; areolis prominentibus ovalibus subtomentosis albidis; aculeis centralibus 4-6 rigidis, longis, flavis, apice fuscis, radiantibus 
numerosissimis flavidis, $4-6$ superioribus acicularibus, inferioribus $16-20$ setaceis, omnibus rectis.

Planta 2-3 ped. alta, 2-3 poll. diam. Areolae 4 lin. distantes. Aculei centrales 8-10 lin., exteriores $(20-24) 3-4$ lin. longi.

B. pallidior.- C. multangular. spin. albis, C. ochracanthus Honт. - Aculeis exterioribus albidis, centralibus pallide flavis.

\section{C. strigosus H. Angt.}

Hort. Dyck. p. 334. - An C. myriophyllus GiLuies? Pa. Chile.

C. erectus 15-18-angularis (tandem e basi ramosus); costis approximatis obtusis; aculeis e tomento griseo rectis, rigidis, exterioribus $13-16$ radiantibus, acicularibus, flavidis, centralibus 4 longioribus, infimo longissimo, validioribus, fuscescentibus.

Planta pedalis (et ultra?), $2-2^{1 / 2}$ poll. diam. Areolae $3-4$ lin. distantes. Aculei exteriores $3-5$, centrales superiores $3-5$, infimus 10-12 lin. longus.

\section{C. Lecchii Colla.}

Hort. ripul. 1824. - Linnaea IV. 1829. Lit. - C. lanuginosus aureus H. Medrol.

$\mathrm{Pa}$ ?

C. ovato-erectus 20-angularis, angulis approximatis obtusis, spinis aureis, lana valde longioribus.

An praecedenti aequalis?

\section{C. lanatus DC.}

Prodr. III. p. 464. - Cact. lanatus Hunb., Bonpl. et Kunth nov. gen. amer. 6. p. 68.

Pa: Quito (prope Rio Aranza et Guancabamba.).

C. erectus ramosus multangularis albo-lanuginosus; angulis membranaceis tuberculatis stellato-aculeatis; aculeo centrali caeteris octies longiore.

Caulis 2-3 orgyalis. Aculeus centralis $1-1^{1 / 2}$ poll. Flores ex fissura caulis laterali et longitudinali erumpentes, lanugine involuti. Fructus obovatus ruber, carne albo virescente (DC.). 


21. C. ferox Haw.

Philos. Magaz. 1830. p. 109.

Pa: Brasilia.

C. oblongo-teretiusculus; costis sub-18, spinis divaricantibus fulvis densissime tectis.

Caudex diam. subbiunciali, atro - viridis, spinis extantibus intricatis horridis fere tectus; harum sub-6 exteriores in singulo fasciculo, 4-5 mediocres, 1 centralis, duplo longior seu uncialis et sexies crassior plusve.

\section{C. magnus Haw.}

Philos. Magaz. 1830. p. 109.

Pa: Insula St. Domingo.

C. validissimus, simplex, profunde sub-12-porcatus, spinis inaequalibus brevibus rigidissimis atris.

Diam. 4-5 uncialis, porcis fere biuncialibus subacuatis, apice depresso, spinis variantibus usque ad 12 in singulo subdistante fasciculo, validis, sesquilineam longis, lana ordinaria densissima inconspicua, spinis breviore.

Floret mense Augusto. Flores diurni speciosi solitarii, parum suaveolentes. Tubus cylindraceus virescens, squamulosus et spinulosus, supra medium duplo inflatior pallidior, petalis albis lorato-lanceolatis acutis, toto mane apertis patulis usque ad 4 uncias. Stamina numerosissima pallide sulphurea, antheris minutis. Stylus parum declinatus, altitudine staminum, stigmatibus 14 radianter recurvulis obtusis.

Num Cereis globosis adscribendus? Num forsan $C$. Eyriesie?

\section{b. Tenues.}

\section{C. parvisetus H. BEROL.}

Pa: Brasilia.

C. erectus simplex gracilis 12-angularis; costis subcompressis; areolis approximatis albidis; aculeis superioribus $4-5$ brunneis, inferioribus $6-8$ albis piliformibus. Truncus $6-7$ lin. diam.

\section{C. flavescens Oтrо.}

\section{$\mathrm{Pa}$ ?}

C. suberectus gracilis, basi ramosus, 10-16-angularis; costis obtusis; areolis confertis minutis fuscis vel flavis; aculeis numerosis piliformibus rigidiusculis flavidis.

Truncus 1 poll. diam., setae 4 lin. longae. 


\section{0}

\section{C? micracanthus DC.}

Revue p. 115.

Pa: Mexico.

C. basi multiplex, ovato-oblongus subvirens obtusus; costis 13 verticalibus subobtusis; sinu lato, vix acuto; fasciculis approximatis; areola tomentosa; aculeis 3 brevibus setaceis divergentibus.

Cauls vix pollicem longus et crassus. An Echinocactus?

$$
\text { 粠. 5-12-angulares. }
$$

Caule erecto columnari 5-12-sulcato, areolis lanuginosis vel nudis.

\section{a. Lanuginosi.}

Areolis praeter tomentum brevissimum spiniferum lanugine floccosa instructis.

\section{C. lanuginosus Haw.}

Syn. p. 182. - Cact. lanuginosus L. - HERM. Lugd. bat. par. t. 115 sine fl. - C. repandus MiLu. dict. ed. 8.

Pa: Ins. Carib., Amer. aequinoct.

C. erectus longus sub-9-angularis, angulis obsoletis, spinis lana brevioribus (LiNN.).

C. erectus 8-10-angulatus viridis; angulis obsoletis; areolis subconfertis lanatis; aculeis flavis elongatis, centralibus 3 , exterioribus $10-12$, lanam albam crispulam aequantibus.

Truncus $3-6$ pedalis, $1 \frac{1 / 2}{2}-2$ poll. diam. Areolae 4 lin. distantes. Aculei 6-10 lin. longi.

Flores colore herbaceo, fructus magnitudine nucis, rubri, inermes (Liama rck.).

B. glaucescens. - C. Royeni H. Goert. - Trunco glaucescente, aculeis flavis.

\section{2\%. C. Royeni Haw.}

Syn. p. 182. - Cact. Royeni L. - Royen. Lugd. bat. 279. - Cereus lanuginosus MILL, dict, n. 7. - Herm. par. bot. 114. - Cer. gloriosus HonT. - Nec. C. Royeni DC. pl. gr. t. 143! 


Pa: Insul. Carib., Antill.

C. erectus articulatus 9-angularis, articulis subovatis, spinis lanam aequantibus (HAw.).

C. erectus simplex 8-9-angularis, coerulescens, tandem pallide virens; costis obtusis undulatis; areolis approximatis, tomentum fuscum et lanam albam crispulam persistentem gerentibus; aculeis gracilibus rectis laete fuscis, lana vix longioribus, exterioribus 10 , centralibus $3-4$ paulo validioribus.

Truncus 2-3 poll. diam. Areolae 2-3 lin. distantes. Aculei 4-10 lin. longi.

Planta in DC. pl. gr. delineata Cereo repando potius adscribenda est. - Flores ignoti. Fructus secundum Herm. ruber.

\section{C. Ploccosus H. BeroL.}

Pa: S. Thomas, insula Tortola.

C. erectus 10-angularis; sinubus profundis acutis; costis compressis obrepandis; areolis approximatis tomentosis, lana copiosissima alba, aculeis longiore, instructis; aculeis exterioribus $8-10$ inaequalibus, centralibus $3-4$ longioribus, ommibus rectis rigidiusculis fuscis.

Truncus 3 poll. diam. Areolae 3 lin. distantes. Aculei sub pollicares. - Species rarissima!

\subsection{C. armatus OтTо.}

Pa: St. Thomas.

C. erectus $\boldsymbol{\gamma}$-angularis pallide virens, vix glaucescens; sinubus latis; costis subcompressis; areolis approximatis floccosis; aculeis $8-10$ inaequalibus divergentibus flavidis, tenuibus, rigidis.

Specimina in horto Berolinensi $2-3$ poll. diam. Aculei partis originariae interdum bipollicares. Differt a Cereo Royeni et floccuso colore trunci, aculeis longioriblis, areolis minus confertis et lana parciore

\section{C. Curtisi H. Berot.}

Cactus Royeni bot. mag. 3125, nec C. Royeni L. Cereus octogonus H. Avgl.

Pa: Granadą.

C. erectus obscure viridis 8-angularis; sinubus profundis; costis compressis; areolis convexis, tomento fulvo et 


\section{2}

lana sericea alba, aculeos aequante, instructis; aculeis rectis acicularibus brunneis, centralibus 4 , exterioribus 8 -10, supremis minimis.

Truncus 2 poll. diam. Areolae 4 lin. distantes. Aculei maximi subpollicares.

Flores mense Junio fere Echinocactorum forma, tubo brevi pollicari nudo, sepalis parvis brevibus rubescenti-viridibus, petalis biseriatis albidis, basi roseis. Corolla expansa $1 \frac{1}{2}$ poll. diam. Stamina numerosissima alba, antheris albis. Stylus multo longior.

\section{C. fulvispinosus Haw.}

Syn. p. 183. - Cactus Royeni Milu. dict. ed. 8.

Pa: Amer. merid.

C. erectus longus sub-9-angularis, sulcatus ramosusve; aculeis validis fulvescentibus, senectis subinde uncialibus.

An praecedenti aequalis?

\section{C. Alavispinus SALM.}

Obs. botan. 1822. p. 5. - An C. flavispinus ColtA hort. ripul. 24?

Pa: Amer. calid.

C. erectus simplex laetevirens 8-9-angularis; costis subcompressis; spinis gracilibus flavicantibus, lanam mox evanescentem aequantibus (SALMr).

C. erectus simplex viridis 6-9-angularis; costis obtusis; areolis approximatis albo-lanuginosis; aculeis exterioribus 8-12 flavidis patentibus, centralibus $3-4$ divergentibus, fulvis, longioribus, supremo erecto longissimo.

Plantae originariae in horto Dyckensi 4-5-pedales, diam. fere 3-pollicari, in hortis cultae semper graciliores. Areolae 3 lin. distantes. Aculei $4-8$ lin. longi.

\section{C. Haworthii DC.}

Cactus Haworthii Sprge. - Cer. nobilis HAw. syn. p. 179 (??).

Pa: Insul. Carib.

C. erectus magnus sub-5-angularis, sulcis profundis, spinis numerosis saepe uncialibus fulvis ( $\mathrm{H}_{\mathbf{A}} \mathbf{W}_{\mathbf{*}}$ ).

C. erectus simplex 5-, rarius 6-angularis; sinubus plasin; costis junioribus compresso-repandis, tandem obso- 



\section{3}

tetıs; areolis subremotis albo-lanuginosis; aculeis exterioribus sub-10 gracilibus, irregulariter radiantibus, centralibus $3-4$ longioribus rigidioribus fulvis.

Truncus $1 \frac{1 / 2}{2} 2$ poll. diam. Areolae $4-5$ lin. distantes. Aculei subaequales, $5-7$ lin. longi.

Haw orthius Cereum nobilem sum Cereo heptagono forte nimis affinem dicit, et quia sulci profundi in descriptione notantur, hanc speciem non pro nostra, sed potius pro varietate pentagona Cerei peruviani habendam censeo.

\section{C. strictus DC.}

Cactus strictus W. enum. suppl. 32.-Cereus mollis, nigricaus, repandus spin. aureis Hont.

$\mathrm{Pa}$ : America calida.

C. erectus robustus olivaceus 7 -8-angularis; sinubus latis profundis; costis subcompressis repandis; areolis parum distantibus albo-tomentosis, vix lanatis; aculeis exterioribus 8 , centralibus 4 longioribus, omnibus rectis, rigidis, fulvis, basi brunneis, senectis griseis.

Truncus $2-3$ poll. diam. Areolae $4-5$ lin. distantes. Aculei subaequales, $6-8$ lin. longi.

\section{C. niger Salm.}

Observ. botan. 1822. p. 4. - HAw. rev. p. F0. - Cactus niger SpngL. syst. 2. p. 495.

Pa: America calida.

C. erectus simplex ater 6 - 7 -angularis; costis compressis; spinis gracilibus fulvis, lanam mox evanescentem superantibus (SALM 1. c.).

C. erectus simplex 6-8-angularis, apice atrovirens, tandem niger; costis subcompressis subcrenulatis; areolis approximatis, paululum prominentibus, albidis, lanugine parca; aculeis rectis inaequalibus gracilibus fulvis, exterioribus 6-8 divaricatis, centralibus 2-3 longioribus.

Specimina originaria in obs. bot. descripta 4-5-pedalia, diametro bipollicari. Plantae juniores $1^{1 / 2}$ poll. diam. Areolae $2-4$ lin. distantes. Aculei 5-8 lin. longi-

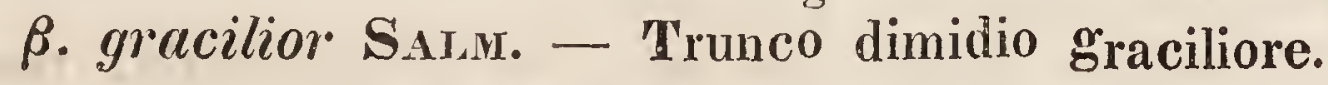

\section{C. aureus Salm.}

Pa?

C. erectus atrovirens 7 -8-angularis; sinubus latis; 
costis compressis valde aculeatis; areolis approximatis magnis convexis aureo-tomentosis, lana parca instructis; aculeis aureis, exterioribus 8-16 subaequalibus, centralibus 3-4 multo longioribus, omnibus rectis, rigidis.

Specimina in horto Dyckensi 3 pedes alta, 2 poll. diam. Areolae vix 3 lin. distantes. Aculei in parte vetustiore numerosissimi, magni, straminei, fere intertexti, centrales subpollicares.

Plantae juniores a $\boldsymbol{C}$. nigro vix distingui possunt.

\section{C. lutescens Salim.}

Cer. aureus $\beta$. pallidior Hont. Dyck. $\mathrm{Pa}$ ?

C. erectus viridis 6 - 7 -angularis; sinubus, subacutis; costis compressis subrepandis vel rectis; crista obtusiuscula; areolis subremotis, parum prominentibus, griseo-stramineis; lana parca alba; aculeis exterioribus 10-12 inaequalibus stramineis, centralibus $4-6$ duplo longioribus et crassioribus, omnibus rectis rigidis tenuibus flavis.

Specimina in hoŕto Dyckensi $21 / 2$ ped. alta, 11/2 poll. diam. A Cereo aureo primo intuitu satis differunt colore trunci, tomenti et praecipue aculeorum, areolis remotioribus, etc.

\section{C. Morilzianus отто.}

\section{Pa: La Guayra.}

C. erectus 7 -8-angularis viridis, apice lanuginosus; sinubus latis acutis; costis obtusis vix repandis; areolis albidis lanuginosis; aculeis gracilibus rectis rigidis flavidis, centralibus 3 , exterioribus $6-8$.

Specimina originaria nuper advecta $1^{1 / 2}-2$ poll. diam. Areolae 5 lin. distantes. Aculei semipollicares. Cereo lutescenti proximus, sed lana copiosiore, spinis brevioribus, minus copiosis et crista obtusiore distinctus.

\section{C. crenulatus SALM.}

Observ. botan. 1822. p. 6. - Cact. Royeni Wilud. Cer. acromelas Ind. Cact. hort. Berol. 1833.

Pa: Amer. merid., Curaçao.

C. erectus simplex cinereus 9-10-angularis, costis obtusis, crenulatis, spinis albis elongatis, apice nigris, lanam persistentem aequantibus (SALM l. c.).

C. erectus cinereo-virens 9-angularis; sinubus acutis; 


costis subcompressis crenulatis; areolis subconfertis magnis griseo-tomentosis, lanugine defiuente instructis; aculeis exterioribus $9-12$, supremis minimis, centrali 1 reliquis duplo longiore, omnibus rectis rigidis, cinerascentibus, apice nigris.

Specimina originaria 4 poll. diam., apice conico. Costae supra areolas (5 lin. distantes) transversim subplicatae vel sulcatae. Sinus semper, etiam in plantae vefustissima parte, profundi et acuti. Aculei exteriores $3-5$, centrales $8-12$ lin. longi.

Varietas $\beta$. gracilior (Hort. Dyck. p. 63.) ad C. albispinum potius referenda, sed alia instituenda est:

$\beta$. griseus SAlm. - Colore trunci obscuriore, aculeisque longioribus.

\section{C. albispinus Salm.}

Observ. botan. 1822. p. 5. - Cer. octogonus, decagonus Hon'.

Pa: Amer. merid.

C. erectus simplex, cinereo-viridis $\mathbf{9 - 1 2}$-angulatus, costis rotundatis, fasciculis approximatis, spinis numerosis albis lanam persistentem aequantibus, una erecta elongata.

C. erectus simplex (rarius basi ramosus) cinereo-virens 8-10-angularis; sinubus mox obsoletis; costis obtusis; areolis approximatis griseo-tomentosis; aculeis rectis rigidis gracilibus albis, apice nigricantibus, exterioribus 10-13, centralibus $2-4$ longioribus.

Plantae in horto Dyckensi originariae $4-5$ pedes altae et diametro 3-pollicari, senectae ad apicem et juniores ex toto lanuginosae. Plantae nostrates $1 \mathrm{l} / \mathrm{a}$ poll. diam., areolis $2-3$ lin. distantibus, aculeis exterioribus $2-5$, centralibus $10-12$ lin. longis.

Differt a $C$. crenulato statura graciliore, costis minus crenulatis, sinubus planis, aculeis brevioribus et apice magis lanato.

\section{C. coerulescens Salm.}

Hort. Dyck. p. 335. - Cer. Aethiops HAW. (philos. magaz. 1830. p. 109.)? - Cer. Mendory Hort.

Pa: Brasilia.

C. (Aethiops) erectus obtuse sub-8-angularis, angulis brevibus, spinarum fasciculis lanaque brevissima centrali omnino nigerrimis (HAw.).

C. erectus attenuatus coerulescens 8-angularis; costis 
obtusis; areolis approximatis; aculeis setaceis e tomento nigro bicoloribus, albis aut nigris, exterioribus 12 radiantibus, centralibus $3-4$, summo saepe validiore.

Truncus 1-1 1/2 poll. diam. Areolae $8-10$ lin. distantes, interdum magis confertae. Aculei exteriores 3-5, centrales 8-10 lin. longi.

\section{C. azureus Parn.}

\section{Pa: Brasilia.}

C. erectus attenuatus, pruina azurea obductus, hucusque 6-angularis; costis obtusis repandis; sinu acuto; areolis remotis, tomento brunneo lanaque grisea instructis; aculeis exterioribus 8 radiantibus albis, apice sphacelatis, centralibus $1-3$ validioribus brumneis (IIl. Pr. a SAlM-D yck in litt.).

Differt a $C$. coerulescente colore magis coerulescente, cauleque magis attenuato, costis repandis, minus numerosis, sinubusque acutis, areolis remotioribus lanuginosis et aculeis paucioribus, sed validioribus.

\section{C. spinibarbis H. BERoL.}

Pa: Chile (Coquimbo.).

C. erectus 9-angularis; sinubus acutis; costis obtusis obrepandis; areolis immersis magnis ovalibus albidis sublanuginosis; aculeis rectis rigidis cinereis, apice nigris, centralibus $2-4$ crassioribus, exterioribus 8 radiantibus.

Truncus $1^{1 / 2}-2$ poll. diam. Aculei maximi pollicares.

\section{b. Glabri.}

Areolis nudis tomentosis, lanugine nulla.

\section{c. Robusti.}

\section{C. chilensis Colua.}

Pl. rar. hort. ripul. app. 2. p. 342. - Cer. coquimbanus Hort., non Molis. - Cer. Quintero H. Goetriva. Echinoc. pyramidalis, elegans, Cer. subrepandus HorT.

Pa: Chile (Coquimbo et insula Chiloe?).

C. ovato-erectus 10-angularis, angulis obtusis, spinis pallido-pellucidis, media validiore, lanugine brevissima (Colla.).

C. erectus crassus simplex $10-12$-angularis viridis; 


sinubus obsoletis; costis rotundatis; areolis remotis oblongis magnis; aculeis e tomento brevissimo cinereo 8-10 validis fusco-albidis rectis divaricatis, inaequalibus, centralibus $1-2$ validissimis, conicis rectis brunneis, basi latiore tomento insertis.

Specimina in lortis 2 ped. alta, $3^{1 / 2}$ poll. diam. Areolae 6 lin. distantes. Aculei centrales pollicares, reliqui $4-5$ lin. Iongi.

\section{C. stellatus Prr.}

Oтто's GZ. 1836̉. No. 33. S. 258.

\section{Pa: Mexico.}

C. erectus robustus 9-angularis laete viridis; sinubus acutis; costis compressis obtusis obrepandis; areolis approximatis immersis albo-tomentosis; aculeis exterioribus $\mathbf{8 - 1 0}$ gracilibus, centralibus 4-6 majoribus, summo maximo, omnibus albis rectis rigidis.

Specimen originarium in horto Goettingensi $2^{1 / 2}$ poll. diam. Aculei exteriores $4-5$, centrales $6-8$ lin., summus fere 1 poll. longus.

\section{C. Dyckii MarT.}

\section{Pa: Mexico.}

C. erectus 8-angularis viridis; sinubus latis acutis; costis verticalibus subcompressis, vix repandis; areolis subimmersis ovalibus grise -tomentosis; aculeis exterioribus $\mathbf{1 0 - 1 1}$ brevibus albis rigidis patentissimis, centralibus $\mathbf{3}$, infimo longiore, albis, apice et basi fuscescentibus.

Specimen in horto Monacensi $1^{1 / 2}$ ped. altum, 21/2 poll. diam. Areolae 6 lin. distantes. Aculei exteriores $2-4$, centrales superiores $2-3$, infimus $3-4$ lin. longi.

\section{C. alacriportanus H. Monac.}

Pa: Brasilia (Porto Alegre.).

C. erectus simplex 6-angularis, obscure viridis, apicem versus coerulescens; sinubus profundis; costis compressis rectis verticalibus; areolis approximatis, vix prominentibus, tomento fuscescente, lanaque alba parca instructis; aculeis acicularibus rectis brunneis, apice flavidis, centrali 1, exterioribus -8 patentissimis.

Plantae diam. 11/2 poll. Areolae 4 lin. distantes. Aculei 3 lin. longi. 


\section{8 \\ 48. C. peruvianus TABerN.}

Kr. B. 705. c. ic. - DC. pl. gr. t. 58. $\rightarrow$ Cactus peruvianus, heptagonus, hexagonus et pentagonus Liss.? Cact. hexagonus WiLLD. enum. suppl. 32. - Cereus heptagonus et hexagonus Hort.

Pa: Peru, forsan tota Amer. merid. calida.

C. erectus crassus altissimus obscure viridis, tandem ramosus, 5-8-angularis; sinubus latis, tandem obsoletis; costis verticalibus vix obrepandis, vel rectis; areolis subconfertis; aculeis e tomento griseo, brunneis, rigidis, exterioribus $6-8$, centralibus $1-3$ paulo longioribus.

Specimen in horto Parisiensi 40 pedes altum. Costae plerumque 7 , in trunco adulto ligneo omnino evanescentes, ita ut teres fiat. Areolae 5 lin. distantes. Aculei $4-5$, rarius $6-8$ lin. longi.

Flores (mens. August. - Octob.) solitarii albi, 6 poll. longi, per unam noctem expansi, 5 poll. diam. Tubus viridis glaber; sepala sordide purpurascentia; petala biserialia subacuminata, exteriora fusco-rubentia, interiora nivea. Stamina alba, antheris pallidissime flavescentibus. Stylus paulo longior, albus, stigmatibus $10-12$ albis patentibus.

ß. monstrosus DC. 1evue p. 42. t. 11. - Cactus abnormis WilLd. enum. suppl. 31.-Cer. monstrosus Hort.

Pa: Amer. calida, Peru.

C. erectus crassus ramosus, irregulariter costatus et tuberculatus; areolis nunc proximis, nunc remotis, griseotomentosis; aculeis exterioribus $6-8$, centralibus $1-2$ paulo longioribus, omnibus brevibus rectis brunneis.

Flores in hortis rarissime obvii, $C$. peruviano simillimi, forsan magis expansi, ampliores.

Speciem propriam non esse, sed nil nisi abnormem Cerei peruviani formam, specimen mihi probavit, Francofurti in horto dom. Andrea e cultum, quod e parte trunci inferiore ramum emisit, jam sesquipedalem, omnino regularem hexagonum.

\section{C. monoclonos DC.}

Revue p. 46. - Cact. hexagonus Layr. dict. 1. p. 538. - Melocactus monoclonos flore albo, fructu atropurpureo Puun. catal, 19. ed. Burm. t. 191. - Cer. surinamensis Ephem. nat. c. 3. p. 349. t. 8 et 8.

Pa: Insul. Carib. et Surinam. 



\section{9}

C. erectus longus 8-angularis; angulis obtusis compressis; spinis stellatis subaequalibus.

Species a Plumiero ad $\boldsymbol{C}$. peruvianum, a Liunaeo ad $\boldsymbol{C}$. hexagonum relata, sed ab utroque (?) petalis obtuse emarginatis, fere obcordatis, differt. Limbus floris patulus. Stylus longe exsertus, stigma 5-fidum ex Plum. (DC. prodr. III. p. 464.).

50. C. calvescens DC.

Revue p. 116.

Pa: Mexico.

C. simplex aut apice subramosus, erectus, viridis; apice obtuso subumbilicato; costis $7-8$ verticalibus obtusis; sinu acuto; areola juniore convexa tomentosa, demum glabriuscula; aculeis $8-9$ fuscis rigidis divergentibus, centrali ab exterioribus vix distincto.

Affinis C. peruviano. Fasciculi intervallo 6-9 lin. distantes.

\section{C. candelaris Meyen.}

Reise um die Welt. B. I. S. 447. - Oтт0's GZ. 1833. No. 27. S. 211.

Pa: Peru (prov. Arequipa.).

C. trunco erecto crasso, vix anguloso, aculeis atrofuscis densissime tecto, basi nudo, apice ramoso.

Truncus 6-8-pedalis. Ex apice trunci rami excurrunt 5, 8-12, divergentes, laete virides, $\mathbf{2} \longrightarrow \mathbf{3}$ poll. diam., pilis gracilibus obsiti. - Num praecedenti aequalis?

\section{C. arequipensis MEYeN.}

Reise B. II. S. 41.

Pa: Arequipa.

C. erectus 8-angularis (20-25-pedalis); costis tuberculatis; areolis in tuberculis villosis et aculeatis.

Flores elongati albi.

53. C. curvispinus Bertero.

Meyen Reise B. I. S: 289.

Pa: Peru.

Cereo peruviano similis, trunco saepe 18 ped. alto, floribus albis 6-7 poll. longis.

\section{C. caesius Salm.}

Cer. glaucus Hont. 


\section{Pa?}

C. erectus caesius 6-angularis; sinubus profundis; costis subcompressis, obtusis, rectis; arcolis magnis albis sublanuginosis; aculeis rigidiusculis acicularibus, exterioribus $10 f l a v i d i s$, basi fuscis, centralibus $4-5$ longioribus brunneis.

Plantae $1^{1 / 2}-2$ poll. diam. Areolae 6 lin. distantes. Aculei exteriores $4-6$, centrales $6-7$ lin. longi.

\section{C. geometrizans MART.}

C. aquicaulensis HorT.

Pa: Mexico.

C. erectus simplex, 5-6-angularis, coeruleus, quasi arcubus acutis notatus; sinubus latis, fere planis; costis obtuse angulatis tuberculato-repandis; areolis remotis rotundis albis, brevissime tomentosis; aculeis 3 (rarius 4-5) inaequalibus rigidis nigris, tandem cinereis, basi crassioribus, 2 lateralibus longissimis, infimo breviore, supremis 1-2 (saepius deficientibus) brevissimis.

Specimen originarium in horto Monacensi mortuum 4 poll. diam., costis $8-9$, fere inerme. Juniora $2-3$ poll. diam. Areolae $1^{1 / 4}-1^{1 / 2}$ poll. distantes. Aculei laterales $4-5$, infimus $2-3$, supremi 1 lin. longi, interdum omnes brevissimi, vix lineares.

\section{C. eburnéus SALm.}

Observ. botan. 1822. p. 6. - Cactus eburneus LINK enum. 2. p. 22. - Cactus coquimbanus Molis. Chil. ed. gall. p. 140. ex Bentol. virid. bon. 1824. p.4. - Cact. peruvianus Willd. enum. suppl. 32, non LiNv. - BradL. succ. t. 12 (sine flore.).

\section{Pa: Curaçao, Chile.}

C. erectus simplex glaucus 8-angularis; costis obtusissimis glaberrimis; spinis subulatis eburneis, una centrali procera, apice nigra (SALM I. c.).

C. erectus simplex glaucescens 7 -8-angularis; sinubus planis; costis obtusis; areolis subremotis ovalibus cinerascentibus, nudis; aculeis rigidis elongatis, radiantibus 8-10, infimo minimo, centrali 1 (rarius 3), omnibus nascentibus purpureis, dein eburneis, apice nigris.

Crassitudine fere C. peruviani, ex toto rore glauco obductus. 




\section{1}

Specimina juniora $3-3^{1 / 2}$ poll. diam. Areolae $5-6$ lin. distantes.

Aculei exteriores $4-5$, centrales 9-11 lin. longi.

ק. polygonus. - C. griseus Haw. syn. p. 182? - Cer. polygonatus Honт. - Costis 9-10, magis compressis, aculeis brevioribus cinereis, centralibus 3-4.

y. monstrosus cylindricus SALM (obs. bot. 1822.p.7.). Costis obliteratis et spinarum fasciculis spiraliter confluentibus.

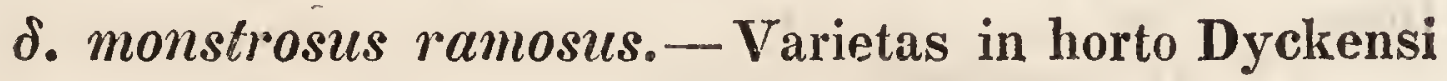
vigens, ex hortis Belgicis oriunda, Cereo peruviano monstroso analoga, irregulariter ramosa. Proles hinc inde ex areolis enascentes, initio regulares, tandem semper in formam moustrosam transire affirmantur.

\section{C. Hystrix Salm.}

Observ. botan. 1822. p. \%.

Pa: Antill.

C. erectus simplex perviridis nitidus 9-angularis; costis valde compressis, spinis elongatis, junioribus pictis ( $\mathbf{S}_{\mathrm{ALIM}}$ l. c.).

C. erectus brunneo-olivaceus nitidus 8-9-angularis; costis subacuatis; areolis prominentibus rotundis griseotomentosis; aculeis rigidis, rectis, ex albo et brunneo fasciatim pictis, exterioribus 9-10, supremis minimis, centralibus $3-4$ validioribus.

Truncus 2 poll. diam. Areolae 3-4, lin. distantes. Aculei exteriores $3-6$, centrales $8-10$ lin. longi.

\section{C. candicans Gillies.}

Hort. Dyck. p. 335. - Echinoc. candicans HorT.

$\mathrm{Pa}$ : Mendoza.

C. erectus pallide virens 9-10-angularis; costis latis obtusis; aculeis ex areola lata albido-tomentosa, stramineis, exterioribus $9-10$ radiantibus, centralibus 4 validioribus, infimo validissimo.

Specimen maximum in horto Berolinensi $1^{1 / 2}$ ped. altum, 6 poll. diam. Areolae 4 lin. distantes, 3 longae. Aculei 11/2 poll. longi. - Plantae juniores plerumque oblongo-ovatae, echinocactiformes.

B. tenuispinus. - C. Montezumae Hont. - Aculeis 


\section{2}

gracilioribus, brevioribus et crispatulis. - In speciminibus junioribus differentia vix observanda est.

\section{C. regalis Haw.}

Suppl. p. 75.

Pa: Amer. trop.

C. magnus simplex erectus 9-angularis; angulis profundissimis ; spinis fulvis elongatis, junioribus lanam aequantibus.

An praecedenti aequalis?

\section{C. euphorbioides Haw.}

Suppl. p. 75.

Pa: Amer. trop.

C. erectus sub-10-angulatus; angulis validis; spinis pallidis mediocribus subternis, duabus subbilinearibus, una 7 -lineari, lana nulla inconspicuave.

\section{C. serruliflorus HAw.}

Phil. magaz. 1830. p. 109. - Meloc. arborescens, cereiformis et spinosissimus Plum. ed. Bury. p. 188. t. 195. f. 1. - Cer. fimbriatus DC. prodr. III. p. 464.

Pa: India occidental.

C. erectus simplex 8-angularis; costis compresso-rotundatis subrepandis; areolis distantibus; aculeis gracilibus $12-13$ radiantibus.

Flores (ex Plumieri icone) tubulosi, 3 poll. diam. Tubus squamosus, $4^{1 / 2}$ poll. longus; petala ${ }_{0}^{5}$ biserialia, intima serratula. Stamina numerosa; stylus sub-6-fidus longe prominens. Fructus obtuse conici, squamulosi, inermes.

Ill. Lamarck et $\mathbf{D}$ e $\mathbf{C a n d o l l e ~ h a n c ~ s p e c i e m ~ c u m ~ a l t e r a ~ i n ~}$ Plumieri tab. 195 delineata (nempe C.grandispino Haw.) confundunt, et ex ambabus figuris Cereım fimbriatum formant, cujus flos ex fig. 2 , truncus vero ex fig. 1 descriptus est.

\section{C. grandispinus Haw.}

Phil. magaz. 1830. p. 109. - Opuntia altissima, cereiformis, etc. Plum. catal. pl. p. 6. ed. Burm. p. 188. t. 195. f. 2. - Cactus fimbriatus LAM. dict. 1. p. 539. - Cer. fimbriatus DC. prodr. III. p. 464. 




\section{3}

\section{Pa: India occident.}

C. altissimus simplex crassus 8-angularis; costis obtusis undulatis; sinubus angulosis ; areolis subremotis magnis; aculeis $10-14$ validissimis, bipollicaribus, subulatis, rectiusculis, irregulariter radiantibus.

Flores (ex Plumieri icone) tubo brevissimo, petalis paucis fimbriatis, staminibus numerosissimis, stigmate multifido, longe prominente. - Fructus pomiformes, spinulosi, semina continentes numerosa subrotunda.

B. Altenuati.

\section{C. repandus Haw.}

Syn. p. 183. Suppl. p. 78. - Cact. repandus L.- Cer. gracilis MILL. dict. ed. 8. n. 8. - Trew ehret. 3. t. 14.Bot. regist. t. 336. - DC. revue p. 44 . t. 13 (?).-Cact. Royeni DC. pl. gr. t. 143.

Pa: Insul. Carib., Antill.

C. erectus longus octangularis, angulis compressis undatis, spinis lana longioribus ( $\mathbf{H}_{\mathrm{AW}}$.):

C. erectus altus simplex viridis, 8-9-angularis; sinubus acutis subundulatis; costis angustis obtusis repandis; areolis subremotis albo-tomentosis; aculeis subaequalibus, brevibus, rigidis, albis, exterioribus $7-8$, centralibus 2 .

Truncus $3-4$ pedalis et ultra, $1^{1 / 4}-1^{1 / 2}$ poll. diam. Areolae 8 lin. distantes. Aculei 4-5 lin. longi.

Flores oblique erecti, albi, per pancas horas expansi, 5 poll. diam. Receptaculum subglobosum, squamis obscure viridibus et pilis albis obtectum. 'lubus $3 \frac{1}{2}$ poll. longus fusco-virens inermis, squamis viridibus parce pilosis obsitus. Sepala linearia fusca. Petala biserialia, lanceolata, exteriora fusco-virentia, interiora nivea, $\mathbf{1}^{3 / 4}$ poll. longa, 6- 7 lin. lata. Stamina filiformia alba, limbo longiora, antheris sulphureis. Stylus staminibus longior, stiginatibus 8-10 flavis. - Fructus maturus obovatus, 2 poll. longus et diam., apicem versus attenuatus, sordide citrinus, tuberculis latis, squamisque brevibus brunneis pilosis instructus.

64. C. subrepandus Haw.

Suppl. p. 78. - Cer. imbricatus Hort.

Pa: Ins. Carib.

C. erectus longus 8-angularis, angulis obtusis undatis, spinis senioribus fulvicantibus, superne nigris, 4-9-linea-

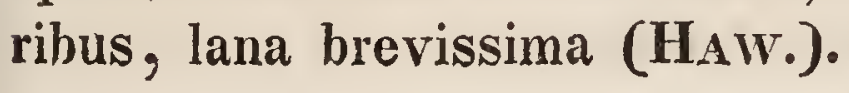


C. erectus 8-12-angularis; sinubus acutis; costis obtusis confertis, infra areolas inflatis; areolis approximatis; aculeis $6-8$ e tomento brevissimo, inaequalibus, albidis, apice nigris, divergentibus, centrali nullo vel 1 vix longiore.

Truncus 1/2 poll. diam. Areolae 5 lin. distantes. Aculei $6-8$ lin. longi.

Flores mense Majo albi, maximi. Receptaculum subglobosum, squarnis viridibus dense obtectum. Tubus $7-8$ poll. longus, subhorizontaliter patens, fuscescens, squamis viridibus elongatis instructus. Sepala linearia fusco-virentia. Petala latiora nivea. Fructus obovati lutei, tuberosi, squamis linearibus viridibus instructi, $2^{1 / 2}$ poll. longi, 2 poll. diam.

\section{C. eriophorus H. BeroL.}

\section{C. cubensis Zucc. - C. subrepandus Hort.}

Pa: Insula Cuba.

C. erectus simplex perviridis 8-angularis; sinubus primum acutis, mox obsoletis; costis obtusis sinuato-repandis; areolis remotis ovalibus albis; aculeis e tomento brevissimo, exterioribus 8 , centrali 1 paulo longiore, omnibus rectis, acicularibus, albis, apice nigris.

Truncus $1 \frac{1}{2}$ poll. diam. Costae 4 lin. latae. Areolae 12-14 lin. distantes. Aculei 4-5, supremi 8 lin. longi.

Specimina 6-8 poll. alta jam florifera. Flores mensibus Majo-Julio ex areolis prope apicem, inodori, nocturni, albi. Gemmae florales globulos formant lana alba omnino supertextas. Tubus oblique erectus 4 poll. longus, squamulis viridibus, apice rubellis, lanatissimis instructus. Sepala angusta acnminata fuscorubra, petala biserialia, exteriora lanceolata virentia, interiora latiora, acuminata, nivea, limbum formantia cyathiformem $3 \frac{1 / 2}{2}$ poll. diam. Stamina alba stylo virescente multifido breviora. - Fructus subglobosus, apice attenuato sulcatus, 2 poll. longus, $\mathbf{1}^{3 / 4}$ diam., parcissime tuberosus et squamulis viridibus laniferis obsitus, basi virens, superne aurantiacus.

ß. laetevirens Salmi (Hort. Dyck. p. 335.). - Colore trunci laete flavescenti-viridi satis distinctus.

\section{C. undalus H. BeroL.}

$\mathrm{Pa}$ ?

C. erectus gracilis 10-angularis, obscure viridis; costis obtusis undulatis; areolis subconfertis albidis; aculeis exterioribus $6-8$ albidis, centralibus $3-\frac{4}{2}$ longioribus fuscescentibus, omnibus rigidulis rectis. 

Truncus $1 / 2-3 / 4$ poll. diam. Areolae 6 lin. distantes. Aculei $4-8$ lin. longi.

Flores solitarii magni albi, 5 poll. diam. Receptaculum subglobosum, squamis viridibus laniferis imbricatum. Tubus subhorizontalis 5 poll. longus, viridis, squamis obscurioribus obsitus. Sepala longa linearia flavescenti-viridia patentissima. Petala latiora, apice denticulata, nivea. Stamina alba, antheris magnis flavis. Stylus crassus, viridis, staminibus longior, multifidus. - Fructus obovatus flavus, $1^{1 / 2}$ poll. longus, 1 poll. diam., subtuberculatus, squamis viridibus albo-pilosis obsitus.

\section{C. divergens H. BenoI.}

\section{Pa: S. Domingo.}

C. erectus 9-angularis; sinubus subacutis; costis obtusis repandis; areolis subremotis cano-lanuginosis; aculeis numerosis gracilibus albis rigidis in inferiore areolae parte, 5 majoribus divergentibus flavescentibus, centrali maximo, erecto, fuscescente.

Truncus 11/4 poll. diam. Areolae 5-6 lin. distantes. Aculei inferiores $5-6$ lin., centralis $1 \frac{1}{1} 2-2$ poll. longus.

\section{C. divaricatus DC.}

Prodr. III. p. 466. - Cact. divaricatus Lay. dict. 1. p. 540. - Plum. ed. Burar. t. 193. - C. fimbriatus Hort.

Pa: S. Domingo.

C. erectus ramosus, ramis divaricatis multangulis, angulis obtusis, spinis approximatis (Sprat.).

C. erectus 9-angularis; sinubus acutis undatis; costis obtusis obrepandis, tandem obsoletis; areolis subremotis minutis, parce tomentosis; aculeis subaequalibus, exterioribus 8-10 albis, summis rigidioribus, centralibus 4 longioribus fuscescentibus.

Specimina in hortis 3 pedes alta, $1^{3 / 4}$ poll. diam., semper simplicia, basi lignosa, spinosissima, nondum floruerunt. Areolae 10 lin. distantes. Aculei 4-6, parte inferiore 8-10 lin. longi.

Flores (ex Plum.) longe tubulosi. - Fructus globosus aureus pugno major verrucosus, inermis, pulpa alba dulci.

\section{C. erectus Karw.}

Pa: Mexico.

C. erectus simplex subteres 8-angularis viridis; costis obtusissimis subundulatis; areolis subremotis griseis; acu- 


\section{6}

leis e tomento brevissimo, exterioribus $8-9$ albidis, apice nigris, centralibus $1-3$ longioribus fuscescentibus, omnibus rectis rigidis.

Plantae $1^{1 / 4}$ poll. diam., areolis $6-7$ lin. distantibus, aculeis exterioribus $4-5$, centralibus $6-7$ lin. longis.

Num a speciebus omnibus praecedentibus satis differat, flores hucusque ignoti monstrabunt.

\section{C. chlorocarpus DC.}

Prodr. III. p. 466. - Cact. chlorocarpus H. B. et Kunth nov. gen. am. 6. p. 68.

\section{Pa: Quito.}

C. erectus (?) ramosus; ramis fastigiatis 10-12-angularibus; angulis tuberculatis; tuberculis stellulato-aculeatis; aculeo centrali caeteris quadruplo longiore (DC.).

\section{c. Gemmati.}

Areolis gemmaeformibus, approximatis, interdum confluentibus.

\section{C. gemmatus Zucc.}

Pa: Mexico.

C. erectus laete viridis, 5-6-angularis, basi ramosus; sinubus fere planis; costis compressis, cristis obtusis; areolis confertis convexis ovalibus, junioribus albo-velutinis; aculeis $8-10$ brevibus cinereis radiantibus, centralibus $1-2$ a reliquis vix diversis.

Truncus $1-1^{1 / 2}$ poll. diam. Areolae $1-2$ lin. distantes. Aculei plantarum juniorum setacei, brunnei, decidui.

\section{C. anisacanthus DC.}

Revue p. 116.

$\mathrm{Pa}$ : Mexico.

C. simplex erectus intense viridis, costis $5-6$; sinu et crista acutis; fasciculis confertis; areola juniore convexa velutina; aculeis $10-20$ setaceis flavescentibus rigidis, valde inaequalibus, exterioribus divergenti-radiantibus.

B. ortholophus. Costis 6 verticalibus, aculeis 10. An C. gemmalus Zucc.?

r. subspiralis. Costis 5 subspiraliter intortis, aculeis 20. 

93. C. marginatus DC.

Revue p. 116. - Cer. incrustatus H. Berol. - C. cupulatus Hort. - Cer. Mirbelii II. BELG.

Pa: Mexico.

C. simplex aut apice subramosus, erectus, obscure viridis, apice obtuso; costis 5-7 verticalibus; sinubus acutis; crista obtusa, areolis ovalibus confluentibus albovel fusco-tomentosis per totam longitudinem lanata; aculeis - 9 conicis rigidis, griseis, brevibus, centrali a caeteris vix distincto.

Truncus 2-3 poll. diam., saepe crusta lignea obductus. Areolae saepe geminatim, interdum omnes confluentes. Aculei $2-3$ lin. longii, nascentes atrop!rpurei.

\section{C. Olfersii H. Berou.}

Hort. Dyck. p. 335.

Pa: Brasilia.

C. erectus pallide virens 9-angularis; costis compressis; sinu lato; areolis subnudis; aculeis radiantibus fulvis, 3 superioribus setaceis deciduis, 3 inferioribus persistentibus, rigidis, infimo longissimo deflexo.

Specimen in horto Dyckensi vigens circa 20 poll. altum, $2-2^{1 / 2}$ poll. diam. Areolae $3-4$ lin. distantes. Aculeus infimus $6-8$ lin. longus. - Plantarum juniorum areolae aculeis instructae sunt 6-7, gracillimis, brunneis, subaequalibus.

\section{จึั. C. conicus H. BEROL,}

\section{Pa: Mexico.}

C. erectus crassus laete viridis 8-angularis, apice attenuatus; sinubus latis acutis; costis compressis subrepandis; areolis approximatis griseis, vix lanuginosis; aculeis 2, nascentibus nigricantibus, mox cinereis, apice nigris, rectis, rigidis, superiore horizontali, inferiore multo minore deflexo.

Specimen in horto Berolinensi descriptum $1 \frac{1}{2}$ ped. altum, 4 poll. diam. Areolae 3-4 lin. distantes. Aculeus supremus subpollicaris. - Plantarum juniorum areolae aculeis instructae sunt $6 \mathrm{ra-}$ diantibus albis, gracilibus, supremo brevissimo, centrali 1, rigidiore, fuscescente, 4 lin. longo. 


\section{8 \\ 犊棌 $4-5$ - angulares.}

Caule erecto simplice vel basi ramoso, $4-5$-sulcato, areolis nudis vel lanuginosis.

\section{g6. C. Jamacaru SALM.}

Hort. Dyck. p. 336. - C. glaucus HorT.

Pa: Brasilia.

C. erectus grandis caesius vel coeruleus, 4-5-angularis; costis compressis obrepandis; sinu lato; aculeis fulvis ex areola lata griseo-tomentosa, exterioribus $7-9$ radiantibus, centralibus 4 validis rigidissimis.

Truncus in hortis $3-4$ pedes altus, $4-5$ poll. diam., apice rore coeruleo tectus, parte inferiore pallide virens, obtusissime angulatus, sinubus planis. Areolae 10-12 lin. distantes. Aculei

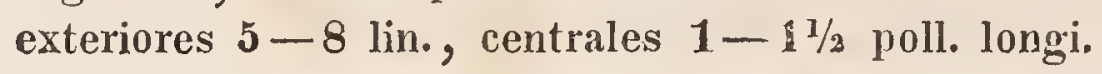

\section{\%. C. glaucus SaLM.}

\section{Hort. Dyck. p. 335.}

$\mathrm{Pa}$ ?

C. erectus glaucescens $\mathbf{5}$-angularis; costis compressis; sinu lato profundo; areolis confertis; aculeis brevibus validiusculis flavicantibus e tomento albido, exterioribus 6 -8 radiantibus, centralibus 3 vix longioribus.

Planta unica in horto Dyckensi nunc 1/2 ped.alta, 2 poll. diam.

98. C. lividus PrR.

Oтто's GZ. 1835. No. 48. S. 380.-C.PerotettiHor'T.

Pa: Brasilia, La Guayra.

C. erectus robustus plumbaceo-viridis 5-angularis; sinubus profunde incisis; costis compressis, vix undulatis; cristis obtusatis; areolis remotis latis sublanuginosis, junioribus fuscis, serius cinereis; aculeis rectis rigidis brunneis (junioribus apice luteis), centralibus $\mathbf{3}$ validis, exterioribus $5-7$ brevioribus patentibus, nonnullis saepius abortivis.

Cereo glanco Salm proxime affinis, sed aculéis multo majoribus et rigidioribus, areolisque remotis distinctus. Specimina in horto Berolinensi e La Guayra nuper advecta, quac ad hanc speciem sine dubio pertinent, 6 poll. diam. - Plantae juniores 2 poll. diam., areolis $5-6$ lin. distantibus, aculeis exterioribus $3-5$, centralibus 4 lin. longis. 




\section{C. laetevirens H. BERoL.}

\section{Néc C. laetevirens SalM!}

$\mathrm{Pa}$ ?

C. erectus simplex 4-angularis, caesius, tandem laetissime viridis; simubus planis; costis obtusis, vix obrepandis; areolis convexis tomentosis subconfertis; aculeis brunneis gracilibus inaequalibus, centralibus 4 , exterioribus $10-12$.

Truncus 2 poll. diam. Areolae $5-6$ lin. distantes. Aculei exteriores $3-6$, centrales $7-8$ lin. longi.

\section{C. grandis Haw.}

\section{Suppl. p. 76.}

Pa: Brasilia.

C. mágnus exacte tetragonus, simplex, erectus; aculeis saepe uncialibus divaricanter fere intertextis.

Statura C.tetragoni, vel major, spinis longe majoribus, 3-7 in singulo fasciculo, harum 2 et praecipue 1 praelonga et valida, et fere uncialis, caeterae $0-7$ bilineares tantum. Lana brevissima apice torta, mox evanescens (Haw.).

Num Pitaliay is forte adscribendus?

\section{C. telragonus Haw.}

Syn. p. 180. - Cact. tetragonus L. - Hort. kew. ed. 2. v. 3. p. 186.

Pa: Amer. merid.

C. erectus longus 4-gonus viridis ramosissimus; ramis e basi et lateribus trunci verticaliter adscendentibus 4-, rarius 5-, rarissime 3-vel 6-gonis; sinubus planis; costis compressis transversim plicatis; areolis approximatis, vix albolanuginosis; aculeis gracilibus fuscis inaequalibus, exterioribus $8-8$, centrali 1 vix longiore.

Truncus et rami diam. $1^{1 / 2}-3$ poll. Areolae $2-4$ lin. distantes. Aculei $3-4$ lin. longi.

Flores maximi albi, in hortis europaeis nondum observati.

B. minor Salu (Hort. Dyck. p. 33\%.).-Cact. pentagonus Wuids. - Caule tenuiore et humiliore, saepe pentagono.

\section{C. virens DC.}

Revue p. 116. - C. exerens Link. - Cer. affinis H. BEROL. 
Pa: Mexico.

C. simplex erectus, laetevirens; costis 5 verticalibus, crassis, obtusis; fasciculis remotis; areola juniore velutina; aculeis 4 rigidis, conicis, sriseis, subnigricantibus, 3 brevissimis subdivergentibus, 1 magno horizontali (DC.).

C. erectus simplex 5-angularis; sinubus acutis, tandem planis; costis rotundatis; areolis subremotis, fulvis, vix prominentibus, lanuginosis; aculeis $4-5$ subulatis fulvis brevissimis deorsum spectantibus, centrali 1 horizontali fusco rigido.

Species distinctissima! Plantae in horto Monacensi 3 ped. altae, 1/2 poll. diam. Areolae 7 lin. distantes. Aculei inferiores 1-2 lin. longi, centralis pollicaris. - Plantae juniores interdum 6-8-angulares. - In speciminibus nonnullis loco aculei centralis solitarii hinc inde 2,3 vel 4 subpollicares, tunc divergentes, occurrunt. Num haec differentia solummodo ab aetate plantae oritur? Num varietas instituenda pluribus aculeis centralibus?

\section{C. sublanatus SALr.}

Hort. Dyck. p. 33\%.

Pa?

C. erectus laetevirens 4 - (rarius 5-) angularis; costis latis; areolis confertis parvulis, tomento fulvo, lanaque persistente longa grisea instructis; aculeis exterioribus 7 radiantibus, minutis, binis supremis saepe abortivis, centrali 1 erecto valido.

Specimen maximum in horto Dyckensi vigens $1^{1 / 2}$ ped. altum, $11 / 3$ poll. diam., luteribus fere planis et apicem versus solım sulcatis, lana longa dependente. Areolae 3-4 lin. distantes. Aculei exteriores $z-3$, centralis $8-10$ lin. longus.

\section{C. tilophorus PFr.}

Oтто's GZ. 1835. No. 48. S. 380. - C. retroflexus Hont. Pa?

C. erectus viridis 5-angularis; costis obtusis ad areolas subinflatis, repandis; sinubus latis; areolis subremotis, floccis lanae albae defluentibus instructis; aculeis fulvis rectis, exterioribus $6-8$, centrali 1 longiore.

Species dubia! Descriptio speciminis junioris. 



\section{1}

\section{S. 3. Polylophi.}

Caule humili carnoso, flaccido, subramoso, tuberculato, tuberculis in costas $5-8$ confluentibus.

85. C. cinerascens DC.

Revue p. 116. - Cer. Deppei H. Berou. - Hort. Dyck. p. 338. - Jamacaru Pison. hist. nat. p. 100?

Pa: Mexico.

C. simplex erectus griseo-viridis; costis $7-8$ obtusis, tuberculosis; sinu angusto; areola juniore convexa velutina; aculeis 14 albis setaceis rigidis, exterioribus $10 \mathrm{ram}$ diantibus, centralibus 4 erecto-divergentibus longioribus, saepe fuscis.

Truncus $8-10$ poll. altus et ultra, 2 poll. diam. Areolae 5-6 lin. distantes. Aculei exteriores 6-9 lin., centrales 1 poll. longi. Plantae juniores fere semper 7 -angulares, aculeis omnibus albis, centrali 1 .

B. crassior DC. - C aciniformis H. BER0L. - Fasciculis magis distantibus, caule crassiore.

$\gamma$. tenuior DC. - Caule tenuiore, costis magis approximatis.

Num hae varietates constantes?]

86. C. pentalophus DC.

Revue p. 117.

Pa: Mexico.

C. erectus cinereo-viridis obtusus; costis $\mathbf{5}$ vertical". bus obtusis; fasciculis approximatis; areola juniore velutina; aculeis $5-7$ setaceis divergentibus, junioribus albido-flavidis, adultis griseis.

a. simplex (C. propinquus DC.). Caule simplice, sinubus latis obtusis, costis parum prominulis, aculeis albidis, areolis subnudis.

Specimina interdum pedalia, 1 poll, diam., basi ramosa.

B. subarliculalus (C. leptacanthus DC.). Caule ramosissimo subarticulato, costis irregularibus subrepandis, vel tuberosis, sinubus angustioribus, aculeis junioribus fiavescentibus, areolis albo-lanatis.

Plantae graciliores, quam var. $\alpha$, costis subtortis. 
87. C. iuberosus Prr.

Pa: Mexico.

C. erectus viridis 8-angularis; sinubus acutis undulatis; costis obtusis tuberosis; areolis subremotis in tuberculis positis, albo-lanuginosis; aculeis 9-10.gracilibus patentissimis subaequalibus, nascentibus rubellis, dein albidis, apice fuscis, centrali nullo.

Plantae (adhuc rarae!) 11/2 poll. diam., hucusque 5 - 6 poll altae. Areolae 6-8 lin. distantes. Aculei 3-4 lin. longi.

\section{S. 4. Opuntiacei.}

Cerei serpentini globosi SalM (Hort. Dyck. p. 338.). - Otro's GZ. 1835. No. 40. S. 314.

Caule articulato diffuso, articulis subglobosis vel ovatis, tuberculato-areolatis, opuntiaeformibus, sed foliis omnino carentibus.

88. C. moniliformis DC.

Revue p. 60. - Prodr. III. p. 4\%0. - Hort. Dyck. p. 338. - Cactus moniliformis LrNn. - LAM. dict. 1. p. 541. - Melocactus ex pluribus globulis Opuntiae modo nascentibus, spinosissimis Puum. catal. p. 19. - Tourn. 653.Plum. ed. Burm. p. 191. t. 198.

Pa: St. Domingo.

C. articulato-prolifer, articulis globosis spinosis glomeratis (Lins.).

C. articulato-procumbens; articulis diffusis globosis; areolis approximatis; aculeis elongatis, subulatis, acutissimis, solitariis, vel $3-5$ divergentibus.

Articuli (ex Plumieri icone) $1-1^{1 / 4}$ poll. diam. Aculei subpollicares. - Flores in articulis summis, solitarii, rubri, tubo squamoso, $1^{1 / 2}$ poll. longo, corolla $1^{1 / 2}$ poll. diam., petalis explicatis, sinuosis, staminibus numerosis, stylo longissime prominente, multipartito, stigmatibus longis. - Fructus ovo columbino paulo major, ruber, squamis apice flavescentibus tectus.

89. C. ovatus Prr.

Op. ovata H. Avgu. - Op. Gilliesii Catal. Cact. Berol. 1833.

Pa: Mendoza. 




\section{3}

C. articulatus, articulis crassis ovatis, glaucis, glabris, subtuberosis; areolis in tuberum summitate, remotis, tomentosis; aculeis biformibus, 8-10 brevibus setaceis rufis, vix e tomento prominentibus, et $2-6$ inaequalibus validis divergentibus rectis serratulis nigricantibus vel cinereis.

Articuli 2 poll. longi, $\mathbf{1}^{1 / 2}-2$ diam., e vertice et lateribus trunci globosi enascentes. Aculei minores $4-6$ lin., maximi $2-2^{1 / 2}$ poll. longi.

\section{C. articulalus PFr.}

Opuntia articulata H. Berol. (OTTo's GZ.1833. No.46.) - Op. polymorpha H. Avgr.

Pa: Mendoza.

C. articulis oblongo-globosis glaucescentibus, subtuberculato-areolatis; areolis in series subverticales dispositis inermibus, tomento albo brevissimo, setisque brunneis, vix longioribus, instructis.

Articuli $1^{1 / 2}-2$ poll. longi, $1-2$ diam.

\section{C. syringacanthus PFR.}

Opuntia platyacantha H. ANgr.

Pa: Mendoza.

C. suberectus articulatus; trunco globoso; articulis e vertice trunci, crassis, subglobosis, viridibus, tuberculosis; areolis magnis, fasciculo setarum brunnearum et aculeis 1 - 2 latis flexibilibus arundinaceis fuscis instructis.

Articuli $1^{1 / 2}-2$ poll. diam. Aculei 2 poll. longi et ultra, basi $1-1^{1 / 2}$ lin. lati.

\section{C? serpens DC.}

Prodr. III. p. 480. - Cact. serpens H. B. et Kun'H nov. gen. am. 6. p. 68.

Pa: Quito (in collibus siccis ad ripas flum. Guancabambae prope Sondorillo.).

C. repens ramosus subangulatus, articulis sexangularibus apice aculeatis.

Flores tubulosi incarnati. Petala $8-12$ acuta. Stigmata 8 approximata. 


\section{C? nanus DC.}

Prodr. III. p. 470. - Cact. nanus H. B. et Kuv'H nov. gen. am. 6. p. 68.

Pa: Quito (prope Sondorillo et Guancabamba.).

C. repens articulatus, articulis teretibus subcompressis areolatis aculeatis parum ramosis.

Caet. ignota.

\section{S. 5. Protracti.}

Caule suberecto, cereastriformi, sed fulcro indigente, subarticulato, articulis elongatis, non radicantibus.

* Miltangulares.

\section{C. serpentinus Lagasca:}

Anal. cienc. nat. 1801. p. 261. - LINK et Otro icon. t. 42. - DC. revue p. 51. t. 12.

Pa: Mexico.

C. suberectus, flexuoso-subscandens, tandem ramosus, 11-angularis, viridis; sinubus mox evanescentibus; costis compressis obtusis fere rectis; areolis subconfertis minutis albo-tomentosis; aculeis rectis gracillimis, rigidiusculis, exterioribus $9-12$, centrali 1 , nascentibus roseis, tandem albis, nonnullis fuscis.

Specimina $12-16$ ped. alta et ultra, $1^{1 / 2}-1^{3 / 4}$ poll. diam. Areolae 5-6 lin. distantes. Aculei 5-7 lin. longi.

Flores magni albi, expansi $6-7$ poll. diam. Receptaculum viride, areolatum et spinosum. Tubus 5 poll. longus, viridis, glaber, squamis parcis, rubris, pilosis instructus. Sepala olivacea, petala exteriora purpurascentia acuminata, intima nivea, apice dentata. Stamina alba, antheris magnis flavis. Stylus vix longior, stigmatibus $\%$

\section{C. ambiguus DC.}

Prodr. III. p. 46\%.- Cact. ambiguus Bonpl. nav, t. 36.

- Reichens. fl. exot. 179.

$\mathrm{Pa}$ ?

C. erectus longus obtusissime 9-11-angularis, setis spinescentibus lana longioribus, tubo florali basi setifero.

Flos C. serpentino simillimus. - Num huic aequalis, an varietas caule erectiore et setis brevioribus? 



\section{C. polygonus DC.}

Prodr. III. p. 466. - Cact. polygonus LaMr. dict. 1. p. 539. - Plum. ed. Burm. p. 189. t. 196.

$\mathrm{Pa}$ : St. Domingo.

C. erectus subarticulatus sub-11-angularis, tandem ramosus; costis compressis verticalibus; sinubus repandis; areolis magnis approximatis; aculeis $10-16$ gracilibus, rectis, radiantibus, griseis.

Flores albi 3 poll. longi, expansi 2 poll. diam., limbo parum patente. Stanina innumera; stylus longissime prominens.--Fructus rubro-fuscus tuberculosus, carne rubro-ignea.

Species ex Lam. Cereo repando affinis, ex Sprengel $\boldsymbol{C}$. griseo conjungenda.

\section{**itahayae.}

Caule erecto 3 -5-angulari, articulis elongatis obtuse costatis.

\section{9\%. C, obtusus Haw.}

Revis. p. 80.

Pa: Brasilia.

C. erectus laetevirens 3 -angularis; costis obtusis; fasciculis aculeorum valde remotis; aculeis fulvis e tomento brunneo, 4 radiantibus, centrali 1 elongato erecto (DC.).

Truncus 2 poll. diam. Areolae 1 poll. et ultra distantes. Aculei $5-8$ lin. longi.

Floruit in horto Berolinensi et Monacensi Octobri 1835. Flores magni, diurni, albi, expansi $4^{1 / 2}$ poll. diam. Receptaculum a tubo nuclo flavescenti-viridi, squamis parcissimis, apice purpurascentibus, inferioribus minimis, deltoideis, superioribus sensim majoribus lanceolatis instructo, $6-7$ poll. longo, haud distinctum. Sepala viridia, $13-15$, lineari-lanceolata, refiexa. Petala biserialia, exteriora pallide virentia, interiora 2 poll. longa, 8 lin. lata, apice denticulata, nivea, patentia. Stamina plurima e tubo et e fauce, alba, antheris lineari-oblongis, flavescentibus. Stylus crassus, cylindricus, glaber, stamina superans, albus, 14-partitus, radiis stellatim patentibus, teretibus, undique papillosis, sulphureis.

98. C. variabilis PFr.

Cactus Pitajaya JAcQ. select. stirp. amer. p. 151. Cer. Pitajaya DC. prodr. III. p. 466. - Plum. ed. Burm. t. 199. f. 1.-Cer. undulosus DC. revue p. 46. Prodr. III. 
p. 467. - Plum. ed. Burm. t. 194. - Cer. laetevirens Salm (Hort.' Dyck. p. 336.). - Jamacaru PIsov. hist. nat. brasil. p. 100. f. 1? - Cer. quadrangularis, trigonus, prismatiformis, hexangularis, cognatus, affinis, glaucus speciosus HorT.

Pa: Mexico, Peru, Brasilia, India occidental.

C. suberectus subarticulatus simplex, vel basi ramosus, viridis vel glaucescens; costis $\mathbf{3}-\mathbf{5}$ subcompressis obtusis obrepandis; areolis plus minusve remotis, albo-vel fusco-tomentosis, parum lanatis; aculeis rectis rigidis, exterioribus $6-8$, centrálibus $1-2$, albis, flavidis vel nigricantibus.

Plures species distinctae verosimiliter sub nomine $C$. variabilis conjunctae sunt. Sed formae adeo mutabiles sunt, ut omnes una in alteram transeant, quare species in hortis sub nominibus citatis cultae recte describi non possunt. Nam saepe in una plante articuli adsunt longissimi tetragoni, alii ovati trigoni, areolae tunc albae, tunc brunneae, aculei tunc breves albi, tunc elongati rigidi fusci. - Cer. obtusus $\mathrm{Haw}$. etiam vix a variabili separari potest, et solummodo ob florem cognitum servatus est. - Quando plures plantae hujus formae floruerint, aliac forsan species statui et accuratius describi poterunt.

Specimina laete vigentia plerumque $1 \frac{1}{2}-3$ poll. diam., areolis $4-8$ lin. remotis, aculeis 3 supremis rigidioribus $8-10$ lin., $4-5$ inferioribus gracilioribus $3-4$ lin., centralibus $6-12$ lin. longis.

\section{C. validus HAw.}

Philos. magaz. Dec. 1831. vol. X. p. 414.

Pa: America calidior.

C. tetragonus firmus; apice glauco; lateribus fere planis vel primo convexiusculis; ipsis angulis obtusissimis, mediocriter spinosis.

Affinis Cereo obtuso, sed valde robustior. Spinaria inter se valde distincta, lana ordinaia densissima, centrali brevi, spinis saepe fulvicantibus et $3-6$-linearibus.

100. C. laetus SaLM.

Hort. Dyck. p. 336. - Cer. formosus Hort.

Pa: Montevideo.

C. erectus subarticulatus 5-angularis, coerulescens; costis compressis obrepandis; aculeis flavicantibus ex areola 


\section{,}





\section{7}

latiuscula brunneo-tomentosa, vix lanifera, exterioribus 6 radiantibus validiusculis, binis supremis cum centrali 1 duplo longioribus.

Truncus $13 / 4$ poll. diam., aetate ramosus. Areolae 4 lin. distantes. Aculei 4-6 lin. longi.

An idem cum sequente ( $\mathrm{S}$ al m)?

\section{C. laetus DC.}

Prodr. III. p. 466 . - Cact. laetus H. B. et Kunth nov. gen. am. 6. p. 68.

Pa: Quito (prope pagum Sondorillo.).

C. erectus laete virescens articulatus; articulis 7 -angularibus; angulis tuberculatis; tuberculis fasciculato-spinosis.

\section{C. paniculatus DC.}

Cact. paniculatus LAsr. dict. 1. p. 540. - Melocactus arborescens, tetragonus, flore exalbido. PuUm. cat. pl. p. 19. - Tourn. inst. p. 653. - Plun. ed. Burn. t. 192.

C. trunco erecto, ramis ex apice trunci paniculatis, 4-gonis, basi articulatis; spinis fasciculatis brevibus.

Flores albi, lineis rabris, tubo longo ciliato-squamoso, petalis apice rotundatis, stylo longe prominente. Fructus pomiformes, tuberculosi, flavescentes.

Ad hanc speciem accedere videtur Jamacaru prima species (M a rgr. hist. nat. bras. p. 125. f. 2.), sed ex icone rudi et descriptione nulla non patet, an eadem aut affinis species? (DC.)

\section{料垱 Wxtensi。}

Caule suberecto, ramis plerumque diffusis, gracilibus, 3-5-gonis, costis compressis.

\section{C. acutangulus H. Beror.}

Cer. undulatus Hort. Dresd.

Pa: Mexico.

C. suberectus subarticulatus 4 -angularis, perviridis, nitidus; costis compressissimis obrepandis, circum areolas inflatis; sinubus latis profundis, serius planis; areolis distantibus transverse ellipticis; aculeis e tomento brevi fuscidulo, radiantibus $4-6$, binis infimis semper minimis, centrali plerumque 1 subulato cinerascente. 
Truncus 1/1/2 poll. diam. Areolae 4-5 lin. distantes. Aculei exteriores $3-5$, infimi $1-1 \frac{1}{2}$, centrales $5-8$ lin. longi.

\section{C. pellucidus H. Berou.}

Pa: Cuba.

C. suberectus, basi ramosus, 5-angularis, pellucide viridis; costis junioribus acuatis, fere membranaceis, serius obtusis, obrepandis, infra areolas inflatis; areolis subnudis; aculeis rectis, junioribus aureis, tandem fulvis, radiantibus 9, centrali 1 longiore.

Truncus $1-1^{1 / 2}$ poll. diam. Areolae $4-5$ lin. distantes. Aculei exteriores $3-4$, centrales $10-12$ lin, longi.

\section{C. princeps H. WüRzB.}

\section{$\mathrm{Pa}$ ?}

C. erectus ramosus, subarticulatus, 3-, rarius $4-5-$ angularis; sinubus planis; costis compressis infra areolas inflatis; areolis subremotis, tomento brevissimo albido; aculeis rectis crassiusculis flavescentibus vel albis, centralibus 3 , exterioribus $7-8$, supremo brevissimo vel nullo.

Truncus 1-1 $1 \frac{1 / 2}{2}$ poll. diam. Areolae $4-5$ lin. distantes. Aculei centrales $6-8$ lin. longi.

\section{C. Bomplandii PARu.}

Pa: Brasilia.

C. erectus' subarticulatus 4-5-angularis, glaucescens; costis subrectangularibus; cristis obtusis undulatis; areolis subremotis; aculeis rigidis eburneis, basi crassiore et apice nigricantibus, e tomento brevissimo griseo, centrali 1 , exterioribus $5-6$, superioribus 2 majoribus, $3-4$ infimis brevissimis, tenuissimis.

Truncus $1^{1 / 4}$ poll, diam. Areolae $6-7$ lin. distantes. Aculei exteriores 4 , supcriores (nascentes purpurei) 6 lin. longi, centralis subpollicaris.

\section{C. ramosus KARW.}

\section{Pa: Mexico.}

C. suberectus subarticulatus; articulis diversiformibus 3 -5-angularibus perviridibus; sinubus planis ; costis compressis; areolis non prominentibus, vix tomentosis; acu- 

leis albis, inferioribus $5-6$ brevibus, centralibus 3-4 subulatis vix longioribus.

Articuli usque ad 2 poll. diam. Areolae nunc $3-4$ lin., nune 1-1 1/2 poll. remotae. Aculei $2-3$ lin. longi.

\section{C. baxaniensis KARW.}

\section{Pa?}

C. suberectus subarticulatus, ramosus, perviridis, 5angularis; sinubus latis; costis compressis, vix repandis; areolis approximatis albis minutis; aculeis exterioribus $6-8$ gracilibus albis, centralibus 4 fuscescentibus, longioribus, omnibus rigidis.

Truncus 1-1/2 poll. diam. Areolae 4 lin. distantes. Aculei exteriores 3 , centrales $5-6$ lin. Iongi.

Cereo ramoso forsan nimis affinis!

\section{C. pentagonus Haw.}

Syn. p. 180. - Cact. pentagonus L. - Cact. prismaticus et reptans W. - Cer. reptans et prismaticus HAW. suppl. p. $8 \%$

Pa: Amer. calida.

C. erectus articulatus tenuis laetevirens $\mathbf{5}$-angularis; costis repandis; aculeis basi nudis subaequalibus gracilibus stramineis, radiantibus $6-7$, uno centrali (DC. pr.).

C. suberectus, articulatus, ramosissimus; ramis 3-5(rarius 6-7-) gonis; sinubus latis; costis subcompressis, mox obsoletis, subrepandis; areolis albo-tomentosis magis minusve remotis; aculeis in ramis robustioribus rigidis, nascentibus nigricantibus, mox albidis, radiantibus 5 , centrali 1, in ramis gracilibus radiantibus 6-7, centrali 1 , omnibus brunneis, setiformibus.

Species polymorpha, quare a.Cl. Haworth sub 3 nominibus assumta! Truncus et rami $4-8$ lin. diam. Variat angulis 3 , 4, 5, quandoque valde compressis, quandoque omnino obliteratis, ramis aliis robustis erectis (areolis 6 lin.), aliis gracilibus repentibus, areolis $3-4$ lin. remotis. Aculei semper $3-4$ lin. longi. Radices laterales nunquam profert, quo signo a nonnullis speciebus similibus facile distinguitur.

\section{C. tenellus SaLm.}

Cer. candelabrius HoRT. 
Pa: Brasilia.

C. suberectus articulatus 4- 5 -gonus, tenuis; sinubus planis; costis subcompressis; areolis subconfertis nudis; aculeis setiformibus brunneis brevibus $\mathbf{3}-\mathbf{4}$ divaricatis, supremis adpressis.

Truncus 4-6 lin. diam. Areolae $4-5$ lin. distantes. Aculei $3-4$ lin. longi.

\section{S. 6. Repentes.}

Caule subarticulato, ramis longis, repentibus, diffusis, costatis vel subtuberculatis, radiculas laterales proferentibus.

* Multangulares.

\section{C. Martianus Zucc.}

Pa: Mexico (Sultepec Zimapari).

C. suberectus ramosus 8-angularis; sinubus latiusculis; costis vix prominentibus; areolis approximatis in cristae tuberculis positis; aculeis exterioribus $6-8$, setiformibus albidis (nascentibus rubris), radiantibus, centralibus $2-3$ fuscis, vix majoribus.

Truncus suberectus, basi ramosus, $6-8 \mathrm{lin}$. diam. Areolae 4 lin. distantes. Aculei $2-4$ lin. longi.

Flores mense Majo ignescenti-lateritii, expansi $2-2 \frac{1}{2}$ poll. diam: Tubus $21 / 2$ poll. longus, rubellus, basi areolatus et pilosus. Petala lanceolata acuta, dorso pallidiora, extima reflexa; intima sub-12 erecta, 4 lin. lata. Stamina corollam aequantia, conferta, sulphurea, antheris albis. Stylus exsertus flavus, stigmatibus 6 .

\section{C. Reigelliformis NiLL.}

Dict. ed. 8. n. 12. - HAw. syn. p. 135. - Cact. flagelliformis LinN. - DC. pl. gr. t. 12\%. - Botan. magaz. t. 1\%. - Tnew ehret. t. 30.

Pa: America calida (et Arabiae deserta?).

C. repens gracilis ramosissimus; ramis teretibus, 10-12 tuberculorum seriebus instructis; areolis vix tomentosis; aculeis brevibus rigidiusculis, $8-\mathbf{1 2}$ stellatis fuscidulis, centralibus $3-4$ brunneis, apice aureis, paulo majoribus.

Rami 8-10 lin. diam., pedales et ultra, repentes vel pendentes; areolae $3-4$ lin. distantes, aculei $2-3$ lin. longi, nascentes rubri. 



\section{1}

Flores primo vere copiose erumpentes, tubulosi, rubri, $21 / 2-3$ poll. longi, limbo expanso 1/2 $^{1 / 2}$ poll. diam. Tubus gracilis, sepalis fusco-rubris pilosis muuitus. Petala mucronulata purpureorosea, exteriora revoluta; limbi lobi antici expansi, postici erecti. Stamina albida supra corollam exserta, antheris sulphureis. StyIus staminibus brevior albidus, stigmatibus 5 non expansis. Fructus vere sequente maturescens globosus, rubicundus, 1/2 poll. diam., areolis confertis setigeris obtectus, carne viridi-flava, sapore prunaceo. ribus.

ß. minor Salm. - Caule ramisque dimidio gracilio-

Aliis Cacteis C. Alagelliformis facile inseri potest. Sic Cl. D c Candoll e eun supra Pereskiam aculeatam insertum, laete vigenten vidit, nosque ipsi. Cereo grandifloro insertum copiose florentem observavimus.

\section{C. Smillii H. AvgL.}

Cereus crimson creeping: Botan. regist. t. 1565. Cer. Mallisoni HonT.

C. suberectus ramosus 6-angularis viridis; ramis junioribus purpureis; sinubus latis angulatis; costis verticalibus repandis; areolis subremotis convexis; aculeis e tomento brevissimo albido, centralibus $5-6$ divergentibus rigidis fuscescentibus, exterioribus setaceis flavis deorsum spectantibus.

Planta hybrida, parentibus C. speciosissimo et flagelliformi ab Anglo Mallison primum culta.

Truncus 1/2 -1 poll. crassus. Rami nounulli Céreo speciosissimo potius similes. - Flores mensibus Junio et Julio speciosi coccinei, 5 poll. diam. Tubus ruber areolatus et spinosus; petala lanceolata, nervo igneo. Stamina alba, antheris flavis. Stylus paulo longior coccineus, stigmatibus 8 albis.

11\%. C. Alagriformis. ZucC.

Pa: Mexico (S. Jose de l'Oro.).

C, repens ramosissimus; ramis $\mathbf{1 1}$-angularibus viridibus; sinubus obsoletis; costis obtusis tuberculatis; areolis subconfertis; aculeis exterioribus $6-8$ radiantibus, gracilibus, corneis, centralibus $4-5$ brevioribus, rigidioribus, brumneis.

Rami 5-12 lin. diam. Areolae 2-3 lin. distantes. Aculei exteriores 2 , centrales $1 \frac{11}{2}$ lin. longi.

Flores Epiphyllo truncato similes, 4 poll. longi,. 3 poll. et 


\section{2}

ultra diam. Tubus fusco-rubellus, 11/2 poll. longus, 4 lin. diam., areolato-pilosus. Petala 3 -serialia mucronata, coccinea, margine coerulescentia, reflexa, intima 5 lin. lata, limbum formantia campanulatum. Stamina inaequalia rubella, antheris flavis; stylus e medio vix prominens, stigmatibus 6 confertis albidis.

115. C. leptophis DC.

Revue p. 11\%. - Mém. p. 21. t. 12.

Pa: Mexico.

C. subradicans cylindraceus, serpentinus; costis $7-8$ obtusissimis subrepandis; areolis velutinis, etiam adultis convexis; aculèis $12-13$ setaceis, vix rigidulis, flavidis, expanso-radiatis, $2-\mathbf{3}$ centralibus erectiusculis.

Cereo flagelliformi (gallice: Serpent nominato) valde affinis, sed dimidio gracilior est (quare nomen!), costisque differt paucioribus, aculeis vix pungentibus, junioribus rubris, dein flavidis, floris limbo multo magis expanso, styloque staminibus longiore.

Flores sessiles, solitarii, $2^{1 / 2}$ poll. longi, 2 poll. diam., lucide coccinei. Tubus squamulis pilosis et sepalis lanceolatis obtectus. Petala oblonga, fere linearia, apice retroflexa, exteriora $6-7$ subcallosa et aequaliter rubra, intima longiora, violascentia, mucronata. Stamina 20, petalis breviora, roseo-albida, filiformia, antheris minutis flavis. Stylus filiformis, staminibus longior, stigmatibus 4 crassis, papillosis, roseis, obtusis.

\section{C. Humboldtii DC.}

Cact. Humboldtii H. B. et Kunth nov. gen. am. 6. p. 66.

Pa: Quito (prope Sondorillo et San Felipe.).

C. caule procumbente 10-12-costato glabro; angulis tuberculosis; tuberculis setas rigidas gerentibus; stylo corollam multo superante.

Cereo Ragelliformi valde affinis dicitur!

\section{C. icosigonus DC.}

Cact. icosigonus H. B. et Kunth nov. gen. am. 6. p.66. Pa: Quito (in locis siccis prope pagum Nabon.).

C. caule procumbente simplice sub-20-angulari; angulis fasciculato-setosis, stylo longitudine petalorum, apice 8-fido.

An, ex cl. auctoribus, a C. Humboldtii sat diversus (DC.)? 


118. C. sepium DC.

Cact. sepium H. B. et Kuvin nov. gen. am. 6. p. 66. Kusth syn. pl, aeq. III. p. 370.

Pa: Quito (in arenosis prope Riombamba ad radicem montis Chimborazo, ubi Pitahaya dicitur.).

C. caule erecto $\mathbf{1 1 - a n g u l a r i ; ~ a n g u l i s ~ f a s c i c u l a t o - a c u - ~}$ leatis; staminibus styloque inter se aequalibus, corollam paulo superantibus, stigmate 8-partito.

Ad sepes construendas inservit, unde nomen! - Flores incarnati, fructus rubri. - An, ex cl. auct., a Cereo Humboldtí satis diversus (DC.)? - Num C. Martiano affinis?

$$
\text { 粠 } 4 \text { - } 8 \text {-angulares. }
$$

119. C. grandiflorus MiLs.

Dict. ed. 8. n. 11. - HAw. syn. p. 184. - Cact. grandiflorus L. - DC. pl. gr. t. 52. - Revue p. 50.- Trew ehret. t. 31. 32. - Allg. teutsch. Gartenmagazin I. 421.Bot. magaz. t. 3381 .

Pa: Insul. Carib., Antill.

C. repens diffusus pallide virens; articulis radicantibus longissimis flexuosis, 5-8-angulatis, parum sulcatis, fere teretibus; aculeis radiantibus $4-8$ brevibus vix pungentibus flavidis vel albis, centralibus $1-4$, longitudine setas albas aequantes.

Rami 6-10 lin. diam. Areolae 5-7 lin. distantes. Aculei 2-3 lin. Iongi.

Flores plerumque mense Julio apparent, vespere expansi, poll. diam., per unam noctem durant, rarius ad meridiem usque diei sequentis, odorem spargentes vanillaceum intensum. Receptaculum subglobosum dense squamatum et lanatum; tubus 6 poll. longus, basi 7-8 lin., infra corollam 1/2 poll. diam., pallide virens, squamis ciliatis viridibus, apice aurantiacis, elongatis obsitus. Sepala linearia, acuta, 4 poll. longa, patentissima, aurantiaca. Petala latiora, 3 poll. longa, nivea. Stamina numerosa alba, antheris sulphureis, stylum 10-12-partitum aureum aequantia.

$\beta$. speciosissimus. - E foecundatione artificiali cum C. speciosissimo ortus. Flores hucusque ignoti.

120. C. nyclicalus Link.

Verhdl. d. GBV. f. Pr. X. S. 373. T. 4. - C. pteranthus Link (Oтто's GZ. 1834. No. 2\%. S. 209.). - Cer. 
brevispinulus SAla (Hort. Dyck. p. 339.).-Cer. Antoini II. Vindob. - Cer. obtusus, rosaceus Hont. - Otro's GZ. 1835. No. 28. \$. 221.

Pa: Mexico.

C. suberectus longissime articulatus radicans; articulis diversiformibus, aliis subcylindraceis, cum 4-5 seriebus areolarum; aliis 4-6-gonis; costis junioribus acuatis, mox obtusis; areolis nunc remotis, nunc confertis; aculeis $1-4$ minutissimis rigidis, setisque nounullis albis, saepe deciduis.

Rami 8-12 lin. diam. Areolae 4-10 lin. distantes. Aculei $1-2$, setae $2-3$ lin. longae.

Flores mense Julio, Cereo grandifloro similes, majores, nocturni, inodori. Teceptaculum subglobosum, 1 poll. diam., dense squamato-areolatum et pilosum. Tubus 7 poll. longus, horizontaliter patens, basi 8 lin., infra corollam 11/2 poll. diam., squamis fusco-virentibus, vix lanatis obsitus. Sepala patentissima, linearia, $2-4^{1 / 2}$ poll. longa, extima rubra, interiora fusco-virentia, canaliculata. Petala alba, 41/2 poll. longa, 15 lin. lata, basi attenuata, cuneata, obtusa, mucronata, limbum formantia campanulatum. Stamina petalis breviora, basi viridia, superne flavescentia, antheris flavis. Stylus staminibus paulo longior, cylindricus, albidus, stigmatibus 15 subulatis, sulphureis.

\section{C. caripensis DC.}

Prodr. III. p. 46\%. - Cact. caripensis II. B. et Kuvth syn. pl. aeq. III. p. 390.-Cer. quadrangularis Haw. syn. p. 181? (Sprevaen).

Pa: Nova Andalusia (in ligno putrido prope Caripe).

C. caulibus fasciculatis elongatis repentibus ramosis subtetragonis; angulis tuberculosis, tuberculis stellulatosetosis.

Flores et fructus ignoti. - Cereo fagelliformi similis dicitur,

sed ramis subtetragonis satis distinctus. - An forte C. mycticalus?

122. C. radicans DC.

Prodr. MI. p. 468. - Cer, reptans Salin, nec Wut.d. - Cer. biformis Hont.

Pa: America calida, Antill.

C. prostratus articulatus radicans, laetevirens, $3-5-$ 




\section{5}

angularis; aculeis rigidis gracilibus rufis, basi nudis, radiantibus $6-9$, centrali 1 elongato.

Truncus 6-8 lin. diam. Areolae 3-6 lin. distantes. Aculei 2-3 lin. longi. Latera initio profunde sulcata (costis compressis acutis), tandem plana, imo convexa.

\section{C. spinulosus DC.}

Revue p. $11 \%$.

Pa: Mexico.

C. subramosus, radicans, subserpentinus, teretiusculus; costis $5-6$ vix exsertis acutiusculis; sinubus latis obtusissimis; areolis junioribus velutinis; aculeis 8 brevissimis rigidis conicis, junioribus flaviòis, dein subfuscis, lateralibus radiantibus (DC.).

C. suberectus ramosus; ramis divergentibus 4-5-angularibus; sinubus planis; costis subacuatis, tandem obtusis; areolis brunneo - velutinis; aculeis exterioribus $6-8$ corneis, rigidiusculis, brevissimis ( 2 infimis longioribus, gracilioribus, flavidis), centrali $\mathbb{1}$ aequali.

Truncus 5-6 lin. diam. Areolae $4-6$ lin. distantes. Aculei $11 / 2$, infimi 2 lin. longi.

\section{C. albiselosus Haw.}

\section{Suppl. p. $9 \%$.}

Pa: Insula S. Domingo.

C. repens viridis 5-angulatus; aculeis setiformibus albis, in stellum expansis, lana rufa brevioribus.。

C. reptanti Haw. (pentagono) simillimus; differt in spinis gracilioribus magis expansis albis (Haw.).

\section{C. himilis DC.}

Prodr. III. p. 468. - Cer. gracilis SAIM.

Pa: America calida.

C. suberectus ramosus 4-5-angularis; costis subacuatis repandis ; areolis subnudis; aculeis exterioribus 8-12, centralibus 4 paulo rigidioribus, junioribus fuscis, tandem albidis.

Truncus 1 poll. diam. Areolae 4 lin, distantes. Aculei $2-4$ lin. longi.

B. minor. - C. myriacaulon MART. - Cer. Mariculi 


\section{6}

Hont. - Ramis fasciculatis tenuioribus, aculeis subsetaceis.

\section{C. setiger HAw.}

Philos. magaz. 1830. p. 109.

Pa: Brasilia.

C. suberectus, ramis paucis 4-angularibus; setarum fasciculis sub-20-setatis; setis 3-4-linearibus subaequalibus radiantibus pallidis.

Plantae facies paululum refert ad Stapeliam Asterias.

127. C. inermis Oтто.

Pa: La Guayra.

C. repens viridis 4- (ramis junioribus 5-) gonus; angulis compressis; ramis nascentibus dense areolatis et setosis, adultis omnino inermibus.

$$
\text { 粠棌 } 3=4 \text {-angulares. }
$$

Costis subacuatis, areolis junioribus squamula carnosa suffultis.

\section{a. Tripteres.}

Articulis 3-angularibus, acute costatis, floribus (specierum notarum) albis.

\section{C. triangularis HAW:}

Syn. p. 180. - Cact. triangularis I. - Cereus compressus Milu. dict. n. 10. - Cactus triangularis aphyllus JAcQ. amer. 152. - Plum. ed. Burm. t. 200. f. 1. - Bradu. succ. 3. - Botan. regist. t. 180\%. - Otro's GZ. 1836. No. 3. S. 22.

Pa: Mexico, insul. Carib.

C. suberectus radicans articulatus laete viridis; articulis latis elongatis 3- (rarissime 4-) angularibus; costis junioribus compressissimis, quasi alatis ; uno sinu fere plano, reliquis 2 profundis; areolis subremotis fere nudis; aculeis 2-4 nigricantibus, subdecussatis, brevibus, rigidis, recurvulis, infimo longissimo.

Articuli pede longiores, $2-3$ poll. lati, interdum torti; margines articulorum adultorum crusta lignea obducti; vetustissimi 

prismatiformes, omnino lignosi. Areolae 1 poll. distantes. Aculei $1-2$ lin. longi.

Floret mense Septembri. Flores albi, hora sexta pomeridiana aperti per 17 horas durantes, 8 poll. diam. Receptaculum squamis latis brunneis retusis obtectum; tubus viridis, 6 poll. longus, 1 poll. diam, squamis elongatis, apice spathulatis obsitus. Sepala lanceolata olivacea patentissima. Petala biserialia, 1 poll. lata, longe acuminata, nivea. Stamina flavescentia, antheris citrinis. Stylus crassus sulphureus, multo longior, stigmatibus permultis aurantiacis. - Fructus nudus coccineus, magnitudine et forma ovi anserini.

B. major. - Cer. undatus Haw. (philos. magaz. 1830. p. 109.) - Cereo triangulari simillimus, sed duplo major (HAw.). An varietas modo e cultura orta?

$\gamma$. pictus. - Articulis nonnullis omnino flavis, aliis e flavo et viridi variegatis, aculeis saepe setiformibus, nec rigidis.

\section{C. Napoleonis Grahau.}

Botan. magaz. t. 3458. - Otro's GZ. 1836. No. 10. S. 80. - Cer. triangularis major SAlm. - Plum. ed.Burm. p. 191. t. 199. f. 2.

Pa: India occidentalis.

C. suberectus longe articulatus viridis; articulis trigonis gracilibus; sinubus planis; costis acuatis undulatis subtuberculatis; areolis remotis vix tomentosis in parte superiore tuberculorum; aculeis $3-4$ inaequalibus subulatis rectis nigris, infimo plerumque longissimo, setis interdum paucis albis.

A Cereo triangulari toto coelo distinctus! Articuli pedales et ultra, 10-12 lin. diam. Aleolae 6-8 lin. distantes. Aculei 4-8 lin. longi.

Floruit in horto Edinburgensi mense Septembri 1835. Flores 8 poll. Iongi, 6 poll. diam., mane aperti vesperem versus claudebantur. Tubus crassus, 3 poll. longus, viridis, squamis rubris. Sepala virescenti-straminea, lanceolato-linearia. Petala nivea, spathulato-lanceolata, apice crenata. Stamina numerosa, flara, corolla breviora, antheris erectis minutis. Stylus multo longior albidus, stigmatibus numerosis expansis flavis. - Fructus (si Plumieri planta revera nostra est) violaceus, 4 poll. longus, $3^{1} / 2$ diam., squamis spinosis obsitus. 


\section{8}

\section{C. triqueter Haw.}

Syn. p. 181. - Cactus triqueter HAw. in misc, nat. p. 189. - Cactus prismaticus Desf. hort. Par.

Pa: Amer. merid.

C. decumbens triqueter, spinis fasciculatis divaricatis septenis, 2-3-linearibus (HAw.).

C. suberectus articulatus viridis 3-angularis; sinubus planis; costis acuatis repandis; areolis brevissime tomentosis griseis; aculeis 4-6 fulvis rigidiusculis, inferioribus 2-3 gracilioribus albis.

Truncus et rami 1 poll, diam. Arcolae 6 lin. distantes. Aculei 2 lin. Iongi.

\section{C. trigonus Haw.}

Syn. p. 181. - Cactus triqueter $\beta$ HAw. in misc. nat. p. 190. - Plum. ed. Bury. t. 200. f. 2. - Cactus triangularis foliosus JACQ. amer. 152. ex LAM. dict. 1. p. כૅ41.

Pa: Insul. Carib.

C. repens triqueter; angulis vix canaliculatis; spinis 5-7 stellatim fasciculatis sublinearibus (HAw.).

Flos ex Plum. albus et fructus violaceo-coccineus. Fructus ex Jacq. nitide coccineus, squamis vestitus. An duae species hic confusae (DC.)?

ß. quadrangularis Haw. syn. p. 181. - Plum. ed. Burm. t. 199. f. 1. ex HAw.

\section{C. tripteris Sala.}

DC. prodr. III. p. 468.

$\mathrm{Pa}$ ?

C. articulatus suberectus radicans 3-4-angularis; costis valde compressis subrepandis; fasciculis confertis; aculeis basi subnudis, aequalibus, albicantibus, radiantibus 8 , centralibus 3 rigidiusculis.

Articuli $10-15$ lin. diam. Areolae $1-3$ lin. distantes. Aculei $1-1 \frac{1}{2}$ lin. longi.

\section{C. prismaticus SaLM.}

DC. prodr. III. p. 469.

Pa: Amer. trop.

C. articulatus suberectus radicans viridis 3 -angularis; 


costis repandis; fasciculis aculeorum confertis; aculeis subaequalibus fulvis e tomento fusco, superioribus $7-10$, quorum $3-4$ centrales, infimis $3-6$ gracilioribus, brevioribus.

Truncus fere 1 poll. diam. Articuli saepe torti, rarus 4 -angulares. Areolae 3 lin. distantes. Aculei superiores $2-3$, inferiores 1 lin. longi.

\section{C. extensus SAJM.}

DC. prodr. III. p. 469. - Wendrand in: OTTo's G2. 1836. No. 39. S. 306. - Cer. subsquamatus PFr. (Otтo's GZ. 1835. No. 48. S. 380.)? - Cer. horridus Hont.? $\mathrm{Pa}$ ?

C. longissime articulatus radicans viridis 3 -angularis; costis repandis subacuatis; areolis remotis fulvo-tomentosis; aculeis fulvis, rigidis, recurvulis, brevibus, $\mathbf{2}, \mathbf{3}, \mathbf{4}$ decussatis, interdum 1 centrali; setis nonnullis albis, plerumque deciduis.

Articuli pedales et ultra, $1-1^{1 / 4}$ poll. diam., vetustiores teretes, angulis obsoletis. Areolae $1^{\mathrm{J} / 2}$ poll. distantes. Aculei $1-3$ lin. longi.

Flos a Cl. Wendland observatus, horizontaliter patens, 1 ped. longus, albus, odore Daturae suaveolentis simili, diurnus, duratione brevissima. Receptaculum subglobosum, tuberculatoareolatum et spinosum. Tubus calycinalis rectus, 5-6 poll. longus, sursum dilatatus, laete virens, squamis lanceolatis, acutis, basi viridibus, apice vivide rubris obsitus. Sepala $2 \frac{1 / 2}{3} 3$ lin. lata, linearia, acuta, sursum canaliculata, flavescenti-viridia. Corolia alba, campanulato-expansa. Petala $4 \frac{1}{2} / 2$ poll. longa, obcuneata, infra apicem 14 lin. lata, obtusa, mucronata. Stamina petalis breviora alba, antheris sulphureis. Stylus paulo longior, pallidissime flavescens, stigmatibus 20 subulatis sulphureis.

\section{3ě. C. sètacens SALm.}

DC. prodr. III. p. 469.

Pa: Brasilia.

C. articulatus suberectus radicans; articulis triangalaribus elongatis divergentibus perviridibus, junioribus malgine purpureis; costis acutis, fere rectis, vix repandis; areolis vix convexis albo-tomentosis; aculeis fulvis $2-4$, gracilibus, rigidis, setis $8-10$ longioribus, plerumqne utrinque adpressis. 
Rami $1 / 2-1$ poll. diam. Areolae 6-18 lin. distantes. Acu Jei $1-2$, setae $3-4$ lin. longae.

Flos in horto Berolinensi ex areola prope apicem rami vetustioris, magnus, pendulus. Tubus $6-7$ poll. longus viridis. squamis parcis inermibus, apice purpureis instructus, receptaculo subgloboso tuberculato - spinoso adnatus. Sepala linearia $4-5$ poll. longa, viridia. Corolla campanulata 4 poll. longa, petalis niveis, latis, apice denticulatis. Stamina numerosa flavescentia, antheris sulphureis. Stylus longior 16-partitus flavus.

B. viridior Salu (Hort. Dyck. p. 65̃.). -- C. coccineus DC.

\section{b. Speciosi.}

Articulis suberectis $3-4-$, rarius 5 -gonis, floribus speciosis rubris.

\section{C. speciosissimus DC.}

Cactus speciosissimus Desf. mém. Mus. 3. p. 190. t. 9. - Cactus speciosus WilidD., Cavan. - Allg. teutsch. Gartenmagazin B. V. 1820. - ColdA hort. ripulo t. 10. Botan. regist. t. 486. - Reichenb, fl. exot. 180. - DC. revue p. 54. - Green (Otтo's GR. 1834. No. 39.).

Pa: Mexico, Guatimala.

C. suberectus ramosissimus; ramis elongatis divergentibus 3-4-angularibus, junioribus purpureis; costis acutis dentatis; areolis convexis albo-tomentosis; aculeis subaequalibus rectis rigidulis, nascentibus roseis, tandem albidis, centrali 1 , superioribus $6-8$, inferioribus $2-3 \mathrm{mi}-$ noribus.

Haec distinctissima species primum a Cl. Cavanilles sub nomine Cacti speciosi ex horto Madridensi horto Monspessulano communicata est. Cl. De Candolle specimina hujus speciei et C. phyllanthoidis Cl. Bomplandio misit, qui ambo confudit, et phyllanthoidem sub nomine Cacti speciosi edidit. Ad vitandam confusionem Desfontaines huic speciei nomen Cacti speciosissimi tribuit, et Haw orthius (secundum DC.) eum C. bifrontem nominavit. (Sed $C$. bifrons $\mathrm{Haw}$. verosimiliter ad $C$. coccineum $\mathrm{S}$ alm potius referendus est.)

Truncus et rani ultrapedales, 1-2 poll. diam. Areolae 1/2-1 poll. distantes. Aculei $4-6$ lin. longi. Radiculae parcissimae breves in apice articulorum.

Flores a primo vere per tolam aestatem, copiosi, insignes, rubri, per $3-4$ dies continuo aperti, Tubus 3 poll. iongus vi- 
$+2$ 



\section{1}

ridis, areclato - spinosus et squamis purpureis obsitus. Sepala crassa linearia rubescenti-viridia. Corolla expansa $5-6$ poll. diam. Petala biserialia, 2 poll. longa, 1 poll. lata, acuminata, exteriora coccinea, interiora coerulescenti-purpurea. Stamina numerosissima filiformia, fasciculata, basi viridia, subtus coccinea, antheris minutis albidis. Stylus stamina aequans, coccineus, stigmatibus 8-10 albidis. - Fructus, anno sequente maturescens, magnitudiue ovi gallinarii, flavescenti-viridis, parcissime tuberculato-spinosus, intus pulpa succulenta, grata, acidula, semina numerosissima continente, repletus.

E commixtione pollinis cum $\boldsymbol{C}$. phyllanthoide perplures varietates ortae sunt, quorum omnium rami mox 3 -vel 4-angulares, setosi vel spinulosi, mox dipteri, inermes sunt, formaque valde variant:

ß. lateritius Bot. reg. t. 1596. - Cer. hybridus H. BeroL. - Epiph. hybridum Hort.

Flores, uti reliquis hybridis, a $C$. speciosissimo diversi. Tubus $21 / 2$ poll. longus, areolatus et spinosus, areolae squamula violacea suffultae. Corolla campanulata, $\mathbf{3}$ poll. diam., cum petalis exterioribus patentibus f poll. diam. Petala lateritia, nervo igneo. Stamina corolla breviora rubella, basi viridia, antheris albis. Stylus pallide rubens, stamina aequans, stigmatibus 8 albis fimbriatulis.

y. Jenkinsonii H. ANGL. - Ramis 3-gonis setosis, vel planis inermibus.

Flores mense Majo rubri, 4 poll. longi, totidem diam. Tubus brevis viridis, squamulis inermibus rubris obsitus. Petala biserialia, exteriora reflexa, ignescentia, margine coerulescentia, interiora coccinea, apice obtusa. Stamina alba, antheris albis. Stylus coccineus, stigmatibus 8 albis.

$\delta$. Vandesii H, AvgI.

ع. ignescens H. Dresd.

५. Guillardieri.

$\eta$. Curtisii.

9. Roydii.

¿. Devauxii.

x. Lothii.

ג. Kiardi.

$\mu$. coccineus grandiflorus.

v. unduliflorus.

క. Hugenia.

o. May fly.

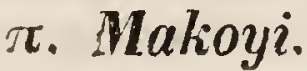




\section{९. aurantiacus.}

Omnes hae varietates, in diversis hortis ortae, neque structura, neque floribus, valde variantibus, inter se sufficienter distingui possunt.

\section{б. albiflorus?}

x. grandiflorus. - $\mathbf{E}$ foecundatione cum $\boldsymbol{C}$. grandifloro ortus. Rami nonnulli $5-6-$ goni, parce aculeati. Flores hucusque ignoti.

\section{9\%. C. Schrankii Zucc.}

Cer. formosus Catal. Cact. Monac. 1834. - Otro's GZ. 1834. No. 31. S. 244.

\section{$\mathrm{Pa}$ : Mexico (Sultepec Zimapan.).}

C. suberectus ramosus; ramis 3-4-gonis viridibus longis gracilibus divergentibus; costis subacuatis repandis; areolis remotis convexis, albo-tomentosis; aculeis $6-8$ rectis, rigidulis, fulvis, fasciculatis, inaequalibus; setis nonnullis, interdum deciduis, in parte inferiore areolae.

Rami bipedales, $5-6$ lin. diam. Areolae $1^{1 / 2}-2$ poll. distantes. Aculei $2-3$ lin. longi, setae $1-2$ lin. Differt a $C$. speciosissimo, praeter florem, ramis gracilioribus, areolis multo remotioribus, aculeis pancioribus fulvis et setis.

Flores C. Ackermanni simillimi minus expansi, igneo-coccinei, nusquain coerulescentes. Tubus rectus, 2 poll. longus, areolato-spinosus. Corolla 6 poll. diam. Petala intima 1 poll. lata, lanceolato-acuta, nervo saturatiore. Stamina rubella, antheris albis. Stylus exsertus coccineus, stigmatibus 8 elongatis albis.

\section{C. coccineus Saty.}

Cer. bifrons Haw. suppl. p. 76 ?

Pa: Mexico.

C. quadrangularis erectus, ramis saepius decumbentibus; radiculis longis filiformibus ( $H_{A} W_{\text {. }}$ ).

C. diffuso-suberectus ramosus 3-4-angularis; costis dentatis; areolis prominentibus albis subtomentosis; aculeis 4-6 supremis brevissimis acicularibus brunneis, inferioribus $4-8$ longioribus setaceis.

Articuli pedales, 3/4 poll. diam., saepe decumbentes. Areolae 6-8 lin. distantes. Aculei 1, setae 3 lin. longae. Radiculae numerosae, filiformes.

Flores coccinei, 6 poll. diam. Tubus $1 \frac{1}{12}$ poll. longus, viridis, areolato-spinosus. Petala biserialia, lanceolata, acuminata, intima 




\section{3}

3 poll. longa, 9 lin. lata, coccinea, margine coerulescentia. Stamina filiformia rubra, antheris albis. Stylus coccineus, stigmatibus 7 albis.

\section{S. \%. Alati.}

Epiphyllum Herм. par. bat. add. (ex Dirx.) - Haw. syn. p. 197. Suppl. p. 84. - Phyllanthus Neck. elan. 1. p. 85. - Cerei alati DC. prodr. III. p. 469. (excl. spec.) - Hort. Dyck. p. 339.

Caule ramoso ramisque oblongis, basi attenuatis teretibus, superne membranaceo - dilatatis, compressissimis, dipteris, ad margines crenatis.

Hawortur genus: Epiphyllum, Cactẹas omnes caule compresso et alato continens, si characteres botanicos consideremus, statui non potest. Nam forma caulis et ramorum hic decidere non potest, sed florescentia, quare Epiphylla floribus tubulosis ad Cereos, floribus rotatis ad Rhipsalides referenda suut. Cachus truncâtus autem receptaculo nudo a Cereis satis diversus, proprium genus evidenter format, cui nomen: Epiphyllum aptissime servandum videtur.

\section{C. Ackermanni H. BenoL.}

Epiphyllum Ackermanni Haw. (philos. magaz. Aug. 1829.) - Bot. regist. t. 1331.

Pa: Mexico.

C. diffuso-ramosus; ramis laete viridibus elongatis, parte inferiore teretibus, superiore alatis membranaceis, tuberculato-crenatis; crenarum interstitiis valde sinuosis; ramis nonnullis basi $3-4$-angularibus, repandis, setosis.

Flores e crenis lateralibus plerumque mense Majo et Junio, rarius Novembri, coccinei, 5-6 poll. diam., per plures dies aperti. Tubus $1 \frac{1}{2}$ poll. longus, viridis, glaber, squamis paucis inermibus rubellis instructus. Sepala pauca angusta fuscidula. Petala 12 latiora, igneo-coccinea, acuminata. Stamina basi alba, superne rubra, antheris albis. Stylus stamina aequans, rubellus, stigmatibus 8 albis. - Fructus ovi columbini magnitudine, glabri, purpurei.

Varietatibus Cerei speciosissimi hybridis haud dissimilis, tamen ramis tenuibus, minime carnosis, florisque tubo inermi ab omnibus diversus. 


\section{C. phyllanthoides DC.}

Cactus phyllanthoides DC. catal. h. monsp. 1813. p.84. - Cactus speciosus Bompr. nav. t. 3. - Hers. mex. 292. f. 3, et t. 45\%. - Pluk. phyt. t. 24\%. f. 5. - Herb. amat. t. 244. - Allg. teutsch. Gartenmag. I. 1815. S. 154. Botan. magaz. t. 2092. - Botan, regist. t. 304. - Cactus alatus WILLD. enum. suppl. 35. - Colla hort. ripul. t.20. - Epiphyllum speciosum HAw. suppl. p. 84. - Cactus elegans Link enum. 2. p. 25. - DC. revue p. 59. Epiph. phyllanthoides Hort.

Pa: Mexico.

C. diffusus ramosissimus; ramis vetustioribus caules teretes ligneos formantibus; articulis junioribus e basi attenuata vel ex apice ramorum, omnibus perviridibus, foliaceis, sinuato-crenulatis.

Hanc speciem pulcherrimam et ob florum copiam, facilemque culturam ab amatoribus nume undique cultam, Cl. Bompland cum C. specioso confudit, et sub loc nomine descripsit. Cl. Willde now eam pro Cacto alato $\mathrm{S}$ wartzii habuit, unde nomen vulgare, sed, errore mox detecto, Cl. Link nomen ei tribuit $C$. elegantis. Servandum tamen est nomen Cerei phyllanthoidis.

Flores a primo vere ad autumnum usque copiosi e crenis ramorum, 4 poll. Iongi, rosei; per plures dies aperti. Tubus viridis inermis; $1 \frac{1}{2}$ poll. Iongus, squamulis parcis rubellis retroflexis obsitus. Petala exteriora saturate rosea, acuminata, expansa, illteriora initio albida, sensim rubescentia, longiora, tubum formantia limbo pollicari. Stamina tubi orificio affixa, fasciculata, alba, antheris erectis albis. Stylus gracilis albus, staminibus paulo longior, stigmatibus 5-8 albis. - Fructus, $4-6$ menses ad maturitatem requirens, initio corollae reliquiis coronatus, tunc apice nudus, obtusatus, ovatus, $1^{1 / 2}$ poll. longus, $3 / 4$ poll. diam., obscure purpureus, nitidissimus, costis nonnullis apice areolatis et setiferis instructus. Semina in pulpa succulenta purpurea copiose dissiti.

B. albiflorus. - Num vera, num hybrida varietas?

\section{C. oxypetalus DC.}

Epiph. oxypetalum Hont.

Revue p. 60. t. 14.

Pa: Mexico, Guatimala. 



\section{5}

C. suberectus diffusus (interdum parasiticus), ramis clongatis crassiusculis, crenatis.

Flores (ex D e Candollii icone et descriptione) 4 poll. longi, extus fusco-rubentes, intus albidi. Bacca rubra oblonga costata, utrinque attenuata.

\section{C. latifrons ZuCCAR.}

Epiphyllum latifrons $\mathbb{Z} u c c$.

Pa: Mexico.

C. ramis viridibus magnis foliaceis, apice obtusis; marginibus parum et remote crenatis, potius undulatis.

Flores insignes e crenis apici proximis, albidi, expansi 6 poll. diam. Receptaculum viride, 4 lin. crassum; tubus 6 poll. longus, nudus, fusco-rubens, subsulcatus, parcissime squamulosus. Sepala linearia rosea, petala latiora, extus virentia, margine subrosea, intus alba. Stamina alba, antheris oblongis flavis; stylus paulo longior, coccineus, stigmatibus 8 flavis.

\section{C. Hookeri H. BeroL.}

Epiphyllum Hookeri Haw. (philos. magaz. Aug. 1829.) - Cer. Plyyllanthus flore majore DC. prodr. III. p. 469. C. Phyllanthus Hook. bot. magaz. t. 2692. - Cer. marginatus Salm (Hort. Dyck. p. 340.).

Pa: Brasilia, Demerary.

C. ramis latis elongatis, erectis, irregulariter sinuatocrenatis, laevibus, saepe margine rubro cinctis (SALM.).

Floret noctu mense Junio - Octobri, odorem exhalans Cerei grandiflori, sed multo debiliorem. Receptaculum 1 poll. longum, 5 lin. diam., albido-virens, angulis 5 subacuatis, squamis brevibus purpureis obsitum. Tubus 6 poll. longus, flavo-viridis, nudus. Sepala pollicaria coccinea. Petala lanceolata, 2 poll. longa, 4 lin. lata, nivea, exteriora pallide virentia, dorso rubella, apice purpurascentia. Stamina omnia tubi orificio affixa, filiformia, alba, antheris erectis, 3 lin. longis, griseo-sulphureis. Stylus coccineus, basi albus, $71 / 4$ poll. longus, 1 lin. crassus, stigmatibus 11 semipollicaribus flavis.

\section{C. Phyllanthus DC.}

Epiphyllum Phyllanthus Haw. syn. p. 197. Suppl. p. 84. - Cactus Phyllanthus L. - Cereus Scolopendrii folio brachiato Dill. h. elth. 73. t.64. f. 94. - Phyllanthus americana, sinuosis foliis longis Puuck. alm. 296. t. 247. f. 5. 
- Opuntia Phyllanthus Milu, dict. ed. 8. n. 9.-DC. pl. gr. t. 145.

\section{Pa: Brasilia, Surinam, Guadeloupe.}

C. prolifer ensiformi-compressus serrato-repandus (Linn.).

C. caule suberecto; ramis diffusis longissimis foliaceis, viridibus (junioribus saepe rubro-marginatis), marginibus irregulariter undulatis et incisis.

,Flores noctu explicantur, interdiu clausi sunt, nec una vice plus explicantur. Odcrem spirant florum benzoes debiliorem. Mensibus Aug. et Septemb. gemmae nascuntur ab initio squamosae. Tubus pedalis incurvus e viridi albicans, hinc inde ligulis aliquot praeditus, corolla ex herbaceo albicans, petala 19-20, exteriora longiora et latiora. Stamina plurima, antheris fuscis; stylus multifidus. Fructus maturus dilute puniceus, octo angulis extantibus praeditus, apice nudus, floris vestigiis non remanentibus, hinc inde squamulatus ${ }^{66}$. Corolla $15-16$ lin. diam.

Quamvis haud raro in hortis florere soleat, florem observare hucusque mihi non contigit, quare Dillen $i$ verbis usus sum. 



\section{Rpiphyluum.}

Haw. syn. p. 197. excl. spec. Suppl. p. 85.

Char. gen. Sepala calyciformia, ovario nudo adnata, exteriora brevia, media longiora reffexa, intima petaliformia in tubum concreta, orilicio obliquo. Stamina filiformia (circa 100) media breviora receptaculo, exteriora longiora tubo affixa, limbo multo longiora. Stylus filiformis, stigmatibus paucis, vix expansis. Bacca et germinatio ignotae.

Frutices carnosi articulati, articulis alatis subtruncatis, subinermibus, apice tomentoso, interdum spinuloso ramosis et floriferis. Flores speciosi hiemales, forma singulari. Receptaculum pyriforme in sepala 8 vera brevia imbricata vircuti-rubella abiens; sequuntur sepala $\mathbf{5}$ vivide colorata, petaliformia, reflexa, tubi basi affixa. Orificium tubi obliquum ex 9 petalis compositum, quorum 4 suprema suberecta, 5 inferiora maxime reflexa.

\section{F. trunculum HaW.}

Suppl p. 83. - SALar observo botan. 1891. p. 40. Cer. truncatus DC. prodr. III. p. 480. - Cactus truncatus Link enum. p. 24. - Botan. regist. t. 696. - Botan. magaz. t. 2526. - Hook. exot. fl. t. 20. - LoDd. bot. cab. t. $120 \%$. - Reichend. fl. exot. 325.

Pa: Brasilia.

E. suberectum, ex apice, rarius e crenis lateralibus articulorum ramosum; articulis oblongis viridibus. (saepe margine purpureis) compresso-foliaceis denticulatis, basi angusta insertis, apice truncato tomentoso.

Articuli $1^{1 / 2}-2$ poll. Iongi, $10-11$ lin. lati, post florescentiamp plerumque decidui.

Flores mense Decembri solitarii, rarius gemini, ex apice articulorum, 21/2 poll. longi, per plures dies aperti. Receptaculum nudum, crassum, ovatum, viride, margine modo rubro. Folia calycinalia igneo-coccinea, reflexa; tubus roseus; petala limbum formantia acuminata, basi rosea, apice et marginibus igneo-coccinea, superiora suberecta, inferiora patentia. Stamina ex órificio lubi rubro-marginato, 4 lin. diam., longe prominentia, fasciculata 
alba, antheris flavidis. Stylus staminibus longior purpureus, stigmatibus 5 rubris, parum expansis.

Trunco Opuntice brasiliensis inserta haec species et sequens laetissime viget, articulos profert majores et crassiores, moxque flores oriuntur copiosi et perfectissimi.

$\beta$. coccineum. - Articulis minoribus, ovalibus, vix undulosis. - Flores mihi ignoti.

$\gamma$. aurantiacum HoRT.

\section{E. Altensteinii Prri.}

Cer. truncatus Altensteinii H. Beror. - Epiphyllum truncatum multiflorum HonT.

Pa: Brasilia.

E. suberectum articulato-ramosum; articulis oblongis subcarnosis laete viridibus, longe dentatis, apice profunde sinuato,

Articuli 2 poll. et ulíra longi, 8-10 lin. lati, dentibus usque 5 lin. longis. Differt ab E. truncato (praeter florem) articulis longioribus, crassioribus et magis dentatis.

Flores mensibus Novembri et Decembri copiosissimi (jam in plantis novellis) e sinu articulorum terminalium, $2-2^{1 / 2}$ poll. longi. Receptaculum nudum, conico-oblongum, roseum, margine superiore dentatum. Folia calycinalia saturate rosea. Petala acuminata, apice coccineo - rosea, tubum formantia pallide roseum, fere album; orificium tubi purpureo-narginatum, obliquum, limbi petalis superioribus erectis, inferioribus retroflexis. Stamina corolla longiora, alba, antheris sulphureis. Stylus staminibus brevior, filiformis, coccineus, stigmatibus $5-6$ rubris, vix expansis. 



\section{Rmipsalus.}

Gärtn. fi. 1. p. 136. - Haw. syn. p. 186. - DC. prodr. III. p. 4\%5. - Hariota Adans. fam. 2. p. 243.

Char. gen. Calycis tubus ovario adhaerens laevis; limbus superus 3-6-partitus brevis, dentibus acuminatis membranaceis. Petala 6-8 oblonga patula, calyci inserta. Stamina 12 - 30, petalis basi affixa. Stylus filiformis. Stigmata 3-6 patula. Bacca pellucida subrotunda, calyce marcescente coronata. Semiua intra pulpam nidulantia, exalbuminosa, radicula embryonis crassa, cotyledonibus 2 brevibus acutis (DC.).

Frutices pseudo-parasitici, in patria plerumque super arbores orti, saepius penduli, subaphylli, ramosi, teretes, costati aut alati, subnudi squamulosi, aut setas minimas gerentes, fasciculis tunc ordine quincunciali dispositis. Flores laterales, seșsiles, parvi, albidi. Baccae (fere Visci) albae, pellucidae, plerumque globosae, rarius compressoangulosae.

Hoc genus ab Adpansonio primum institutum est sub nomine ,Hariola6". Deinde a Gäkineno sub nomine ,Rhipsalis" descriptum, nomenque ab Hawortwio servatum est. Cl. Insk plantas ad hoc genus pertinentes: „Cactos tereles $^{65}$ nominavit. $\mathrm{Cl}$. De Candolde ex hoc genere tribum II Cactearum format, axin centralem statuens in baccis, cui ovula ideoque semina affixa sint.

Sed hic axis non existit, seminum vero insertio reliquis Cacteis omnino analoga est *). Quamobrem suadente Ill. Pr. a Salm-Dyck locum aptiorem generi dedimus, et ob analogiam florum conspicuam Cereos alalos flore rotalo (Hort. Dyck. p. 66.) cum Rhipsalidibus conjunximus. Rhipsalidem salicornioidem autem cum Cl. De Candolle (mémoire p. 23.) ob characterum botanicorum diversitatem a genere nostro separavimus, et Hariolam DC. (nec Adans.) assumsimus.

*) Ill. Pr. a Sa $1 \mathrm{~m}-\mathrm{D}$ y ck in: Otto's GZ. 1836. No.19. S.146.-. Pfeiffer in: Otto's GZ. 1836. No. 24. S. 185. 


\section{0}

\section{S. 1. Alatae.}

Trunco terete vel alato, ramis compressissimis, dipteris, foliaceis, crenatis.

1. R. crispata PrR.

Epiphyllum crispatum HAw. - Cer. crispatus H. Berou. Pa?

R. suberecta articulata; ramis (plurimis ex apice, rarius e crenis lateralibus articulorum) orbicularibus vel oblongis, subpetiolatis, flavido - viridibus, fere membranaceis, profunde crenatis, margine crispulis.

Floret mense Decembri. Flores minuti, albidi, parum odorati. Ovarium minutum nudum, lobi calycinales brevissimi. Petala 6 ovata, reflexa, virescenti-albida. Stamina numerosa alba expansa, antheris pallidissime sulphureis. Stylus albus, staminibus crassior et longior, stigmatibus 3 angulato-expansis. Bacca aestate maturescens, globosa, alba, pauca continens semina.

B. latior Salm. Articulis multo majoribus et latioribus.

2. R. rhombea PFr.

Cer. rhombeus Salm (Hort. Dyck. p. 341.). - Cer. crispatus crenulatus H. BERoL - Cactus torquatus H. LuGD. - Epiphyllum crenulatum, rhombeum HoR'.

\section{$\mathrm{Pa}$ ?}

R. caule ramulisque suberectis, articulatis, diffusis; articulis breviusculis alatis foliiformibus, ovato - aut lanceolato-rhombeis, glaberrimis, nitidis, apice proliferis, ad margines inciso-crenatis.

Caulis teres aut varie compressus, a basi ramosus, ramulis subdichotomis diffusis suberectis, apice recurvulis; articuli $1-3$ poll. longi et $12-15$ lin. lati, parum carnosi, concaviusculi, basi subcuneati, medio rhombeo-dilatati, apice obtusiusculi, laevissimi, margine rubro cincti. - Flores solitarii parvuli rotati viride-albidi, sicut in sequente.

\section{3. $\boldsymbol{R}$. ramulosa PrR.}

Cer. ramulosus Salm (Hort. Dyck. p. 340.). - Epiphyllum ramulosum, ciliare, ciliatum HonT.

$\mathrm{Pa}$ ?

R. caule ramisque suberectis, teretibus, hinc inde squamulatis, tandem lignosis; ramulis pendulis alatis laete 



\section{1}

viridibus (in planta novella ciliatis), anguste lanceolatis, ad margines remote crenulatis; crenis infimis squamula distincta foliacea instructis.

Caulis pedalis et ultra, 2 lin. diam., ramuli alati $3-5$ poll. longi, 6-12 lin. lati, crenis 6-10 lin. distantibus. - Flores solitarii e crenis ramorum frequentes, parvuli, expansi vix 3 lin. diam. Ovarium nudum oblongum; petala $7-8$ ovato-lanceolata, virescenti-albida. Stamina $12-18$; stylus filiformis, stigmate inconspicuo. Bacca rotunda, primum viridis, dein alba subdiaphana, $2^{1 / 2}-3$ lin. diam., squamulis $2-3$ concoloribus quasi cicatriculata et corolla marcescente coronata. Semina parvula nigra, versus medium baccae collecta.

\section{R. platycarpa PFR.}

\section{Epiphyllum platycarpum Zucc.}

\section{Pa: Brasilia.}

R. alata; ramis sinuato-crenatis viridibus (interdum margine rubente), crenis junioribus luculenter squamatis.

Articuli $4-8$ poll. longi, $1 \frac{1 / 2}{2}$ lati, ramis C. Phyllanthi similes, crenis minus remotis.

Flores prope apicem, 8 lin. longi, sordide albidi. Receptaculum subtetragonum viride, cristis obtusis rubentibus. Corolla vix aperta; petala ovata, 4 lin. longa. Stamina alba; stylus vix longior, stigmatibus 5 subulatis patentibus albis. Bacca nuda, virens, compresso-angulosa.

\section{R. Swartsiana PFr.}

Cactus alatus SwARTz fl. Ind. occ. p. 878. - Cer. alatus DC. prodr. III. p. 480. - Epiphyllum alatum HAw. suppl. 84 ?

\section{Pa: Jamaica.}

C. ramis foliaceis petiolatis ensiformibus crenatis; floribus sessilibus parvis albidis (SpRgu.).

C. tubo brevissimo, floribus ad crenas ramorum sessilibus, bacca nigrescente (DC.).

R. alata diffusa; ramis foliaceis obscure viridibus, ovalibus vel ensiformibus, profunde crenatis, inermibus.

Flores mense Februario solitarii, rarius bini vel terni e crenis apici articulorum proximis, inodori, albi, $7-8$ lin. diam., Rhips. funalis simillimi. Sepala $3-4$ brevia, ovario nudo brevi affixa, virescentia. Petala 5-6 ovalia, acuminata, virescenti-albida. Stamina numerosa, stylusque 4-partitus filiformia, alba. Baccae nobis nunquam hucusque maturuerunt. 


\section{2}

6. R. pachypter $\boldsymbol{\text { PFR. }}$

Cereus alatus Link et Oтто icon. t. 39. - Ep. alatum Haw. suppl. p. 84.-Cactus alatus Botan. magaz. t. 2820.

$\mathbf{P a}$ : India occidentalis.

E. articulis grosse nervosis, obtusatis, floribus sessilibus ad crenas ramorum, tubo brevissimo (L. et 0.).

R. suberecta, alata vel triptera; ramis expansis magnis viridibus, rubro-marginatis, subrotundis vel elongatis, apice attenuatis, nervosis, carnosis, tuberculato-crenatis, inermibus, rarius subciliatis, interdum e nervo medio bifarie radicantibus.

Caulis saepe basi teres, Articuli crassi, plani, saepe 4-6 poll. diam., alii tripteri, elongati, Cereo triangulari valde similes, tamen cristis acutioribus, incisis, inermibus, $4-5$ poll. longi, $2-3$ diam.

Flores hiemales copiosissimi albidi, suaveolentes, 1 poli. diam. Ovarium subglobosum, 2 lin. longum et crassum, laeve; petala $5-6$ ventricosa, $4-6$ lin. longa, $2-3$ lata, virescenti -alba. Stamina numerosissima alba, stylo albo 4 -partito vix breviora.

B. crassior Salm. - Articulis viridibus, orbicularibus, crassicribus, subrigidis.

\section{S. 2. Angulosue.}

Trunco suberecto costato, costis squamato-areolatis.

\section{R. pentaptera PFr.}

Oтто's GZ. 1836. No. 14. S. 105.

Pa: Brasilia,

R. suberecta, longe articulata, perviridis; caule 5-6gono, ramis gracilibus subtortis 5-gonis; sinubus profundis; costis membranaceo-compressis et interruptis; areolis remotis; crenulis costarum junioribus tomentosis, folioloque acuminato squamaeformi suffultis, inermibus.

Planta in horto Berolinensi Februario et Martio 1836 florifera 11/2 ped. alta, trunci pars infima digitum crassa; rami laterales non fasciculati, fere semipedales; areolae 1-2 poll. distantes. Flores copiosissimi e crenis ramorum et trunci partis supremae, plerumque terni, in apice ramorum fasciculati. Calyx receptaculo adnatus, 2 lin. longus, ovalis, margine brevissimo quadrifido. $\mathrm{C}_{0}-$ rolla alba, expansa $1 / 2$ poll. diam. - Petala $6-7$, hiserialia, ex- 


teriora breviora albida, vix fuscidula, pellucida, interiora 3 alba, 3 lin. longa, $1-1 \frac{1}{2}$ lin. lata, obtusa. Stamina numerosa (plus quam 30), corolla paulo breviora, alba, antheris albis. Stylus petalis vix longior, stigmate 4-lobo, lobis brevibus, ovatis, conniventibus. - Baccae mense Julio maturae, subglobosae, diaphane albae, 3 lin. longae, corollae reliquiis coronatae, margine rubro.

\section{R. trigona PFr.}

Pa: Brasilia.

R. suberecta subarticulata, laete viridis, trigona; sinubus planis; costis acuatis; areolis subconfertis, parce tomentosis, squamula viridi, mox marcescente, suffultis.

Truncus 4-6 lin. diam. Areolae 2-4 lin. distantes. Flores hucusque ignoti.

Num forsan Lepismii species?

\section{R. micrantha DC.}

Prodr. III. p. 476. - Cactus micranthus KunTH syn. pl, aeq. III. p. 369.

Pa: Quito (in arboribus prope Olleros.).

R. pendula glabra ramosa; ramis 3-4-angularibus vel compresso-ancipitibus; floribus ex angulis ortis.

Flores albi minuti.

\section{S. 3. Teretes.}

Caule ramisque teretibus, glabris, inermibus, vel parce pilosis.

\section{R. Cassytha Gärtn.}

Sem. I. 137. t. 28. f. 1. - HAw. syn: p. 186.-Cactus pendulus Swartz fl. Ind. occid. p. 876. - Kunth syn. pl. aeq. III. p. 369. - Cassytha baccifera Miru. dict. Botan. magaz. t. 3080. - DC. revue p. 80. - Rhips. pendula Hont.

Pa: Jamaica, Hispaniola (in ramis arborum).

R. caule erecto, tandem lignoso; ramis gracilibus, viridibus, teretibus, pendulis, magis minusve verticillatis, remote squamulatis, apice obtusis.

Truncus tandem 4-5, ramuli $1-2$ lin. diam., plerumque 


\section{4}

ex apice vetustiorum, rarius ex areolis lateralibus provenientes, 8-12 poll. longi, penduli.

Flores mense Februario, et altera vice Julio, minutissimi, albidi, 4 lin. longi, expansi 2 lin. diam. Receptaculum nudum, 11/4 lin. longum. Folia calycinalia 6 viridia. Petala $6-7$ albida, apice viridia. Stamina alba, stylum 4-partitum album aequantia. - Baccae oblongae, primum virides, tunc diaphane roseae, tandem cereo-albidae, cicatriculis perpaucis rubris notatae et corollae reliquiis coronatae, semina continentes pauca in centro baccae nidulantia.

c. Swartsiana DC. - Antill. - Stigmata 3-6. Bacca secundum Swartz quasi sexlocularis.

B. Hookeriana DC. (Hook, exot. fl. t. 2.) - Mexico? - Calyx 4-partitus, petala 4, stigma 3-partitum, semina $12-20$.

r. Moçiniana DC. revue t. 21. - Mexico. - Calyx e lobis 3 acutis, petala 6 , stigma 3 -partitum, semina 6 .

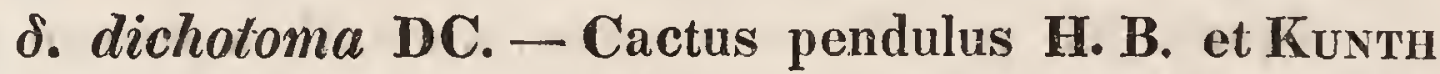
nov. gen. am. 6. p. 65. - Nova Andalusia et Nova Granada. - Rami dichotomi, non verticillati, calyx 3-partitus, petala 6, semina 30-40, bacca Ribis Grossulariae.

E. Mauritiana DC. - Cactus pendulinus Sieber fl. maurit. 2. n. 2599. - Isle de France et Isle Bourbon. Repens, ramis confertis articulatis.

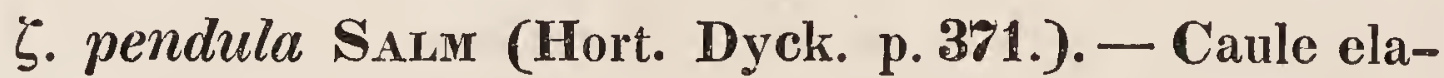
tiore, ramulis numerosioribus, flaccidioribus et undique arcuatim dependentibus.

\section{R. floccosa Salm.}

Rh. Cassytha $\beta$ major Hort. Dyck. p. 371. Pa?

R. suberecta; ramis pendulis (non fasciculatis) crassitie pennae cygneae, rugulosis; areolis sparsis, squamula suffultis, nudis, floriferis lanatis.

Differt a $\boldsymbol{R}$. Cassytha ramis duplo crassioribus et rugulosis (nascentibus valde squamosis), floribus duplo majoribus, petalis lanceolatis et areolis lana persistente instructis. - Floret hieme et Junio. Flores 1-2 successive e singulo fasciculo lanato enascuntur, albidi, expansi 6 lin. diam. Sepala $6-7$ in tubum brevem connata, duobus minutissimis et $5-6$ petaliformibus erecto- 



\section{5}

patulis albidis aut virescentibus, germini immersa. Stamina (circa 16) uniserialia. Stylus albus, staminibus longior, stigmatibus $3-4$.

- Bacca ignota.

Haec species squamis valde conspicuis, floccis pilosis, floribus subtubulosis et pluries ex eadem areola provenientibus ad Lepismia proxime accedit; quare his forsan adnumeranda?

\section{2. $R$. funalis SALM.}

DC. prodr. III. p. 476. - Cactus funalis Sprat. syst. I. p. 479. - Rhipsalis grandiflorus HAW. suppl. p. 83. Revis. p. F1. - Botan. magaz. t. 2740. - LiNK et Oтто icon. t. 38. - Rhips. calamiformis HonT.

Pa; Amer. merid.

R. erectiuscula ; ramis longis teretibus obtusis, obscure viridibus, subglabris; areolis sparsis subnudis, squamula purpurascente, mucronulata suffultis.

Truncus $2-3$ ped. altus, tandem lignosus $6-10$, rami $3-4$ lin. diam. Flores copiosisșimi mensibus Februario - Aprili (interdum altera vice Julio), albidi, expansi circa 10 lin. diam., inodori, basi pube minuta cincti. Petala $7-8$ lanceolata, obtusa, virescenti-alba, ovario brevi nudo affixa, tandem reflexa. Stamina numerosissima alba; stylus vix longior, albus, stigmatibus 4 angulatis. - Fructum nunquam vidimus.

B. minor. - Rhips. Cassytha $\delta$. pilosiuscula SAly (Hort. Dyck. p. 228.). - Ramis gracilioribus, areolis squamula rubra distincta et setis albis instructis.

\section{R. fasciculaía Haw.}

Suppl. p. 83. - Cactus parasiticus Linn. - LAMr. dict. 1. p. 541.-DC. pl. gr. t. 59. - Cactus fascieuleius WiLLD. enum. suppl. 33. - Rhips. parasiticus HaW. syn. p. 187. - Botan. magaz. t. 3089. - Turp. observ. p. 63. t. 3.

$\mathrm{Pa}$ : Ins. Carib.

C. repens teres striatus muticus (LinN.).

R. ramis pendulis verticillatis teretibus viridibus, junioribus subpilosis, pilis albis fasciculatis; fasciculis ordine quincunciali dispositis (HAw.).

R. repens ramosa; ramis fasciculatis, viridibus, teretibus, parcissime setosis, junioribus spiraliter subangulosis, rubentibus; areolis subconfertis, squamula minutissima purpurea, pilisque 4-6 mollibus albis instructis. 


\section{6}

Rami 2-3 lin. diam. - Flores copiosi, Rh. Cassythae simillimi, sed minores, $1 \frac{1}{2}$-lineares. Petala 5 oblonga, obtusa, sordide flavescentia. Stamina 15-18; stylus 3-partitus. Bacca matura alba, corollae reliquiis coronata, semina continens minuta nigra. - Delineatio baccae in Turpini observ. omnino falsa!

\section{R. undulata Prr.}

Opuntia minima flagilliformis Puur. catal. 6.-Tourn. 240.-Plum ed. Bury. p. 190. t. 197. f. 2. - Rh. parasitica DC. prodr. III. p. 476.

Pa: Insul. Carib.

Cactus inermis, aphyllus, ramosus; ramulis gracilibus, compressis, articulatis, dichotomis et trichotomis, undulatis (Plum.).

Flosculi ad ramorum supremam partem, Rh. Cassythae similes. - Fructus videntur conuli obtusi et quasi truncati.

Species e Plumieri opere non satis nota!

\$. 4. Articuliferae.

Caule elongato, ramoso, articulis minutis lateraliter instructo.

\section{R. mesembrianthoides Haw.}

Revis. p. 71. - Rh. salicornioides $\beta$. Haw. suppl. p. 83. - Botan, magaz. t. 3078. - Rh. echinata HorT.

$\mathrm{Pa}$ : Amer. merid.

R. glomerato-ramosa ; ramis suberectis teretibus strictis, radicantibus, articuliferis; articulis lateralibus confertis teretibus, utrinque attenuatis, nebulosis; fasciculis setarum capillacearum albis, pallidis, demum mortuisve nigris (DC.).

Rami 8-10 poll. longi, $1-\mathbf{1}^{1 / 2}$ lin. diam.; articuli $4-8$ lin. longi. Flores ex articulorum lateribus mensibus vernalibus nascentes, albi, 1'a poll. diam. Ovarium oblongum, nudum, superne denticulatum, pallide virens. Petala 5 ovato-acuminata, patentissima. Stamina expansa alba, antheris minutis. Stylus erectus, stigmatibus compressis. - Bacca alba. 




\section{7}

\section{6. $R$. Cereuscula Haw.}

Philos. magaz. 1830. p. 109.

Pa: Brasilia.

R. subflexuose scandenter radicans, articulata; ramis exiguis subfasciculatis quadrangularibus, setarum radiis interradiis longioribus, criniformibus, expansis.

Rhips. mesembrianthoidi similis, sed duplo altior, minus ag. gregata, magisque angularis. 


\section{Lepismium.}

Pentefer in: Otro's GKa. 1835. No. 40, S. 314. 1836. No. 24. S. 185.

Char. gen. Sepala ovario subnudo pyriformi adnata, in tubum brevissimum concreta, exteriora $4-5$ subimbricata, interiora $5-7$ petaliformia, lanceolata, acuta, recurvato-patula, alba vel rosea. Stamina filiformia pluriserialia, externa longiora, petalorum basi adnata, antheris minutis reniformibus. Stylus crassiusculus columnaris, staminibus intimis longior. Stigma 4-5-radiatum. Bacca subglobosa, laevis, calyce marcescente coronata. Semina in pulpa nidulantia. Cotyledones latae, acuminatac, foliaceac.

Frutices carnosi, axi ligneo praediti, elongati, articulati, saepe subradicantes, angulati; anguli 3-5 repando-crenati; crenae inermes, squamula, seu foliolo minuto acuto (marcescente, sed non deciduo) instructae. Areolae axillares (singulari modo in corticem plus minusve immersae) juniores nudae aut pilis perpaucis, seniores floriferae pilorum fasciculo instructae penicillatim collecto et e fissura in crenarum axillis egresso. Flores parvuli $2-3$ successive e singulo pilorum fasciculo enascentes, tubo omnino immerso, limbo solum exserto.

\section{L. commune Prr.}

Otтo's GZ. 1835. No. 40.- Cer. squamulosus Satim (DC. prodr. III. p. 469.) - Cer. elegans HorT.

Pa: Brasilia.

C. articulatus erectus subradicans, laete viridis, 3-angularis; costis valde compressis repando-crenatis, ad crenas squama ovato-acuta, pilisque numerosis albis instructis (DC. prodr.).

L. suberectum, articulatum, subradicans; articulis laete viridibus (saepe purpurascentibus) 3-angularibus, plerumque subtortis; sinubus latis; marginibus acutis obrepandocrenatis; crenis remotis, squama ovato-acuta foliacea suf- 

, 



\section{9}

fultis, in ramis primariis vix pilosis, in floriferis fasciculo denso pilorum cinereorum instructis.

Truncus pedalis et ultra, rami divergentes, $1^{1 / 2}-2$ poll. diam. Crenae 6-10 lin. distantes.

Florere solet per totam aestatem ad Decembrem usque, initio in ramis anni praecedentis, hiemem versus etiam in recentibus. Flores parvuli, $6-7$ lin. diam., tubo brevissimo, pilorum fasciculo immerso. Sepala $4-5$ virescenti-albida; petala $5-7$, lineari-obtusa, refiexa, primo die alba, secundo flavescentia. Stamina alba, antheris albis; stylus albus, vix longior, stigmatibus $4-5$, elongatis, retroflexis, virenti-albidis. - Baccae (inde a Januario maturae) compresso-globosae, $3 \frac{1 / 2}{2}$ lin. longae, 4 diam., glabrae, subdiaphane coccineae, corolla marcida coronatae, pulpa coccinea succulenta, seminibus paucis nigris in cavitate centrali collectis.

\section{L. Myosurus PrR.}

Cer. Myosurus SALM (DC. prodr. III. p.469.),-Cactus tenuis Schotт. - Cer. tenuispinus HAW. (philos. magaz. 1827.)

Pa: Brasilia.

C. (tenuispinus) debilis ramosus, subarticulosus, facile scandenter radicans; ramis gracillimis 3 -angularibus; setis tenuissimis flexis sublanaeformibus ( $\mathrm{H}_{\mathrm{A}} \mathrm{W}_{\text {. }}$ ).

L. diffuso-suberectum, subarticulatum; articulis elongatis gracilibus, 3-4-gonis; marginibus acutis crenulatis purpureis; crenulis subremotis, albo-pilosis, squamula foliacea suffultis.

Articuli saepe pedales et vitra, plerumque 4-5, interdum 8-10 lin. diam. Crenulae 1/2 -1 poll. distantes. - Flores mensibus Aug. - Novembri, parvuli, rosei, expansi 6 lin. diam. Sepala brevia, sordide rubella; petala lanceolata, acuminata, rosea, basi pallidiora. Stamina alba; stylus paulo longior ruber 4-partitus. - Bacca coccinea, 3 lin. longa, semina continens numerosa nigra.

\section{L. Knightii Pfr.}

Otт0's GZ. 1835. No. 48, S. 380. - Cer. Knightii Parment.

Pa: Brasilia.

L. suberectum subarticulatum, pallide virens; articulis divergentibus elongatis, 4-5-gonis; costis acuatis, 
subcrenulatis, junioribus purpureis; sinubus repandis ; areolis confertis, squamula minima suffultis, fasciculis densis pilorum alborum instructis.

Articuli pedales et ultra, 4-10 lin. diam., hinc inde constricti, saepe fasciculati. Crenulae 2-4 lin. distantes. - Flores (in horto Berolinensi Julio 1836 primum a me observati) sordide albidi, 10 lin. diam. Sepala fusca, petala albida pellucida, apice sordide rubella. Stamina brevia alba; stylus vix longior, albus, stigmatibus $3-4$.

\section{L. paradoxum Salm.}

Cer. pterocaulis Hon't.

Pa: Brasilia.

L. suberectum subarticulatum viride; articulis elongatis diversiformibus, plerisque interrupte trigonis, carnosis, internodiorum lateribus cum angulis compressis alternantibus; areolis remotis, squamula foliacea rubente, pilorumque alborum tenui fasciculo instructis.

Haec naturalis forma esse videtur, sed nonnulli articuli observantur multo graciliores, pentagoni, magis pilosi, sensim tamen in formam normalem transeuntes.

Num Rhipsalidibus adscribendum? 




\section{1}

\section{Hariota.}

DC. mémoire p. 23. nec Adans.

Char. gen. Calycis tubus brevissimus ovario adhaerens laevis, limbus superus submembranaceus cyathiformis truncatus, sepalis $4-5$ exsertis brevibus. Petala $7-10$ oblongo-lanceolata subacuta. Stamina cum petalis basi concreta. Stigmata 5 crassa erecta valde papulosa. Ovarium uniloculare, ovulis ad parietes affixis. Bacca albida, corollae reliquiis coronata. Semina nitida nigra. Germinatio ignota.

Fruticulus erectus ramosus articulatus, articulis ramorum inferiorum subangulatis, pilos fasciculatos parvos gerentibus, caulinis brevibus subcylindraceis, ramorum superiorum verticillatis, elongatis, basi contractis tenuissimis apice subclavatis. Flores terminales flavi solitarii aut gemini parce aperti.

A Rhipsalidibus, quibuscum unica hujus generís species nota hucusque conjungebatur, donec Cl. De Candolle eam ab illis separaret, non quidem seminum insertione, sed aliis characteribus, calycis sc. forma, petalorum numero et colore, florescentia terminali et ramorum constructione satis differt.

\section{H. salicornioides DC.}

Mémoire p. 23. - Opuntia salicornoides Sprac. Rhipsalis salicornioides HAw. succ. suppl. p. 83. - Link et Oтто icon. p. 49. t. 21. - Botan. magaz. t. 2461.

Pa: Brasilia.

C. (Rhips.) articulato-prolifer, ramis patulis, teretibus subangulatisque, spinis capillaceis minutissimis ( $\mathbf{L}$. et $\mathbf{O}$. l. c.).

H. erecta ramosa articulato-prolifera; articulis brevissimis obclavatis teretibus angulatisque pilis minutissimis, apice floriferis (DC. prodr. III. p. 476. sub Rhips.). 
Caudex circa pedem altus, ramosissimus, ramis semper ex apicibus subtomentosis pronascentibus, binis ternisve, nonnunquam pluribus verticillatis, inferioribus subangulatis, superioribus teretibus, 2-3 lin. diam. crassis, laete virentibus. Rami angulati pilorum alborum fasciculis in angulis instructi, reliqui basi contracti, unde clavati, nudi, foliorum rudimentis vix conspicuis. Flores mensibus Decemb. - Mart. copiosi ex apicibus ramorum, sessiles, solitarii aut gemini, inodori. Germen inferum, calyce coronatum ad basin 5-partito, laciniis lanceolatis reflexis, petalorum forma et magnitudine. Petala $7-10,6$ lin. longa, 2 lin. lata, ventricosa, acuta, aurantiaco-citrina, vix expansa. Stamina multa breviora, calycis margini inferiori inserta. Stylus brevis 4-5-partitus. - Baccas maturas mense Junio observavimus, subglobosas, pellucide albidas, vertice purpureo-marginatas, umbilicatas et corollam marcidam gerentes. Semina nigra parvula parietibus affixa. - Germinationem observare mihi non contigit.

B. ramosior Hort. Dyck. p. 228. - Ramulis numerosioribus, magis fasciculatis. 




\section{Opuntia.}

TOunNef, inst. 239. t. 12\%. - HAW. syn. p. 18\%. DC. prodr. III. p. 471. - Hort. Dyck. p. 358.

Char. GEN. Sepala numerosa ovario adnata foliiformia, summa plana brevia, intima petaliformia obovata, expansa, tubo supra ovarium nullo. Stamina petalis breviora, filamentis tenuibus, tactu subirritabilibus. Stylus cylindricus, basi constrictus. Stigmata 3-8 erecta crassa. Bacca ovata, apice umbilicata, tuberculosa, saepius spinifera. Embryo subspiralis, teretiusculus. Cotyledones semiteretes, germinantes foliaceae, planae, crassae. Plumula parva.

Frutices, trunco ramisque cylindricis aut compressoarticulatis, articulis ovatis aut oblongis, fasciculos aculeorum aut setarum, ordine quincunciali seu spirali dispositis, gerentibus. Folia subulata sediformia, caducissima sub quoque fasciculo juniore. Flores e fasciculis aut marginibus articulorum orti, flavi, rubri aut albi. Fructus minuti vel magni, virides, flavi aut purpurei, saepe ficiformes, edules, plerumque secundo vel tertio anno maturescentes.

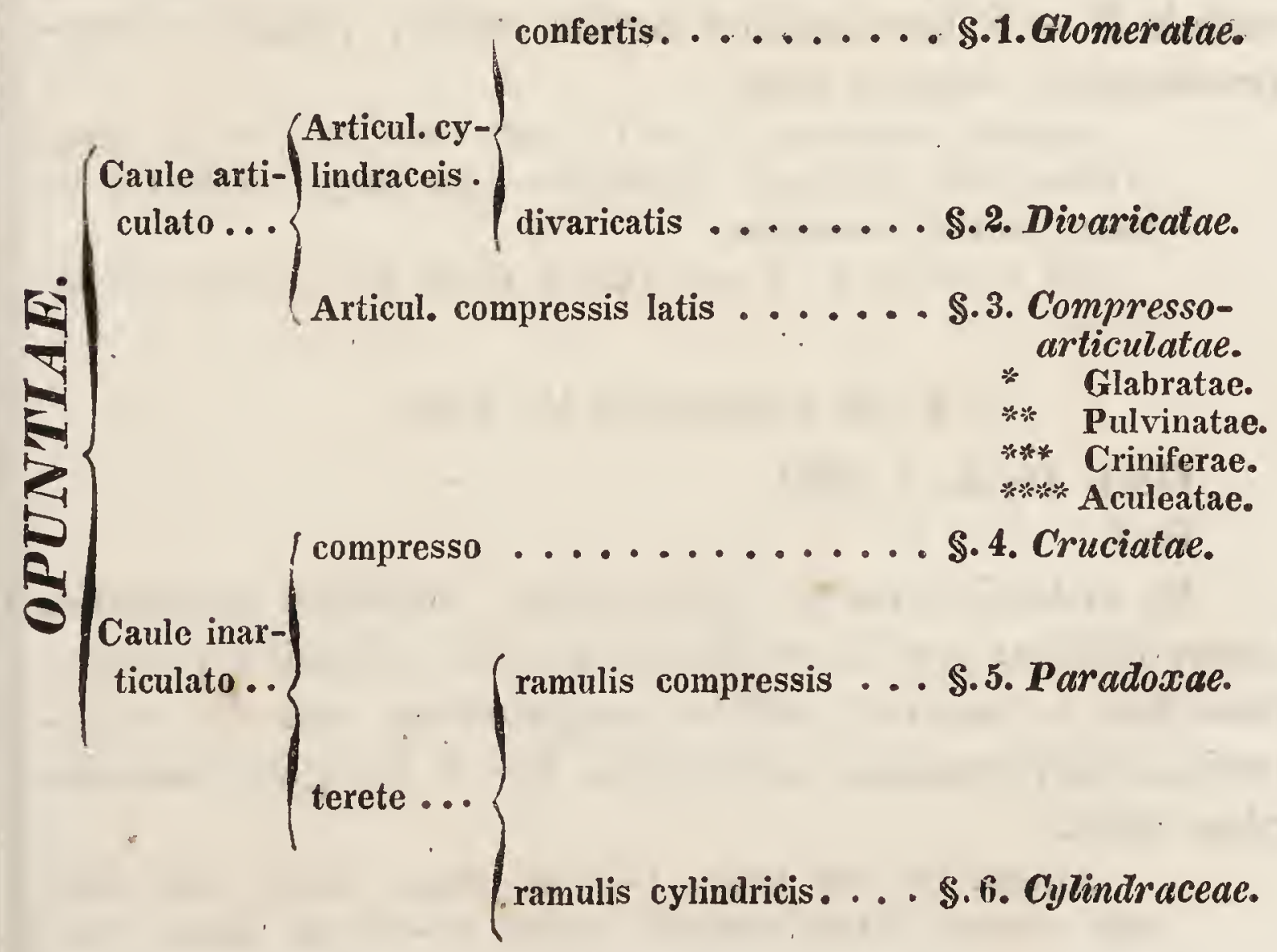




\section{4}

\section{S. 1. Glomeratae.}

Caule articulato, humili, articulis cylindraceis subglobosis vel ovatis, aculeis setaceis aut rigidis.

\section{O. sulphurea GiLl.}

Hort. Dyck. p. 360.

\section{Pa: Chile.}

0. articulis erectis subglobosis laete-viridibus; areolis subconfertis; aculeis biformibus e tomento pallido, superioribus setaceis atro - purpureis minutissimis, penicillatim collectis, inferioribus $6-12$ elongatis, acicularibus, albidis, apice purpureis, centrali longissimo.

Articuli 2 poll. longi, diametro fere sesquipollicari, crassi; areolae foliolo minutissimo, acuto, purpureo, mox deciduo, suffultae. Aculei minores, in suprema parte areolae collecti, atropurpurei, majores pollicem et ultra longi, aciculares, albidi aut pallide rosei, saepe purpureo fasciatim picti, cum apice atropurpureo. An flos sulphureus?

\section{O. ovata PFr.}

\section{Pa: Mendoża.}

0. articulis viridibus glabris ovatis; areolis approximatis, magnis, pulvinatis, densissime fusco-lanuginosis; aculeis -8 inaequalibus rigidis rectis, junioribus fuscescentibus, tandem albis.

Articuli oviformes, 11/4-11/2 poll. longi, $8-10$ lin. diam. Areolae 4 lin. distantes. Aculex̀ 2-5 lin. longi.-Foliola 1 lin. longa, viridia, subconica.

Ab O. ovata H. Angl. (Cereo ovato Pfr.) toto coelo diversa!

\section{O. corrugata H. ANGL,}

Hort. Dyck. p. 360.

$\mathrm{Pa}$ ?

O, articulis erectis cylindraceis, utrinque attenuatis, laeteviridibus; areolis confertis; aculeis biformibus, subradiantibus e tomento pallido, superioribus setaceis minutissimis fulvicantibus, inferioribus $6-8$ elongatis acicularibus albis.

Articuli 11/2 poll. longi, 4-6 lin. diam., erecti, facile decidui, nitentes, valde aculeati. Aculei 4-6 lin. longi. Folia 


parvula rosea. - Ab O. sulphurea differt articulis gracilioribus, magis oblongis, areolis confertis, aculeis tenuioribus, brevioribus.

\section{O. pusilla Saum.}

Observ. botan. 1822. p. 10.

$\mathrm{Pa}$ : America calid.

O. prostrata, divaricata, sordide virens; articulis cylindraceis cucumeriformibus; fasciculis spinarum approximatis; spinis setaceis albis, quibusdam elongatis erectis.

Articuli sesquipollicares, omnino cylindracei, nec compressi, 5-6 lin. diam., utrinque attenuati. Areolae approximatae; spinae inermes in apice articulorum elongatae, numerosae; tomentum albidum. Foliola lata brevia rubella.

\section{O. longispina HAw.}

Philos. magaz. 1830. p. 109.

Pa: Mendoza.

O. articulis compresso-teretiusculis; spinis purpurascentibus, aliisque minoribus fulvis, unaque tenui tereti, antiquissima triunciali.

Articuli $10-16$ lin. longi, glabriores et crassiores, quam $O$. pusillae. Aculei saepe $2-3$ inaequales, b-10 lin. longi. - Folia linearia fuscescentia.

\section{O. glomerata HAw.}

Philos. magaz. 1830. p. 109.

$\mathrm{Pa}$ : Mendoza.

O. ramis caespitose confertis; spinis centralibus solitariis linearibus acuminatis, utraque planis longissimis.

Ramuli sublanceolato - teretes, carne farctim crassi, subvirides, vix semunciam lati. Areolae ordinariae setis brevissimis densissimis uniformibus, unaque spina plus minus centrali cornea, corneoque colore, biunciali, vix flaccida, neque rigida, sed in arcum flexibili (Haw.). - Foliola minutissima fusca, squamaeformir Articuli vix pollicares.

\section{\%. O. andicola H. ANgL.}

0. horizontalis GiLI.

\section{Pa: Mendoza.}

O. prostrata ramosissima; articulis cucumeriformibus elongatis, apice attenuatis, brunneo-virentibus nitidis, tandem lignosis; areolis subconfertis setosis; acuelis $3-4$ 


\section{6}

gracilibus albis subrigidis, $1-2$ longioribus, albis, basi applanatis.

Articuli 4-6 lin. diam. Aculei infimi 11/2-2-pollicares. Foliola minuta brunnea.

\section{O. tuberosa H. Angl.}

0. alpina Gius.

$\mathrm{Pa}$ : Mendoza:

O. articulis cylindraceis; divaricatis, brunneis, imbricato-tuberosis; areolis minutis albis in tuberculorum vertice; aculeis $7-8$ brevibus setaceis albidis.

Articuli 2-3 poll. longi, 4 lin. diam. Foliola minuta brunnea.

B. spinosa. - O. platyacantha H. ANGL.-Aculeis pluribus et longioribus, nonnullis applanatis.

9. 0 . mesacantha NuTT.

Seringe bullet. 1831. p. 216. - Linnaea VII. Lit. S. 81 .

\section{Pa: Kentuky.}

0. humilis decumbens; articulis subrotundis; spinulis fasciculatis rufescentibus, spina centrali fuscata longiore.

Calyces fructusque ovati, solitarii, squamis carnosis spinosis; flores lutei.

\section{O. caespilosa NutT.}

Seringe bullet. 1831. p. 216. - Linnaea VIII. Lit. S. 81 .

\section{Pa: Kentuky.}

O. humilis caespitosa; articulis obovatis concavis; spinulis fasciculatis minutissimis rufis, retrorsum barbatis; spina centrali longissima.

Calyces aggregati subpedicellati turbinati, fructus oblongi unciales, spinuliferi, cute crassa, intus viscida.

\section{O. humifusa NutT.}

Num uni praecedentium aequalis?

\section{S. 2. Divaricatae.}

Caule articulato, humili ant subelato, articulis subcompressis, rotundatis aut lineari-lanceolatis, divergentibus. 


$$
\text { . }
$$





\section{O. fragilis HaW.}

Suppl. p. 82. - Cactus fragilis Nutr. gen. am. 1. p. 296. - Opuntia Sabinii HorT.

Pa: America borealis (in sterílibus Missouriensibus).

0. articulis brevibus compresso-teretiusculis farctis; fragilibus; spinis variantibus valde numerosis erecto-patulis albis, nee deflectentibus, senioribus vix semuncialibus (HAw.).

Articuli subcylindracei divaricati, vel ovati compressi, $2-3$ poll. longi, $1 / 2-1 \frac{1}{2}$ poll. lati. Areolae confertae, in tuberculis positae, foliolo minutissimo rubello suffultae. Aculei inferiores $6-8$ albi, patentes, 3 lin. longi, superiores et centrales $6-8$, suberecti, validiores, pallide fuscescentes, $3-5$ lin. longi. Flores (ex $\mathbf{N} u t t$ ) solitarii parvi in articulorum apicibus. Fructus aculeati.

\section{O. aurantiaca GiLL.}

Botan. regist. t. 1606. - Otro's GZ. 1833. No. 44. S. 349.

Pa: Chile.

o. articulis linearibus, vel lineari-lanceolatis, divaricatis, apice compressis, basi teretibus, perviridibus, circa areolas macula atrovirente notatis; areolis magnis convexis, albido-tomentosis; aculeis inaequalibus, 3 longioribus rigidis brunneis divergentibus, $\mathbf{2}-\mathbf{3}$ infimis albis, brevibus, setiformibus.

Plantae interdum bipedales; rami $3 / 4-1$ poll. diam., $6-7$ poll. longi; aculei pollicares et ultra. Folia minutissima acuta rubra.

Flores solitarii lutei. Germen breve crassum viride, areolatum. Corolla expansa 13/4 poll. diam. Petala obovata, marginibus inflexis. Stamina alba in cylindrum ordinati petalis breviorem. Stylus haud prominens, stigmatibus 7 virescentibus.

\section{O. extensa SAIM.}

\section{$\mathrm{Pa}$ ?}

0. ramosa; articulis lineari-elongatis; areolis remotis prominentibus, setarum fuscescentium fasciculo et aculeis $1-4$ albidis vel fuscis, rigidis, inaequalibus instructis.

o. aurantiacae affinis, sed articuli longiores, magis teretes, aculei breviores. Articuli $2-8$ poll. longi, 6 lin. diam. Aculei 3-6 lin. longi, apice saepe rubelli. Folia minuta viridia. 


\section{8}

\section{O. foliosa Salm.}

DC. prodr. III. p. 471. - Cactus foliosus Willd. enum. suppl. 32. - Op. pusilla HAw. syn. p. 195. nec Salu! - Cactus pusillus HAw. in: misc. nat. p. 189. Op. Hystrix Hon'T.

Pa: Amer. calid.

O. articulis sublanceolatis, compressis, ramosis, laete viridibus, junioribus foliosis, senioribus aculeatis; aculeis $1-2$ elongatis validis stramineo-albidis e tomento flavicante.

Articuli 3-6 poll. longi, 6-8 lin. diam. Aculeus solitarius $8-10$ lin. longus, alter, si adest, inferior $4-5$ lin. longus. Folia trilinearia.

Flores (mense Junio) numerosi, ramulos juniores terminantes, Intei, Opuntiae vulgaris simillimi. Calyx 5-phyllus (Haw.), foliolis valde inaequalibus. Petala circiter 8 cuneato-oblonga, obtusa, ad solem pulchre micantia. Stamina numerosa, erecta, valida, fulva, antheris albis. Stylus validissimus teres albidus, antheras paululum superans, stigmatibus $3-4$ validis albis.

\section{0. curassavica MILL.}

Dict. ed. 8. n. 7. - Haw. syn. p. 196. - Cactus curassavicus LiNN. WILLD. - Opuntia minima americana spinosissima BradL. succ. 1. p. 5. t. 4.

Pa: Curaçao, S. Thomas.

C. articulato-prolifer, articulis cylindrico - ventricosis compressis (Lins.).

O. suberecta; articulis fragilibus cylindrico-ventricosis compressis, valde divaricatis, atrovirentibus; areolis confertis albo-tomentosis, parce lanatis; aculeis $3-5$ inaequalibus, fuscis, tandem albidis, rectis, acutissime punonntibus.

Articuli 4-8 poll. longi, 6-8 lin. diam. Aculei $3-6$ lin. longi. Folia brevia rubescentia.

$\beta$. media HAW. syn. p. 196. - Ramis spinisque paulo minoribus.

y. minor Haw. ibid. - Ramis duplo minoribus, junioribus fere inermibus, purpurascentibus, foliis minutissimis.

ঠ. longa HAw. revis. p. 71. (Brasilia). - Ramis ma- 


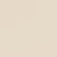

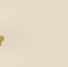

.

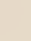

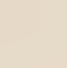



gis firmis, duplo longioribus, minus divaricatis et aculeis longioribus, foliis gracillimis rubellis. - An species propria?

Flores in Europa rarissimos, vix unum diem persistentes, in horto Berolinensi observavimus Junio et Julio 1836. In medio ramorum solitarii proveniunt, aperti $1 \frac{1}{2}$ poll. diam., sordide lutei. Ovarium elongatum, 11/2 poll, longum, tenue, viride, areolis griseo - tomentosis obsitum. Petala fere biserialia, lanceolata, sordide flava, nervo rubello. Stamina sulphurea, antheris sulphureis. Stylus albus, stigmatibus $3-5$ vix prominentibus.

\section{O. pubescens Wendi。}

Catal. horti Herrnhus. 1835.

Pa: Mexico.

O. suberecta; articulis cylindricis, basi et apice attenuatis, divergentibus, perviridibus, pubescentibus, vix tuberculosis; areolis subremotis convexis albis; aculeis linearibus $4-6$, longioribus $1-2$, albicantibus, rectis, gracilibus.

Articuli 1-4 poll. longi, 4-5 lin. diam. Aculei semipollicares. Foliola tenuissima rubella.

\section{S. 3. Compresso-articulatae.}

Caule articulato, articulis compressis, planis, lanceolatis, ovatis vel rotundis, glabris, pulvinatis, criniferis vel spinosis.

\section{* Glabratae.}

Articulis inermibus, areolis tomentosis, setulis brevibus instructis.

18. O. vulgaris MiLs.

Dict. ed. 8. n. 1. - HAw. syn. p. 190. - SAlm-D. observ. botan. 1822. p. 9. - Cactus Opuntia L. - Cactus Opuntia vulgaris et nana DC. pl. gr. 138. - Op. italica Tenore?

Pa: Americae borealis provinciae australes, in Europa culta.

C. articulato-prolifer laxus, articulis ovatis, spinis setaceis (LiNN.). 
0. decumbens divaricata laetevirens; articulis obovatis compressis parvulis; spinis vix setaceis tomentum griseum aequantibus (SALM-D. 1. c.).

ß. media SArm l, c.-Paulo elatior, articulisque majoribus. - Opuntia nana DC. - E Peru et Mexico.

Articuli in var. $\alpha$ subrotundi, 2 poll. longi, latitudine fere aequali, in var. $\beta$ magis obovati, 3 poll. longi et 2 lati. Folia bilinearia rubella. Interdum ex areolis vetustioribus nonnullis aculeus solitarius subulatus, corneo-albidus, 2-4 lin. longus provenit.

Flores mensibus Julio et Augusto, per unum diem expansi, citrini, 2 poll. diam. Ovarium 10 lin. longum, ovatum, viride, nitidum, vix areclatum. Sepala minuta fusca. Petala biserialia, rosacea, citrina, exterioria mucronata, dorso subpurpurascentia, interiora cordata. Stamina conniventia aurantiaca, antheris oblongis sulphureis. Stylus crassus, stamina aequans, flavus, stigmatibus 5 albidis. - Fructus, sequente anno maturescens, pollicem longus, coccineus, edulis.

\section{O. intermedia SALM.}

Hort. Dyck. p. 364. - Op. vulgaris $\gamma$ major SALM-D. observ. botan. 1822. p. 9.

Pa: Europa australis? Dalmatia?

o. articulis suberectis valde compressis oblongo-ovatis perviridibus nitidis; areolis remotis setaceis fulvidis.

Articuli 4-5 poll. Iongi et $2-3$ poll. lati. Areolae valde remotae, foliolo crasso erecto brevi ochraceo suffultae, tomentososetaceae, setis fulvidis. - Ab 0 . vulgari differt articulis erectioribus perviridibus, areolis foliolo brevi erecto ochraceo, nec elongato, incurvo-recurvulo viridi, setisque fulvidis instructis. - Flores sulphurei, O. vulgari paulo majores, petalis pallidioribus et acutioribus et ovario suffultis duplo longiore, sulcato:

20. O. coccinellifera MILL。

Dict. ed. 8. n. 6. - HAw. syn. p. 192. - Cactus cochenillifer L. - Tuna mitior flore sanguineo cochinellifera DiLL. h. elth. 399. t. 297. f. 383. - Botan. magaz. t. 2741. 2742. - DC. revue p. 68. - O. mexicana HonT.

Pa: America tropica.

C. articulato-prolifer, articulis ovato-oblongis subinermibus (LiNN.).

0. erecta; articulis crassiusculis viridibus, ovato-oblongis, subinermibus, quasi reticulatis. 




\section{1}

Articuli 6-12 poll. longi, 2-4 lati, basi nonnunquam teretes. Folia reflexa rubella.

Floret Majo (in horto Berolinensi; secundum Dillenium Septembri). Flores rubri, vix expansi, $1^{1 / 4}$ poll. diam. Ovarium 11/2 poll. longum, 14 lin. diam., obovatum, obscure viride, subimbricato-areolatum. Sepala brevia, acuta, coccinea, margine flavescentia. Petala erecta, biserialia, rosacea, acuminata, sordide coccinea, nervo saturatiore, intus versus basin macula oblonga rubra picti. Genitalia corolla multo longiora, compacta. Stamina vivide rubra, antheris luteis. Stylus incarnatus, stigmatibus 8 luteo-virentibus.

\section{O. tuberculata HAw.}

Suppl. p. 80. - Cactus tuberculatus WiLld. enum. suppl. 34.

Pa: America tropica.

0. articulis compressissimis ovato-oblongis, utrinque attenuatis, nervosis, subtuberculatis; areolis subremotis, fasciculo spinarum setacearum brevissimarum instructis.

Articuli $4-6$ poll. longi, $2-3$ lati, adulti circa areolas macula purpurascente notati. Folia trihinearia viridia. - Affinis $O$. monacanthae quoad formam et substantiam articulorum tenuem; sed areolae minus remotae sunt et aculeis omnino carent.

Flores mensibus Junio et Julio, lutei, expansi s poll. diam. Ovarium viride, elongatum, $1^{1 / 2}$ poll. longum, gracile, $6-8$ lin. diam., nudum, parce areolatum, sulcấo-tu’erosurs. Sepala angusta viridia. Petala lata mucronatula. Stumian numerosa, filiformia, flava, antheris minutis sulphuieis. Stylu wirsus, staminibus longior, stigmatibus 5 flavidis.

\section{O. stricta HAw.}

Syn. p. 191. - Cactus strictus HA in: misc. nat. p. 188. - Op. inermis DC. pl. gr. No. 138. c. ic.

\section{$\mathrm{Pa}$ : America calid.}

o. stricte erecta; articulis carnosis ovato-ellipticis, pallide viridibus; spinis uniformibus brevissimis, piliformibus, numerosissimis.

Articuli subpedales, $3-5$ poll. lati. Folia acuta viridia. Flores utrinque flavi, patentes, 3 poll. diam. Ovarium ficiforme, $\mathbf{1}^{1 / 2}$ poll. longum, basi attenuatum, squamis nonnullis patentibus instructum. Petala basi angusta, sultus dilatata, obtuse acumiyุata, flava. Stamina flava, antheris flavis. Stylus vix longior. 


\section{O. lanceolata Haw.}

Syn. p. 192. - Cactus lanceolatus HAw. in: misc. nat. p. 188.

Pa: Amer. merid.

O. suberecta; articulis lanceolatis, glabris, viridibus; areolis remotis inermibus vel flavido-setosis; aculeis nullis.

Articuli carnosi, 5-6 poll. longi, $1-1^{1 / 3}$ lati, juniores valde foliosi. Folia majora, quam in affinibus, nempe trilinearia et ultra, rubella.

Floret mense Julio. Flores nitide lutei, 4 poll. diam., Opuntice vulyaris similes. Stamina lutea, petalis duplo breviora. Stylus longitudine staminum, albidus, stigmatibus 5 crassis sulphureis.

\section{O. Decumana HAw.}

Suppl. p. 1.' - Cactus decumanus WIrLd. enum. suppl. 34. - Cactus elongatus W. 1. c. - Op. maxima Mill. dict. ed. 8. n. 5. - Haw. syn. p. 191.

Pa: Amer. merid.

o. articulis ovato-oblongis crassissimis, spinis inaequalibus (MrLu.).

o. articulis ovato-oblongis obtusis; aculeis deciduis longitudine lanuginis (DC. prodr.).

Articuli $1-1^{1 / 2}$ ped. longi, $8-10$ poll. lati. Folia gracilia apice ferruginea.

Floruit aestate 1835 in horto Vindobonensi. Flores sordide aurantiaci.

\section{O. elata H. BeroL.}

Hort. Dyck. p. 361.

Pa: Brasilia, Curaçao.

O. articulis erectis oblongis magnis perviridibus; areolis latis remotis albido-tomentosis, inermibus, aut aculeo solitario subulato erecto instructis.

Articuli saepe 10 poll. longi et $4-5$ lati. Specimina e patria advecta aculeis solitariis instructa, in hortis (etiam sub dio culta) inermia evadunt. Ab Op. Decumana, cui proxima, differt areolis remotioribus, albidis, nudis, absque aculeis setaceis. Foliola

- perviridia, apice ferruginea.

\section{O. Ficus indica MiLt.}

Dict. ed. 8. n. 2. - HAw. syn. p. 191. - Cactus Ficus indica L. - WILLd. enum. suppl. 34. - Op. vul- 

garis Tenore syll. flor, neap. p. 239.- C. Opuntia GussoNe prodr. flor. sicul. p. 559. excl. synon.

Pa. Amer. merid. (Italia et Sicilia.)

C. articulato-prolifer, articulis ovato-oblongis, spinis setaceis (LINN.).

o. erecta; articulis magnis, viridibus, ellipticis, crassiusculis, margine attenuatis; areolis regulariter dispositis, immersis, inermibus, rarius aculeos solitarios minutos gerentibus.

Truncus aetate teres, lignosus. Articuli 1\%/a ped. longi, 1 ped. diam., 1 poll. crassi. Folia minuta rubra. - Flores sulphurei. In Sicilia (teste G u s s on e) varietates sequentes coluntur: a. fructu lutescente, b. fructu albido, c. fr. sanguineo, d. fr. aspermo, inter quas varietates b. et $d$. praestantiores sunt.

$\beta$. Arliculis Grevioribus H. DYcK.

\section{O. crassa Haw.}

Suppl. p. 81:

Pa: Mexico.

0. erecta, articulis ovatis oblongisve, carne farctis, crassissimis, glaucescentibus; areolis remotis fuscis, fere inermibus, rarissime aculeos $\mathbf{1}-\mathbf{2}$ albos, rectos gerentibus.

Articuli $3-4$ poll. longi, $2-3$ lati, $8-10$ lin. crassi, interdum orbiculati. Folia acuta, apice ferruginea.

B. major. - O, glaberrima H. BeroL. - Articulis multo majoribus, areolis glabrioribus, foliis rubellis.

\section{O. parvula SALM.}

Hort. Dyck. p. 364. - Op. glauca HonT.

Pa: Chile.

o. articulis suberectis, oblongo-ovatis, parvulis, crassis, glaucescentibus; areolis parvulis; setis minutissimis flavidis e tomento fulvido.

Articuli 2 poll. Iongi, 1 poll. lati, subfarcti. Areolae subconfertae, foliolo bilineari rubente suffultae, tomentoso-setaceae, inferne setulis quibusdam, vix lineam longis instructae. Opuntia crassa et spinulifera triplo minor.

\section{O. Hernandezii DC.}

Revue p. 69. t. 16. - Prodr. III. p. 474. - Cactus cochenillifer Flor. mex. ic. ined. - Nopalnochetzli Hers. 


\section{4}

mex. 78. ic. et 489. f. 1. - Nopal sylvestre 'ThernyMenonv. voy. guax. 2. p. 27\%. c. icone.

Pa: Mexico.

0. erecta; articulis crassis, subrotundo-obovatis, viridibus; areolis confertis, inermibus, fusco-setaceis. .

Articuli (ex DC. icone) $2-3$ poll. longi, 1//2 $-1^{3 / 4}$ lati. Flores $1^{1 / 2}$ poll. longi, expansi $1^{1 / 2}$ poll. diam. Ovarium viride, sulcato-tubersulosum, areolatum. Petala secundum Thierry in eadem planta alii purpureo-rosea, alia griseo-lilacina. Stamina rubella, stylo rubro breviora; stigmata 5 flava.

\section{*** Pulvinatae.}

Areolis setulis numerosissimis aut lana densa pulvinato-convexis, aculeis nullis aut solitariis.

a. Inermes.

30. O. microdresys LeHм.

Ind. sem. Hamb. 182\%. - Nov. act. nat. cur. XVI. P. I. p. $31 \%$.

Pa: Mexico.

O. ramosa laxa; articulis lanceolatis, elongatis, compressis, junioribus teretiusculis, spinis fasciculatis minutissimis (LEHM.).

o. suberecto-diffusa; articulis obovatis vel lanceolatis, viridibus, basi crassis; reolis regulariter confertis, penicillo setarum flavarum instructis.

In parte vetustiore penicilla longiora, magis expansa, superne fusca, inferne flava, superficiem omnino tegentia.

Articuli 4-6 poll. longi, $2-3$ poll. lati. Folia minutissima, vix conspicua, viridia. Setae partis adultae $3-4$ lin. Iongae.

B. minor Salm (Hort. Dyck. p. 186.). - 0. pulvinata DC. revue p. 119.

\section{O. decumbens SALM.}

Hort. Dyck. p. 361. - Op. repens KARw. - Op. irrorata MART.

Pa: Mexico.

0. articulis decumbentibus, compressis, obovatis, viridibus, ad areolas saturatioribus; areolis confertis laniferis; aculeis biformibus, superioribus setaceis flavidis, inferioribus $1-2$ validis albidis: 



\section{5}

Articuli crassi, $6-7$ poll. longi, $3-4$ poll. lati, valde proliferi, decumbentes, repentes, sub areolis macula perviridi (teste Cl. de Karwinski in patria rubra) notati, apud nos semper inermes. Foliola glancescenti-viridia. - Flores rubri.

\section{O. glaucescens H. Berou.}

Hort. Dyck. p. 362.

Pa: Mexico.

o. articulis erectis, oblongis, glaucescentibus; areolis subconfertis; aculeis biformibus e tomento griseo, superioribus setaceis, penicillatim collectis, fulvo-roseis, inferioribus $1-4$ elongatis, acicularibus, albis.

Articuli $5-6$ poll. Iongi, 2 poll. lati, utrinque attennati; areolae juniores solummodo setis penicillatim collectis instructae, adultiores in parte infera aculeis pollicaribus armatae. - Folia minuta ferruginea.

\section{Aculealae.}

\section{0. grandis H. ANGL.}

0. glaucescens Hor't.

Pa: Mexico.

O. articulis ovalibus vel ellipticis, compressis, glaucescentibus; areolis subremotis, in tuberculis viridioribus positis, penicillo setarum nigricantium et aculeis 2 albis rigidis instructis.

Articuli $4-5$ poll. longi, 3 poll. lati, parte inferiore inermes, juniores pulchre coerulei. Aculeus maximus pollicaris, alter $4-5$ lin. longus. Folia acuta rubra.

\section{O. albicans SAlm.}

Hort. Dyck. p. 361. - O. Prate SABIN.

Pa: Mexico.

O. articulis erectis, compressis, oblongis, angustis, subglaucescentibus; areolis confertis; aculeis biformibus e tomento rufo, superioribus numerosissimis setaceis luteis, inferioribus $1-4$ elongatis, acicularibus, albis.

Articuli valde compressi, 5-6 poll. longi, pollicem lati. Aculei majores albi, pollicem longi, in areola inferne positi, minores laetissime flavi. Folia minuta virescenti-ferruginea.

35. O. sericea Don.

Hort. Dyck. p. 363. - 0. coerulea GiLL. 


\section{6}

\section{Pa: Chile.}

o. articulis erectis, ovato-oblongis, compressis, viridibus; areolis confertis pulvinato-convexis; aculeis biformibus e tomento griseo, superioribus setaceis, numerosis, aurantio-fulvidis, inferioribus $3-5$ validis, acicularibus, stramineo-albidis, centrali aut infimo longiore, saepe deflexo.

Articuli $3-4$ poll. longi, $1^{1 / 2}$ poll. lati, nitidi. Aculei 4-8 lin. longi. Folia brevia viridia.

\section{O. orbiculala Salim.}

O. sericea $\beta$. longispina Hort. Dyck. p. 363. - Op. longispina Нонт.

\section{Pa: Chile?}

O. erecta subramosa; articulis orbicularibus crassis perviridibus (senioribus saepe elongatis); areolis regulariter plus minusve distantibus, setis brunneis penicillatim collectis et aculeis $4-5$ inaequalibus, gracilibus, stramineis, basi fulvis, horizontaliter patentibus instructis.

Articuli 3-4 poll. diam., 6 lin. crassi. Aculei minores 3-6 lin., longissimi $1^{1 / 4}$ poll. longi. Folia acuta viridia.

\section{O. puberula H. Vindoв.}

\section{Pa: Mexico.}

O. articulis obovatis crassis, viridibus, puberulis ; areo$l_{\text {is }}$ subremotis, vix convexis, macula rubra circumdatis, superne fasciculum setarum fulvarum brevissimarum, aculeosque $2-4$ inaequales, graciles, albidos, divergentes gerentibus.

Articuli $3-5$ poll. longi, $2-3$ poll. lati. Aculei maximi 4 lin. longi. Folia bilinearia acuta, apice rubella.

\section{粠垱 Criniferae.}

Areolis confertis, aculeos biformes, rigidiusculos breves et longissimos setaceo-capillaceos gerentibus.

\section{O. leucotricha DC.}

Revue p. 119. - Hort. Dyck. p. 362.

Pa: Mexico.

0. articulis oblongis erectis, junioribus sub lente velutinis ; areola juniore convexa velutina; aculeis biformibus, 




\section{7}

2-3 longissimis setaceo-capillaceis inermibus, albis, patentibus, $4-5$ minimis setosis rectis flavidis (DC.).

0. articulis erectis oblongis laeteviridibus; areolis confertis; aculeis biformibus e tomento griseo, superioribus setaceis fulvidis, inferioribus 15-20 longissimis flexuosis, criniformibus albis (SALM-D. 1. c.).

Articuli $6-7$ poll. longi et $2^{1 / 2}-4$ poll. lati, crassiusculi. Areolae juniores planae et foliolo minutissimo rubello suffultae, solummodo aculeis $5-6$ tenuissimis, strictis, vix $3-4$-linearibus instructae sunt; sed adultiores convexae evadunt et aculeos biformes gerunt. Aculei in areolae suprema parte setacei, fulvidi, vix lineam longi, in media et infima parte vero $1-2$-pollicares, criniformes, albi, apice rigidi pellucidi, numerosissimi, varie distorti et plantam basin versus omnino tegentes, Cerei senilis instar.

Specimina nonnulla observavi caule elongato, inarticulato, $O p$. leucacanthae simili. Num haec propriae speciei adscribenda?

\section{O. crinifera Salu.}

Opuntia senilis Parm.

Pa: Brasilia.

O. suberecta; articulis ovatis vel elongatis tenuibus, obscure viridibus; areolis subconfertis albis convexis, parte inferiore aculeolos 3-4 gracillimos, rigidiusculos, rufos superiore copiam setarum albarum longarum sericearum, crinium mollissimorum instar defluentium, gerentibus.

Articuli $2-5$ poll. longi, $1-2$ poll. lati, juniores lana omnino carentes. Aculei $3-4$ lin. longi; lanae filamenta ultrapollicaria, torta truncum involvunt. Folia 1 1/2 lin. longa, recurvula, apice rubella.

ß. O. lanigera Panu. - Articulis laete viridibus, tomento ferrugineo, aculeis rufis nullis, lana brevi crispula. - Num propria species?

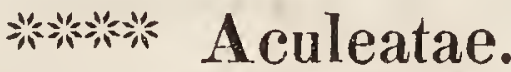

Areolis tomentosis, aculeos gerentibus plus minusve numerosos et validos, albos, flavos, fulvos vel nigricantes.

$$
\text { a. Albispinae. }
$$

40. O. spinuliferce SALm.

Hort. Dyck. p. 364. - Op. oligacantha. H. Vindoß. 
Pa: Mexico.

o. articulis suberectis obovatis crassis, glaucescentiviridibus; areolis subconfertis parvulis; aculeis setaceis e tomento griseo, minutis, albis, uno alterove longiore.

Articuli $4-5$ poll. Iongi, $2-3$ poll. lati. Areolae juniores foliolo minuto rubello suffultae, et setis $2-3$ ( 3 lin. longis) quandoque evanidis instructae; seniores vero, ad basin plantae, aculeis numerosioribus, quorum medius aut infimus 6 lin. longus.

\section{O. missouriensis DC.}

Prodr. III. p. 472. - Hort. Dyck. p. 363. - Cactus ferox Nutr. gen. am. 1. p. 296. non Wilum. - Opuntia polyacantha HAw. suppl. p. 82.

Pa: America borealis (in planitiebus aridis ad Missouri frequens).

o. articulis compressis obretuso-rotundatis; spinis horridis variabilibus albis, $2-3$ senectis subuncialibus divaricato-deflexis (HAw.).

0. articulis latis suborbiculatis aculeatissimis; aculeis biformibus, majoribus radiatis persistentibus (DC.).

O. articulis subdivaricatis compressis obovato-rotundatis, laete viridibus, subtuberculato-areolatis; areolis confertissimis; aculeis biformibus e tomento fulvido, superioribus setaceis fulvidis, inferioribus $8-10$ validis subradiantibus adpressis albis, centrali longiore deflexo (SALM-D. l. c.).

Articuli 3 poll. longi, 2 poll. lati, juniores tuberculato-areolati; areolae valde approximatae, foliolo minutissimo rubello suffultae. Aculei adpressi, deflexo-subradiantes, semipollicares. Articuli senecti aculeis adpressis omnino tecti.

Flores, secundum Nuttall, numerosi, dilute sulphurei, stigmatibus 8-10 subvirescentibus. Fructus sicci et aculeati.

\section{O. media Haw.}

Suppl. p. 82. - Hort. Dyck. p. 363.

Pa: America borealis (prope flumen Missouri).

0. articulis ovato-oblongis compressis; spinis valde numerosis variantibus albis, senectis $2-3$ subsemiuncialibus divaricato-deflexis ( H $_{\text {Aw. }}$ ).

Articuli 2 poll. longi, $1 \frac{1 / 2}{2}$ poll. lati, quandoque ovato-oblongi et aculeis instructi brevioribus ac tenuioribus, quam 0 . misson- 

riensis. Folia $1^{1 / 2}$ lin. longa; acutissima, apice rubra. Ill. Pr. a Salm-Dyck eam pro mera varietate seminali $O$. missouriensis habet, speciemque delendam censet. Ab $O$. fragili articulis latioribus, magis compressis, aculeisque aequalioribus differt.

\section{O. splendens H. AvaL.}

\section{Pa?}

0. articulis minutis; areolis subconfertis, albo-tomentosis; aculeis niveis subsetaceis, subflexuosis, brevibus, radiantibus 7 , centralibus $1-2$.

O. missouriensi similis, sed nondum satis cognita. Aculei 3-4 lin. longi (Ill. Pr. a S a lm-D yck in litt.).

\section{O. Amyclaea Tenore.}

Flor. neap. app. 5. 1826. - Tenonè sylloge p. 240. - Op. maxima Salur.

Pa: in rupibus calcareis prope Amyclas veterum (Monticelli).

0. erecta articulato-prolifera glauca; articulis ellipticis latissimis planis compressis; aculeis validis divergentibus teretiusculis candidis; lanugine obsoleta.

Articuli rite elliptici, nec ovato-oblongi, 12 - 15 poll. longi, 6 poll. lati, valde compressi, idcirco crassitudine congenerum duplo tenuiores. Spinae pollicaris longitudinis e basi subtriquetra refracta, caeterum teretes reflexae, $4-6$ in quovis fasciculo. Folia bilinearia acuta rubra.

Flores lutei. Fructus minores quam O. Fici indicae, luteorubri, minus sapidi et carnosi.

\section{O. dejecta SaLm.}

Hort. Dyck. p. 361. - Op. diffusa, horizontalis HonT. Pa: Havannah.

0. articulis erecto-divaricatis, valde compressis, elongatis, angustis, viridibus; areolis remotis, vix tomentosis; aculeis biformibus, superioribus setaceis albicantibus, inferioribus $\check{\mathbf{5}}-\mathbf{6}$ albis, infimo longiore.

Articuli $8-9$ poll. longi, vix $1 \frac{11 / 2}{2}$ poll. lati, varie diffusi seu dejecti. Areolae remotae, foliolo elongato reflexo, apice rubescente, suffultae. Aculei validi, infimo validiore pollicari.

\section{O. candelabriformis H. Monac.}

Pa: Mexico. 
o. suberecta; articulis obovatis vel ellipticis, farctis, glaucescenti-viridibus; areolis subconfertis, superficiei immersis, penicillum setarum albidarum brevium, aculeosque $4-5$ albos longiores, 1 longissimum applanatum album deflexum gerentibus.

Articuli $6-7$ poll. longi, $3-4$ lati. Aculeus deflexus ultrapollicaris. Folia elongata, apice rubescentia.

\section{O. lasiacantha H. Vindob.}

\section{O. leucacantha SAlM (Hort. Dyck. p. 362.)? \\ $\mathbf{P a}$ ?}

O. articulis ovato-oblongis farctis viridibus, vix tuberosis; areolis subremotis albido-setosis et spiniferis; aculeis albis gracilibus rectis, superioribus $3-4$ brevibus, infimo longissimo.

Articuli 4-5 poll. longi, 2-21/2 lati, 5-6 lin. crassi. Aculeus infimus 6 lin. longus. Folia brevia rubella. - Specimen descriptum ex horto Vindobonensi oriundum affirmatur, sed unde nomen O. lasiacanthae? - Praecedenti valde affinis!

\section{O. megacantha SALM.}

Hort. Dyck. p. 363. - O. mexicana Hont.

Pa: Mexico.

o. articulis erectis, compressis, oblongis, magnis, crassis, perviridibus; areolis confertis; aculeis biformibus e tomento griseo, superioribus setaceis brunneis, inferioribus $7-10$ validis subradiantibus albis, uno alterove bipollicari deflexo.

Articuli 7 poll. longi, 3 lati et pollicem ultra crassi. Areolae juniores foliolo parvulo rubente suffultae. Aculei minores setacei, primo fulvidi, dein nigricantes, majores albi, longitudine inaequales, aciculares, rigidi, 6-18 lin. longi.

\section{O. tomentosa Salm.}

Observ. botan. 1822. p. 8. - Cactus tomentosus Link enum. 2. p. 24.

Pa: America trop.

O. erecta laetevirens tomentosa; articulis lanceolatis compressis; spinis omnibus setaceis tomentum vix superantibus, infimis elongatis deflexis, albidis.

Articuli semipedales, plerumque lanceolati, quandoque obovati, 



\section{1}

juniores infra areolas valde tuberosi. Areolae satis remotae, inferne aculeis 4 lin. longis, setaceo-inermibus 4-6 instructae. Folia acuta, apice ferruginea.

Flores rubicundi.

\section{O. oblongata Wendu。}

\section{Catal. h. Herrnh. 1835.}

\section{Pa: Mexico.}

o. erecta; articulis oblongis aut obovato-oblongis, obscure viridibus, subpubescentibus; areolis subremotis griseo-tomentosis, superne setas brevissimas brunneas, inferne aculeos albos, rigidiusculos, rectos $2-6$ gerentibus.

Articuli 4-6 poll. longi, $2-3$ lati. Aculei $4-6$ lin. longi (originarii bipollicares). Folia bilinearia acuta rubella.

\section{b. Flavispinue.}

\section{O. Tuna Hitut.}

Dict. ed. 8. n. 3. - IÁw. syn. p. 188. - Cactus . Tuna Linn. Willd. - Cactus Tuna a Hort. Kew. ed. 2. v. 3. p. 179. - 'Tuna major flore gilvo DILI. h. elth.' p. 396. t. 295. f. 380. - Op. coccinellifera DC. pl. gr. t. 137. - Cactus Bomplandii H. ${ }^{B}$. et KuntH nov. gen. am. 6. p. 69. - Op. coccinea Hor'T.

Pa: Quito, Mexico.

C. articulato-prolifer, articulis ovato-oblongis, spinis subulatis (Lins.).

O. erecta; articulis late ovato-oblongis; aculeis subulatis longis flavicantibus, lana brevi (DC. pr.).

O. articulis magnis ellipticis repandis; areolis remotis griseo-tomentosis, superne fasciculum setarum fuscescentiflavarum, inferne aculeos $4-6$ rigidos, subulatos, flavos, inaequales gerentibus.

Articuli magni, $4-8$ poll. Iongi, fere totidem diam. Aculei 4-10 lin., setae 3-4 lin. longae. Folia trilinearia, acuta, viridia.

Flores subsordide rubentes, 3 poll. diam. Ovarium pyriforme, 11/2 poll. longum, viride, tuberculato-areolatum. Petala rosacea, obtusa, mucronulata. Stamina flava, antheris flavis. Stylus rubellus, stigmatibus 5 viridibus.

ß. laevior SAlm (Hort. Dyck. p. 186.). - Op. flexibilis, Bomplandii Hort. - Areolis remotioribus, aculeis parcis. 


\section{O. Pseudo-Tuna SAlM.}

Observ. botan. 1522. p. \%.

Pa: America calid.

O. erecta ramosa laetevirens; articulis obovatis, compressis, crassis, maximis ; fasciculis distantibus; spinis setaceis productis, penicillatim confertis, infima subulata, valida.

Opuntiae Tunae proxina, sed elatior, ramosior et multo minus spinosa. Articuli pedales, fasciculi remoti et spina unica subulata pollicari inferne instructi, reliquae flavicantes setaceac 5lineares. Folia brevia subulata, apice rubella. - Flores navi.

B. spinosior H. Drck.

$\gamma$. elongata SAlm-D. (in litt.) - An species?

\section{O. glancophylla WExDL.}

Catal. h. Hermh. 1835.

$\mathrm{Pa}$ ?

O. erecta; articulis oboratis subundulatis glaucis; aculeis 1-2 subulatis subuncialibus e tomento setaceo flavido. Num O. Pseudo-Tuna spinosior?

\section{O. horrida Salm.}

DC. prodr. III. p. 472. - O. humilis HAw. syn. p. 189. - Cactus humilis Hiw. in: misc. nat. p. $18 \%$.

Pa: America calida, Ital. cult.

o. erecta; articulis cuncato-obovatis repandis; fasciculis aculeorum remotis tuberculatis; aculeis diversiformibus luteis, brunneo pictis, e tomento setaceo flavido ortis, horridis, uno alterove longiore biunciali (DC.).

omentide. Tunae sinillima, sed floribus distincta. Floret mensibus Junio et Julio. Flores sulphurei, expansi $3^{1 / 2}-4$ poll. diam. Orarimm elongatum (2 poll.), ficiforme, viride, nudum, areolis sparsis setiferis iustructum. Sepala virescenti-rubella. Petala ampla, mucronulata, flara, biserialia. Stamina mmuerosa flava, basi rubella, antheris mimuti flaris. Stylus promin ens crassus ruber, stigmatibus 5-6 luteis. - Fructus maturus (biemnis) pyriformis, $2^{3 / 3}$ poll. longus, $1^{3 / 4}$ poll. diam., atropurpureus.

\section{5ัง. O. Dillenii DC.}

Prodr. III. p. 4\%2. - Cactus Dillenii Botan. regist. 


t. 2555. - Op. Tuna $\beta$ Haw. syn. p. 188. - Tuna major flore sulphureo Disu. h. elth. p. 398. t. 294. f. 382.

Pa: America calid.

o. erecta; articulis obovato-rotundis, undulatis, glaucis; areolis flavo-, tandem fusco-tomentosis, fasciculo setarum flavarum, tandem fuscarum superne instructis; aculeis validis divaricatis flavicantibus, $3-5$ minoribus, 1 validiore, longiore.

Articuli 6-8 poll. longi, 4-6 diam. Aculei minores 6 lin. longi, unus pollicaris. Setae brevissimae. Folia bilinearia, apice rubella. - Flores sulphureo-flavi, fere 3 poll. diam. Ovarium pollicare, viride, penicillis paucis setarum instructum. Petala rosacea vel obcordata, subbiserialia. Stamina flavicantia; stylus crassus, stigmatibus 6 viridibus. - Fructus maturus obscure purpureus ovatus.

\section{0. polyantha Haw.}

Syn. p. 190. — DC. pl. gr. t. 138. - Cactus polyanthos Botan. magaz. t. 2691.

$\mathrm{Pa}$ : America calid.

o. suberecta; articulis oblongis utrinque attenuatis, vix tuberosis; areolis subremotis, fasciculum setarum flavidarum, aculeosque $6-8$ subaequales flavos vel brunneo pictos gerentibus.

Articuli semipedales, 2-3 poll. lati. Aculei longissimi subpollicares. Folia minuta rubella.

Flores mense Julio copiosi ad apices articulorum, pallide sulphurei, 21/2 poll. diam. Ovarium pyriforme, parce areolatum, viride, pollicem longum, basi attenuatum. Petala $7-8$ lata obtusa. Stamina alba, medio collecta circa stylum 5-7-partitum album.

\section{5\%. O. triacantha DC.}

Prodr. III. p. 473. - Cactus triacanthos Willd. enum. suppl.

Pa: America calid.

o. erecta; articulis ovato-ellipticis viridibus planis; areolis subconfertis convexis, medio fasciculum setarum fulvarum, aculeosque 3 , rarius 4 , gerentibus; aculeis rigidis, rectis, flavescentibus, supremo longissimo, reliquis subaequalibus. 


\section{4}

Opuntiae polyanthae affinis, sed articuli plerumque majores, aculeique semper panciores, albido-flavescentes. Areolae juniores lanuginosae. Foliola minutissima rubra.

c. Fulvispinae.

58. 0. fulvispina SAlM.

O. elongata HAw. suppl. p. 81?

$\mathbf{P a}$ ?

o. (elongata) erecta, articulis oblongis ovalibusve, spinis numerosis variantibus fuscis, $2-3$ longioribus, una praelonga, stramineis (HAw.).

O. erecta; articulis ellipticis crassiusculis, perviridibus; areolis magnis brumeo-tomentosis et setosis; aculeis 12-16 inaequalibus, rufo-flavicantibus, centralibus $3-4$ duplo vel triplo longioribus rufis, apice flavidis, gracilibus, acicularibus, infimis deflexis.

Species distinctissima! Articuli 4 poll. longi, $2-21 / 2$ lati, fi-8 lin. crassi. Aculei centrales $1-1^{1 / 2}$ poll. longi. Setae superiores $m o x$ in aculeolos gracillimos, aciculatos, $4-6$ lin. longos excrescunt. Folia acuta viridia.

B. laevior Salm (in litt.). - 0. Tuna $y$ uno latere laeviore Hort. Dyck. p. 186.

\section{O. monacantha HAw.}

Suppl. p. 81. - Cactus monacanthos WiLld. enum. suppl. - Cactus Opuntia T'una DC. pl. gr. t. 138. - Botan. regist. t. 1726. - Oтто's GZ. 1835. No. 6. S. $4 \%$

Pa: Brasilia, America aequinoctialis.

O. articulis ovato-oblongis; aculeis solitariis subulatis validis (DC. prodr. III. p. 472.).

O. erecta; articulis magnis ellipticis vel ovato-oblongis, compressissimis, glabris, perviridibus; areolis remotis, tomentum brevissimum setaceum cinereum et aculeum 1 rigidum, brunneum, apice flavum, gerentibus.

Articuli pedales, 4 - 5 poll. diam. Aculei pollicares, primo anno solitarii, tandem gemini vel terni. Folia mox decidua rubra.

Flores mensibus anctumnalibus, insignes, 3 poll. diam. Ovarium $1^{3 / 4}$ poll. longum, 1 poll. crassum, pyriforme, viride, brunneo-areolatum. Sepala brevia purpurea, margine flavida. Petala ovata, obtusa, acuminata, biserielia, exteriora dorso purpurascentia, interiora omnino citrina. Stamina flava patentissima. Stylus crassus flavus, stigmatibus 6 hrevibus ereclis. 

60. O. nigricans Haw.

Syn. p. 189. - Cactus nigricans Haw. in: misc. nat. p. 18\%. - Cactus Tuna $\beta$ nigricans: Botan. magaz. t. $155 \%$. - Opuntia coccinellifera DC. pl. gr. t. 13\%. - Cactus pseudo-coccinellifer BERT. exc. p. 11. virid. 1824. p. 4. excl. synon?

Pa: America calida.

O. erecta; articulis oblongis lanceolatisque; aculeis diversiformibus fulvo-nigris, majoribus divaricatis (HAw.).

O. erecta; articulis magnis ovatis vel lanceolatis, obscure viridibus; areolis remotis fulvis; aculeis $2-3$ inaequalibus, divergentibus, rectis, rigidis, nigricantibus.

Articuli 1-11/2-pedales et ultra, $6-8$ poll. diam., 5-6 lin. crassi. Aculei $1-3$ poll. longi, initio sordide fulvi. Foliola minuta, planiuscula, horizontaliter patentia, apice ferruginea.

Flores mense Augrasto, 2 poll. diam. Ovarium 2 poll. longnm, areolatum, setis brunneis. Sepala rosea, extus saturatiora, cuneata, petala luteo-fulvicantia. Stamina numerosissima saturate rosea, antheris roseis. Stylus magnus albicans, stigmatibus $\mathbf{5}$ crassis luteo-virescentibus. - Fructus maturus pyriformis, areolatus, purpureus, $2^{1 / 2}$ poll. longus, 2 poll. diam.

\section{O. elation Minu.}

Dict. ed. 3. n. 4. - HAlv. syn. p. 188. - Cactus Tuna $\beta$ WrLld. - Tuna elatior, spinis validis nigricantibus Dilı. h. elth. p. 395. t. 294. f. 379.

Pa : Amer. merid.

o. erecta; articulis glaucescentibus, late ovato-oblongis; aculeis subulatis longissimis, e fusco nigricantibus, lanugine obsoleta.

Articuli 7-10 poll. longi, $3^{1 / 2}-5$ diam. Aculei inaequales, 8-14 lin. longi.

Flores (mense Septembri) 13/4 poll. diam., obsoletius purpurascentes (e flavo in purpureum vergentes). Ovarium 12-14 lin. longum, 9 lin. diam., areolatum. Petala lata acuminata. Stamina purpurea. Stigma 5 -fidum. - Fructus ruber ovatus, 11/a poll. longus, 1 poll. diam.

Opuntiae nigricanti valde (forsan nimis!) affinis.

$$
\text { 62. } 0 \text {. robusta WENDI. }
$$

Catal. h. Herrihus. 1835.

Pa: Mexico. 
O. erecta; articulis obovato-oblongis pulverulentis glaucis; aculeis validis diversiformibus $8-\mathbf{1 2}$, basi fuscis, apice albicantibus, bipollicaribus e tomento setaceo fusco.

Articuli magni 8-10 poll. longi, $4-5$ lati. Folia bilinearia acuta rubella.

\section{S. 4. Cruciatae.}

Caule inarticulato compresso erecto, ramis compressis lateralibus, plerumque oppositis.

\section{O. rubescens SALM.}

Hort. Dyck. p. 360.

Pa: Brasilia.

o. caule erecto integro; ramis lateralibus elongatis, suboppositis, rubro-virescentibus, subtuberculato-areolatis; areolis tomentosis, inermibus, albidis.

Caulis bi- aut tripedalis, strictus, complanatus, 2 poll. latus, ad latera articulis seu ramis patentibus instructus. Caulis et rami purpurascentes; areolae confertae, magnae, foliolo minutissimo suffultae, inermes, vel aculeis nonnullis brevibus, rigidis, albis instructae, tomentosae, tomento pulvinato albido.

\section{O. catocantha H. BEROL.}

Pa: St. Thomas.

O. caule erecto inarticulato compresso rubro, apice vix tuberoso, mox laevi; areolis subremotis oblongis albidotomentosis; aculeis 6-8 inaequalibus, acicularibus, divergentibus, albis, rectis, rigidiusculis.

Truncus $1 \frac{1}{1}-3$ poll. latus. Aculei longissimi pollicares, saepe deflexi, reliqui $3-5$ lin. longi, nascentes rubelli. Foliola subulata, $1^{1 / 2}$ lin. longa, apice ferruginea.

Praecedenti affinis, sed aculeis numerosis, elongatis satis distincta!

65. O. spinosissima MiLc.

Dict. ed. 8. n. 8. - Cactus spinosissimus LAM. enc. 1. p. 53\%. - Haw. syn, p. 193. - Croix de Lorraine.

Pa: Jamaica, Antill.

o. articulis oblongis; aculeis flavescentibus setaceis subulatisque numerosissimis fasciculatis, lana longioribus (DC. prodr.). 



\section{8}

o. caule inarticulato, altissimo, compresso ; ramis oppositis; tuberculis parum prominentibus; areolis confertis tomentosis, parte superiore fasciculum setarum fulvarum, inferiore aculeos $6-8$ rigidos, inaequales, flavos gerentibus.

Caulis $10-12$-pedalis, $2-3$ poll. latus. Rami ex utroque margine plerumque regulariter cruciformes excurrunt, decidui. Aculei 1-2 poll. longi, trunco tandem copiosissimi, intertexti. Foliola minutissima rubella.

Flores in Furopa fere nunquam observati, semel tantum, teste Haworth, in Anglia, reliquis Opuntiis similes.

\section{O. ferox Haw.}

Suppl. p. 82. - Cactus ferox WiLld. enum. suppl. 35. non Nutr. - Op. cruciata, dolabriformis HoRT.

Pa: America calida.

o. articulis oblongis elongatis; aculeis validis setaceisque numerosis fasciculatis albicantibus, lana longioribus (DC. prodr.).

o. caule inarticulato compresso, utrinque ramoso, subtuberculato; areolis subconfertis convexis, superiore parte fasciculum setarum flavarum, inferiore aculeos $4-6$, inaequales, aciculares, albidos gerentibus.

Caulis 1-2 poll. latus. Aculei nascentes rosei, 1-2 longissimi subpollicares. Foliola minuta viridia.

\section{6\%. O. leucacantha H. BEROL.}

Non Saly Hort. Dyck. p. 362!- O. subferox Schotr.

Pa: Mexico.

o. trunco erecto, inarticulato, compresso, superficie subimbricato; areolis confertis, setarum flavidarum fasciculum et aculeos aciculares, rectos, albos, 3-4 breves, 1-3 longiores gerentibus.

Caulis pedalis et ultra, 2 poll. latus, ramis lateralibus suboppositis $3-4$ poll. longis, crassiusculis. Aculei minores $3-4$ lin. longi, majores subpollicares. Setae superiores sensim usque ad 3-4 lin. longitud. crescunt. Folia minutissima viridia.

\section{O. leucosticta WENDL.}

Catal. hort. Herrnh. 1835.

Pa: Mexico. 
O. erecta; articulis elongatis viridibus; aculeis diversiformibus gracilibus albidis, 1-2 elongatis; pollicem longis, e tomento albo, apice brunneis (WENDL.).

o. caule erecto compresso ramoso, superficie fere plana; areolis subconfertis, regulariter seriatis, albido-tomentosis convexis, superne fasciculo setarum brunnearum brevissimarum instructis; aculeis $4-5$ brevibus inaequalibus, albis, acicularibus, $1-2$ longioribus.

Specimen a Cl. Wendland mihi communicatum hucusque erectum, inarticulatum, $g$ poll. altum, 11/2 $-1^{3 / 4}$ poll. diam. Aculei minores $2-3$, majores $6-8$ lin. longi. Folia minuta atropurpurea. - Num forsan \$. 3: albispinis adscribenda?

\section{S. 5. Paradoxae.}

Caule erecto lignoso terete, areolato, ramos teretes et articulos laterales compressissimos gerente.

\section{O. brasiliensis Haw.}

Suppl. p. 79. - Botan. magaz. t. 3293. - Orto's GZ. 1834. No. 8. S. 63. - Cactus brasiliensis WIILL. enum. suppl. 33. - Cactus paradoxus Hornen. hort. hafn. 2. p. 443. - Pison. de medic. brasil. p. 100. f. 2.

$\mathrm{Pa}$ : Brasilia.

o. altissima arborescens; caule cylindrico crasso lignoso; areolis remotis, subtomentosis, aculeis longis albis $1-3$ instructis; ramis horizontalibus ovalibus, basi saepe attenuatis, renuibus, fere membranaceis, tubcrculatis; ramorum areolis subnudis, aculeis longis solitariis armatis.

,Trunco est admodum spinoso, eoque rectissimo $. J a-$ racatia, etiam species Jamacaru, vere Pinum diceres, si rectitudinem et altitudinem consideres, verum in caeteris differt, quod foliis potius se invicem protrudentibus, quam ramis in arboris summitate decoratur, quae rotunditate et crassitie palmam, longissimis spinis digitos manus aemulantur. Dissitae hujus arboris, nuper $a$ nobis detectae, fructus mihi et senioribus Brasilianis mecum peregrinantibus hactenus minus innotuerunt" (PIsos. 1. c.).

Truncus in hortis $10-15$ ped. altus, $1-1 \frac{1 / 2}{2}$ poll. crassus. Rami plantae vetustioris teretes, $6-10$ poll. Iongi, articuliferi. 




\section{9}

Articuli membranacei, nitide virides, $3-6$ poll. longi, $2-3$ lati. Aculei 1 - 2 poll. longi. Foliola brevissima, conica, viridia. Rami inferiores semper decidui.

Flores in plantis $6-8$-pedalibus per totam aestatem e marginibus articulorum, citrini, expansi 1/2 $^{1 / 2}$ poll. diam. Ovarium crassum, nitide virens, tuberculis areolatis et foliolis brevissimis crassis obsitum, pollicare. Sepala crassa, brevia, virescenti-flava. Petala inaequalia, crassiuscula, circa 15, exteriora flava, nervo saturatiore, intima maxima, citrina, basi angusta, versus apicem latiora (4-5 lin.), vix mucronulata. Stamina numerosa lutea patentia, antheris albidis. Stylus sulphureus, stigmatibus 5, dorso sulcatis, villosis. - Fructus ovati, $1-1 \frac{1}{1 / 2}$ poll. diam., diaphane flavi, fasciculis setarum brunnearum instructi. Pulpa succulenta, acidula, flavo-albida, in centro semina continens $2-4$ majuscula rotunda $(3-4$ lin. diam. $)$, substantia villoso-fibrosa involuta.

$\beta$. spinosior H. BEROL.

$\gamma$. minor H. Dyck.

\section{S. 6. Cylindraceae.}

Caule erecto ramoso, carnoso-lignoso, ramisque cylindraceis, tuberculato-areolatis, aculeis validis, saepe epidermide secedente tunicatis.

\section{O. cylindrica DC.}

Prodr. III. p. 471. - Cactus cylindricus LaMr. dict. 1. p. 539. - Cereus cylindricus Haw. syn. p. 183. - Botan. magaz. t. 3301. - OTro's GZ. 1834. No. 10. S. 80.

Pa: Peru.

C. erectus debilis cylindricus, non angulatus, superficie sulcis decussatis reticulata (HAw.).

0. altissima cereiformis, tandem ramosa, perviridis; trunco tandem lignoso terete; tuberculis rhomboideis, in parte suprema areolam albo-lanuginosam et spiniferam gerentibus; aculeis $4-6$ rectis, albidis, deorsum spectantibus, $1-2$ elongatis.

Plantac $10-12$ ped. altae, $2-2^{1 / 2}$ poll. diam. Aculei majores 6-10 lin. longi. Folia crassa, viridia, $\{$ lin. longa, jam ab Haworthio observata, qui plantam Opuntiis quidem affinem, sed ab his, nec non a Cereis diversam putat.

Flores (in Europa nusquam observati) plures prope apicem 


\section{0}

ramorum coccinei, parum expansi, 11/2 poll. diam. Ovarium crassum, 11/2 poll. longum, tuberculoso-areolatum. Sepala crassa, subulata, purpurea. Petala brevia, rosacea, erecta, subsordide coccinea. Stamina numerosa incurva, antheris albis. Stylus teres, pallide viridis, stigmatibus 8 viridibus.

\section{\%1. O. imbricata DC.}

Prodr. III. p. 471. - Cer. imbricatus HAw. rev. p.\%0. Pa: Mexico.

o. erecta teretiuscula, non sulcata, superficie porcis sublobulaeformibus varie subimbricatim tessellatis.

Num sequentis varietas, vel eadem?

\section{\%. O. exuviata DC.}

Revue p. 118. - Hort. Dyck. p. 360. - o. undulata Hont. - O. decipiens major H. Vindoв.

$\mathrm{Pa}$ : Mexico.

o. ramosa erecta teretiuscula; ramis tuberculis compressis vel irregulariter cristatis instructis, fere pentagonis; areolis orbiculatis velutinis ad axillas tuberculorum; aculeis 6-12 stramineis rigidis rectis, senioribus epidermide secedente exuviatis.

Truncus pedalis, $1^{1 / 2}$ poll. crassus (DC.) $f$ - Species ad $O$. imbricatam proxime accedens, foliolis duplo longioribus, acu!eisque numerosioribus ab ea differt (Salm-D. l. c.).

ß. angustior DC. 1. c. - Trunco tenuiore, aculeis paucioribus, areola angustiore.

$\gamma$. spinosior DC. 1. c. - Caule nano, aculeis longioribus, crebrioribus, spinosissimo. - Num O. tunicata?

\section{O. Iuricata H. BEROL.}

Cereus tunicatus IEHM. (Nov. act. nat. cur. XVI. P.I. p. 319.) - 0. furiosa Wendu. (catal. h. Herrnh. 1835.)

Pa: Mexico (sec. LewM. Brasilia merid.).

C. suberectus, articulato-ramosissimus; articulis basi attenuatis tuberculatis; tuberculis apice impressis, lanatis, spiniferis; spinis membrana mobili subdiaphana tunicatis (Lенм.).

o. erecta ramosa; caule ramisque tuberculosis; tuberculis oblongis depressis; aculeis rectis bipollicaribus et tunicatis (Wendu. I. c.). 



\section{1}

O. suberecta, ramosissima; ramis obscure viridibus, divergentibus, basi attenuatis, tuberculato-areolatis; areolis in tuberculorum obtusorum, oblongorum parte suprema positis, oblongis, albo-tomentosis; aculeis e parte infima areolae 4-6 majoribus, $2-3$ infimis brevibus, omnibus albis, membrana subpellucida tunicatis.

Truncus pedalis, $1-1^{1 / 2}$ poll. diam., tandem fere teres. Articuli 8-10 lin. diam. (in calidariis fere inermes.) Aculei (plantarum originarium vel sub divo cultarum) $1-2$ poll., infimi $4-6$ lin. longi. Folia brevia viridia.

\section{O. rosea DC.}

Revue p. 66. t. 15. - Prodr. III. p. 471. - Cactus subquadrifiorus Fl. mex. ic. ined.

\section{Pa: Mexico.}

O. erecta rosea; caule ramisque tuberculosis; tuberculis oblongis depressis, spiraliter seriatis, folia caduca et aculeos rectos fasciculatos albos apice gerentibus.

Truncus ex icone (a Cl. De Candolle descripta) 11/4 poll. diam. Rami divergentes, apice floriferi. Flores subquaterni, rosei, $1^{1 / 2}$ poll. diam, ovario crasso, viridi, tuberculato, foliola et spinas gerente, petalis rosaceis, acuminatis, staminibus rubris, antheris flavis, stylo rubro.- Fructus subglobosi, 11/4 poll. diam., tuberculosi, pallide fuscescentes.

Species dubia, non ad naturam, sed ex icone mexicana solum descripta, verosimiliter 0 . imbricatae, forsan tunicatce aequalis.

\section{O. Stapelia DC.}

Revue p. $11 \%$.

Pa: Mexico.

O. ramosa, irregulariter caespitosa; articulata, intense viridis; articulis ovatis oblongisve; areolis parvulis tomentosis ad axillas tuberculorum; aculeis $5-6$ rigidis, stramineis, setaceis, senioribus epidermide secedente exuviatis.

Truncus inarticulatus, basi subteres, lignosus, 6 lin. diam. Aculei 4 lin. longi. Folia brevia viriơia, apice ferruginea. - Habitus fere Stapeliae caespitosae, aculeis omissis (DC.).

\section{O. Kleiniae DC.}

Revue p. 118.

Pa: Mexico.

o. erecta ramosa, cinereo-viridis; amis erectis cy- 
lindricis tuberculatis; fasciculis ordine spirali sinistrorso dispositis; areola velutina; aculeis biformibus, aliis setosis innumeris ex albido rufis, 1 maximo inferiore patenti-deflexo, gracili, albido.

Caulis digiti majoris crassitie, caulem Cacaliae Kleiniae referens. - Rami pedales et ultra. Aculeus major pollicaris. Folia viridia oblonga decidua.

\section{7\%. O. decipiens DC.}

Revue p. 118.

Pa: Mexico.

o. erecta ramosa viridis; ramis patentibus cylindricis, basi attenuatis; tuberculis paucis subspiraliter dispositis; areola parva; aculeis biformibus, centrali maximo, luteo, tunicato, patenti-deflexo, caeteris $3-4$ minimis setiformibus subradiantibus.

Differt ab 0 . Kleinice, cui proxima, ramis brevioribus et tenuioribus, patentibus, et aculeo centrali luteo, ab op. ramuli-fera aculeis multo longioribus tunicatis, caule tuberculato. Folia minuta viridia.

B. minor Hont. Dyck.

\section{\%8. O. grucilis H. Monac.}

Pa: Mexico.

o. caule ramisque cylindricis tenuibus, elongatis ; areolis remotis, tuberculo suffultis, albo - tomentosis, superne fasciculum minimum setarum brunnearum brevissimarum, inferne aculeum 1 rigidum, horizontalem, pollicarem, corneum, apice album, vagina flava involutum, gerentibus.

Truncus lignosus vix $3^{1 / 2}$, rami $21 / 2-3$ lin. diam. Foliola minora, quan O. leptocaulis.

Num forsan 0 . decipiens minor?

\section{O. Salmiana Parv.}

Pa: Brasilia.

o. erecta ramosa, cinereo-laeteviridis; ramis cylindricis etuberculatis; areolis subconfertis tomentosis albidis, senioribus pulvinatim globosis, inferne aculeis $3-4$ setaceis, minutis, rufescentibus instructis. 

Caulis bipedalis et ultra, crassitie digiti minoris, cortice laevi. Rami superne attenuati, apice floriferi. Areolae tomentosae, tomento albido, in areolis junioribus brevi, in vetustioribus longiore et pulvinatim collecto. Aculei pauci, $3-4$ in areola inferne positi, graciles, subsetacei, vix $3-4$ lin. longi, primo rosei, dein rufescentes, mortui decolorati. - Flores (teste Parmentier) albi. - Fructus turbinatus ant ficiformis umbilicatus (9 lin. Iongus, apice 4 lin. diam.), etuberculatus, areolatus, areolis sicut in ramis (IIl. Pr. a $\mathbf{S a l m - D ~ y c k ~ i n ~ l i t t . ) . ~}$

\section{O. leptocaulis DC.}

\section{Revue p. 118. - O. virgata H. BeroL.}

\section{Pa: Mexico.}

o. erecta, ramosa; ramis cylindricis erectis tuberculatis; fasciculis linea spirali sinistrorsa dispositis; areola subtomentosa; aculeis biformibus, aliis, circiter 3 , inferioribus setaceis nigrescentibus, patenti-deflexis, caeteris setosis, confertis, rufescentibus.

Caulis crassitie digiti minoris, rami 3 lin. diam. Areolae juniores pilis multis longis albis instructae. Aculei $2-3$, setae rufae $1^{1 / 2}$ lin. longae. Foliola aculeis duplo longiora, acutissima, apice rubra.

\section{O. ramulifera Salm.}

Hort. Dyck. p. 360.

Pa: Mexico.

0. erecta ramosissima; ramulis gracilibus, basi attenuatis, subtuberculatis; areolis nudis confertis; aculeis fulvo-brunneis, exterioribus $6-8$ subradiantibus, centrali 1 validiore, epidermide secedente tunicato.

Differt ab 0 . leptocauli caule humiliore et ramosiore, 4-5 lin. diam., areolis nudis, nec lanuginosis, et bus atque rigidioribus, $3-7$ lin. longis, quorum unus centralis tunicatus. Foliola aculeo centrali triplo breviora, apice ferruginea.

\section{O. clavarioides H. BERoL.}

Cer. clavarioides Catal. Cact. Berol. 1833. - Cereus sericeus, Opuntia microthele Hont.

Pa: Chile.

o. diffuso-ramosa; trunco terete, inaequali, suberecto; articulis viridibus elongatis, gracilibus, cylindraceis vel 


\section{4}

obclavatis; areolis regulariter confertis albo-lanuginosis; aculeis 8-10, flavido-rubellis vel albidis, tenuissimis, rectis, stellatim adpressis.

Articuli rarius compressi, cristam quasi undulatam formantia, plerumque columnares, $3-4$ lin. dian. Aculeoli 1-2 lin. longi. Areolae confertissimae, juniores foliolo minutissimo rubescente, subulato suffultae.

\section{3. О. Poeppigii Отто.}

Pa: Chile.

O. humilis; trunco erecto tenui, irregulariter cylindraceo, basi ligneo; ramis teretibus divergentibus viridibus; areolis subconfertis albo-tomentosis; aculeis albis rigidiusculis, plerumque 3 , lateralibus 2 brevibus, medio erecto longiore.

Truncus 4 lin. diam., $6-8$ poll. altus. Aculei longissimi $8-10$, reliqui $2-4$ lin. longi. Folia trilinearia, cylindracea, viridia. 




\section{Pereskia.}

Plum. gen. p. 35.-Haw. syn. p. 197. - DC. prodr. III. p. 474.

Char. gen. Sepala plurima, ovario adnata et super fructum saepe persistentia foliiformia. Corolla rotata fere Opuntiae. Stamina numerosa, petalis multo breviora. Stylus filiformis. Stigmata spiraliter aggregata. Bacca globosa aut ovata. Semina in pulpa nidulantia. Cotyledones magnae foliaceae virides.

Frutices aut arbores, ramis teretibus. Aculei ad axillam foliorum tomentosam vel nudam solitarii aut in caule fasciculati. Folia distincta plana in ordine maxima, hieme decidua. Flores subpaniculati solitarii, plerumque ramulos terminantes, rarius sublaterales?

\section{P. aculeala Plum.}

Nov. gen. 37. - Dilu. h. elth. p. 305. t. 227. f.294. Haw. syn. p. 198. - Cactus Pereskia L.-Portulaca americana etc. Pluk. alm. 135. t. 215. f. 6. - Groseiller des Barbades Dum. Cours.

Pa: India occidentalis.

C. caule arboreo tereti, aculeis geminis recurvis, foliis lanceolato-ovatis (LinN.).

P. foliis ellipticis carnosis, spinis subinde semuncialibus, gemmis parum lanatis (HAw.).

P. trunco lignoso erecto; ramis gracilibus, longissimis, scandentibus; areolis sublanatis; aculeis geminis recurvulis, tandem in trunco fasciculatis; foliis viridibus, oblongis, acuminatis, glabris.

Truncus 1 poll. crassus et ultra; rami juniores $2-3$ lin. diam. Aculei gemini $2-3$ lin., fasciculati, recti $4-6$ lin. Iongi. Folia $2-3$ poll. longa, $1-1^{3 / 4}$ lata.

Flores subpaniculati albi vel flavescentes, 2 poll. diam. Sepala viridia lanceolata. Petala subbiserialia, ovata, expansa. Fructus globosi flavescentes, 1 poll. diam., sepala foliacea gerentes. 


\section{6}

B. rubescens. - Areolis magis lanatis, foliis ovatis acuminatis, dorso violaceo-rubentibus, $2^{1 / 2}$ poll. longis, $11 / 2$ poll. latis.

$\gamma$. rotundifolia Hont. Dyck. - P. acardia PARM. Areolis sublanatis, foliis rotundis acuminatis, initio dorso rubris, tandem viridibus, $2-2^{1 / 4}$ poll. latis, 3 poll. longis.

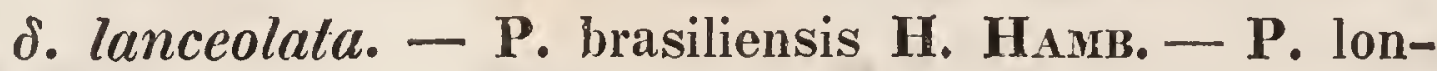
gispina HAw. syn. p. 198? - Areolis parum lanatis, foliis lanceolatis, valde acuminatis, dorso rubentibus, 4 poll. longis, $1-1^{1 / 2}$ poll. latis.

\section{P. spathulata H. BeroL.}

P. crassicaulis Zucc.

Pa: Mexico.

P. trunco ascendente tenui, tandem lignoso; ramis sparsis deflexis; areolis remotis tomentosis, junioribus lanatis; aculeis $1-2$ riøidis, albidis in inferiore, setarum brevium brunnearum fasciculo in superiore areolarum parte; foliis crassis, viridibus, spathulatis.

Specimina in horto Berolinensi 5-pedalia, basi vix 6 lin. diam. Aculei pollicares. Folia $1-2$ poll. longa, 6-10 lin. lata. Flores, teste Cl. de Karwinski, rubri.

\section{P. Pitilache Karw.}

\section{Pa: Mexico.}

P. trunco lignoso, erecto, spinosissimo; ramis subhorizontaliter divergentibus; areolis approximatis tomentosis; aculeis 3-6 inaequalibus, rectis, rigidis; foliis carnosis viridibus lanceolato-ovatis.

Truncus 4-6 lin. diam. (in patria crassior.) Aculei $1-1 \frac{1}{2}$ poll. longi. Folia $1^{1 / 2}$ poll. longa, 8 lin. lata.

\section{P. Bleo DC.}

Prodr. III. p. 475̃. - Cactus Bleo H. B. et Kunth nov. gen. am. 6. p. 69. - Botan. regist. t. 1473. - Botan. magaz. t. 348. - OrTo's GZ. 1836. No. 20. S. 158. Reichenb. fl. exot. 328. - P. cruenta Hort.

Pa: Nova Granada (prope Bandillas in ripa flum. Magdalenae) et Mexico.

C. arborescens teres, spinosus; spinis $5-6$ fas- 




\section{8}

ciculatis; foliis alternis, petiolatis, oblongis, acuminatis (KuNTh.).

P. arboresceńs, ramosa; ramis teretibus viridibus; areolis remotis fulvo-tomentosis; acule is $7-8$ inaequalibus, nigris, rigidis, subfasciculatis; foliis viridibus, subtus asperi-punctatis, obovatis, acuminatis.

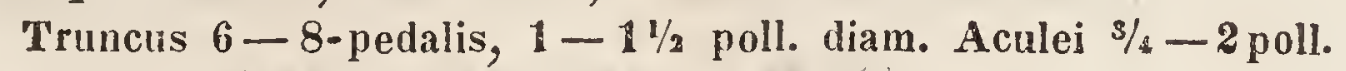
longi. Folia 4 poll. longa, prope apicem $13 / 2$ lata.

Flores ad apicem ramorum $2-4$, breviter pedunculati, incarnati vel rosei, $11 / 2$ poll. diam., Chironice frutescenti similes. Sepala brevia viridia. Petala obovata retusa, extus albida. Stamina rubra, basi alba. Stigma 5-7-fidum.

\section{P. grandifolia HAw.}

Suppl. p. 85. - Cactus grandifolius Link enum. 2. p. 25. - Reichenb. fl. exot. 329. - P. grandiflora. Hont.

Pa: Brasilia.

P. spinis numerosis variis validis, majoribus biuncialibus nigricantibus, foliis lanceolato-oblongis saturate viridibus, carnosulis, costa subtus valida, deorsum fere in petiolum desinente (HAw.).

P. arborescens, altissima, ramosa; areolis confertis fulvo-tomentosis; aculeis $8-10$ brunncis inaequalibus; foliis viridibus, subtus asperis, lanceolatis.

Truncus et rami praecedenti similes. Aculei $1 / 2-1$ poll. longi. Folia 4 poll. longa, $1 \frac{1 / 2}{2}$ poll. lata.

Flores verni; ad apices ramorum, subpedunculati, lilaceo-rosei, $1^{3 / 4}$ poll. diam. Sepala obscure viridia. Petala basi angusta, sursum latiora, acuminata. Stamina rubra, antheris flavis.

\section{P. sinniaeflora DC.}

Revue p. 75. t. 17. - Cactus zinniaeflorus Fl. mex. ic. ined.

$\mathrm{Pa}$ : Mexico.

P. foliis ovatis, acutis, undulatis; aculeis axillaribus geminis, demum in caule circa cicatrices subfasciculatis.

Flores solitarii, terminales, splendide rubro-violacei, extus virescentes, 1 poll. diam. Petala obcordata. Ovarium sepalis obsitum.

\section{\%. P. lychnidiflora DC.}

Revue p. \%5. t. 18. - Cactus fimbriatus Fl. mex́. ic: ined. 


\section{8}

P. foliis ovatis acutis; areolis fusco-tomentosis; aculeis in axilla solitariis.

Truncus 1-2 poll. diam., lignosus. Aculei 1-2 poll. Iongi, recti. Folia $2-3$ poll. longa, $1-1 \frac{1 / 2}{2}$ lata.

Flores solitarii, terminales, croceo-armeniaci, Lychnidi chalcedonicae similes, 2 poll. diam. Ovarium viride, ficiforme, margine superiore sepaliferun. Petala biserialia, cuneata, apice fimbriata.

\section{P. opuntiaeflora DC.}

ic. ined.

Revue p. 76. t. 19. - Cactus opuntiaeflorus Fl. mex.

Pa: Mexico.

P. foliis obovatis mucronatis subgeminatis; aculeis axillaribus solitariis longissimis.

Truncus lignosus, 1 poll. diam. Aculei $2-3$ poll. longi. Folia 11/3 poll. longa, $9-10$ lin. lata.

Flores solitarii, subpedunculati, sordide rubentes, 1 poll. diam. Ovarium viride, subglobosum, basi attenuatum, superne sepaliferum, fasciculis pilosis obsitum. Petala biserialia, ovata, subacuta.

\section{P. rolundifolia DC.}

Revue p. 7\%. t.20. - Cactus frutescens Fl. mex. ic. ined. $\mathrm{Pa}$ : Mexico.

P. foliis subrotundis mucronatis; areolis setosis; aculeis axillaribus solitariis.

Truncus crassus lignosus, ramosus; rami floriferi $3-4$ lin. diam. Aculei ramorum juniorum breves, in ramis senioribus solitarii pollicares, e fasciculo setarum orti. Folia viridia, $5-7$ lin. diam. et longa.

Flores (ex icone citata) laterales, solitarii, flavi, coccineosubvariegati, fere $1 \frac{1}{2}$ poll. diam. Ovarium viride sepaliferum. Petala rosacea, mucromulata. Stamina patentissima; stylus ruber, stigmatibus flavis. - Fructus obovatus, apice umbilicatus, 10 lin. longus, 6 diam., ruber, setoso-areolatus.

\section{P. portulacaefolia DC.}

Prodr. III. p. 4\%5. - Cactus portulacifolius 'L: LAy. dict.1. p, 543. - Luv. hort. jam. 2. p.256. - Opuntia arbor spinosissima, foliis Portulacae cordatis PLUr. cat. p. 6. ed. Burm. p. 190. t. 19\%. f. 1. - Jamacaru sexta PISON. p. 191?

Pa: Ins. Carib. 



\section{9}

C. caule tereti arboreo spinoso, foliis cuneiformibus retusis (LiNn.).

P. foliis obovato-cuneatis; aculeis sub folio solitariis, demum in caule fasciculatis (DC.).

Arbor Mali magnitudine. Aculei nigricantes, semipollicares. Folia in ramis cumeiformia, emarginata, crassa, succulenta ( $\mathbb{P} 1 \mathrm{~m}$.) Flores solitarii terminales, purpurei, 1/1/2 poll. diam. Ovarium sepalifertim. Petala subrotunda, emarginata. - Fructus sunt poma subrotunda, subangulosa, nullis foliis suffulta, umbilicata, $1^{3 / 4}$ poll. diam., virescentia, carne albida, seminibus numerosis nigris.

\section{P. horrida DC.}

Prodr. HI. p. 485. - Cactus horridus II. B. et KUNTH nov. gen. am. 6. p. 10. - Kuмтн syn. pl. aeq. III. p. 322.

Pa: Brasilia (in collibus siccis prov. Jaen de Bracamoros ad flumen Marannon).

P. arborescens, ramis teretibus spinosis; spinis $1-3$ subulatis in axilla lanuginosa foliorum; foliis alternis oblongis, utrinque acutis (Kuv'r).

Flores $2-5$ axillares, pedunculati, parvi, rubri, stigmatibus $3-4$.

\section{P. glomerala PFR.}

Mryen Reise I. S. 452. - OtTo's GR. 1833. No.27. S. 212,

Pa: Peru (Andes Tacnenses).

P. humilis spinosissima; foliis confertissimis; aculeis bipollicaribus fulvis.

Flores foliis circumdati, supra aculeos non prominentes. Cumulos format $1-1^{1 / 2}$ peđ̃. altos, colore fulvo. $-\mathbb{E}$ descriptione non patet, utrum folia aculeis obtecta sint, an truncus?

13. P? planlaginea H. Görting.

Planta novella, parum hucusque nota! 


\section{Addenda:}

Pag. 13. Mamm. cirrhifera. Flores copiosissimi mensibus Aprili et Majo, rosei, e fasciculis densis lanae, setarumque longarum albarum provenientes.

Ibid. Mamm. subangularis. Flores mense Majo, minus copiosi, fere sanguinei, patentissimi, e fasciculo lanae inermi provenientes.

Ibid. Mamm. loricata ad Heteracanthas potius transferenda est, aculeorum centralium causa, in plantis adultis luculentissime distinctorum.

Pag. 16. Mamm. pycnacantha. - Echin. radiatus Hort. BELG.

Pag. 26. Mamm. acanthoplegma. - M. leucocephala H. Paris.

Pag. 29. Mamm. tentaculata. - M. olivacea Hort.

Pag. 3\%. Mamm. Wildiana. - Dietrich in: Otтo's GZ. 1836. No. 18. S. 13\%. - Flores 6 lin. longi. Germen in axillis occultatum; obclavatum. Sepala $6(4-5$ ) lin. longa) basi viridia, superne albida, nervo dorsali fuscorubente. Petala 6, lineari-lanceolata. Stamina corolla dimidio breviora, alba, basi virentia, antheris fere globosis. - Bacca obclavata, apice lato, impresso, fusco-rubra.

Pag. 54. Corolla exsiccata Echin. ingentis ope aquae calidae perfecte examinari poterat. Sepala rigida, cartilaginosa, lanceolata. Petala obtusa, 3/4 poll. longa, 3 lin. lata. Stamina numerosissima tubo affixa. Stylus crassus, stamina extima vix superans, stigmatibus 12 elongatis. Semina 2 lin. longa, apice attenuata.

Pag. 60. Echin. spiralis. Receptaculum viride, squamis acutis, purpurascentibus, margine albidis, obsitum. Sepala brevia, rigida, lineari-lanceolata. Petala tenerrima, linearia, 1 poll. longa, 2 lin. lata, acuminata, nonnulla apice lacinulata. Stamina numerosissima purpurea, antheris minutis flavidis. Stylus crassus purpureus, stamina vix 



\section{1}

superans, stigmatibus 16 flavis, dorso rubris. Semina minutissima, nitide nigra.

Pag. 61. Rchin. robustus. Sepala brevia, lata, obtusa, reflexa. Petala acuminata, 15 lin. longa, 3 lin. lata. Stamina brevia, antheris minutis albidis. Stylus tenuis, stamina vix superans, stigmatibus 10 elongatis. Semina 1 lin. longa, nigricantia, non nitentia.

Pag. 65. Hichin. exsculptus. - Ech. crenatus, guyannensis Hodt. Galt.

Pag. 111. Cer. Mallisoni. - Verhdl. d. GBV. f. Pr. B. XII. S. 134. T. 1. - C. erectiusculus, multangularis; angulis obtusis tuberculatis; areolis albo-tomentosis; aculeis rectis subaequalibus; stylo petalis breviore; stigmate 7 -radiato. - Truncus 6-7-angulatus. - Fructus ovatus, 8 - sulcatus, angulis crenatis.

Pag. 121. Cer. speciosissimus \& ignescens. Floruit mense Novembri. 'Tubus 2 poll. longus, sordide viridis, areolis tomentosis et spinulosis, squamulisque purpurascentibus obsitus. Squamulae sursum longiores in sepala abeunt roseo-lilacea. Corolla campanulata 3 poll. diam., e 4 seriebus petalorum constans. Petala ignea, $2^{1 / 2}-3$ poll. longa, 10 lin. lata, acuminata, mucronatula, extima parum patentia, dorso pallidiora. Stamina numerosissima coccinea, basi et apice alba, antheris minutis pallide sulphureis. Stylus carneo-albidus, staminibus paulo longior, stigmatibus 10 albis, 3 lin. longis. 




\section{I n d e x.}

Cactere 1.

Cactoideae 1.

Cactus 1. 40.

abnormis 88.

alatus 124. 131. 132.

ambigutus 104.

aureus 68.

Bleo 176.

Bomplandii 161.

brasiliensis 168.

canescers 38.

caripensis 114 .

chlorocarpus 96.

cochenillifer 150. 153.

columnaris 26 .

communis 42.

coquimbanus 90 .

coronatus 33.42.

curassaricus 148.

cylindricus 33.169 .

decumanus 152.

depressus 67.

Dillenii 162.

divaricatus 95 .

eburneus 90.

elegans 124.

elongatus 152.

Erinaceus 52.

fasciculatus 135 .
Cactus ferox 158. $16 \%$.

Ficus indica 152.

fimbriatus 92. 177.

flagelliformis 110 .

flavescens 10.

flavispinus 82.

foliosus 148 .

fragilis $14 \%$

frutescens 178.

funalis 135 .

gibbosus 74 .

glomeratus 39.

grandiflorus 113.

grandifolins 177.

Haworthii 82 .

Helicteres 39 .

heptagonus 88.

hexagonus 88.

horridus 179.

Humboldtii 112.

humilis 162 .

Hystrix 44.

icosigonus 112.

intortus 67.

laetus $10 \%$.

lanatus 78.

lanceolatus 15.2 .

lanuginosus 80 .

latispinus 56. 
Cactus macrocanthos 45 .

mammillaris 9 .

- prolifer 10.

Melocactus 41. 42.

micranthus 133 .

microthele 9 .

monacanthos 164 .

moniliformis 102.

multangularis 57.77.

nanus 104.

niger 83.

nigricans 165.

nobilis 57.67 .75$.

nudus 39.

obvallatus 63.

Opuntia 149. 153.

- Tuna 164.

opuntiaeflorus 178.

paniculatus 107.

paradoxus 168.

parasiticus 135.

parvispineus 52 .

pendulinus 134.

pendulus 133.

pentagonus 88. 99. 109.

Pereskia 175.

peruvianus 88: 90.

phyllanthoides 124 .

Phyllanthus 125.

Pitajaya 105.

polvanthos 163 .

polygonus 105 .

portulacifolius 178.

prismaticus 109. 118.

prolifer 9.

pseudococcinellifer 165 .

pseudomamnillaris 28.

pusillus 36. 148.

pyramidalis 45 .

recurvus 57.

reductus 75 .

repandus 93.

reptaus 109.

Royeni 80. 81. 82. 84. 93.

Scopa 64.

senilis 76 .

sepium 113.
Cactus serpens 103.

speciosissimus 120.

speciosus 120.124.

Spinii 28.

spinosissimus 166.

stellaris 36 .

stellatus 36 .

stramineus 10.

strictus 83. 151.

subquadriflorus 171.

tenuis 139.

tetragonus 99.

tomentosus $\mathbf{1 6 0 .}$

torquatus 130.

triacanthos 163 .

triangularis 116.

- aphyllus 116.

- foliosus 118.

triqueter 118.

truncatus 127.

tuberculatus 151.

Tuna 161.

- nigricans 165.

viviparus 33 .

zinniaeflorus 17 .

Cassytha baccifera 133.

Cereastri 75.

Cereus 69.

aciniformis 101 .

Ackermanni 123.

acromelas 84.

acutangulus 107:

Aethiops 85.

affinis 99. 106.

alacriportanus 87 .

alatuś 131. 132.

albisetosus 115 .

albispinus 85 .

ambiguus 104.

anisacanthus 96 .

Antoini 114.

aquicaulensis 90 .

arequipensis 89 .

armatus 81 .

articulatus 103. 


Cereus aureus 83.

- pallidior 84.

azureus 86.

baxanicnsis 109 .

biformis 114.

bifrons 120. 122 .

Bomplandii 108.

Bradypus 76 .

brevispinulus 114.

caesius 89.

calvescens 89 .

candelabrius 109.

candelaris 89.

candicans 91.

caripensis 114.

chilensis $\mathbf{8 6}$.

chlorocarpus 96.

cinerascens 101.

clavarioides 173.

coccineus 120. 122.

coerulescens 85 .

coguatus 106.

columua, Trajani 76.

compressus 116.

conicus 97.

coquimbanus 86 .

crenulatus 84.

crispatus 130 .

- crenulatus 130.

cubensis 94.

cupulatus 97.

Curtisi 81.

currispinus 89.

cylindricus 169 .

decagonus 85.

denuảatus 73.

Deppei 101.

dichroacanthus $\mathbf{7 6}$.

divaricatus 95.

d vergens 95 .

Dyckii $8 \%$.

eburneus 90.

elegans 138.

erectus 95.

eriophorus 94.

euphorbioides 92.

exerens 99.
Cereus extensus 119.

Eyriesii 72.

ferox 79.

fimbriatus 92. 95 .

flagelliformis 110 .

flagriformis 111.

flavescens 79 .

flavispinus 82.

floccosus 81 .

formosus 106.122.

foveolatus $7 \%$.

fulvispinosus 82 .

gemmatus 72. 96 .

geometrizans 90.

gibbosus 74.

glaucus 89. 98.

- speciosus 106.

gloriosus 80 .

gracilis 93. 115.

grandiflorus 113.

grandis 99.

grandispinus 92.

griseus 91.

Haworthii 82.

heptagonus 88.

hexagonus 88 .

hexangularis 106.

Hookeri 125.

horridus 119.

Humboldtii 112.

humilis $\mathbf{1 1 5 .}$

hybridus 121.

Hystrix 91.

Jamacaru 98.

jasmineus 72.

icosigonus $11 \%$.

imbricatus 93.170.

incrustatus 97.

incurvispinus $7 \mathbf{1}$.

inermis $\mathbf{1 1 6}$.

Kageneckii 77.

Knightii 139.

latevirens 99. 106.

laetus 106. 107.

lanatus 78.

lanuginosus 80 .

- aureus 78. 


\section{6}

Cereus latifrons 125.

Lecchii 78.

leptacanthus 101.

leptophis 112.

leucantluus 71 .

Linkii 48.

lividus 98.

lutescens 84.

Mallisoni 111. 181.

magnus 79.

marginatus 9\%. 125.

Mariculi 115.

Martianus 110.

Mendory 85.

micracanthus 80 .

Mirbelii $9 \%$.

mollis 83.

moniliformis 102.

monoclonos 88 .

monstrosus 88 .

montevidensis 65 .

Montezumae 91.

Moritzianus 84.

multangularis $7 \%$.

multiplex 70.

Myosurus 139.

myriacaulon 115 .

myriophyllus 78.

nanus 104.

Napoleonis 117.

niger 83 .

nigricans 83.

nobilis 82.

nycticalus 113.

obtusus 105. 114.

ochracanthus 78.

octogonus 81. 85 .

Olfersii 97.

Ottonis 47.

ovatus 102.

oxygonus 70.

oxypetalus 124.

paniculatus $10 \%$.

parvisetus 99.

pellucidus 108.

pentagonus 109 .

pentalophus 101.
Cereus Perotetti 98. peruvianus 88. phyllantloides 124 . Phyllanthus 125.

Pitajaya 105. polygonatus 91 . polygonus 105. polylophus $7 \%$. princeps 108. prismaticus 109.118. prismatiformis 106. propinquus 101. pterantluus 113. pterocaulis 140 . pulchellus 74. quadrangularis 106. 114. Quintero 86. radicans 114. ramosus 108. ramulosus 130 . reductus 75 . regalis 92. repandus 80.93 . - spin. aureis 83. reptans 109. 114. retroflexus 100. rhombeus 130. roridus 54 . rosaceus 114. Royeni 80.

Schellasii 73. Schrankii 122.

Scopa 64. senilis 76 . sepium 113. sericeus 173. serpens 103. serpentinus 104. serruliflorus 92. setaceus 119. setiger 116. Smithii 111. speciosissimus 120. 181. spinibarbis 86. spinulosus 115. squamulosus 138. stellatus 87. 

Cereus strictus 83.

strigosus 78.

sublanatus 100.

subrepandus 86. 93. 94.

subsquamatus 119.

surinamensis 88.

syringacanthus 103.

tenellus 109.

tenuispinus 139.

tetragonus 99.

tilophorus 100.

triangularis 116.

- major $11 \%$.

- pictus $11 \%$

trigonus 106. 118.

tripteris 118.

triqueter 118.

truncatus $12 \%$.

- Altensteinii 128.

tuberosus 102.

tubiflorus 71.

tunicatus 170.

turbinatus $\% 2$.

undatus 94. $11 \%$.

undulatus $10 \%$.

undulosus 105.

validus 106.

variabilis 105.

virens 99.

Echinocactus $4 \%$.

Acanthion 65 .

aciculatus $\mathbf{5 1}$.

acuatus 54 .

acutangulus 55 .

acutissimus 64 .

ggglomeratus 60.61 .

anfractuosus 63.

armatus 61 .

aureus 68 .

Boutillieri 73.

candicans 91.

centeterius 65 .

Ceratistes $\mathbf{5 1 .}$

cereiformis 68.

coccineus 50.

cornigerus 56 .

corynodes 55 .
Echinocactus crenatus 181 .

crispatus 62 .

denudatus 73.

depressus 67.

dichroacanthus 62 .

Echidne $5 \%$.

elegans 86.

exsculptus 38. 65. 181.

Eyriesii 72.

Fiscleri 59.

formosus 50.

gibbosus 74.

gladiatus 51.

glaucescens 58.

glaucus $5 \%$

guyannensis 181.

liybocentrus 65 .

Hystrix $5 \%$.

ingens 54. 180.

interruptus 65.

intortus $6 \%$

intricatus 53.

Karwinskii 50.

Langsdorffii 51.

leucacanthus 66 .

leucauthus 71.

Linkii 48.

macrodiscus 59 .

melocactiformis 68.

meonacanthus 46 .

multiplex 80 .

muricatus $\mathbf{4 9 .}$

obvallatus 63 .

oligacanthus 53.

ornatus 62 .

orthacanthus 53.

Ottonis 47.

oxygonus 70.

- oxypterus 57.

pachycentrus 66.

parvispinus 52.

Pfeifferi 58.

phyllacanthus 63 .

platyacanthus 59 .

polyacanthus 52 .

prolifer 61 .

pruinosus 54 . 
188

Echinocactus pulchellus 74. pyramidalis 86 . radiatus 180 . recurvus $5 \%$.

rhodacanthus 50 . robustus 60.61 .181 . rosaceus 55.

Salmianus 44. Scopa 64.

Sellowianus 5.5 . sessiliflorus 56 . spectabilis 61. Spina Christi 59. spiralis 60. 180. subgibbosus 65. subuliferus 61.67 . sulcatus 70 . tenuispinus 48. tephracanthus 53. tortuosus 49. tuberculatus 60 . tubiflorus 71. turbinatus 72.

Echinomelocactos 42 .

Epiphyllum 123. 127.

Ackermanni 123. alatum 131. 132. Altensteinii 128. ciliatum 130. crenulatum 130. crispatum 130. Hookeri 125. hybridum 121. latifrons 125. oxypetalum 124. phyllanthoides 124 . Phyllanthus 125. platycarpum 131. ramulosum 130. rhombeum 130. speciosum 124. truncatum $12 \%$. - multiflorum 128.

Hariota 129. 141. salicornioides 141.
Jamacaru 101. 106. 178.

Jaracatia 168.

Lepismium 138.

commune 138.

Knightii 139.

Myosurus 139.

paradoxum 140.

Mammillaria 5.

acanthoplegma 26. 180. acanthostephes 16 . aciculata 29 . affinis 6.11. albicla 28. ancistroides 36 . Andreae 31. angularis 12. anisacantha 17 . atrata 31. aurata 31. bicolor 27. brevimamma 34 . caespiticia 35. caespitosa 6 . canescens 28. 33. Caput Medusae 2\%. carnea 19. cataphracta 11. centrispina 20 . ceratophora 14. chrysacantha 28. cirrhifera 13. 180. - spin. fusc. 13. columnaris 9 . 31 . compressa 12. confinis 23. conica 38. conoidea 35. cornifera 34. coronaria 33 . crebrispina 35. criniformis 36 . crinita 37. crucigera 25. curvata 15. 

Mammillaria cylindracea 32.

cylindrica $3 \%$.

densa 6.

depressa 28.

diacantlua 26.

disciformis 22.

discolor 28.

divergens $\mathbf{1 2 .}$

Dyckiana 26.

Echinaria 5 .

echinata 5 .

elegans 25.

elongata 6 .

eriacantha 32.

erinacea 31.

exsudans 15.

Fischeri 20.

flavescens 10 .

fulvispina 30 .

fuscata 28.

geminispina 26. $2 \%$.

gibbosa 38 .

gladiata 14.

glochidiata 36 .

- aurea 37.

glomerata 39 .

grandillora 33.

Haageana 26.

hamata 34 .

Helict eris 39.

heteracantha 13.

hexacantha 30 .

hybrida 31.

Hystrix 21.

jalappensis 17.

intertezta $\%$.

inuncta 31.

irregularis 11.

Karwinskiana 19.

lanifera 38.

latimamma 16.

Lehmanni 15. 23.

leucacantla 23.

leucocephala 180.

longimamma 22.

loricata 13. 180.

macracantha 20.
Mammillaria macrothele 24 .

magnimamma 14.

mit is 39 .

Mystax 18. 21.

neglecta 31.

nivea 27.

nivosa 11.

nuda 39 .

octacantha 23.

olivacea 180.

Parmentieri 10.

parvimamma 9.

Perote 26.

Plaschnickii 24.

polyëdra 17.

polygona 17.

polythele 8 .

prolifera 9. 10.

pulchella 28.

pulchra 29.

pusilla 36.

pycnacantha 16. 180 .

pyramidalis 31 .

quadrispina 8.

radians 14.

recurva 15.

rhodantha 31.

rutila 29.

Schiedeana 14.

Seitziana 18.

Sempervivi 22.

setosa 30 .

simplex 9.

sphacelata $\%$.

stella aurata 6 .

stellaris 36 .

straminea 10.

subangularis 13. 180 .

subcrocea 6 .

subpolyëdra 17.

supertex1a 25.

tentaculata 29. 180 .

tenuis 6 .

tetracantha 18.

Toaldoae 27.

tortolensis 11.

triacantha 12. 
Mammillaria uberiformis 23.

uncinata 34.

vetula 32 .

villifera 18.

vivipara 33 .

Wildiana 37. 180.

Zuccariniana 20.

Melocactus 40.

ambiguus 71 .

amoenus 43.

atrosanguineus 44 .

Besleri 41.

- affinis 60.

columna Trajani 46.

communis 42 . 43 .

- conicus 43.

- Grengelii 43.

- havannensis 43.

- Jördensii 43.

- laniferus 43.

- macrocephalus 42.

- oblongus 42.

- viridis 42 .

curvispinus 46.

elegans 71.

Gilliesii 50.

ingens 54 .

Langsdorffii 52.

latispinus 36 .

macracanthus 45.

mammillariaeformis 40 .

meonacanthus 46 .

monoclonos 88 .

placentiformis 41.

pyramidalis 44.

rubens 43 .

Salmianus 44.

spatangus 45.

violaceus 45 .

Nopaleae 1.

Opuntia 143.

albicans 155.

alpina 146.

Amyclaea 159.
Opuntia andicola 145.

articulata 103.

aurantiaca $14 \%$.

Bomplandii 161.

brasiliensis 168 .

caespitosa 146.

candelabriformis 159 .

catocantha 166.

clavarioides 173.

coccinea 161.

coccinellifera 150. 161. 165.

coerulea 155.

corrugata 144.

crassa 153.

crinifera $15 \%$.

cruciata $16 \%$.

curassavica 148.

cylindrica 169.

decipiens 172.

- major 170.

Decumana 152.

decumbens 154 .

dejecta 159.

diffusa 159.

Dillen̈̈ 162.

dolabriformis $16 \%$.

elata 152.

elatior 165 .

elongata 152. 164.

extensa $14 \%$.

exuviata 170.

ferox $16 \%$.

Ficus indica 152.

flexibilis 161.

foliosa 148.

fragilis 147 .

fulvispina 164 .

furiosa 170.

Gilliesii 102.

glaberrima 153.

glauca 153.

glaucescens 155 .

glaucophylla $\mathbf{1 6 2}$.

glomerata $\mathbf{1 4 5}$.

gracilis 172.

grandis 155.

Hernandezii 153. 


Opuntia horizontalis 145. 159 horrida 162.

humifusa 146.

humilis 162.

Hystrix 148.

imbricata 170.

inermis 151.

intermedia 150

irrorata 154.

italica 119.

Kleiniae 171.

lanceolata 152.

lanigera $15 \%$

lasiacantlia 160.

leptocaulis 173.

leucacantha 160. 167.

leucosticta 16\%.

leucotricha 156 .

longispina 145. 156.

maxima 152. 159.

media 158.

megacantha 160 .

mesacantha 146 .

mexicana 150.160.

microdasys 154 .

microthele 173.

missouriensis 158.

monacaintha 164.

nana 150 .

nigricans 165.

oblongata 161.

oligacantha $15 \%$.

orbiculata 156.

ovata 102. 144.

parvula 153.

Phyllanthus 126.

platyacantha 103. 146.

Poeppigii 174.

polyacantha 158.

polyantha 163 .

polymorpha 103.

Prate 155.

Pseudo-Tuna 162.

puberula 156.

pubescens 149 .

pulvinata 154.

pusilla 145. 148.
Opuntia ramulifera 173.

repens 154 .

robusta 165 .

rosea 171.

rubescens 166.

Sabinii $14 \%$.

salicornoides 141.

Salmiana $\mathbf{1 7 2 .}$

senilis 157.

sericea 155.

- longispina 136.

spinosissima 166.

spinulifera $15 \%$.

splendens 159.

Stapelia 171.

stricta 151.

subferox 167.

sulphurea 144.

tomentosa 160.

triacantha 163.

tuberculata 151.

tuberosa 146.

Tuna 161. 163.

tunicata 170 .

undulata 170.

virgata 173.

vulgaris 149.152.

- major 150 .

Opuntiaceae 1. 3.

Pereskia 175.

acardia 176. aculeata 175.

Bleo 176.

brasiliensis 176 .

crassicaulis $\mathbf{1 7 6}$.

cruenta 176.

glomerata 179.

grandiflora 177.

grandifolia $17 \%$.

horrida 179.

lanceolata 176.

longispina 176.

lychnidiflora $17 \%$.

opuntiaeflora 178.

Pititache 176. 


\section{2}

Pereskia plantaginea 179. p.ortulacaefolia 178. rotundifolia 178. spathulata 176. zinniaeflora 177.

Phyllanthus 123. americana 125.

Pitahaya 113.

Portulaca americana 175.

Rhipsatideae 3.

Rhipsalis 129.

calamiformis 135 .

Cassytha 133.

- major 134.

- pilosiuscula 135.

Cereuscula 137.

crispata 130.
Rhipsalis echinata 136.

fasciculata 135.

floccosa 134.

funalis 135 .

grandiflora 135.

mesembrianthoilles 136.

micrantha 133.

pachyptera $13 \%$.

parasitica 135. 136.

pendula 133.

pentaptera 132.

platycarpa 131.

ramulosa 130.

rhomber 130.

salicornoides 141.

Swartziana 131.

trigona 133.

undulata 136.

Tuna elatior 165.

- major 161. 163.

- mitior 150.

Druck von J. Hotop in Cassel. 


a Stück - la pièce M.Pf.

Petiveria alliacea, Herba Scorodoniae.

Phoebe Barbusano, liefert das canarische Ebeuholz - fournit le bois d'ébène des Canaries ............. . .

Phormium tenax, neuseeländ. Flachspflanze - Lin de la Nouvelle-Zélande -6 ) a

Píper Betle, Betelpfeffer - Bêtle. . . . . nigrum, schwarzer Pfefferstrauch -
Poivrier noir . .

) Neesianum

Titodascum - Poivrier du Japon

Plectranthus fruticosus, Hausmittel gegen Krämpfe, auch als mottenvertreibend empfohlen - germaine en buisson, dite de chasser les teignes . . . . . 12 St. 5 -,

Pogostemon Patschouli, die Patschoulipflanze - le Patchouly . . . 12 St. 6-,

Psidium aromaticum. ) Cattleyanum, Guajavabaum - Goyavier - 75

) chinense ........... - 75

Pueraria Thunbergiana

Ravenala madagascariensie, Baum der Reisenden - arbre des voyageurs . . 3 - à $10-$

Rosmarinus officinalis, Rosmarin -50 a 1 -

Sanseviera zeylanica, den Bowstring-Hanf liefernd
1 -

$2-$ 3 -

$-$

150

$1 \overline{50}$ $-50$ 60 75 $1-$ 2
Schinus Molle peruanistick - la pièce M. Pf

Scilla maritina, echte Meerzwiebel - Squille rouge ou Scipoule; sehr starke $\mathrm{Z}$ wiebeln bulbes très-forts . . . . . . . 1-a 2 Seguiera americana, amerikanisches Stinkholz - sipo d'alho .......... Smilax officinalis, Sarsaparilla liefernd fournit le salsepareille......... 2 Sterculia diversifolia ......... . 1 Teucrium fruticans, buschiger Gamander, liefert herba Teucrii veri . . - 50 à 1 1) Marum, Katzenkraut . . . . . - 40 à 1 Thea Bohea, chinesischer Theestrauch, viridis 12 St. $5-,-50$ a -75

Tragia volubilis

Trichilia undulatifolia, Kerseboom, Purgans und Emmenagogum Xanthorrhoea minor ..... ") Preissi ............ 2 Zanonia sarcophylla, dickblättriger Bandelierstrauch

Zingiber Zerumbet, Zerumbet oder Blockingwcr - Gingembre

150

\section{Agave, Dasylirion, Yucca etc.}

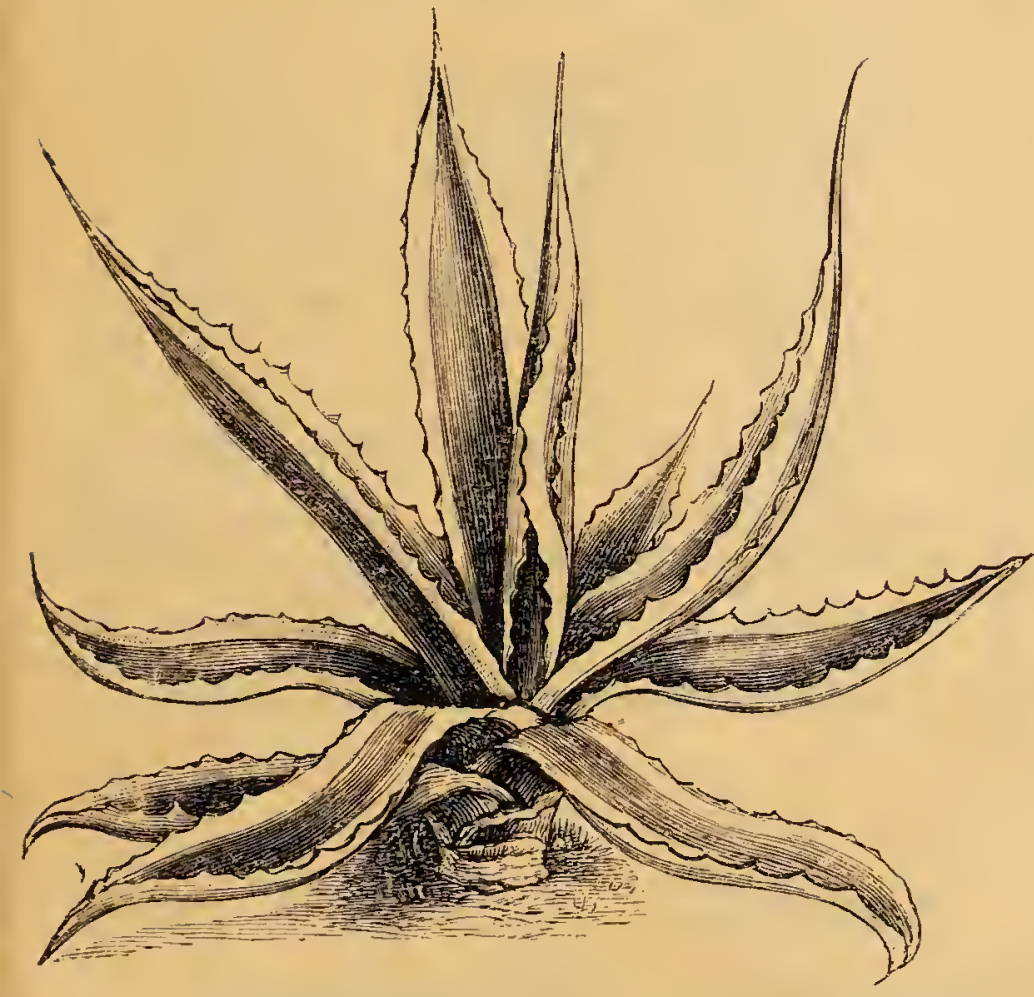

Agave americana fol. aur. marg.

à Stück - la pièce M.Pf.

Agave americana americana fol. var.

" fol. aur. marg. (picta) -50 à 6 1,50 à $6-$ starke - fort 10 angustifolia $\dot{2} \div \dot{2} 6$ applanata. atrovirens attenuata subdentata . . . . . 15 Beaucarnei Bessereriana $5-$ D) longifolia Boucheana vera caribaea Celsiana . . . . . . . 1 - a 3 chloracantha coccinea. conduplicata Corderoyi brevifolia 1) longifolia Yirioides (dealbata) . . 3- a $10-$

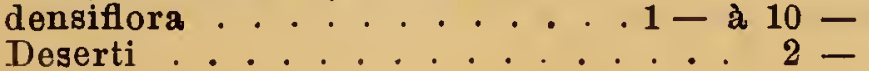

à Stück - la pièce M.Pf́. Engelmanni ............ ensifolia. . . . . . . . . 3 - ̀े 10 erubescens ferox filifera . . 2 -

Ghiesbreghti, stark - fort . . .5 - à 15 Gilbeyi (Roezlii) . . . . . . 4- a 15 grandidentata...... . $1-$ a $6-$ Gustaviana . . . . . . 4- a 20 Henriquesi, Baker . . . . 3- à 5 heteracantha. . . . . 2,50 a 15 horrida (Regeliana) . . . . . $2-$ a $10-$ Hookeri. . . . 150 Houlletiana . . . . . . . 2 Jacquiniana, vide lurida.

Inghami gigantea . . . . . . . . 5 Ixtli ............... $3-$ a 6 Kerchovei . . . 4- a $20-$ ) brevifolia . . . . . . . 250 latissima $\ldots . .30$. $10-$ Lechuguilia $\cdots 2-$ a $5-$ lophantha . . . . . -75 à 15 lurida (Jacquiniana) . . . . . 1 - a 6 maculata, Rgl. in horto Dyckense culta

marmorata ....... $2-\mathrm{a} 10-$ mexicana fol. striatis . . . . i, 50 à 6 micracantha......... 250 miradorensis (Desmetiana) $: 2 \div$ a $6-$ Nissoni ............ . 150 Ousselghemiana. . . . $2-$ a $5-$ Palmeri, Engelm. . . . . 2 - a 5 Parryi, Engelm. . . . . . . . . 10 picta vide americana fol. aur. marg.

polyacantha......... 1 - a $25-$ Regeliana, vide horrida.

rigida var. Sisaliana, den kostbaren

sisalhanf liefernd, wird auf den $\mathrm{Ba}$ -

hama-Inseln in grossem Maassstabe angebaut - fournissant le chanvre de

Sisal . . 12 St. $10-$ à $15-, 1-$ à 150 Robini ............. $15-$ rupicola . . . . . . . . $2-$ a $15-$ Salmiana . . . . . . -60 à 10 " sehr stark - très-fort . . 15 - a 30 Scolymus . . . . . . . . 1 - à 2 Sebastiani . . . . . . . . $2-$ à 3 Shawi, Engelm. . . . . . $6-$ a $20-$ spec. Paso del Macho . . . . . 8 - a 12 spectabilis ............ . 3 - 


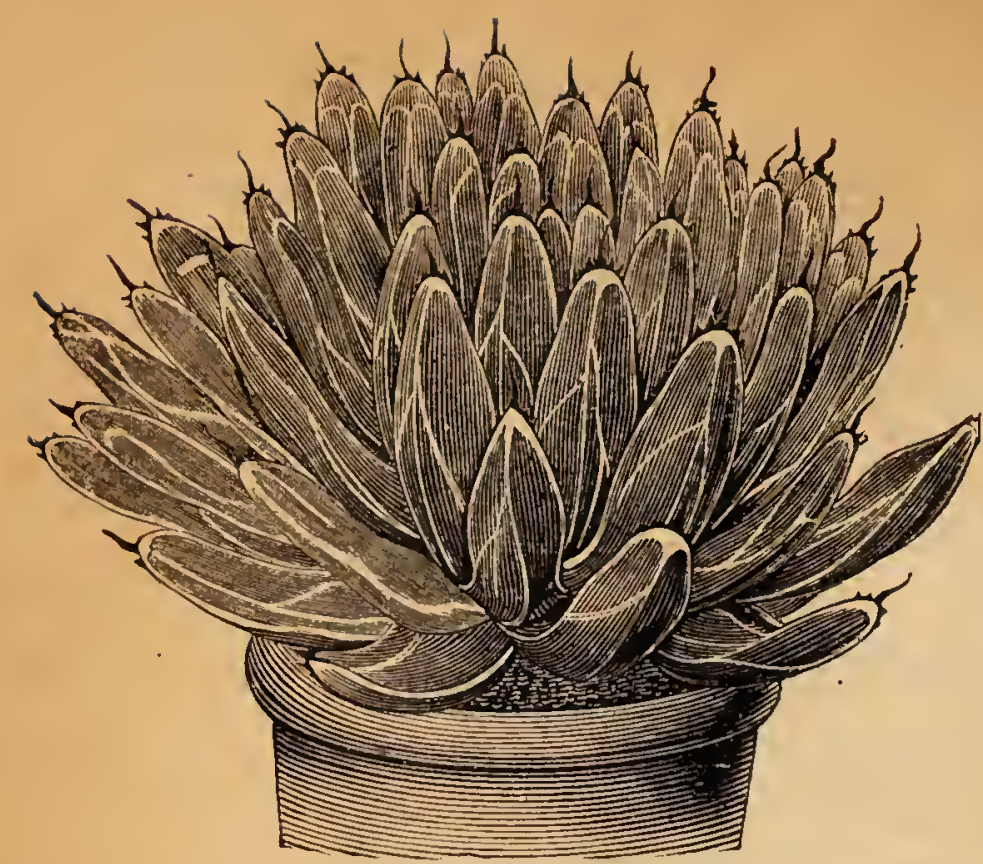

Agave Victoriae Reginae.

à Stück - la pièce Mr. Pf.

Agave striata, prächtige Species, ähnlich stricta (Bonapartea Hystrix) - superbe. ressemblant à stricta ou Bonapartea Hystrix . . . . . . . 20 - à $30-$ "stricta (Bonapartea Hystrix), prachtvoll - magnifique . . . . . 8 - à 20 sylvestris

Troubetzkoyana

2 - à 10 univittata, sehr schön - très-beau 1 - a 10 Vanderwinneni, stark - fort 8 - a 15 Verschaffelti

Victoriae Reginae (Consideranti), die schönste und auffallendste aller Sorten - lo plus beau ot le plus remarquable de tous. . . . . 4- à 25 Wilding

Wislizeni $\therefore \quad 150$ xalapensis - 2 i 250 xylacantha $2-\mathrm{a} 10-$ 12 schöne Sorten unserer Wahl . . $10-$ 12 belles espèces à notre choix. . . 10 "25 " " " ... 30 Elitesortiment von 25 Sorten. . 50 Collection de 25 sortes d'élite.... 50 Beaucarnea, vide Pincenectitia. à Stück - la pièce M. Pf.

Beschorneria yuccoides (Roezlia Regia), 750 Bonapartea Hystrix, vide Agave stricta.

" juncea acrotrich e (serratifolium) 1 - a 8 -

" acrotriche glaucum ..... . 2- $10-$

" gracile ............... 150

) graminifolium ......... 1 -

) juncifolium . • . · · 1,50 à 6 -

) longifolium verum (Roulinia pitcairniaefolia) .......1- d

Wheeleri (Nolina) . . . 2 - a 5 -

Dyckia princeps ........... 4 regalis ........ 2 - à 5 -

"remotiflora.......... 60 à $1-$

"sulfurea................ -75

Fourcroya candelabrum . . . . . . . 2 -

") cubensis ............... . . 4-

) gigantea .................

) Lindeni, buntblättrig - à feuille panachóe......... 6 - . à 12 rigida

$1-a ̀ d-$

Hesperaloë yuccaefolia

Pincenectitia tuberculata (Beaucarnea recurvata)

glauca (Beaucarnea glauca)..... 3 -

Puya coarctata. . . . . . . . 150

Yucca albo-spica (filifera) . . . . . 10 -

1) aloëfolia -50 a 2 ). fol. var., hübsche junge Pfl. - jolies jeunes plantes . 12 St. $10-, 1-$ stark - fort $12 \mathrm{St} .40-, 4-\grave{a} 8$ " angustifolia .............. 1 baccata, Torr. . . . . . $2-a$ canaliculata (Treculeana) . . . 1- à 10 "elata albo-marginata. . 1,50 à 3 " filamentosa, prachtrolle und leichtblühende Freilandsorte - espèce de pleine terre, fleurissant franchement, superbe $12 \mathrm{St} 5-,-50$ a sehr starke blühbare - très-fortes touffes.......... 1,50 à 3 gloriosa. . . . . . . . . 1 pendula variegata aurea, neu nouv.

quadricolor recurva pendula i2 St. 6 - à $15-,-60$ à 150 ) glaucescens variegata... . 5 rupicola............ 3 - . serrulata .............. 150 Whipplei, sehr distinct - très distinct $2-\mathrm{a} 6-$

\section{Cacteen. - Cactées.}

\section{Astrophytum myriostigma varietates novae - Myriostigmées.}

Unsere werthen Cacteen- Kunden werden es mit Freude begrüssen, dass der erfolgreiche CacteenZüchter Herr Abt Beguin in Brignoles uns in den nachstehend angebotenen Exemplaren seine mit viel Liebe und Mühe erzielten, wirklich staunenerregenden Kreuzungen von Astrophytum myriostigma mit Echinocactus ornatus u. a., sowie seine neuesten Sämlinge von Aloe (siebe Seite 215) käuflich überlassen hat. Alle Exemplare sind neu und einzig in ihrer Art und wir sind überzeugt, dass alle Cacteen-Freunde von der Schönheit derselben entzückt sein werden.

Ayant réussi à acquérir une superbe collection d'exemplaires de Myriostigmées, que Mons. l'abbé Beguin de Brignoles, l'habile semeur et cultivateur de Cactées, a obtenues par hybridation de 1'Astrophytum myriostigma avec des espèces d'Echinocactus les plus distinctes et qui sont sans aucune exception très remarquables sous tous les rapports, nous ne doutons pas que tous les amateurs ne seront saisis d'une vive admiration en voyant les plantes.

Astrophytum myriostigma:

à Stück - la pièce M. Pf.

amabile, sechskantig, schwarzstachlig, sehr stark punktirt, $10 \mathrm{~cm}$ Durchmesser -6 côtes,

Bedingillons noirs, fortement ponctué, 10 centim. de diamètre mit sechs bis acht scharfen Kanten, gedreht, wenig bestachelt, fein punktirt, $5-6 \mathrm{~cm}$ Durchmesser -6 à 8 côtes aigues, tortillé, peu d'aiguillons, finement ponctué . $15-$

Beguini, fünfkantig, spiralförmig gedreht, Areolen $3 \mathrm{~cm}$ von einander entfernt, Randstacheln 2-4, schwaiz, fein punktirt auf dunkelgrünem Grund, 7-8 cm Durchmesser, sehr schön - a 5 côtes, fortement en spirale, finement ponctué sur fond très vert, plante singulièrement belle et distincte

conspicuum, 6kantig, schwach punktirt, Stacheln ziemlich lang, ascbgrau; $14 \mathrm{~cm}$ Durchmesser - 6 côtes, epiderme avec quelques faibles clairières, aiguillons forts, cendrés; $14 \mathrm{~cm}$ de diam.

imperiale, 7 kantig, Stacheln braun, regelmässig punktirt; $14 \mathrm{~cm}$ Durchmesser -7 côtes, très régulièrement ponctué, aiguillons brung; $14 \mathrm{~cm}$ de diam. . . . . ........ 40 - 


Astrophytum myriostigma:

a Stück - la pièce M.Pf.

Lapaixi, mit 8 scharfen Kanten, mehr oder weniger spiralförmig gedreht, lebhaft punktirt, Stacheln hell; 6-9 cm Durchmesser - 8 côtes, aigues, plus ou moins tournées en spirale, finement ponctué, aiguillons ombrés

Lesaunieri, 5 kantig, stark punktirt, Areolen grau, Stacheln verschiedenfarbig;lu$12 \mathrm{~cm}$ Durchmess. - 5 côtes, macules fortes et espacées, aréoles grises, aiguillons divers $; 10-12 \mathrm{~cm}$ dediam. 20 - à 30 mirabile, mit S scharf. Kan. ten, gelblichweiss p unktirt, Stacheln unregelmässig; $10 \mathrm{~cm}$ Durchmesser - à

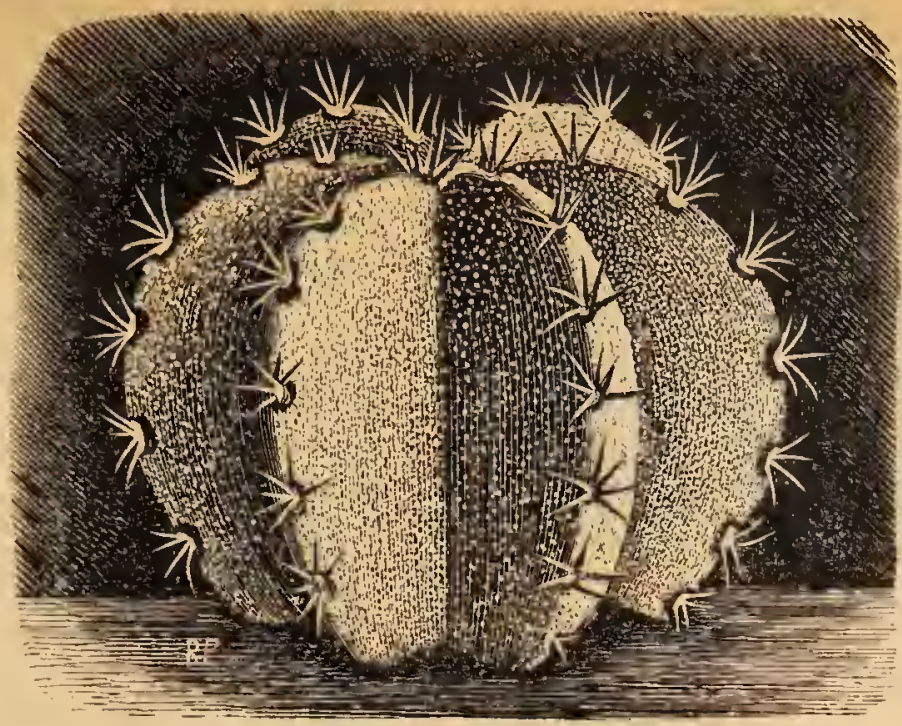

Astrophytum myriost. regale.

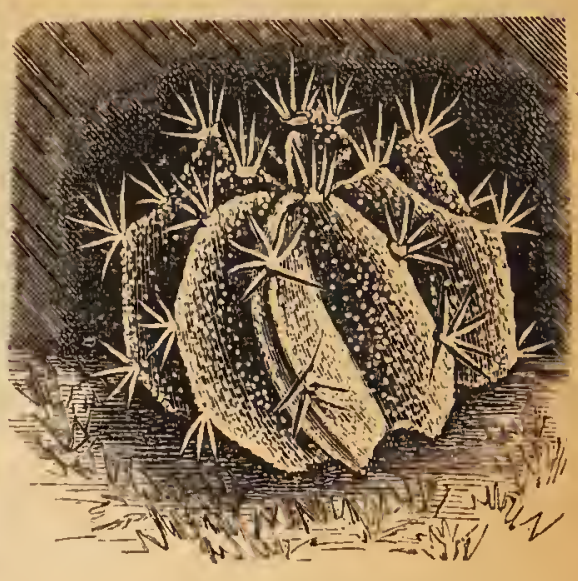

Astrophytum myriost. Lapaixi.

8 cotes tran-

chantes, epiderme jaunâtre vers le centre, aiguillons irreguliers; $10 \mathrm{~cm}$ de diam. . . . . 30-

octogonum, mit 8 scharfen Kanten, Areolen $5 \mathrm{~cm}$ weit von einander, aschgrau punktirt und bestachelt, $10 \mathrm{~cm}$ Durchmesser - à 8 côtes tranchantes, aréoles espacées de 5 centim.,

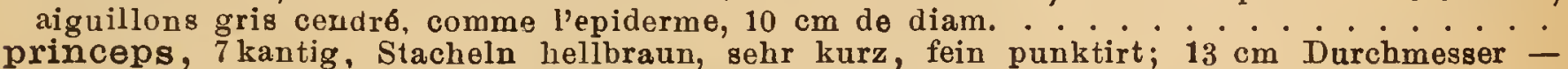
7 côtes, aiquillons courts, brun clair, fiuement ponctué; $13 \mathrm{~cm}$ de diam. . . . . . . . . $40-$ regale, 6kantig, Stacheln gedreht, hornfarbig, fein punktirt: $14 \mathrm{~cm}$ Durchmesser - 7 côtez, aiguillons un peu tortillés, blonds, finement ponctué; $14 \mathrm{~cm}$ de diam

Schilinzkyi, mit 5 umgebogenen Kanten, wenig bestachelt, stark punktirt; $6-10 \mathrm{~cm}$ Durchmesser - 5 côtes à ailes obliquant à gauche, peu d'aiguillons, macules plus distantes, 6 ì $10 \mathrm{~cm}$ de diam.

à Sttack - la pièce M.Pf. Anhalonium prismaticum . . 4- 28 - Astrophytum myriostigma Cereus acutangulus

alacriportanus

albispinus (Pilocereus)

areolatus

azureus

Baumanni

baxaniensis

$1-$ à 3 -

Boeckmanni.

Bonplandi ......... -50 a 3 -

brachiatus. . . . . . 1,50 a 3 -

Bridgesi

) brevispinus

caesius

Carendishi

chalybaeus

chilensis

Chiotilla, Weber

coccineus .

coerulescens

colubrinus

$$
\text { Donati }
$$

Gavispinus

Donkelaari

Dumortieri

Dycki vide Joconostle.

erectus

eriophorus

1,50 à

euchlorus

. . $10-$

farinosus

$\dot{1}-\dot{2} 3-$

fornambucen

$1-\mathbf{a} 3-$

$1-\mathrm{a} 3-$

4 - ̀̀ 15 -

fernambucensis

..
$\therefore \quad 2-$
$. \quad 2-$

1) Aurora hellrosa - roso olair 1 -

1) cristatus

$1-\dot{a} 3-$

$1-3$

$1-\grave{a}$

$3-$

3- a $6=$

3 - ̀̀ 5 -

$\begin{array}{lll}3-50 & \text { a } & 5- \\ 1,5-\end{array}$

- 3 - 3 -

$1-\mathrm{a} 3-$

) Mallisoni

$1-\mathbf{a}$

"Vulcan, scharlach - écarlate 1,50 a 3 Forbesi ........ 1- a 6 formosus ......... 1,50 a 4 Funkij monstrosus . . . • 1,50 a 3 gemmatus (marginatus) . . . 2,50 a 5 geometrizans (pugioniferus) $.2-$ a $6-$ giganteus, vide Pilocereus.

HAAGE \& SCHMIDT, Haupt-Verzeichniss für 1896.

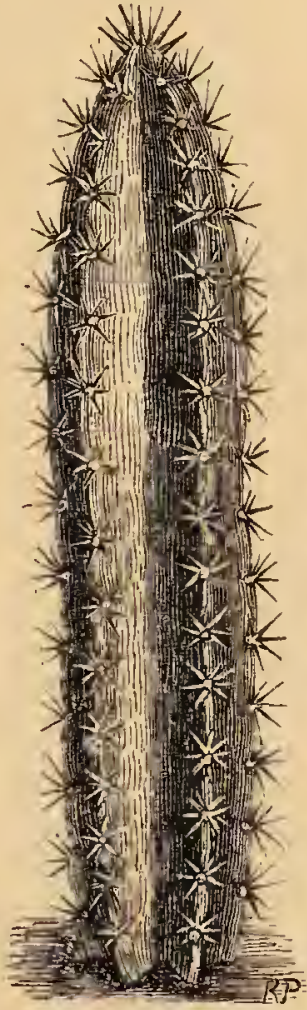

Cereus Jamacaru.

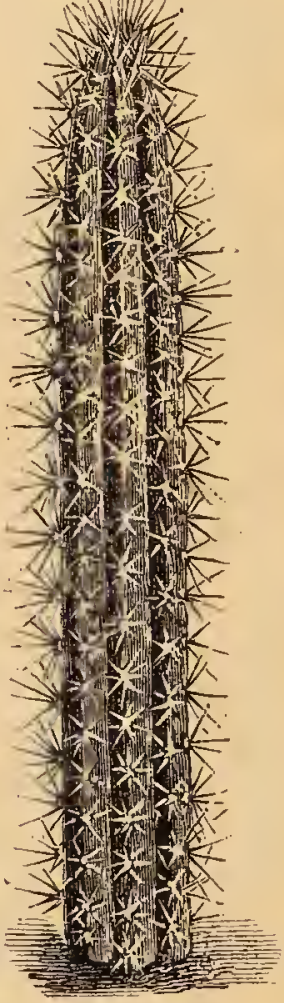

Pilocereus fulvispinus.

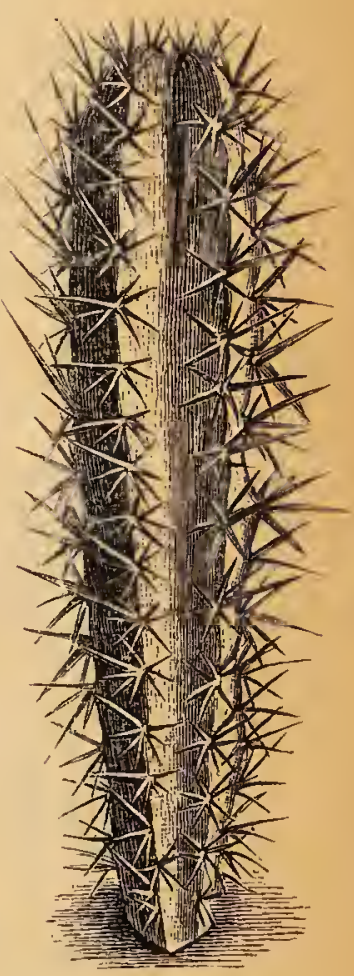

Cereus Forbesi.

a Stück - la pièce M. Pf.

Cereus grandiflorus (Königin der Nacht Reina della noche) .... 1,50 a 5 grandiflorus major . . . . . . 3 Greggi . . . . . $5-$ a $10-$ gumminosus, Engelm. . . . . . 6 Hankeanus ...... $2-$ a 4 heteromorphus ........ 6 intricatus......... 3- a 6 Jamacaru ........ -60 a 3 ) caesius . . . . . . $1-$ b) glaucus ............ 1 Joconostle ......4- a $10-$

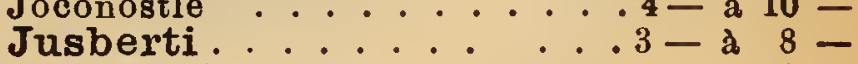
Karwinskii . . . . . . . . 3 - 




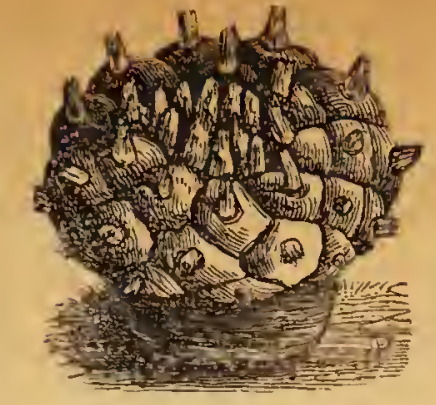

Echinocactus Williamsi.

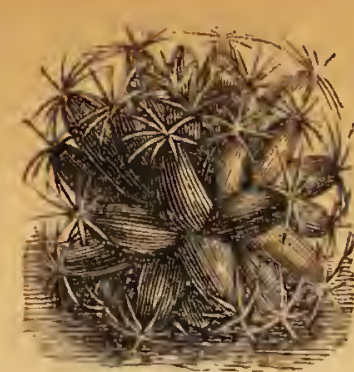

Mammillaria longimamma. à Stück - la pièce M. Pf. Echinocactus Scheeri ... 3 à $5-$ Scopa............ 3- a $6-$ ) candidus ) cristatus $3-$ setispinus "Sämlinge - semis...... 1 Simpsoni, Originale - sujets originaux ......... 3-à sinua

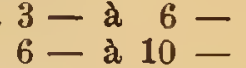
submammillosus tabularis

7,50 à $15-$ texensis tortuosus

$2-\grave{a} 5-$ tulensis undulatus

viridescens

Visnaga, vide ingens.

Williamsi (Anhalonium)

Wippermanni

Wislizeni, Fischhakencactus, pracht-

volle, seltene Species - espèce rare

magnifique ....... . 5 - à xiphacanthus $5-\mathrm{a} 10-$

" 12 Sorten unserer Wahl -12 espèces

a notre choix
Echinocereus acifer:

amoenus (Echinopsis amoena)

\section{Berlandieri}

Blankii, Engelm.

caespitosus.

candicans

carnosus

cinerascens (Deppei)

1) crassior

cirrhiferus

$2 \div 215-$

dasyacanthus

dubius

Durangensis

) nigrispinus

) rufispinus

Ehrenbergi

" cristatus

enneacanthus

gladiatus

glycimorphus

lamprochlorus

papillosus

paucispinus

pectinatus

) cristatus

pentalophus (leptacanthus)

phoeniceus (Leeanus)

polyacanthus

polycephalus, Engelm.

$3 \div$ a $5-$

1 - a 2 -

$2 \div$ à 3 -

$2-\frac{1}{2}$

-75 a 6 -

- 75 a 6 -

-75 a $6-$

- . 3 -

$2-$ à

3 - à 6 -

3 - à 6 -

-75 aे

$3-\mathrm{a}$

1 - े 6

$2-a \quad 4=$

-75 a $3-$

1,50 aे $3-$

1,50 à 5 -

3 - à 6 -

- 50 à $6-$ $4 \begin{array}{rrr}50 & \text { aे } & 3 \\ -\mathrm{a} & 6\end{array}$

$\dot{2}-\dot{a} \quad 4-$

Engelm. . . 2 - a 6 -

procumbens, Blüthe ähnlich der von enneacanthus - \& fleur semblable à celle d'enneacanthue. . . . - 50 à pulchellus (Echinopsis pulchella)

Roemeri

Salmianus

1,50 à

Salm-Dyckianus

1 - à

Scheerii, Engelm. . . . $1-1-2$

stramineus, Engelm. . . . . . 4 -

viridiflorus . . 3 - a

12 Sorten unserer Wahl - 12 espèces à notre choix..........

Echinopsis achatina

750

$2-$

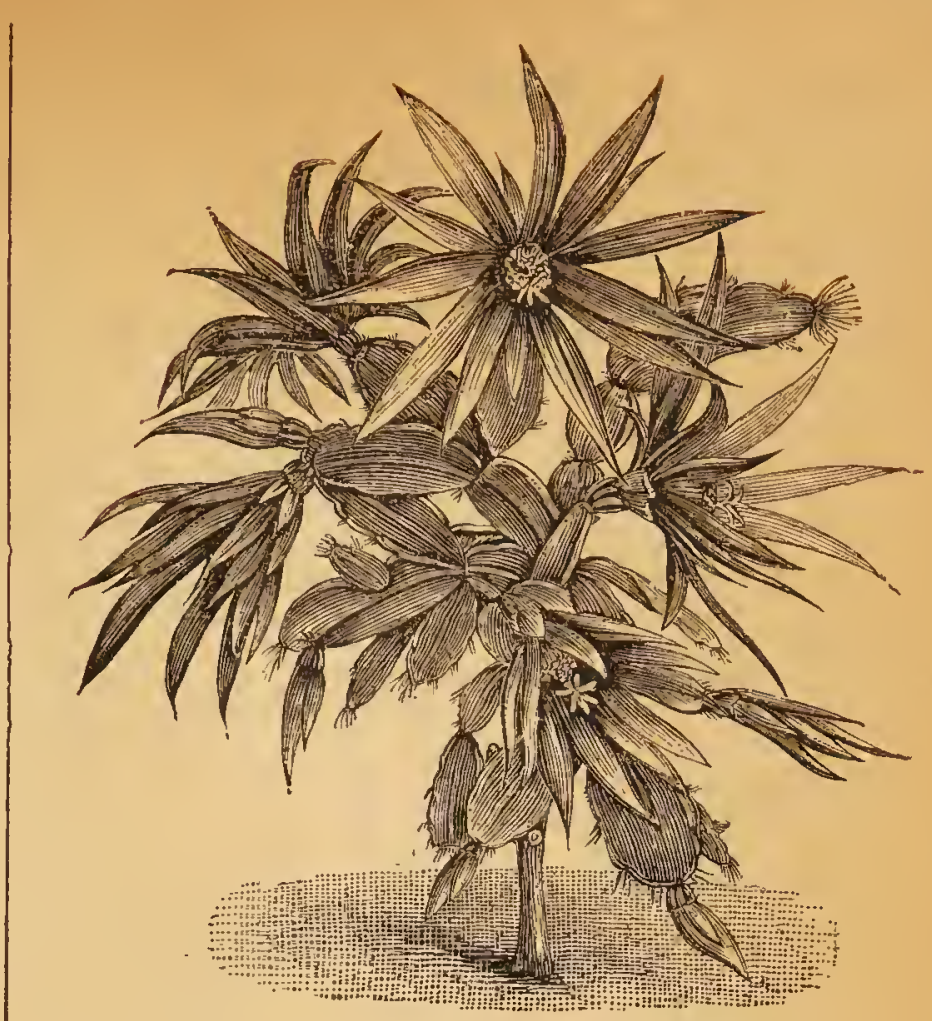

Epiphyllum Russellianum Gaertneri.

à Stück - la pièce M.Pf.

Echinopsis apiculata ....... 3 Bridgesi. . . . . . . . . . . . 8 - 8 Decaisneana . . . . . -50 a 6 denudata . . . . . . . . 1 Duvalli......... - . 50 à 6 Eyriesii ........ . -50 a 6 " cristata ....... 3 - a 5 formosissima. . . . . . . 10- à $20-$ Huotti ....... 1 - à 5 imbricata ......... 150 integra . . . . . . . . . 2 Lagermanni ....... -50 à 6 Lapaixi .......... . . 3 multiplex ...... . -50 a 6 cristata ............ 5 ) picta.......... 1-à $5-$ nigerrima .......... . . 1 oxygona......... -50 a 6 Pentlandi ......... 2 - à 5 ) longispina ......... . . 3 ) Scheeri ............ $3=$ ") tricolor . . . . . . . . . 4 Schelhasei ....... -50 d 3 tephracantha ......... 2 tubiflora .......... 1 - a 3 turbinata..... -50 aे 3 Zuccarini ........ -50 à 6 -

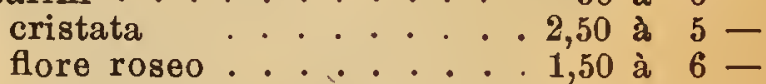
Rohlandi ...... - 50 à 6 -

12 Sorten unserer Wahl -12 espèces a notre choix... . . . . 750

Epiphyllum IMackoyanum $\therefore 1,50$ a $3-$ Ruckerinnum . . . . . 1 Russellianum Gärtneri, Gartenflora 1884, Taf. $1172 \ldots . . .1,50$ a truncatum .

bicolor

) Bridgesi

carminatum

grandiflorum .

Harris oni

multiflorum (Altensteini)

purpureum

salmoneum.

spectabile

$$
\begin{aligned}
& \text { ") sup } \\
& \text { tricolor }
\end{aligned}
$$

violaceum superbum.

- jolid 1 -

Lepigmintes greffees a tige $\ldots$
Lepismium cavernosum . . . . . . . . . 150
commune 150

Knightii . . . . . . . 150 
à Stück - la piece M.Pf.

Malacocarpus acuatus (erinaceus) corynodes

Couranti

Sellowianus

Mammillaria acanthoplegma $\cdot 3-\dot{a} 5-$ amoena............... 150 anguinea, vide elongata.

angularis ..... . . . 1- a 3 applanata, schön - beau $.2-d 3-$ arietina ........ -50 d 3 aulacothele

auricoma Benneckei bicolor

biglandulosa

$\begin{array}{rr}50 \text { a } & 3- \\ . & 3-\end{array}$

Bocasana

Bockii

. 4 - 4

Buchiana

calcarata

candida, vide sphaerotricha.

caput-Medusae

carnea (villifera)

castanoides cristata.

Celsiana (Mühlenpfordti)

$2-\mathrm{a}$ -

centricirrha goniadacantha

$1-\grave{3} 3-$

chrysacantha ...

cirrhifera

" longispina

columnaris

conoïdea

conopsea (Neumanniana)

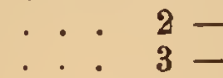

cornifera, sehr schön - très beau $3-$ à

coronaria

$\therefore \quad 2=$

crassispina

3 - ̀̀ 4 -

. 2 - à $6-$

crinita

crocidata

crucigera

decipiens

deflexispina

Deleuili

discolor

divaricata

divergens

dolichocentra

"Galeotti

Donati

Droegei

echinata (caespitosa, densa)

-50 à 4 -

$1-\mathrm{a} \quad 3-$

-50 à $3-$

$\begin{array}{lll}1-50 & \text { à } & 3 \\ -50 & 2\end{array}$

elegans

elephantidens spinosissima

3 - a 5

.. 150

350

-

8 -

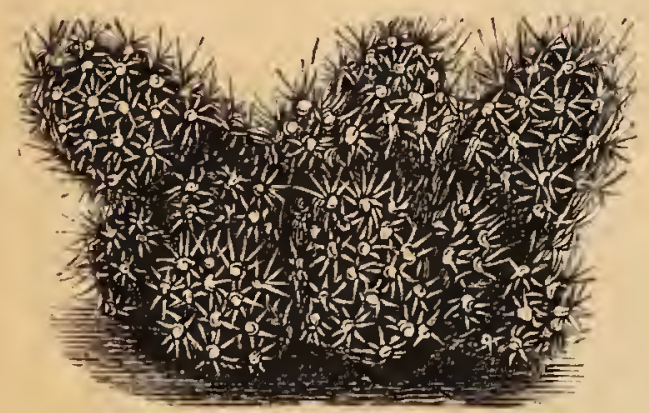

Mammillaria elongata.

Mammillaria elongata (anguinea)

elongata sub
Emundtsiana
eriacantha.
Eugenia.
falcata . .
fertilis
Foersteri .
formosa.
foveolata
fulvispina.
fuscata.
geminiflora
gigantea.
gladiata.
glochidiata
globosa.

.. -50

1,50 a $3-$

$1-$ a 3 -

$1-2 \quad 3-$

$1-\mathrm{a} 4-$

$\therefore \quad 4-50$

Mammillaria gracilis Stück - la pièce M. Pf. à Stück - la piece M.Pf.
. . . . . . $1-$ a $3-50$

") Haagei .............. . . . 3 -

Herrmanni . . . . . . . 2 -

Hevernicki . . . . . : 4

Hopferiana . . . . . . $2-\mathrm{a} 4-$

Hystrix . . . . . . . 1- a 3-

imbricata . . . . . 2- a 4 -

intertexta ........... 1 -

Karwinskiana . . . -50 a 4 -

kewensis ........... 4 . .

Krameri . . : 1 - a $3=$

laeta

lasiacantha..... $2-$ à 4 -

Lehmanni...... 2 - a 5 -

Leona, schön - beau ....2- a 4 -

leucocarpa . . . . . . . . 3 -

longimamma

") compacta.

) $\operatorname{cristata}($ H. \& S.). . 3- a $5=$

I) gigantothele ....... 1,50 à 3-

longiseta

Ludwigii (phymatothele) $\cdot 2$ - 2 à 4 -

macracantha (recurva) . . . 1,50 a 3 -

macromeris, Engelm. . . . 2,50 a 4 -

macrothele 3 -

magni-

mamma

$1-\mathbf{a} 3-$

mazatlen-

sis

megacantha

1,50 à 5

meiacantha 3 -

melaleuca 3 -

melano-

centra

$2-\mathrm{a}$

)) micromeris 4 -

) microthele

) minima

monothele

$\underset{1-a}{1-a}$ -

12 St. $5-,-50$

mutabilis

1 - a 5 - Mammillaria macromeris.

mystax . 4 -

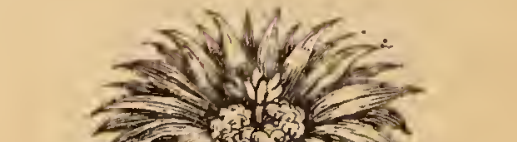

Neumanniana, vide conopsea.

nigra

") euchlora:

) cristata

nitens (discolor nitens)

nivea

) cristata.

nobilis

Nuttalli

obscura

Odieriana.

pachythele

pallescens

Parkinsoni

Peacocki

pentacantha

Perringi.

Pfeifferi

phaeacantha.

phymatothele (Ludwigi)

polyedra

polygona

polythele

1 - a 3 -

porphyracantha

Praelii

pretiosa

..
.$\quad 150$

pretiosa.

1, 50 à 3 -

pulchella

2 - 3 -

)) nigrescens

4 - 6 -

2,50 aे 4 -

- 5 - 5

1,50 dे

- 3 -

1,50 à $3-$

. 1,50 à 3 -

1,50 aे $3-$

$1-\grave{a} 3-$

$2-\mathrm{a} 3-$

$2-\mathrm{a} 4-$

pulchra ..... 1 -

pusilla

) caespititia ........ 150

)neo-mexicana ....... 150

") texensis ............... 1 -

pyramidalis . . . . . . $2-$ a $3-$

quadrispina ....... -50 a 3 -

radiosa, sehr schön - très beau 2 - a 4 -

Radliana, nou - nouv. . . . . . 750

) Sämlinge - semis ...... 250 


Mammillaria a Stück - la pièce M.Pf. recurvispinacantha) rvispina

) rhodantha sanguinea Schelhasei

). sericata

Seitziana

Sempervivi

") tetra

Senkei

simplex (caracasana)

spec. Villa Lerdo

sphacelata

sphaerotricha (candida) spinosissima

) brunea

stella aurata

strobilifera

subangularis

subcrocea, vide elongata.

subechinata

sulcoglanduligera

sulphurea

tentaculata

triacantha.

tuberculata.

uberiformis

"hexacentra

major .

Melaena

umbrina

uncinata

valida

vetula (grandiflora)

villifera, vide carnea.

viridis

I) cristata.

Wildiana.

cristata

12 Sorten unserer Wahl -12 espèces

à notre choix

25 Sorten unserer Wahl -25 espèces

à notre choix

Melocactus spec. Central-America, Säm-

linge - semis

Opuntia albicans:

arborescens

arizonica

atacamensis, Poselg.

aurantiaca

basilaris

bernardina

bicolor

boliviensis, Poselg.

brachyarthra, Engelm.

brasiliensis

camanchica, für Freiland - de pleine terre albispina.

major

) minor

candelabriformis

clavarioïdes

cristata

coccinellifera (Nopalea)

corrugata

crinifera

cylindrica .

"ymochila

Davisi, Engelm.

Dilleni

echinocarpa

elata

elongata

Emoryi

Engelmanni

extensa .

ferox

Ficus indica

filipendula, Engelm.

frutescens .

fulgida nana

$. \dot{1}-\dot{a}-50$

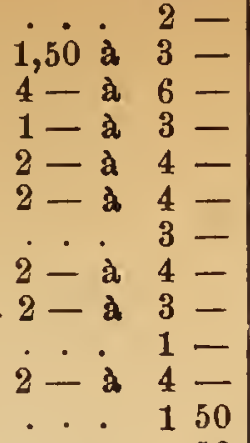

i- 3

$1 \div$ a $3-$

$\dot{3}-\frac{3}{50}$ -50 aे $3=$ ... 1 -

-50 a $4=$

$1-5$ a $5-$

2,50 à

$2-2$

$2-\mathbf{a}$

$2-3$

3 - à

1 - a 4

$1-\mathrm{a} 3-$

-50 a $3-$

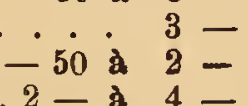
$15-$

$5-$

$-50$ -50 à 1 $.1-$ a $2-$ $.1,50$ a $3-$ $2-a ̀ 3-$ : . $1 \frac{1}{75}$ $1-$ a $3-$ $-\overline{75}$ 75 $-75$ $-75$ $-75$ $\begin{array}{r}75 \\ -75 \\ \hline\end{array}$ $-$ 2 $250-78$ $-\overline{50}$ $1 \frac{5}{50}-\underset{\text { mus }}{\text { albus superbissi- }}$ 3 - 65 Alexandrinae. 4 $1-11$ anguliger.

15012 aurantiacus superbus.

- 5013 Benselerianus.

15014 Boothii.

- 5082 Bruennowi.

- 5015 caulorhizus.

1,50 à 250,46 Conway's Giant. $X$ 1,50 à $3-869$ Cooperi.

- 7517 crenatus lateralis.

$\begin{array}{ll}\text {.. } 1-50 & 19 \\ 19 & \text { " splendens. }\end{array}$

-50 a $150 \quad 3$ Ernesti.

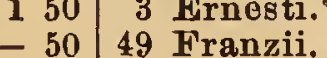

- 50180 grandis. Engelm.

sericea notre choix à Stück - la pièce M. Pf.

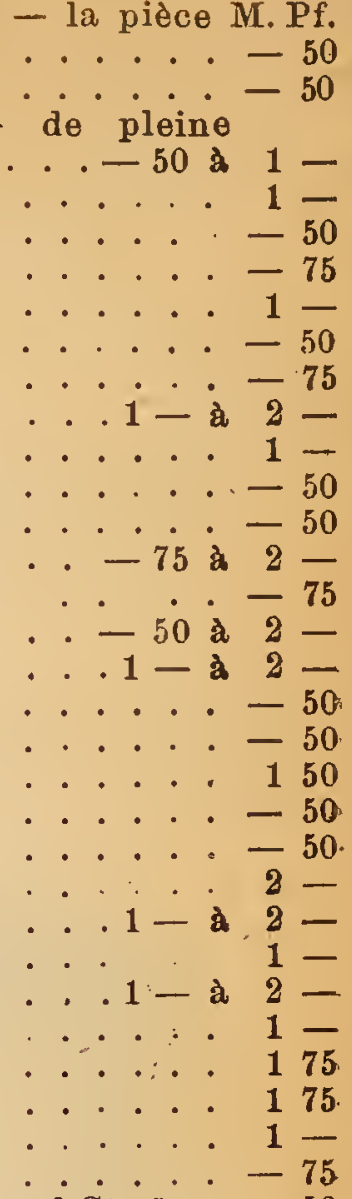

12 St. $5-,-50$

(spec. Kansas), weit nterharter als die

lus robuste et plus 12 St. $4-,-40$

- 50 à 1 -

1 -

$-75$

spec. Linden

1 -

$-50$

$-50$

$-50$

150

$\begin{array}{r}15 \\ -75 \\ \hline\end{array}$

vaginata, Engelm

1 -

12 Sorten unserer Wahl - 12 espèces

$-75$

t.

12 St. $5-, \frac{4}{2} 50$
$.1-$ a $2-$
. .50 a $1-$
$. .6 \div 1-$
$. .6-$ a $10-$
$2-6$

, Species und

variétés:

81 Guedeneyi 2 * à $3-$

79 Haageanus.

76 Hitchensi.

51 Hookerii.

22 Jenkinsonii.

29 " superbus. $千$

23 ignescens.

52 Johnsonii. $x$ rmesinus mag- + nus $1-23$ -

77 Kiardi.

C2 Laloyi 1 - a $3-$

25 latifrons, weiss,gelb

+ schattirt - blanc

54 Makoyi.

jaunâtre 1,50 à 3 -

83 Mayfly.

75 mexicanus.

84 Niedti. 
Phyllocactus et Hybris:

1 Pfersdorffi, sehr 40 Tettaui, Blume schön, gelb-beau, t mittelgross, dunfl. jaune 1,50

X 5 phyllanthoides,schön hellrosa - beau rose clair.

27 ) erubescens.

31 Potstatzkyanus.

32 Preissleri.

33 ruber.

-62 serratus.

- 72 speciosissimus

Feltoni, purpurviolett,grossblumig - pourpre violacé, à gr. fl. 1 - à 3 -

à Sorte - chaque espèce

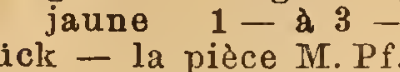
in Stecklingen - en boutures kelviolett mit purpur Rückseiten fleur moyenne violet foncé à revers pourpre 1 - a 3 -

42 triumphans

43 Vonhoffini.

44 Wippermanni.

70 Wrayi, sehr gross, gelb - fl. grande,

Wahl - collection des 12 meilleures sortes a notre choix

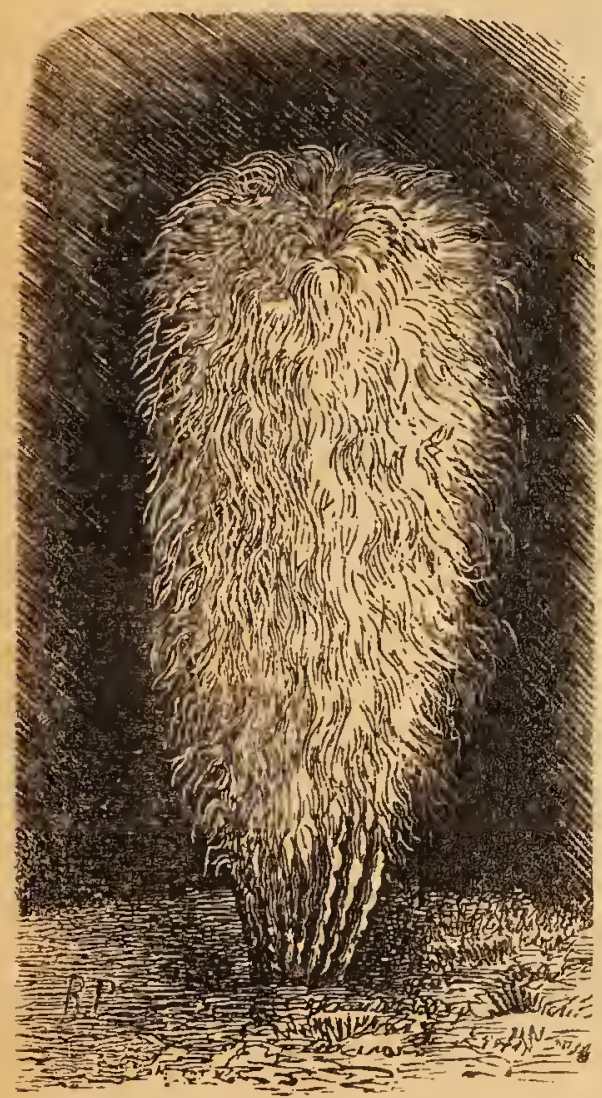

Pilocereus senilis.

Pilocereus albispinus

) barbatus

) Bruennowi

Celsi gracilior

) lanuginosior

chrysomallus (militaris)

Consolei .

Dautwitzi

1) cristatus

euphorbioides

floccosus

fossulatus

fulvispinus
$-40$

750

\section{Billige Cacteen-Sortimente für angehende Liebhaber.}

\section{Collections de Cactées à prix modérés pour amateurs commençants.}

Um die Liebhaberei für die so interessante Familie der Cacteen den weitesten Kreisen zugänglich zu machen, offeriren wir nachstehende Sortimente, welche trotz der äusserst niedrig gestellten Preise eine gute Anzahl sehr schöner charakteristischer Formen enthalten, und welche für Anfänger vollständig genügen, um sich zunächst mit der Cultur vertraut zu machen. - Afin de répandre autant que possible le goat pour la famille si intéressante des Cactées et la faire abordable à toutes les bourses, nous offrons ci-après des collections a prix très-réduit, mais qui se composent tout de même d'un bon nombre d'espèces caractéristiques, et qui suffiront au commençant, pour se rendre d'abord familier avec leur culture.

M. Pf. 12 schöne Sorten Cacteen unserer Wahl, kräftige Exempl. - 12 belles espèces de Cactées à notre choix 450

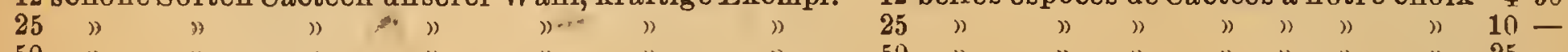






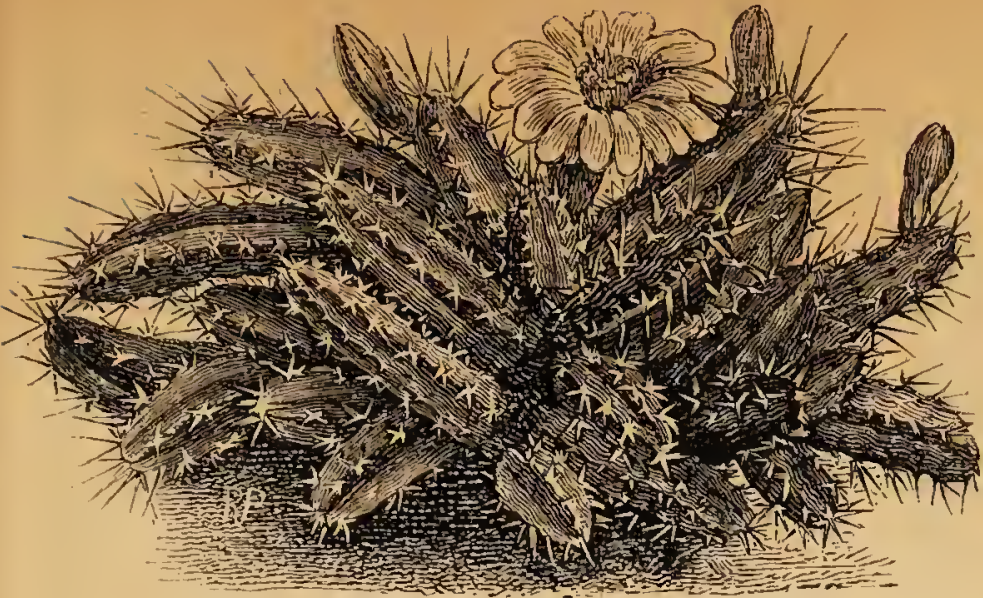

10753. Echinocereus procumbens.

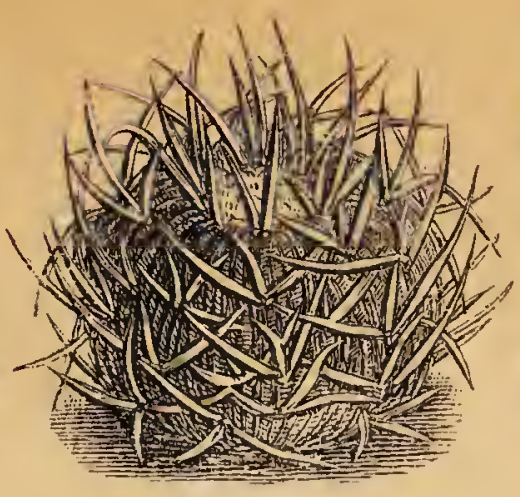

10727. Echinocactus multicostatus.

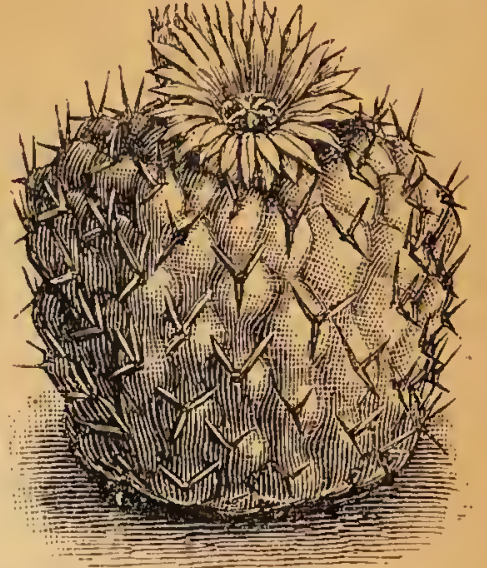

10844. Mammillaria radiosa.
No.

10679 Stapelia uncinata

10680

10681

10682

\section{Uspenskyi}

gemischt-mélange $100 \mathrm{~S} .1,25,10$ )

\section{Cacteen - Cactées.}

10683 Anhalonium prismaticum 100 S. 7 - 5 S. 40 10684 Astrophytum myriostigma 100 S. 7 - , ) 10685 Cereus acutangulus . . $100 \gg 2-, 10 »$ 10686 alacriportanus . 1000 \#,50,50 \#

10687 " Bonplandi . . 100 " 10,20 ”

10688

10689

10690

10691

10692

10693

10694

10695

10696

10647

10698

10699

10700

10701

10702

10703

10704

10705

10706

10707

10708

10709

10710

10711

10712

10713

10714

10715

10716

10717

\section{Cavendishi var. Paxtoniana}

100 S. $1,50,10$

chalybaeus 1000 » $6-, 25$ ) erectus . $1000 \gg 2,50,50 »$ Forbesi gemmatus $100)-80,20$ $1000 \% 2,50,50 »$ $100)-,-, 5$ ) geometrizans 1000 » 8-, 25 » giganteus vide Pilocereus.

Jamacaru ... $1000 S .2,50,50$ » "glaucus . . 1000 » 2,50,50» Martini . . . $100 \#-50,20 \%$ nycticalus . . 100 ” $1,20,20$ ) Olfersii . . . $1000 » 4-, \vdots 0 »$ peruvianus . $1000 » 2,50,50 \%$ speciosissimus $\quad 100 »-80,20$ stellatus . . 100 " $1,25,20$, subrepandus . . 100 " $-80,20$ " tetracanthus . 100 ) $2-, 10$ ) Thurberi .. 100 " $3,50,10$ ” Tinei .... $100 "-80,20$ ” tortuosus . . 1000 》 $4-, 50$ 》 validus . . . . $1000 » 2,50,50 »$ gemischt - varié 1000 "2,50, 100 » hinocactus aulacogonus

100 » $1,60,10 \%$

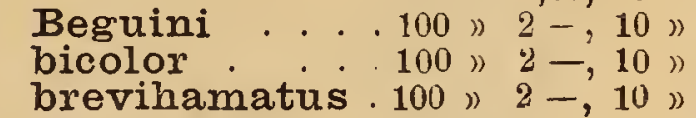
capricornis . 100 ) $3-, 10$ cylindraceus (Leopoldi) 1000 S. 5-, $25 \%$ denudatus ......5 5 electracanthus $100 S .250,10$ )

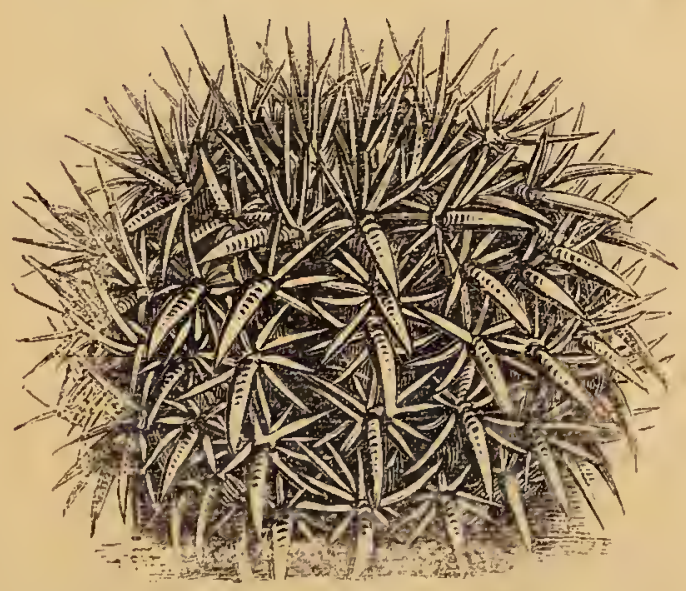

10720. Echinocactus Grusoni.
Pf. No.

2010718 Echinocactus gibbosus

20

10719

10720

10721

10722

10723

10724

10725

$40 \quad 10726$

$30 \quad 10727$

2010728

$20 \quad 10729$

117.00

$20 \quad 10731$

$20 \quad 10732$

$20 \quad 10733$

20

$30 \quad 10734$

$30 \quad 10735$

10736

$20 \quad \mathbf{0 7 3 7}$

$20 \quad 10738$

$20 \quad 10739$

$30 \quad 11.740$

31) 10741

20

$20 \quad 10742$

30
20

$20 \quad 10743$

\begin{tabular}{l|l}
25 & 1074 \\
40 & 1074
\end{tabular}

20

30

20
30

$25 \quad 10746$

$30 \quad 10747$

30 10748

$30 \quad 10747$

$40 \quad 10750$

20 \begin{tabular}{l|l}
10751 \\
10752
\end{tabular}

$30 \quad 10753$

$30 \quad 10754$

10755

1075

10757

10758

10759

107 h0

10761

$1076:$

14763

107 fit

10765

10766

10767

10768

10769

10770

10771

10772

gibbosus ferox Grusoni

ingens recurvus

Scheeri speciosa
Contei, ,Des Teufels Nadelkissen" - ,Pelote du diable" $10 \mathrm{~S}$. leonensis . . 100 S. 2,50, 10 ) 30 leucacanthus ...... 5 》 30 longihamatus . . . . 5 ग 30 lophotele . . 100 S. 3-, 10 " 40 multicostatus . 100 » $2.50,10$ » 30 Orcutti . . . 1000 » $5-, 25$ » 20 Ottonis . . . . . . $10 \mathrm{~m} 40$ pilosus (Steinesi) $100 » 4-5$ ») 30 polyancistrus, selten und schön - beau et rare. $100 \mathrm{~S} .1,25,20 \mathrm{~S} .30$

" solenacanthus 100 S. 3-, $10 » 40$ - $1000.5^{\circ} \cdot 10$ \# 30 "Mierensis . . $10 \% 30$ texensis . . $1000 \mathrm{~S} .5-, 25$ » 20 tortuosus . . 100 \# $1,20,20$ » 30 viridescens •. $1000 \gg 5-, 25 » 20$ uncinatus . . 5 » 30 Williamsi (Anhalonium) 100 S. $4-, 5 \gg 25$

Wislizenii, prachtvoll - superbe 1000 S. 5 -, 25 S. 20 gemischt - varie $.1000 \gg 6-, 25 》 20$

$\begin{array}{lllll} & & \text { \# } & 20\end{array}$ caespitosus, gleichzeitig eine der schönst blühenden und schönst bestachelten Sorten - en même temps l'un des plus beaux par ses fleurs que par ses aiguillons $1000 S .5-, 25 S .20$ cinerascens . . $100 \% 1,20,20$ " Durangensis . . . . 10 » 30 enueacanthus . 100 S. $1,50,10$ \# 20 Laboureti $100 \gg 1,50,10$ » 20 pectinatus ..... 10 \# 40 pentalophus . 1000 S. $5-, 25$ » 20 Poselgerianus . . 1000 " 7,50, 20 ” 20 procumbens . $1000 » 4-, 50 » 30$ Roemeri •........ 5 » 30 gemischt - varié . 1000 S. $4-, 50$ » 30 chinopsis Decaisneana $\backslash$. . . . . 50 » 30 Duvalli . . . 1000 S. $4-, 50 » 30$

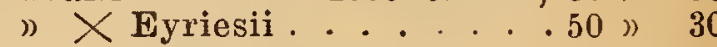
\# X tephracantha ....50 » 30 "X tricolor ........50 Eyriesii $\%$. . 1000 S. 5-, 25 \# 20 ") X Rohlandi speciosa . . 50 ) 30 Fischeri .... 1000 S. $4-, 50$ 》 30 ») fl. roseo .1000 » 4 -, 50 » 30 Huotti . . . . $1000 \gg 6-, 25 \gg 20$ imbricata . . . 1000 » 5-, 25 》 20 Lagermanni . . 1000 » 5 -, 25 » 20 multiplex . . . 1000 » $4-, 50$ » 30 nigerrima .......25" 30 oxygona \%. . . $1000 \mathrm{~S} .4-, 50$ " 30 Rohlandi........ . 25 ) 30

\section{P.} 0 0 0 (1)

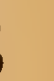
(0) o

0

(3)

.

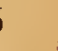

0

.


No.

10773 Echinopsis speciosa $\times$ Duvalli . . $25 \mathrm{~S}$. 10774 "speciosa X tephracantha . 25 »

10775 » Schelhasei ......50 》

1077 » tephracantha ........50

$10777 » \gg \times$ Duvalli ....50

10778 " " Rohlandi speciosa . .50"

10779 " tricolor $\times$ Duvalli $1(00 S .5-, 50)$

10780 » triumphans fl.pl. X Duvalli. 25 »)

10781 " $)$ fl.pl.XRohlandispeciosa 25 "

10782 " tubiflora . . 1000 S. 6-, 25 »

10783 » turbinata

10784 "Zuccariniana ${ }^{\circ} .1000$ » $4-, 50$ »

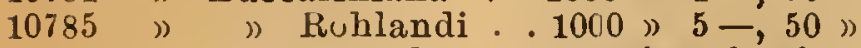

10786 》 neue Hybriden gegonseitig befruchtet in bester Mischung - hybrides nouveaux fécondés réciproquement en beau mélange $1000 \mathrm{~S} .2,50,50 \mathrm{~S}$ 10787 Epiphyllum IMackoyanum . 10 ) 10788 "Russellianum Gaertneri 10 " 10789 " truncatum hybridum . . 10 » 10790 》 " multiflorum . . . 5 》 $1079 \mathrm{~L}$ ” purpureum superbum . . 5 》 10792 " " violaceum grandifiorum . 5 》

10793 Mammillaria amoena . . . . 10 »

11794 ) anguinea.. .20 . . 20

10795 "applanata.. 100 S. $-80,20$ »

10796 ” auricoma........... 10 »

10797 » Bockii ........ 10 »)

10798 " centricirrha .. $1000 S .5-, 50$ »

10799 " " macrothele ..... 20 »

10800

10801 " conopsea (Neumanniana) . . 25 )

$10802 》$ cornifera.... 100 S. $1,25,20$ ”

10803 » deflexispina....... 10 »)

$10804 \gg$ divaricata........... . 20 »

$10805 》$ dolichocentra......2. 20

10806 " "Galeotti ....... 10 »

10807 "Donati.... 1000 S. 8 - 20 »

10808 " elegans . . 1000 " 6,50, 25 ”

10809 ) elongata..... 1000 \# 4 -, 50 »

10810 " eriacantha . . $1000 " 6-, 25$ "

10811 " euchlora ......... 10 "

10812 " falcata . . . . . . . 10 "

10813 "Foersteri . . . . . . . 20 "

10815 » fuscata........20 »

10816

10817

$1081 S$

10819

10820

10821

10822

10823

10824

10825

10826

10827

10828

10829

10830

10831

10832

10833

10834

10835

10836

10837

10838

10839

10840

$108+1$

10842

10843

10844

10845

gigantea

gladiata

1000 S. $4-50 \%$

) deflexispina ..... 20 》

glauca : . 1000 S. 6 -, 25 ”

gracilis........ . . $.25 》$

kewensis . 100 S. $2,50,10$ "

Krameri ... . $1000 » 6-, 25 »$

Krausei .......... 10 )

Leona........ 10

livida ......50

macracantha $\cdot . \cdot 5$. 10

magnimamma . . $1000 S .5-, 25$ )

) $\operatorname{arietina} . . .20$. . .

multiceps ... 1000 S. $4-50$ »

Neumanniana hybrida . 20 )

nigra euchlora ...... 20 "

Nuttalli ....... . 10 »

Parkinsoni . . . . . $20 "$

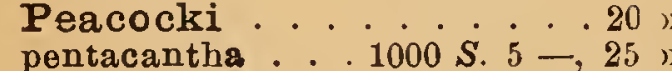

pentacantha *........... 10 "

pulchella nigrescens . . . 20 "

pusilla

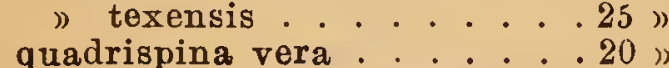

radiosa . . 1000 S. $5-50$

raphidacantha ......5
Pf. $\mid$ No.

Pf.

30 10846 Mammillaria recurvispina . . 20 S. 30

$30 \quad 1084 S \Rightarrow$ Sempervivi $\because 1000$ S. $5-, 25 \# 20$

$3010 \times 49$ " " tetracantba .... 10 » 30

$30 \quad 111850$ » stella-aurata. . 1000 S. 5 -, $25 》 20$

301085 ” spinosissima .............. 10 ” 30

3010852 " subangularis . . . . . . . . . 20 » 30

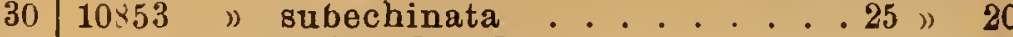

3010854 " subpolyedra................ 10 » 30

2010855 " uberiformis ............. 10 " 30

2010856 » valida ................ 10 » 30

3010857 " viridis ..... 1000 S. $7-, 25$ " 20

3010858 " vivipara ........ . . 25 " 20

10859 Wildiana ....... $20 " 30$

10860 》 gemischt - varié $1000 S .4-, 50$ » $30<$

10861 Opuntia dejecta. . . $1000 » 5,50,25$ » 20

$20-10862$ Dilleni..... $100 » 2,50,10 » 30$

3010863 " elata. . . . $1000 » 5,50,25 》 20$

4010864 " elongata .... . 100 \# 2,50, 10 " 40

4010865 " ficus indica . . 1000 \# $5,50,25$ \# 20

3010866 " " gemischt - varié. 50 " 30

3010867 glaucophylla... 100 S. $-80,20$ ” 20

3010868 "Labouretii . . . 100 »-80,20 \# 20

$30(10869$ » laevis . . . . 100 ») $-80,20$ ») 20

10870 "lanceolata ... . 100 » $-80,20$ » 20

2010871 "leucotricha fulvescens . . 10 \# 30

3010872 " macrophylla .. $100 S_{.}-60,25$ » 20

10873 " maxima .... $100 » 1-20$ » 25

3010874 » missouriensis. . . 100 » $-80,20$ » 20

10875 \# occidentalis . . 100 » $-80,20$ ” 20

2010876 " Piccolominiana. 100 » $-80,20$ " 20

2010877 pseudo-Tuna .1000 » $5-, 25$ » 20

10881

monothele ........ . 20 》)
10878

3010879

10880

10882

10883

10894

Rafinesquiana arkansana

spinulosa .. $1000 \mathrm{~S} .4-, 50 \%)$

$100) 1,25,10,1)(20$

tomentosa ... $100 »-60,25 » 20$

Tuna..... . . 100»-60,25» 20

virens. . . . 100 ") $-60,25$ ) 20

gemischt - mélange $20 \mathrm{~g} 4-$, Pt. 20 10385 Peirescia aculeata . . 100 S. $1,60,10$ S. 20

10887 "albus superbissimus $X$ crenatus speciosus . . $20 \mathrm{~S}$. anguliger . $100 \mathrm{~S}$ 1 $-20 \%$ Boothi........ 20 》 30

Boothi $\times$ Leopoldi 100 S. $1-, 20$ 》 30 Bruennowi... (100) $1-, 20$ » 30 » X Mackoyi .....20 »30 Ernesti $\times$ Laloyi . . . . 20 » 30 fastuosus . . . . . . 20 》 30 Johnsoni . . . 20 (20 30 latifrons........ 20 » 30 Wrayi ........ 20 » 30 beste Sorten gemischt - en mé-

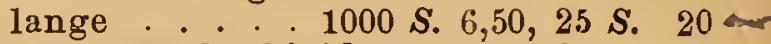

10899 Pilocereus euphorbioides . . 20 20

10900 ") giganteus, Lem. (Cereus giganteus, Engelm.) $1000 S .7-, 25 S .30$ Hermentianus 1000 》 $6,50,25$ 》 20

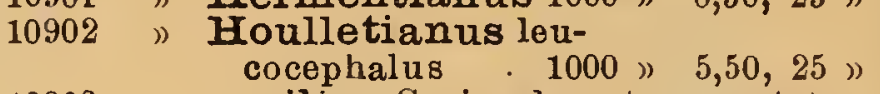

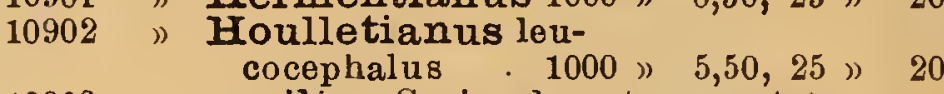

tête de vieillard, attendu . . 5 S. 50

10904 tête de vieillard, attendu

100 S. $1,25,20) 30$

$10905 》$ tilophorus .... 5 » 30

10906 》gemischt - en inélange

30

20 $30 \mathrm{M},-$ Toutes les sortes de Cactées 30
30
10908 Cacteen alle Classen gemischt - Cactées toutes les classes en mélange . . 50 S. 20 10886 Phyllocactus Ackermanni

\section{Wasserpflanzen. Plantes aquatiques.}

No.

10909 Alisma lanceolatum . . $5 \mathrm{~g}$ 1,20, Pt. 10910

10911
Pf. $\mid$ No.

2010912 Aponogeton distachyon, $\downarrow$ extra 10 20 schöne Wasserpflanze für kleinere wie für grössere Aquarien, frische Samen
Pf. 


III. Blumen-Samen. (Graines de fleurs.) - Succulenten. (Plantes grasses.)

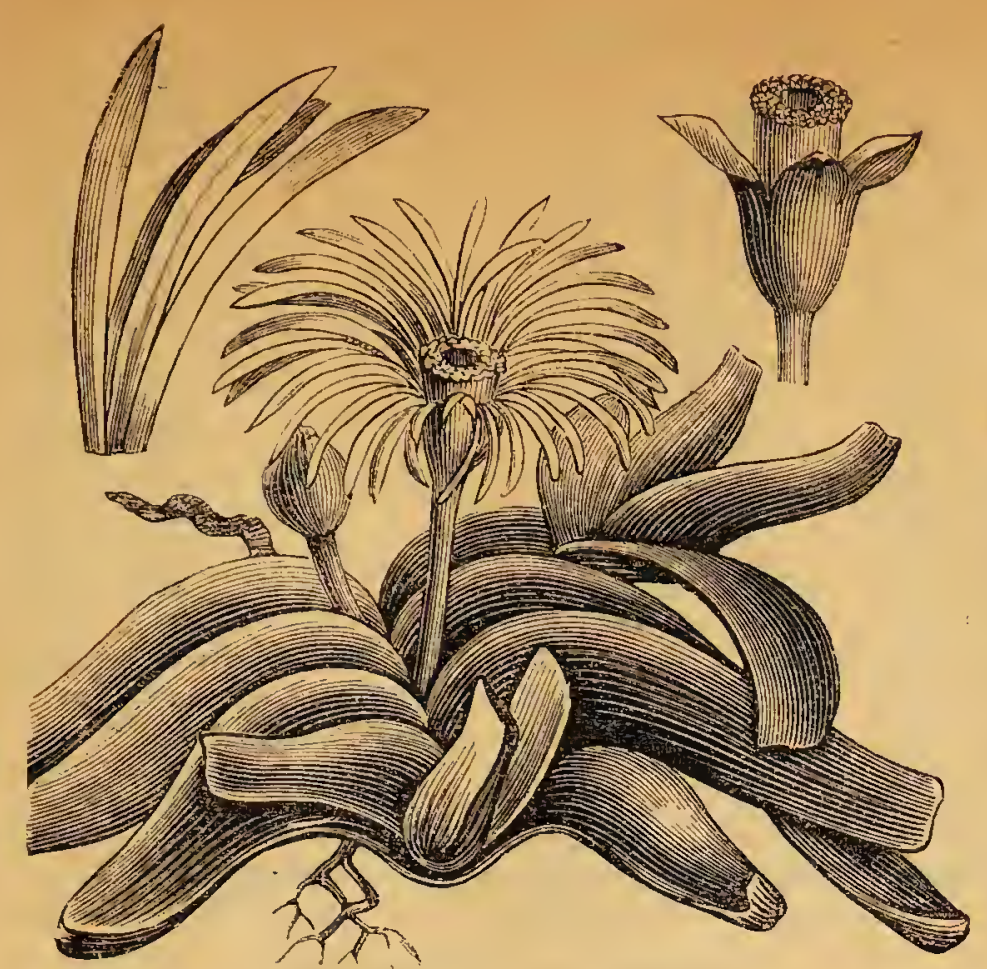

10631. Mesembrianthemum linguaeforme.

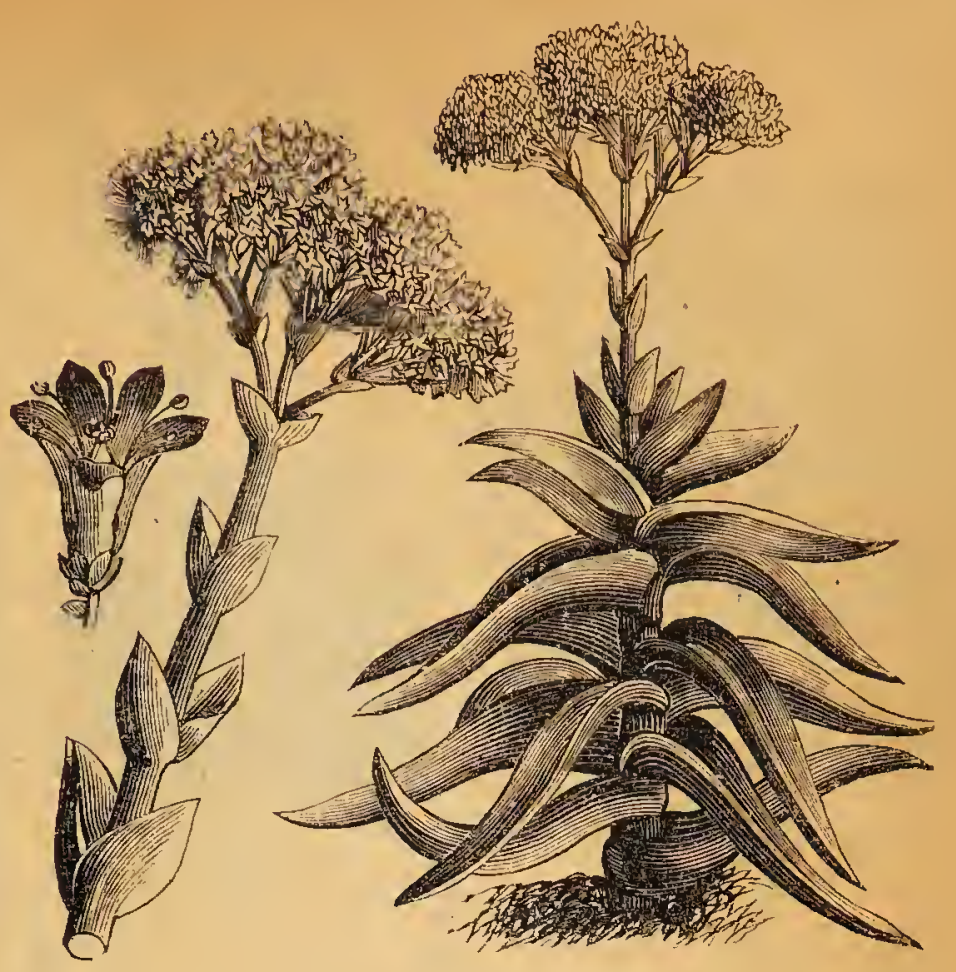

10653. Rochea falcata.
No.

10432 Agare chiapensis . . 1000 S. 4-, 50 S.

10434

10435

10436

10437

10438

10439

10440

10441

10442

10443

10444

10445

10446

10447

10448

10449

10450

10451

10452

10453

10454

10455

10456

10457

10458

10459

$1046^{\circ}$

10461

10462

10463

10464

10465

10466

10467

10468

10469

10470

10471

10472

10473

10474

10475

$104 i f$

10477

10473

10479 coccinea. $1000 \gg 3-, 50 »$ dasylirioides (dealbata)

$$
100 \text { S. } 1-, 20 \text { ) }
$$

densiflora ... 1000 » $4-, 50$ »

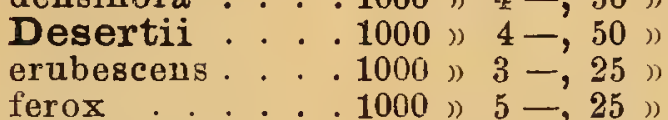

filifera . . . $1000 » 6-, 25$

Funkiana -. $1000 \% 4$ \#, $25 \%$

geminiflora (Bonapartea juncea) 100 S. $1,60,10 S$.

Ghiesbreghti . . 1000 » $4-, 25$ )

macrantha .1000 ) $5-, 25$

grandibracteata $\cdot 1000 ” 6-, 25 \%$

heteracantha. 1000 ) $3-, 50$

horrida : . 1000 »

Houllettiana . . $100 \gg 1-, 20$

Hystrix . . . 100 » $1,20,10$ )

Ixtli . . . $1000 » 3-, 50 "$

Jacobiana . . 100 ) $1-, 20$

Lechuguilla . . 1000 » 7 - 20

lophantha. . . 1000 » 3 -, 50

maculata . . . 1000 » 8 -, 20

maculosa . . 100 " 1,40, 10 )

mexicana . . 20 g $2-, 50$

micracantha 1000 S. $5-, 25$

miradorensis . . 100$)-70,20$

mitis . . . . . 100 » $1,50,10$ )

Nissoni... 1000 ) $4-, 25$

Palmeri . 1000 " 4 -, 25 ,

polyacantha . 1000 ) $3-, 50$ )

Poselgeriana . . . 100 » 1,25, 10

Pringlei . . . . 190 ) $1,25,10$

pulcherrima . . 1000 " $4-, 25$

rigida . . 1000 $) 3-, 50$ )

rupicola . . $1000 » 4-, 50$ )

Salmiana .. $1(00) 2,50,50)$

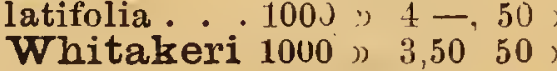

Shawii... $1000 » 7-, 20$

spec. Paso del Macho

$100 \gg(1,50,10)$

spicata ... $1000 » 2,50,50 »$

striata, eine der schönsten Sorten -

l'une des plus belles $100 S .1,50,10 \mathrm{~S}$.

stricta..... $100 \gg 1$ - 20 " 25

Univittata $\dot{0} \cdot 1000 " 3-, 50 "$

schönsten - l'une des plus belles

espèces . . $1000 \mathrm{~S} .5-, 50 \mathrm{~S}$.

10480
Pf. $\mid$ No.

10481 Agave Wildingii . . 1000 S. 7 -, 20 S. 25

2010482 " xalapensis . . . 1000 » 2,50,50 》 20

10483 " xylacantha..1000 \# 6-, 25 » 20 10484 ) gemischt - mélange

30 (1000》2,50,50 》20 20

10485 Aloe acinacifolia ... 100 » $1-20$ 》 30

2510486 . 》 acuminata........ 10 . 30

1510487 " africana......... 20 ” 30

10488 " arborescens ........ 10 ” 20

2010489 " attenuata ......... . . 10 ” 20

2010490 "cernua........... . 10 ) 20

10491 " conspurcata angustior . . 20 ” 80

201049.2 "echinata ... 1000 S. 5 -, 25 》 20

2010493 " elegans . . . . 100 " 1 -, 20 " 30

$(10494$ ) excavata ... 100 » $1-, 20$ » 30

2010495 ” fasciala ........20 2030

2010496 "Hanburyana .. $1000 S .4-, 50$ " 30

10497 " hybrida..... 100 » $1,50,10 » 20$

2010498 " Klugii .......... . . 20 " 30

2510499 " laetevirens . . . . . . . 10 ” 20

2010500 " margaritifera . . $100 \mathrm{S.} \mathrm{L} \mathrm{-} 20$ » 30

$2010501 "$ paniculata... 1000 " $5-, 50$ » 30

2510502 " papillosa.... . . . 10 ” 20

2510503 ” picta ..... 100 S. $1,50,10 » 20$

2010504 " pluridens ........... 10 » 20

2010505 » rigida..........20 21$) 30$

10506 " Rossi .......... 10 ” 30

3010507 "Saponaria . . 1000 S. 3-, 50 » 20

2010548 "Schimperi .... $100 » 1$ », 20 » 30

$(10) 30$

2010510 " subtuberculata ..... 10 " 20

2010511 " umbellata. . . 1000 S. 5-, 50 » 30

2010512 " viele Sorten gem. 1000 » 3 -, 50 》 20

2010513 Anacampseros filamentosa . . 10 ” 40

20 (0514 Beschorneria californ. 100 \# 2,50, 10 ) 30

20 》 yuccoides (Roezlia regia) 5 » 50

20 Bonapartea gracilis $\nabla$. Dasylirion.

2010516 " Hystrix . . . 100 S. $-80,10$ » 20

3010517 juncea .. 100 » 1,60, $10 » 20$

2010518 Bowiea volubilis ..... . 25 》 15

2510519 Bryophyllum calycinum .... . . . 1 n 120

2510520 Bulbine frutescens . . . . . . 50 》 30

2010521 Cacalia Kleinii . . . 2 g i-, Pt. 20

10522 Urassula coccinea . 1000 S. 2 -, $100 S .30$

2010523 »dejecta ... 1000 » $4-, 50$ » 30

2010524 ) lactea. .......25 \# 20

10525 "Schmidti 1000 S. $2,5 n, 100 » 30$ 10526 Dasylirion acrotriche (serratifolium) 20 g $2,50,20 S .20$

10527 \#igelowi . . 1000 S. 9,50, 20 » 25 10528 "glaucophylium. $20 \mathrm{~g} 1,40,50 \mathrm{\#} 20$ 10529 ») gracile ... ” $1,60,50$ » 20 10530 " graminifolium. 10ก S. 1,25, 20 » 30 10531 " juncifolium $.20 \mathrm{~g} 2-20$ 》 20 3010532 "longifolium verum, Prachtpflanze -plante superbe 1000 S. 5 - , 25 S. 20 


Veronica Beccabunga

à Stück - la pièce M.Pf.

Victoria regia, junge Pfanzen vom Mai ab - jeunes plantes, ne livrables qu'a partir de Mai

Villarsia Humboldtiana (Limnanthemum)

ᄂ., sehr schön, mit weissen, stark

Nach unserer Wahl - Au choix de l'Etablissement:

12 Wasserpflanzen zur Cultur in Bassins im Freien - 12 Plantes aquatiques pour bassins en plein air 4 (" " "Gefässen im Zimmer -6 " " 》 en appartements 250

\section{Chrysanthemum indicum fl. pl.}

Beschreibung der Sorten siehe 1895 er Blumenzwiebel-Catalog - pour la description roy, le catalogue des Oignons à fleurs de 1895.

Nach unserer Wahl - à notre choix:

M. Pf.

12 kleinblumige oder Pompon-Sorten - 12 variétés Pompons

12 mittelgross- und grossblumige Sorten - 12 variétés à grandes fleurs . . . . . . . . . . 3 -

12 japanische Sorten -12 variétés japonaises . . . . . . . . . . . . . . 3 -

12 neue japanische frühblühende Sorten - 12 var. nouv. du Japon à floraison précoce . 4 -

5 Straussenfederförmige, japanische Sorten - 5 var. japonaises à flours duvetenses . . . 3 -

6 anemonenblüthige Sorten - 6 var. à fleurs d'Anemone.............. 150

1 Sortiment von 50 schönsten Sorten - collection de 50 sortes des plus belles . . . . . . 15 -

1 Sortiment von 100 Sorten - collection de 100 variétés . . . . . . . . . . . . . 35

\section{Fuchsien. - Fuchsias.}

\section{Gefülltblühende - à fleurs doubles.}

3t9 Dr. Crevaux, Corolle dunkelblau, Sepalen carmin - corolle bleu foncé, sépale carmin.

350 Frau Emma Töpfer, C. zartrosa, S. scharlach - c. rose tendre, s. écarlate.

366 La France, C. hellblau, S. leuchtend roth c. bleu clair, 8, rouge vif.

377 Mrs. E. G. Hill, C. rahmweiss, S. lebhaft roth - c. blanc crème, s. rouge vif.

389 Phénóménal, C. dunkelblau, S. roth, sehr grossbl. - c. bleu foncé, s. rouge, gr. fl.

281 Schneewittchen, C. weiss, S. roth - a. blanche, s. rouge.

Obige 12 Sorten sind die empfehlenswerthesten Sorten - les variêtés énumérées ci dessus sont les var. les plus recominan tables. $\quad$ M.Pf.

Alle 12 Sorten zusammen in jungen Exemplaren - la collection de 12 var. en boutures . . 350

》 12 " " " überwinterten " - " " "12 var. en plantes hivernées $5-$ 12 andere einfachblühende Sorten unserer Wahl - 12 autres var. à fl. simples à notre choix 350 12 " gefülltblühende " 12 " Hochstämmige Fuchsien, hübsche Kronenbäumchen, 100 à $125 \mathrm{~cm}$ hoch per Dtzd. $211-$ à $30-$, per st. 2 - à 3 - M. - Fuchsias a hautes tiges avec jolie couronne, de 100 à $125 \mathrm{~cm}$. de

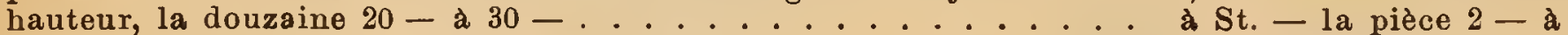

\section{Fuchsien-Species. - Espèces de Fuchsia.}

No.

22 americana elegans.

23 aucubaefolia.

295 Aurora superba.

298 boliviana.

$317)$ penduliflora.

225 coccinea.

39 conica.

1 corallina.

233 cordifolia.

2 corymbiflora.

3 D alba.

4 ) candidissima.

7 ) fol. var.

374 dependens. - 75

26 Dominiana.

9 fulgens.

\section{No.}

284 fulgens obscura.

20 globosa.

21 " grandiflora.

10 " fol. var. - 75

11 gracilis.

12 ) fol. var.

27 integrifolia.

40 longipedunculata.

293 magnificens.

13 Miellezi. - 75

311 myrtifolia.

296 Polhymnia.

299 procumbens.

300 pulchella.

15 pumila (Tom Thumb).

24 Riccartonii.

\section{No.}

373 Riccartonii Télégraphe.

30 Rubin. 1 -

318 semperflorens.

341 splendens.

294 syringaeflora.

343 " Liboniana.

386 triphylla. - 75 .

31 " carnea. 1 -

29 " hybrida, carminroth, in dichten Trauben, ausgezeichneter Winterblüher - rouge ${ }^{\text {car- }}$ miné en grappes serrées, fleurit on hiver.

$$
-75
$$

315 venusta.

M. Pf.

Jede der vorstehenden Sorten, wo kein Preis angegeben, einzeln - Chaque espèce séparément

12 Fuchsien-Species nach unserer Wahl -12 espèces de Fuchsias a notre choix . . . . . . 50 




\section{Pelargonien, grossblumige, englische, diadematum und fünffleckige Sorten. - Pelargonium à grandes fleurs.}

Ansführliche Sortenliste steht auf gefl. Verlangen zu Diensten - la liste détaillée des gortes sera envojée sur demallde.

98 Perle von London, reinweiss, grossbl. - blanc pur, à grande fleur . à Stück - la pièce 12 sorten unserer Wahl je nach Stärke - 12 variétés à notre choix selon la force . . 6 - a

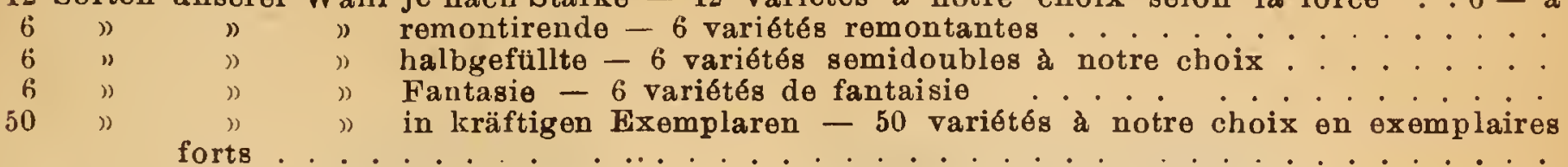

\section{Pelargonium zonale, gefüllt- und einfachblühende -} à fl. doubles et simples.

Gefiiltblühende - à fl. doubles. 374 Aérolithe, orangeroth - rouge orange.

360 Dr. Thouvenet, krapproth - rouge de garance.

379 La Vienne, reinweiss - blanc pur.

340 IVad. Otto Froebel, kirschcarmoisin cramoisi cerise.

381 IM. Fabre, scharlach mit weisser Mitte écarlate a centre blanc.

357 Ravissant, bläulichcarmoisin - cramoisi violacé.

Obige 12 Sorten sind die besten zur Bepflanzung von Gruppen - les variétés énumérées cidessus sont les meilleures pour la plantation on pleine terre.

Alle 12 Sorten zusammen in jungen Exemplaren - la collection des 12 variétés en boutures du printemps

Dieselbe Collection in starken überwinterten Exemplaren - la même collection en plantes hivernées

\section{Neuere Sorten - Var. nouvelles.}

Gefülltbliuhende - $\dot{a}$ fl. doubles.

315 Aug. Buchner, orange - orange.

312 Frrieda, rosacarmin mit weissem Auge, balb. gefülıt carmin rosé à oeil blanc, semidouble.

314 Gustav Emich, scharlachorange - écarlate orangé.

305 Nydia, weiss, innen lachsrosa - blanc à centre rose saumoné.

Sorten in jungen Exempl. - la collection des 8 var. énumérées ci-dessus en

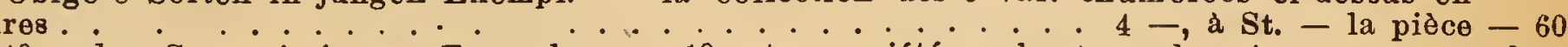
12 andere Sorten in jungen Exemplaren - 12 autres variétés en boutures du printemps . . $3-$

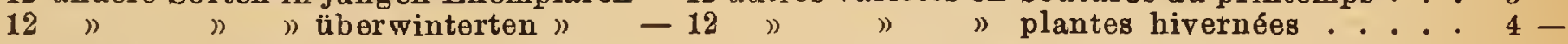
Vor Mai können nur überwinterte Exemplare geliefert werden. - Avant le mois de Mai nous ne pouvons fournir que des plantes hivernées.

\section{Pelargonium zonale, buntblättrige.}

Gold- und bronceblättrige.

Zonales à feuilles dorées et bronzées.

à Stück - la pièce M.Pf.

Golde Vesuvius.......... 1 12 sorten unserer Wahl - 12 variétés à notre choix

\section{Silber - und goldbuntblättrige Sorten.}

Zonales à feuilles panachées et tricolores.

Nach unserer Wahl - à notre choix: M.Pf. 12 Sorten 12 variétés $12 . . .2$ in starken Exemplaren - 12 variétés en fortes plantes ...... $10-$

\section{Pelargonium peltatum, epheublättrige - à feuilles de lierre.} Gefülltblühende - à fleurs doubles.

43 Alice Crousse, purpurviolett mit amarant - 19 Jeanne d'Arc, reinweiss - blanc pur. pourpre violacé et amarante.

24 Fürstin von Hohenzollern, scharlachpurpur - écarlate pourpré.

Obige 6 Sorten zusammen - collection de 6 var. $3 \mathrm{M}$

10 andere einfachblühende Sorten uns. Wahl - 10 autres var, fl. gimples notre choix

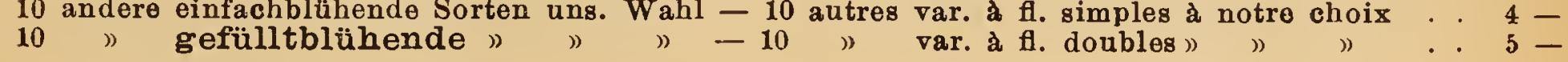


Pelargonien-Species.

à Stück - la pièce M. Pf

athamantoides ........... -60

canariense . . . . . . . . . . . . . -75

cinereum . . . . . . . . . . . . -60

coronopifolium (Campylia), Jacq., sehr schön, dunkelbraunroth, untere Pet. blass-

rosa - très-belle espèce à fleurs d'un rouge

brun foncé, pét. inférieurs rose clair. .

glutinosum malvaeflorum ........... -75

nutans ................. -75

odoratissimum . . . . . . . . . . . . -60

Radula rosodorum . . . . . . . . -60

roseum fol. var. (Lady Plymouth) . . . . -75

stenopetalum ................. 75

tabulaeforme ...............

tetichorum ................... 75

150 tomentosum $\ldots \ldots$

- 75 triste..................... 75

\section{Georginen. - Dahlias.}

Beschreibung der Sorten siehe 1890er Catalog - pour la description voy. le catalogue de 1890.

\section{Preise für Topfknöllchen - Prix pour tubercules élevés en pots.}

12 grossblumige gefülltblühende Sorten 25

50

12 Liliput

$25-1)$

50 )

12 Zwerg

12 einfachblühende

25

6

") niedrige

gestreifte

$1^{00}$ Sorten aus allen Klassen

Dahlia imperialis
12 var. à grandes fl. doubles ..... 350

25 ” " . . . . . 7 -

50 ”

12 "liliputiennes " ..... 350

.... 7 -

50 ग 1 " ...... 15 -

naines

à fl. simples

" " striées . . . . . . . . . 62

" naines "à flriées simples . . . . . . . . . 2

de touter les classes . . . . . . 25

à St. - la pièce 150

Preise für Pfanzen - Prix pour plantes.

12 Sorten nach unserer Wahl - 12 var. à notre choix

\section{Cractus- (Jeorginen.}

No.

400 Ariel, reiuweiss - blanc pur

à Stück - la pièce M.Pf.

401 Astercactus, gelblichrosa mit hellpurpur geflammt, geröhrt, gerundete Cactusform - rose jaunâtre, flammé pourpre clair, tuyauté, en forme deDahliaJuarezi

402 Auguste Weber, leuchtend canariengelb - jaune canari vif .

403 Baron $\checkmark$. Helldorf, carmoisin mit hellem Grunde - cramoisi à fond clair - 50

404 Beauty of Brentwood, violett, purpur schattirt - violet nuancé pourpre.

405 v. Blœdau, ockerfarben mit braun schattirt und weissen Spitzen - Jaune nuancé brun, à bouts blancs

408 Carl Leschkowitz, scharlachcarmin mit weissen Spitzen - carmin écarlate à bouts blancs.

409 Carl Mauch, weinroth mit lillacarmin schattirt - rouge de vin nuancé carmin lilacé.

410 Charming Bride, fleischfarbig mit rosa Spitzen - carné à bouts roses . . - 50

411 Cochineal, dunkelcarm. - cramoisi foncé - Ło

413 Edmund Mauthner, chromgelb jaune chrôme

414 Eduard Meyer, salmroth mit carmin gerandet - rouge saumoné marginé carmin

415 Emil Dietze, weiss mit rosa Streifen, Mitte gelblich - blanc strié rose, centre jaunâtre

416 Empress of India, dunkelcarmoisin mit kastanienbraun - cramoisi foncé et marron

418 Friedr. Spittel, ziegelroth in blutroth übergehend, Rand zuweilen weiss gesäumt - rouge brique passant au rouge sang, bord marginé blanc
Pf. No.

Dahlias - Cactus.

$419 \mathrm{~F}$

à Stück - la pièce M.Pf.

rau N. Fl. Chludow, hellrosa, innen chromgelb - rose clair, jaune chrome au centre.

422 Glare of the Garden, scharlach, sohr reichblühend - écarlate, très florifère - 50

425 Hauptmann v. Pawel, ockergelb mit salmrosa Anbauch - jaune ocre voilé rose saumoné . . . . . . . . .

426 H. E. Locke, gelblichweiss mit ockerfarben bandirt - blanc jaunâtre bordé jaune ............. -50

427 Henry Patrick, schön weiss - beau blanc - 75

428 Herm. Schubert, gelblichweiss, Mitte rosa angehaucht, prächtige Asterform - blanc jaunâtre, centre rose . . . .

429 Hofgärtner Betz, hellpurpur, Mitte braunpurpur - pourpre clair, à centre pourpre brunâtre..... . . .

432 Juarezi, scharlach, reichblühend - écarlate, très florifère . . . . . . . .

433 Jubelbraut (Delicata), prachtvoll, rein centifolienrosa, nach innen blassgelb - magnifique, rose de centfeuilles, jaune clair au centre

435 Kaiserin Auguste Victoria, neu, roinweiss - nouv., blanc pur.

434 King of Cactus, carminroth - rouge car$\min$

437 Kunigunde, lillarosa, dunkelcarmoisin gesprenkelt - rose lilacé strié cramoisi foncé

438 Lady Hume Campbell, purpur, violett schattirt - pourpre, teinté violet.

441 Louis Bechstaedt, violettrosa, sehr reichblühende schöne Form - rose violacé, très florifère 


No.

Cactus-Georginen - Dahlias-Cactus :

444 Marianne Harvey, feurig dunkelblutroth, sehr grossblumig - rouge sang foncé, à gr. fl. . . . . . . . . .

447 Meta, lilla mit hellen Spitzen, grossbl. - lilas à points clairs, a gr. fl.

$446^{\circ}$ Mrs. Hawkins, schwefelgelb mit helleren Spitzen - soufre à bouts plus clairs

451 Mrs. Peart, neu, reinweiss - nouv., blanc pur

450 Otto Stehle, schwefelgelb mit lilla Spitzen - jaune soufre, a bouts lilas - 50

453 Paul Scheloski, dunkelblutroth mit weissen Spitzen - rouge sang foncé, à bouts blancs

454 Picta formosissima, orangeroth mit glänzend scharlachrothen Streifen rouge orange à striures écarlate vif
M.Pf. No Cactus-G à Stück - la pièce M. Pf. rginen - Dahlias-Cactus: 455 Prince Albert Victor, carmin, gelb schattirt - carmin, nuancé jaune . - 50

458 Riesen-Cactus (Deeg.), rein roth, hübsche Form, riesig gross - rouge pur, d'une jolie forme, fleur énorme..... . - 50

461 W. Kapferer, dunkelpurpur mit violetten in rosenroth übergehenden Spitzen - pourpre foncé à bouts violets passant au rose..... · breit462 Yellow Juarezi, canariengelb, breitpetalig, sehr grossblumig - jaune cunari, à petales larges, gr. fl. . . . - 50

$464 \mathrm{Zulu}$, dunkelkastanienbraun - marron foncé . . . . . . . . . - -50

12 Sorten unserer Wahl - 12 var. à notre choix ........ 5

\section{(riufad)e garandete (Georgilten - Dahlias à fl. simples bordées.}

No.

626 Anna Iucas, kupfrigscharlach mit dunklen Rändern und gelben Spitzen - écarlate cuivré à bord foncé, pointé jaune

620 Bagamoyo, rahmweiss, orangeroth gerandet - blanc crème, bordé rouge orange

621 Chilweli Beauty, gelb, carmoisingerandet - jaune borde cramoisi . .

627 Conspicua, weiss, kastanienbraun gerandet - blanc, bordé marron.

$628 \mathrm{Dr}$. Moffat, dunkelblutroth mit hellem Rand - rouge sang foncé à bord clair
No.

622 Duchess of Albany, bläulichweiss, chamois gerandet - blanc bleuâtre, bordé chamois. .

623 F. C. Heinemann, milchweiss, carmoisin gerandet - blanc crème, bordé cramoisi

624 Guilielma, lachsroth,orangegelb gerandet-rouge saumoné, bordé jaune orange - 60

625 Mrs. W. C. Harvey, rothviolett, lillarosa gerandet - rouge violacé, bordé rose lilacé ........... - 60 6 Sorten unserer Wahl - 6 var. à notre choix 2

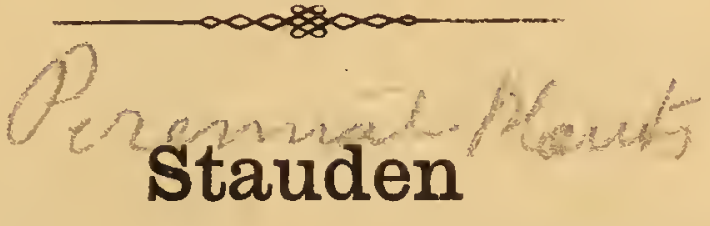

\section{oder perennirende Pflanzen.}

\section{Plantes vivaces.}

Die mit $\Lambda$ bezeichneten müssen im Winter bedeckt oder frostfrei überwintert werden.

$\Lambda$ Signifie que la plante doit être couverte ou rentrée en bâche pendant l'hiver.

à Stück - la pièce M.Pf.

Acaena, Rosaceae, Stachelnüsschen, $\Lambda$

millefoliata

glumaceum........... - . 75

Acanthus, Acanthaceae, Bärenklau, $\Lambda$

candelabrum . . . . . it st. $4-1$ - 40

lusitanicus ........ 12 » $4-,-40$

mollis . . . . . 12 ” $4-,-40$

spinosus

Achillea, Compositae-Anthemideae, Garbe, aegyptiaca.

Clavennae (Ptarmica) $\therefore$ i2 st. $4--60$

filipendulina ........... . . -30

Gerberi . . . . . . . -40

lanata

Millefolium fl. roseo.......

mongolica............. 150

moschata

nana

nobilis

. -75

tarmica fi. pl., gefüllt, reinweiss -

à fl. double, blanc pur .12 St. $3-,-30$

"fl. pl. elegans, grossbl. - à gr. fl. . - 40

12 St. $5-50$

") "The Pearl, beste Sorte zur Binderei - très beau. . . 12 St. 6-, - 60 pubescens....... . 12 " 4 -, -40 umbellata

Aconitum, Ranunculaceae, Eisenhut,

Camarum fl. albo

\section{Aconitum :}

Stück - la pièce M.Pf.

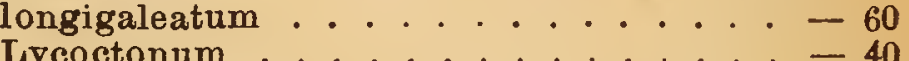

Napellus. . . . 12 St. $4-,-40$

variegatum ................ 50

6 andere Sorten - 6 autres espèces . a - 40

1 Sort. von 6 Sort. - collect. de 6 esp. . 2 -

Acorus, Aroideae, Calmus,

Calamus

graminifolius

fol, var $\frac{\Lambda}{A}$

japonicus fol. $\operatorname{var}, \Lambda \quad . .12$, $4-,-60$

minimus $\wedge$..... 12 „ 5 -, -50

Actaea, Ranunculaceae, Christophskraut,

elegans (racemosa)......... - 50

spicata. . . . . . . . . . -50

) fr. rubro ......... . . . -80

Adenophora, Campanul., Drüsenträger,

denticulata. . . . . . . . . -50

liliifolia . . . . . . . . . . . -50

verticillata . . . . . - 50

Adenostyles, Compos.-Eupatorieae, Drüsengriffel.

albifrons............ -50

Adlumia, Fumariaceae,

cirrhosa \& .......... . . 40

Adonis, Ranunculaceae, Adonis,

hybrida . . . . . . . . 75

vernalis $\quad 100$ St. $7,50,12$ St. $1,20,-15$

Adoxa, Araliaceae,

Moschatellina...... 12 St. 3 -, -30 


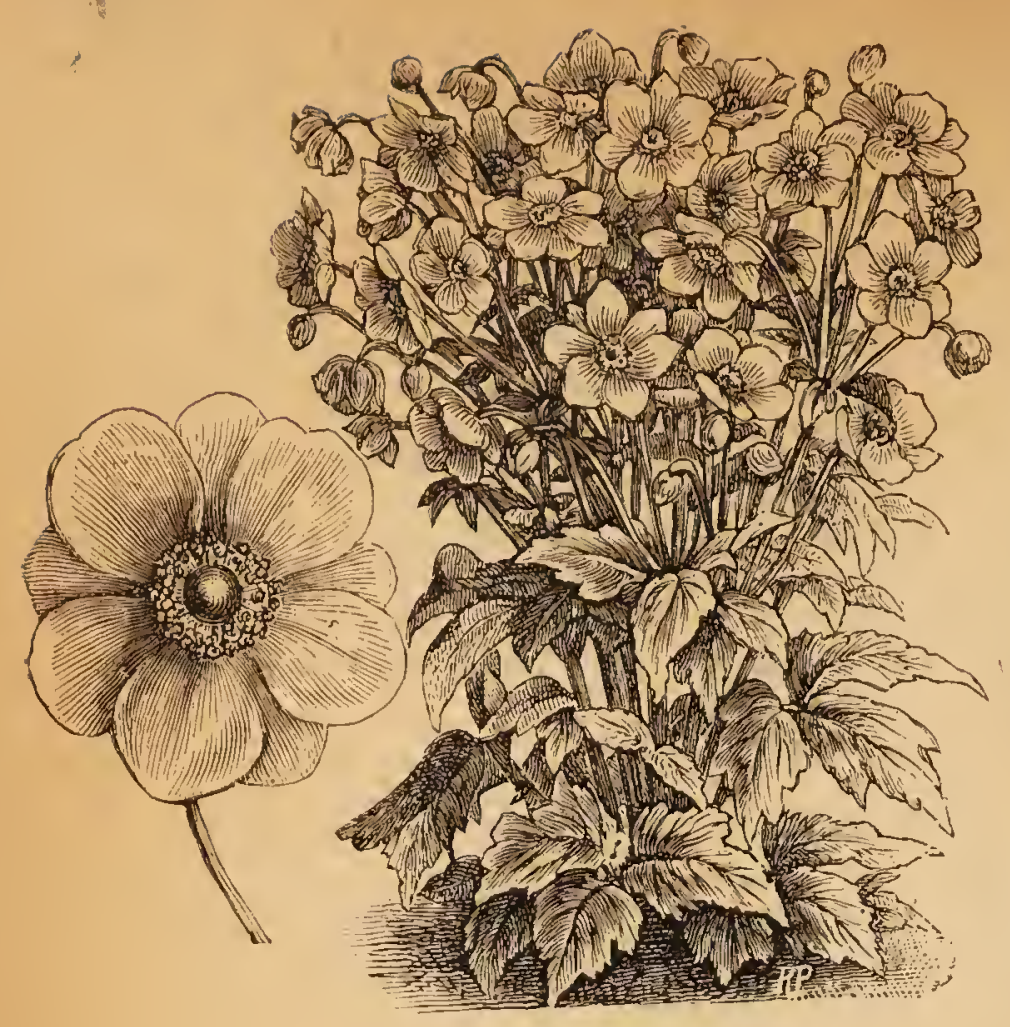

Anemone japonica:

à Stück - la pièce M. Pf.

Aegopodium, Umbelliferae, Giersch,

Podagraria fol. var.

Aethionema, Cruciferae, Steintäschel.

coridifolium ...... 12 St. 5 - , 50

grandiflorum . . . . . . . - 60

persicum ...... 12 st. 3 -, 30

Agrimonia, Rosaceae, Odermennig,

Eupatorium ........... . -40 odorata. . . . 12 st. $3-,-30$ pilosa... . . . 12 . 3 -, -30

Agrostemma, Caryophyll.-Sileneae, Rade,

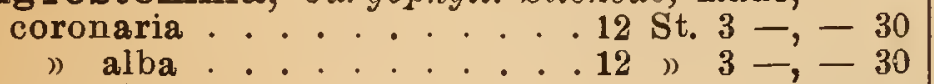
)) bicolor flos Jovis . . . . . . . 12 ) $3-,-30$ hybrida Walkeri, leuchtend rosenroth - rose brillant

Ajuga, Labiatae, Günsel. pyramidalis

reptans fol. argenteis var.

) fol. atropurpureis

Alchemilla, Rosaceae, Frauenmantel,

alpina

fissa

pubescens.

vulgaris

Alfredia, Compositae,

cernua

$-80$

nivea.

stenolepis

Alopecurus, Gramineae, Fuchsschwanz, pratensis fol. var.

Alsine, Caryophylleae, Miere,

Bauhinorum

12 St. $4-,-40$

pinifolia (gracilis)

Althaea, Malvaceae, Eibisch, Malve,

cannabina.

narbonensis

nigra

officinalis

rosea fl. pl., 12 Sorten in Sämlingen 12 variétés, semis

taurinensis

Alyssum, Cruciferae, Steinkraut, argenteum saxatile

Amsonia, Apocyneae,

salicifolia

Anandria, Compositae,

Bellidiastrum, Alpine

Anchusa, Boragineae, Ochsenzunge,

Barrelieri

") fol. varieg., neu - nouv.

italica

sempervirens (Caryolopha) à Stück - la pièce M. Pf.

Androsace, Primulaceae, Mannsschild,

chamaejasme............ 1 coronopifolia. . . . . . . . . -50

lactea ............ . . 60

lanuginosa Leichtlini, weiss mit rosa

Herz - blanc a centre rose..... 150

sarmentosa . . . . . . . . . . . 50

Anemone, Ranunculaceae, Windröschen,

albana ............. . . 50

alpina ............. . . 50

decapetala .. . . . . . . . - 75

fulgens, vide pag. 183.

hepatica, vide Hepatica.

japonica, Brillant. . . 12 St. $5-,-50$

) dunkelrosa - rose foncé. 12 ) 4 -, - 40 elegans, hellrosa - rose clair

12 St. $4-,-40$

) Honorine Jobert, reinweiss, sehr schön - blanc pur, très-beau

12 St. $4-,-40$

Lady Ardilaun, neu, grösstblumige weisse - nouv., blanc pur à très graude fleur . . . 12 St. $8-,-80$

Whirlwind, neu, weiss, halbgefủllt - nouv, blanc semidouble .. . . 1 multifida Hudsoniana ........ . . $1-\overline{50}$ narcissiflora ...... 12 St. 8 - -80 nemorosa fl. albo . 100 St. 3 -, 12 St. -60

") " pleno... 12 St. 3 - , 30 "bracteata flore pleno... 12 ” 3 -, -30 \#) rubro ... $100 \mathrm{st} .3-12 \mathrm{st}$. -60 " " " pleno.... 12 St. $4-,-40$ patens (Pulsatilla) . . . . . . 1 Pulsatilla (Pulsatilla vulgaris) 12 St. $1,50,-15$ ) alba ............... 150 ranunculoides ....... 12 St. 1 - 10 rivularis . . . . . . . . . . -60 silvestris . . . . 12 St. $2-,-20$

Anisodus, Solaneae,

Antennaria. Compositae-Gnaphalieae,

dioica ............. - 30 margaritacea

tomentosa candida

12 st. $3-,-30$

Anthemis, Compositae, Kamille,

nobilis, echt - vraie... 12 St. $3-,-30$ ) flore pleno $\wedge$. . . 12 ” 5 -, -50

Anthericum, Asphodeleae, Zaunlilie,

algeriense . . . . . 12 St. $4-,-40$ Liliago (Phalangium) . . . . .12 ) $4-,-40$ Liliastrum (Czackia), schöni.12 ) 5 -, - 50 ramosum . . . . . 12 ) $4-,-40$

Antirrhinum, Scrophularineae, Löwenmaul,

Asarina . . . . . . . . . - 60

Apios, Leguminosae,

tuberosa (Glycine Apios) . . 12 St. 4 -, - 40

Apium, Umbelliferae,

12 St. $4-,-40$
. . . . -40 chilense

Apocynum, Apocyneae, Hundswolle.

androsaemifolium, Fliegenfänger - Atrappe-

mouche ....... 12 St. $6-1-60$

hypericifolium . 100 St. $6-, 12$ ” $1,50,-20$

Aquilegia, Ranunculaceae, Akelei,

canadensis

canadensis
chrysantha

. -50

) grandiflora alba........ . . 60

coerulea . . . . . . . . . . . . . -60

fl. luteo . . . . . . . . . . -60 erecta nana atrocoerulea plena 12 St. $4-,-40$ flabellata nana alba .... 12 ) $3-,-30$ glandulosa vera .......... . . haylodgensis . . . . . . . . . -50 Jaetschaui . . . . 12 st. $4-,-40$ nivea grandiflora $: . . .12$ ” 3 -, - 30 Skinneri " hybrida flore pleno . . . . . . . 40 Stuarti, grossblumiger als $\dot{A}$. glandulosa vera - à $H$. plus grande, que celle d'A. glandulosa vera ........ - 75 truncata . . . . . . . . . -60 Vervaeneana fol. var. . . . . . . . -60 vulgaris fol. aureis . . . . . - 50 12 andere Species und Varietäten 12 autres espèces et variétés. . . . a a -50 




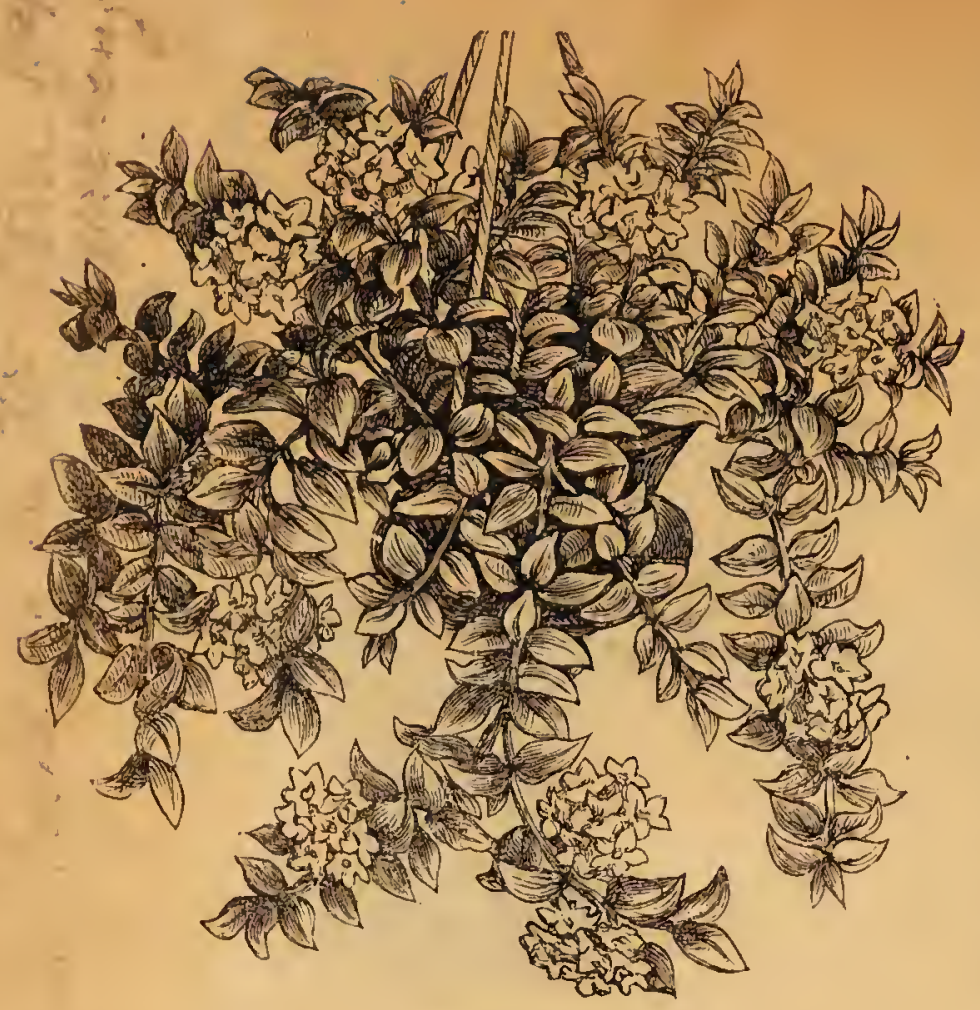

Hoya bella.

à Stück - la pièce M.Pf.

Himantophyllum miniatum:

plus beaux semis de graincs

provenant d'une collection hors

ligne, plantes fortes. . . 4 a 10 -

Houttea leptopus

Hoya $\frac{\text { s angustifolia. }}{\text { ". }}$

carnosa

" fol. var.

cinnamomifolia, sehr grossblumig, schön - à gr. fl., beau

clandestina :

Dalrympleana (australis)

mollis

viridiflora.

Hyobanche sanguinea

Jacaranda mimosaefolia

75

) gracillimum

) grandiflorum

Sambac flore pleno

$$
\text { Maid of Orleans }
$$

Ibatia muricata, Asclepiadee

Impatiens auricoma, gelbbluhend -

\section{Hawkeri \\ Mariannae. \\ Sultani alba (flaccida) saumoné \\ Ipomoea B Bronsoni \\ Horsfalliae . .
") martinicensis . .
" ventricosa. .} fl. jaune

platypetala (Sultani violacea).

"nacré rosé, lachsrosa - rose

$1-$

$2-$

Iresine formosa

) Lindeni.

Wallisi

Justicia carnea.

eustachiana

"Sabiniana

) splendens

Ixora coccinea

") fulgens

Lamprococcus Weilbachi (Aechmea) : 150

\section{Lantana.}

6 Sorten in jungeu Pflanzen - 6 var. en jeunes plantes.

Hochstämme, $1 \mathrm{~m}$ bis $1,20 \mathrm{~m}$ hoeh, mit liübschen Kronen - hautes tiges, $1 \mathrm{~m}$ à 1,20 $\mathrm{m}$ de hauteur.

Lasia spinosa, Aroidee.
$3-$

1 -

$1 \frac{1}{50}$

$2-$

$2-$

150

$2-$

150

150

$2 \frac{1}{50}$

150

$-75$

$1-$

150

$-60$

$-50$

$-50$

$-75$

$-50$

150

$2 \frac{1}{50}$

$\begin{array}{ll}1 & 50 \\ 1 & 50\end{array}$

150

$2 \frac{1}{30}$

$-30$

$-30$

$-60$

$1 \frac{1}{75}$

$-75$

150

150

$3-$
$2-$

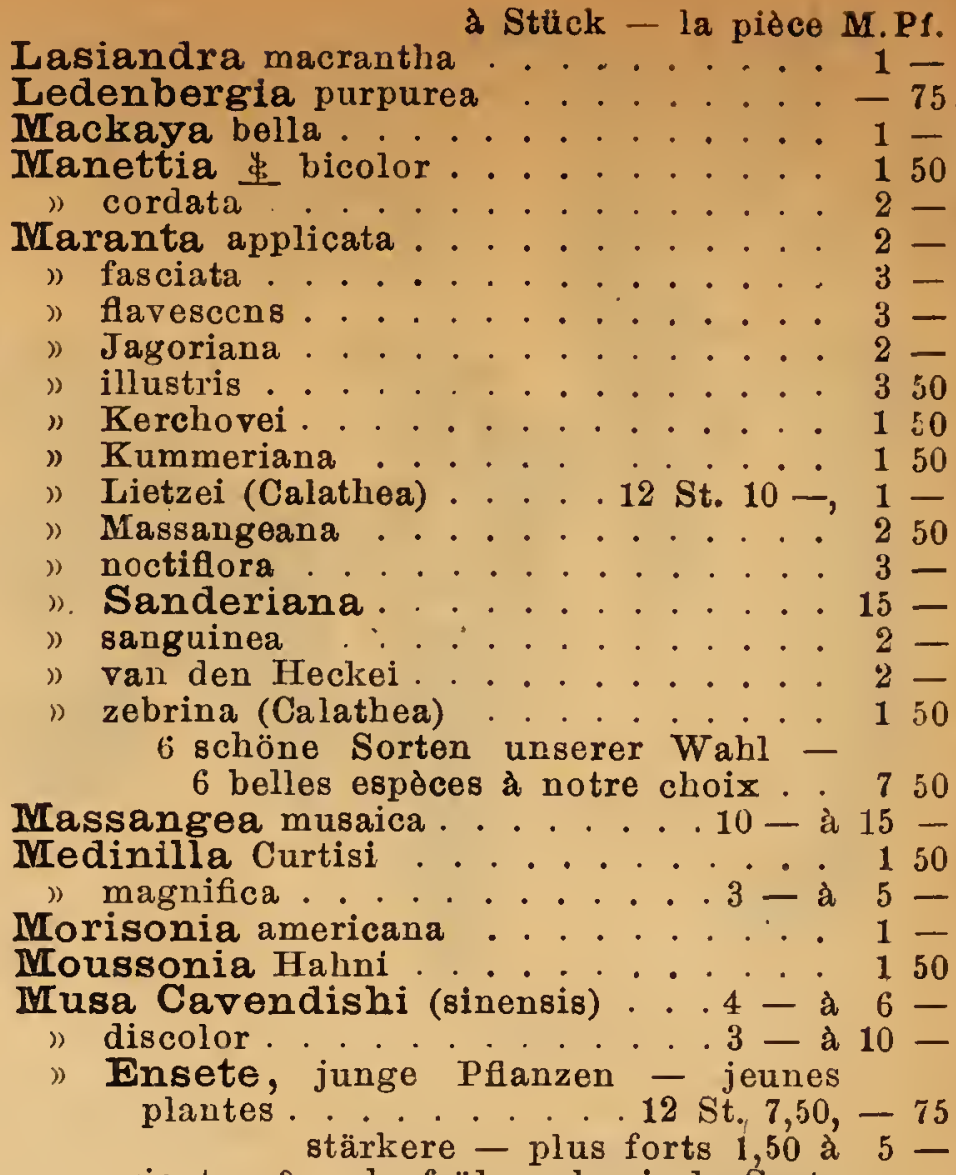
orientum?, sehr frühe cubanische Sorte - espèce très hátive de Cuba

$5 \div$ à $10-$

"paradisiaca . . . . . 3 - a 15 sumatrana.12 St. $20-$ à $30-, 2-a ̀ 3-$ ) superba................ 3 - a $10-$ ) textilis ................ 250 ) vittata......... $10-$ a $30-$ ") zebrina ....... . . 6 6 - a 10 Nematanthus longipes ....... . 1 -

epenthes Dominiana. $10-$

Hookeri ......... 10 - à 15 -

") hybrida maculata. . . . . . . $10-$

intermedia . . . . . . . . 10

... $15-$

O'Brieniana . . . . . . . 15 -

1) paradisae ............ 10 - .

) Stuarti .............. 15 -

Nidularium amazonicum $\therefore .1-\mathrm{a} 3-$

) denticulatum .......... 120

) Innocenti............. 250

) Meyendorffi ............ . . 2 - 2

Norantea guianensis. . . . . . . 150

Nyctocalus Thomsonae ........ 150

Ochna multiflora ....... 2- à 6 -

Olyra floribunda

Oxalis Ortgiesiana . . . . -60

") (Biophytum) sensitiva. . . . . . . . . 1 -

Oxera pulchella .......... 250

Palisota Barteri . . . . . . . 1 - à 2 -

Panax vide Aralia.

Pandanus amaryllidifolius (inermis) . . 5 -

graminifolius ....... 1- a 2 -

) odoratissimus........... . . . . 3 -

utilis . . . . . . . 1,50 à 3 -

") Veitchi ......... 2,50 à 5 -

Panicum (Oplismenus) variegatum . . . -50

) plicatum variegatum ....... - -60

1) sulcatum ............ . . -60

Paradrymonia glabra. . . . . . $2-$

Paratropia Stelzneriana....... 150

") rotundifolia . . . . . . . . . . 120

Passitlora alba. . . . . . . . 1 -

albida ........... 150

) edulis ................ . . -75

") hybr. Arc en ciel ....... . -80

) Mme. Bruckhaus . . . . . . 150

) Prof. Wittmack ...... 150

" Impératrice Eugénie . . . . . . . - 75

Jenmanni, neu - nour. . . . . . 4 -

kermesina vera ........ 2 - 







$\because 300$

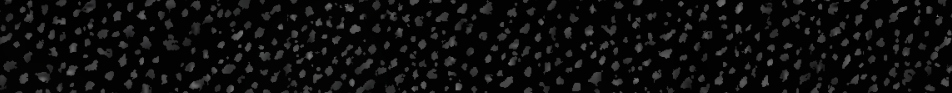

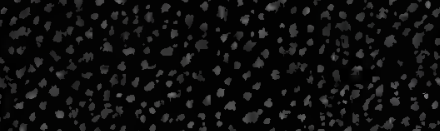

ons

6

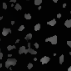

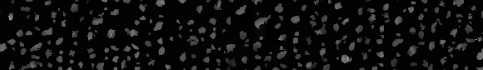

ond

(1)

Whond

Hos

4 Whom

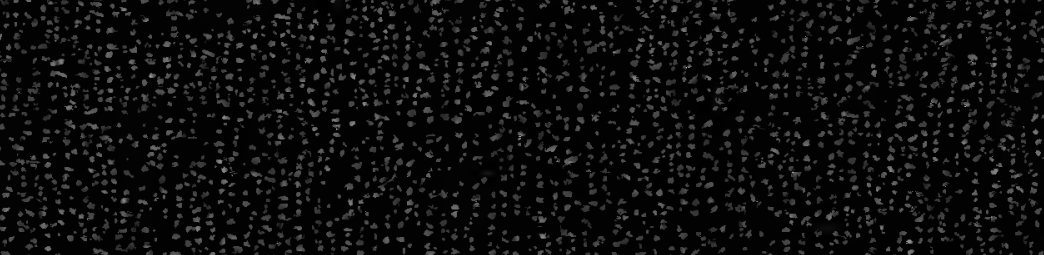

40

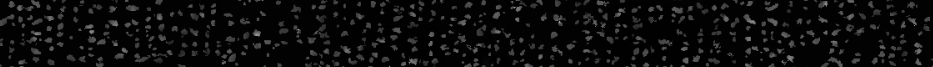

(n)

(n)

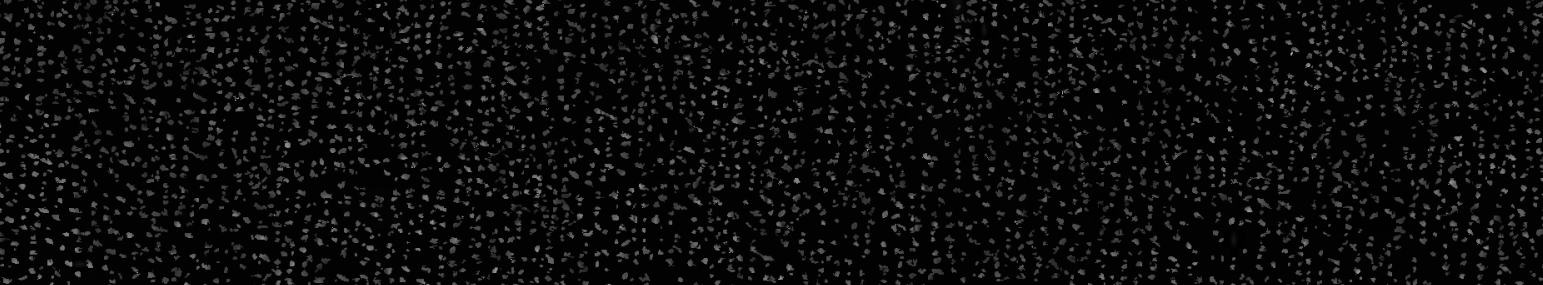

W

W

$40 \%$ ond

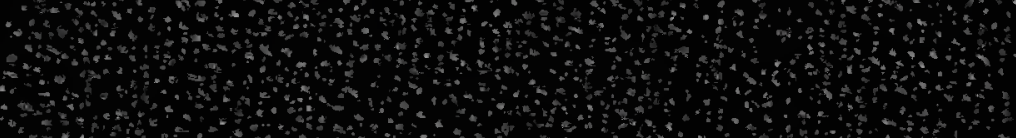

(n) 